UNIVERSIDADE DE SÃO PAULO

ESCOLA POLITÉCNICA

LUCAS MOZELLI PADIAL

Investigação numérica do ruído aerodinâmico irradiado por barras prismáticas transversais

SÃO PAULO 



\title{
Investigação numérica do ruído aerodinâmico irradiado por barras prismáticas transversais
}

\author{
Versão Corrigida
}

Dissertação apresentada à Escola Politécnica da Universidade de São Paulo para obtenção do título de Mestre em Ciências.

Área de Concentração: Engenharia Mecânica de Energia e Fluidos

Orientador: Prof. Dr. Gustavo Roque da Silva Assi 
Autorizo a reprodução e divulgação total ou parcial deste trabalho, por qualquer meio convencional ou eletrônico, para fins de estudo e pesquisa, desde que citada a fonte.

Este exemplar foi revisado e corrigido em relação à versão original, sob responsabilidade única do autor e com a anuência de seu orientador.

São Paulo, 11 de janeiro de 2021

Assinatura do autor:

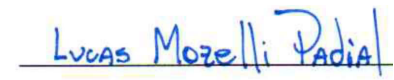

Assinatura do orientador:

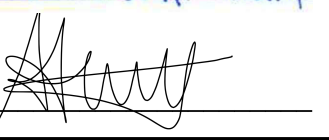

Catalogação-na-publicação

Padial, Lucas Mozelli

Investigação numérica do ruído aerodinâmico irradiado por barras prismáticas transversais / L. M. Padial -- versão corr. -- São Paulo, 2021.

$126 \mathrm{p}$.

Dissertação (Mestrado) - Escola Politécnica da Universidade de São Paulo. Departamento de Engenharia Mecânica.

1.Aeroacústica computacional 2.Lattice-Boltzmann 3.Analogia Acústica 4.Ffowcs-Williams e Hawkings 5.Decomposição em Modos Dinâmicos I.Universidade de São Paulo. Escola Politécnica. Departamento de Engenharia Mecânica II.t. 
PADIAL, Lucas Mozelli. Investigação numérica do ruído aerodinâmico irradiado por barras prismáticas transversais. 2021. 126 f. Dissertação (Mestrado em Ciências) - Escola Politécnica, Universidade de São Paulo, São Paulo, 2021.

Aprovado em: 30/11/2020

\section{Banca Examinadora}

Prof. Dr. Gustavo Roque da Silva Assi (Presidente)

Instituição: EP - USP

Julgamento: Aprovado

Prof. Dr. Reinaldo Marcondes Orselli (Titular)

Instituição: UFABC - Externo

Julgamento: Aprovado

Prof. Dr. William Roberto Wolf (Titular)

Instituição: UNICAMP - Externo

Julgamento: Aprovado 

Dedico este trabalho à minha esposa Anelis pelo apoio incondicional e paciência inesgotável. E aos meus pais, Elyane e Paulo que sempre me incentivaram nos estudos e que precisaram suportar longos períodos de minha ausência. 



\section{AGRADECIMENTOS}

Ao amigo Filipe Buscariolo por ser o grande incentivador e por ter intermediado a primeira conversa com Prof. Dr. Gustavo Roque da Silva Assi que prontamente aceitou a orientação cedendo seu tempo, conhecimento e conselhos para a definição do tema e desenvolvimento desta dissertação.

Aos amigos Flávio Sales, Fernando Braga e César Kamogawa pelos momentos de descontração e apoio que tornaram a soma das atividades de estudar e trabalhar menos extenuante.

Ao aconselhamento técnico de Jacques Ndione (General Motors), Rafael Ihi (Dassault Systèmes) e Murilo Cicolin (Poli - USP) que foram de grande valia para a construção dos modelos em PowerFLOW e para a escrita dos códigos em MATLAB utilizados na obtenção e análise dos resultados.

À General Motors por conceder a possibilidade de realização deste mestrado em paralelo às atividades de desenvolvimento e, por disponibilizar toda a infraestrutura necessária para as incontáveis horas de simulações computacionais realizadas. 



\section{RESUMO}

PADIAL, Lucas Mozelli. Investigação numérica do ruído aerodinâmico irradiado por barras prismáticas transversais. 2021. 126 f. Dissertação (Mestrado em Ciências) - Escola Politécnica, Universidade de São Paulo, São Paulo, 2021.

O ruído aerodinâmico é uma fonte de ruído relevante em automóveis e domina a pressão sonora total no interior do habitáculo em velocidades de cruzeiro acima dos $110 \mathrm{~km} / \mathrm{h}$ superando as contribuições sonoras oriundas da rodagem e do conjunto motopropulsor. Acessórios externos como os racks de teto podem irradiar ruído aerodinâmico com características tonais em adição ao ruído de banda larga, configurando assim um dos problemas mais críticos para o desempenho de aeroacústica de um veículo. Ciente das vantagens de comprovar o desempenho destes acessórios ainda nas fases inicias do projeto, optou-se por analisar, via método híbrido de aeroacústica computacional, o ruído radiado por cilindros submetidos a escoamento de ar transversal em regime subsônico e em diferentes configurações pelo fato destes possuírem vasta documentação técnica disponível e também por irradiarem ruído aerodinâmico com características semelhantes ao ruído emitido pelas barras transversais dos racks de teto. $\mathrm{O}$ método de Lattice-Boltzmann e a analogia acústica de Ffowcs-Williams e Hawkings foram aplicados nas simulações numéricas de casos como o de um cilindro isolado e o de cilindros alinhados em tandem em túnel de vento anecóico e o de um cilindro em túnel de vento semianecóico, sendo que, após a obtenção das curvas de densidade espectral de potência do ruído radiado, utilizou-se a análise de decomposição em modos dinâmicos para determinar as estruturas coerentes presentes no escoamento em cada uma das frequências de interesse. As frequências fundamentais e as harmônicas dos tonais foram capturadas com precisão de ao menos $95 \%$ e as amplitudes das curvas do ruído em campo afastado mostraram boa aproximação com os testes de referência. As estruturas coerentes resultantes da análise de decomposição em modos dinâmicos também apresentaram boa aproximação com a física dos problemas e a natureza do ruído aerodinâmico. O método abordado mostrou-se eficaz e versátil em aplicações de aeroacústica e aerodinâmica servindo de ferramenta importante na solução de problemas nas fases iniciais do projeto onde o custo de modificação é baixo e a facilidade de modificação elevada.

Palavras-chave: Aeroacústica computacional. Lattice-Boltzmann. Analogia acústica. Ffowcs Williams e Hawkings. Decomposição em modos dinâmicos. 



\begin{abstract}
PADIAL, Lucas Mozelli. Numerical investigation of aerodynamic noise irradiated by transverse prismatic bars. 2021. 126 f. Dissertação (Mestrado em Ciências) - Escola Politécnica, Universidade de São Paulo, São Paulo, 2021.
\end{abstract}

Aerodynamic noise is a relevant source of noise in ground vehicles, dominating the total sound pressure level inside the cabin at cruising speeds above $110 \mathrm{~km} / \mathrm{h}$ and exceeding the acoustic contributions of the road and powertrain. External accessories, such as roof racks, can irradiate aerodynamic noise with tonal characteristics in addition to the broadband noise, being this one of the most critical problems for vehicle's aeroacoustic performance. Aware of the advantages of verifying the performance of these accessories in the early stages of the project, it was decided to analyze, via hybrid computational aeroacoustics method, the noise radiated by transverse cylinders in subsonic air flow and in different configurations due to the fact that they have a wide range of technical documentation available and also for radiating aerodynamic noise with similar characteristics to the noise emitted by the roof rack crossbars. The LatticeBoltzmann method and the Ffowcs-Williams and Hawking acoustic analogy have been applied in numerical simulations of cases such as one cylinder and two cylinders arranged in tandem in an anechoic wind tunnel and that of a cylinder in a semi-anechoic wind tunnel and, after obtaining the power spectral density curves of the radiated noise the dynamic mode decomposition analysis was applied to determine the coherent structures present in the flow at each of the frequencies of interest. The fundamental frequencies and the harmonics of the tonal noise have been captured with an accuracy of at least $95 \%$ and the amplitudes of the far field noise power spectral density curves shown good approximation with the reference tests. The coherent structures resulting from the dynamic mode decomposition analysis also presented a good approximation with the physics of the simulated cases and with the nature of the aerodynamic noise. The method employed in the present investigation proved to be effective and versatile in aeroacoustics and aerodynamics applications, serving as important tool in solving problems in the early phases of the project where the cost of modification is low and the ease for modification high.

Keywords: Computational aeroacoustics. Lattice-Boltzmann. Acoustic analogy. FfowcsWilliams and Hawkings. Dynamic mode decomposition 



\section{LISTA DE SIGLAS}

$\begin{array}{ll}\text { BGK } & \text { Operador colisão de Bhatnagar, Gross e Krook } \\ \text { BPF } & \text { Band-Pass Filter } \\ \text { CAA } & \text { Computational Aeroacoustics } \\ \text { CFD } & \text { Computational Fluid Dynamics } \\ \text { DMD } & \text { Dynamic Mode Decomposition } \\ \text { DNC } & \text { Direct Noise Computation } \\ \text { FHP } & \text { Modelo de Frisch, Hasslacher e Pomeau } \\ \text { FW-H } & \text { Analogia acústica de Ffowcs-Williams e Hawkings } \\ \text { GM } & \text { General Motors } \\ \text { HPC } & \text { High-Performance Computing } \\ \text { HPP } & \text { Modelo de Hardy, Pomeau e Pazzis } \\ \text { ISO } & \text { International Organization for Standardization } \\ \text { LBGK } & \text { Modelo de Lattice-Boltzmann com operador colisão BGK } \\ \text { LBM } & \text { Lattice-Boltzmann Method } \\ \text { LGCA } & \text { Lattice Gas-Cellular Automata } \\ \text { NS } & \text { Navier-Stokes } \\ \text { NVH } & \text { Noise, Vibration and Harshness } \\ \text { POD } & \text { Proper Orthogonal Decomposition } \\ \text { PSD } & \text { Power Spectral Density } \\ \text { RMS } & \text { Root Mean Square } \\ \text { RNG } & \text { Renormalization Group } \\ \text { SVD } & \text { Single Value Decomposition } \\ \text { VLES } & \text { Very Large Eddy Simulation } \\ \text { VR } & \text { Variable Resolution }\end{array}$





\section{LISTA DE SÍMBOLOS}

$2 f_{0}, 3 f_{0}, 4 f_{0} \quad$ Frequências harmônicas de $f_{0}$

$\alpha \quad$ Ângulo polar de dipolos e quadrupolos

$\delta_{i j} \quad$ Delta de Kronecker

$\Delta \vec{x} \quad$ Distância entre nós adjacentes

$\Delta t \quad$ Incremento temporal ou timestep

$\varepsilon \quad$ Dissipação viscosa

$\tilde{\eta} \quad$ Combinação dos parâmetros local strain, local vorticity e local helicity

$\eta \quad$ Local strain

$\eta_{\omega} \quad$ Local vorticity

$\theta \quad$ Ângulo que indica posição na superfície do cilindro

$\kappa \quad$ Constante de Von-Kármán

$\Lambda \quad$ Autovalores $\lambda_{k}$ de $\tilde{A}$

$\lambda_{R e} \quad$ Parte real do autovalor $\lambda_{k}$

$\mu \quad$ Viscosidade dinâmica

$\mu_{\infty} \quad$ Viscosidade dinâmica no escoamento livre

$v_{0} \quad$ Viscosidade cinemática do fluído

$\rho \quad$ Massa específica

$\rho_{0} \quad$ Massa específica do fluido não perturbado

$\rho_{\infty} \quad$ Massa específica no escoamento livre

$\Sigma \quad$ Superfície de controle

$\sigma_{k} \quad$ Taxa de decaimento ou crescimento do modo DMD

$\Sigma_{s} \quad$ Valores singulares

$\tau_{r} \quad$ Tempo atrasado

$\tau \quad$ Tempo de relaxação do modelo Lattice BGK

$\tau_{\text {eff }} \quad$ Tempo de relaxação efetivo

$\tau_{w} \quad$ Tensão de cisalhamento

$\phi \quad$ Ângulo de posicionamento do microfone nas medições

$\Phi \quad$ Autovalores de $A$ 


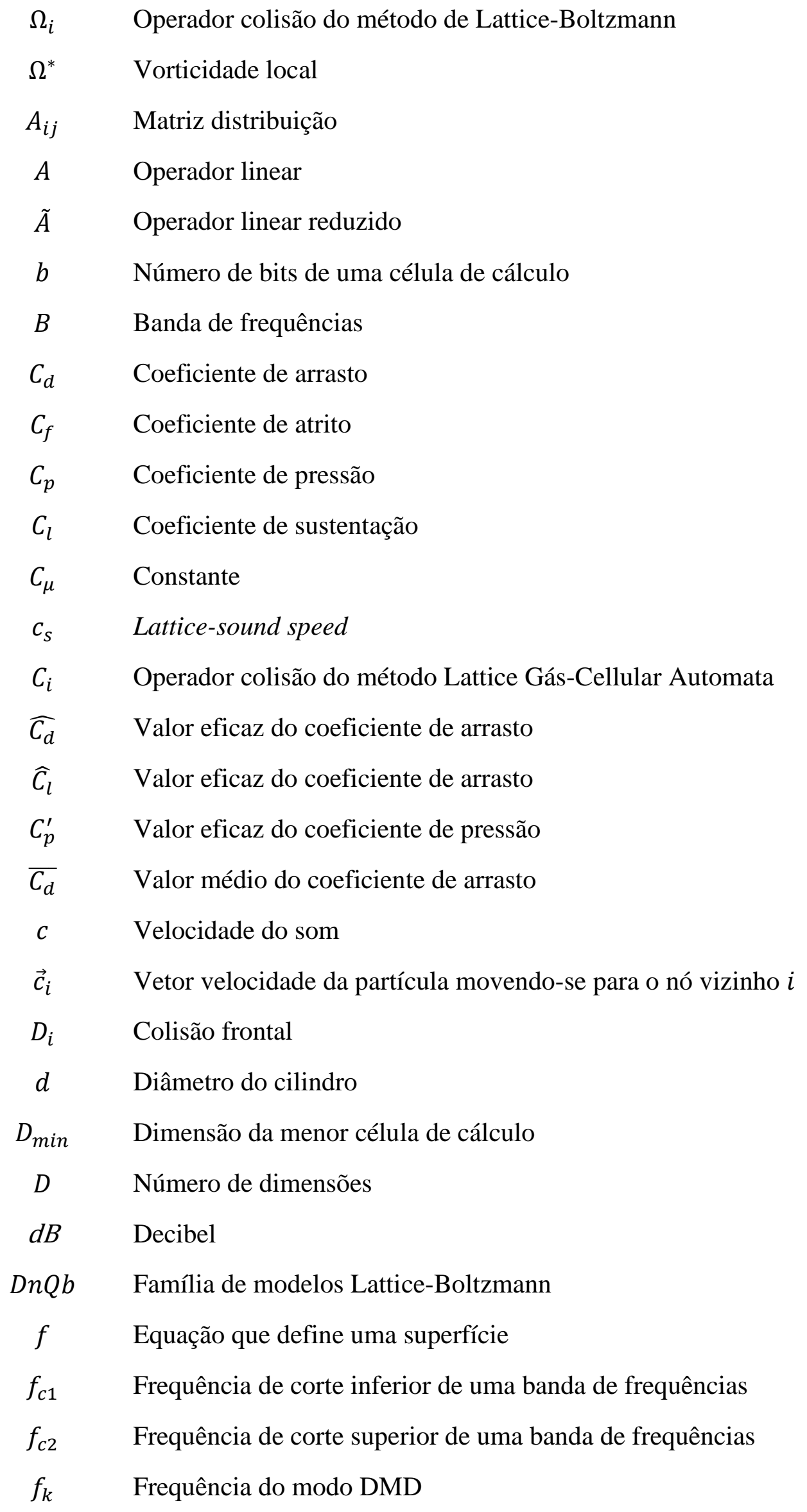




\begin{tabular}{|c|c|}
\hline$f_{0}$ & Frequência fundamental \\
\hline$f_{i}$ & Função distribuição \\
\hline$f_{i}^{e}$ & Parcela de $f_{i}$ em equilíbrio \\
\hline$f_{i}^{n e}$ & Parcela de $f_{i}$ em não-equilíbrio \\
\hline$G$ & Distância entre o cilindro e a superfície planar reflexiva \\
\hline$i$ & Índice que identificam os nós de uma célula de cálculo \\
\hline$k$ & Energia cinética turbulenta \\
\hline$K n$ & Número de Knudsen \\
\hline$\ell_{f}$ & Comprimento de formação de vórtices \\
\hline$l$ & Comprimento do cilindro \\
\hline$l_{u}$ & Distância média percorrida entre duas colisões consecutivas \\
\hline$L$ & Distância que separa os cilindros dispostos em tandem \\
\hline$L_{s}$ & Razão de aspecto do cilindro simulado \\
\hline$M_{r}$ & Componente do número de Mach da superfície $S$ na direção do observador \\
\hline$m$ & Massa de uma partícula \\
\hline$M$ & Número de Mach \\
\hline$n_{i}(\vec{x}, t)$ & Booleana de ocupação \\
\hline$N_{i}(\vec{x}, t)$ & Média de conjunto \\
\hline$\vec{n}$ & Normal apontando para fora da superfície $S$ \\
\hline$N$ & Número de reticulados por unidade de comprimento \\
\hline$O$ & Ordem da expansão matemática \\
\hline$p_{r}^{\prime}$ & Intensidade de flutuação de pressão da onda radiada \\
\hline$P_{i}$ & Força total que a superfície exerce sobre o fluido \\
\hline$p$ & Pressão \\
\hline$p_{\infty}$ & Pressão no escoamento livre \\
\hline$Q_{i j}$ & Contribuição de todos os quadrupolos externos \\
\hline$q$ & Probabilidade de rotação para esquerda ou direita no evento pós colisão \\
\hline$r_{s}$ & Distância radial medida à partir do centro de um monopolo \\
\hline$R^{*}$ & Parâmetro de modelos LGCA \\
\hline$R e$ & Número de Reynolds \\
\hline
\end{tabular}




\begin{tabular}{|c|c|}
\hline$r$ & Distância entre a fonte e o observador \\
\hline$S$ & Gradiente de velocidades local \\
\hline$S$ & Superfície determinada pela equação $f$ \\
\hline St & Número de Strouhal \\
\hline$T_{i}$ & Colisão tripla \\
\hline$t$ & Instante de tempo \\
\hline$T_{L}$ & Lattice-temperature \\
\hline$T$ & Temperatura \\
\hline$T_{i j}$ & Tensor de Lighthill \\
\hline$\vec{u}$ & Campo de velocidades do escoamento \\
\hline$u^{+}$ & Velocidade adimensional paralela a parede \\
\hline$u_{\tau}$ & Velocidade de atrito \\
\hline$U$ & Vetores singulares à esquerda \\
\hline$\dot{v}_{i}$ & Aceleração da superfície $S$ \\
\hline$\vec{v}$ & Velocidade da superfície $S$ \\
\hline$V_{\infty}$ & Velocidade no escoamento livre \\
\hline$V_{s}$ & Vetores singulares à direita \\
\hline$V_{0}$ & Volume delimitado pela superfície $S$ \\
\hline$V$ & Volume delimitado pela superfície $\Sigma$ \\
\hline$W$ & Autovetores de $\tilde{A}$ \\
\hline$w_{i}$ & Fator ponderação \\
\hline$X^{\prime}$ & Matriz com dados experimentais rearranjados \\
\hline$X$ & Matriz com dados experimentais rearranjados \\
\hline$\vec{x}$ & Vetor posição de um nó \\
\hline$y^{+}$ & Distância adimensional da parede \\
\hline$y$ & Distância da parede \\
\hline
\end{tabular}




\section{SUMÁRIO}

1 INTRODUÇÃ

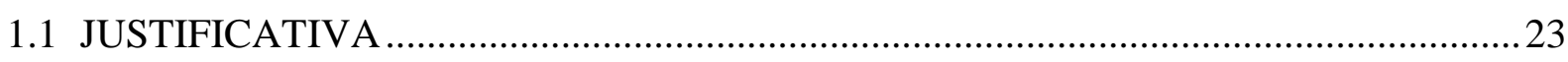

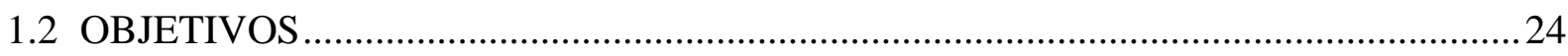

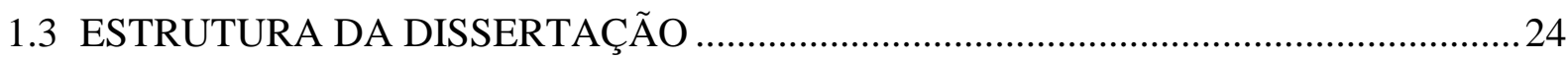

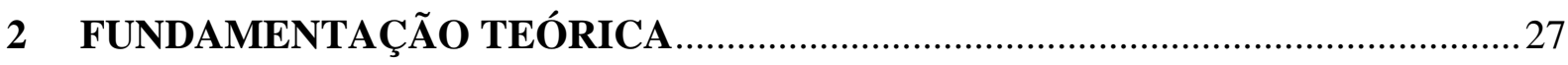

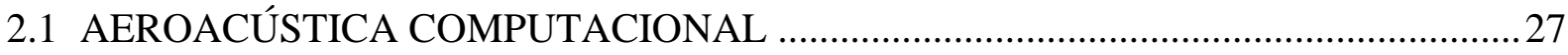

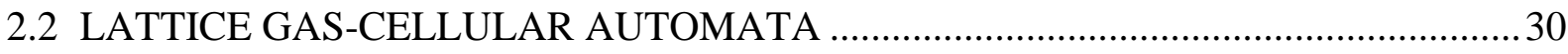

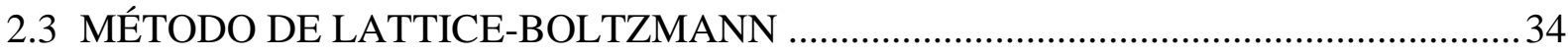

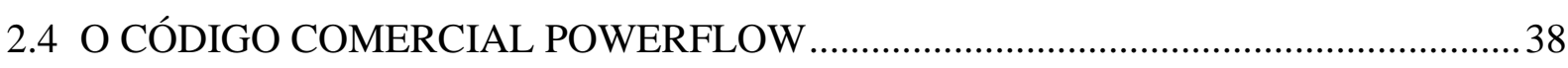

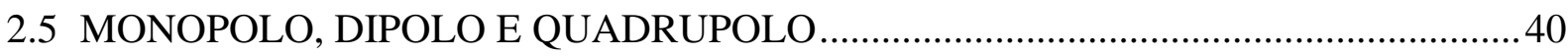

2.6 ANALOGIA ACÚSTICA DE FFOWCS-WILLIAMS E HAWKINGS ............................4

2.7 DECOMPOSIÇÃO EM MODOS DINÂMICOS ......................................................... 44

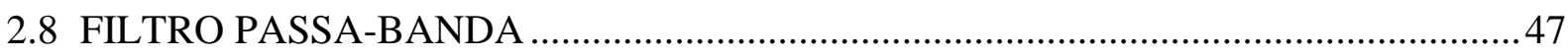

3 VERIFICAÇÃO DA EFICÁCIA DO MÉTODO HÍBRIDO …………......................4 49

3.1 DADOS EXPERIMENTAIS DE REFERÊNCIA ………...........................................49

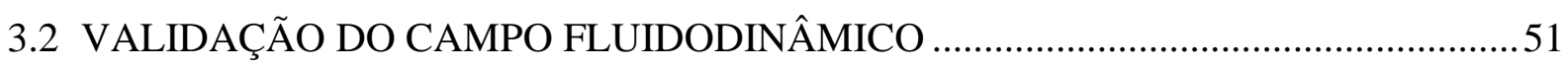

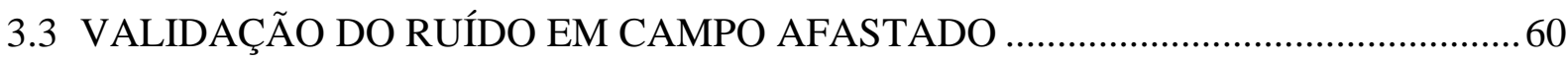

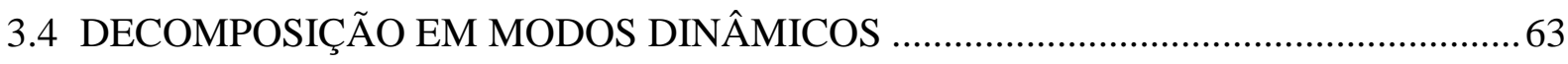

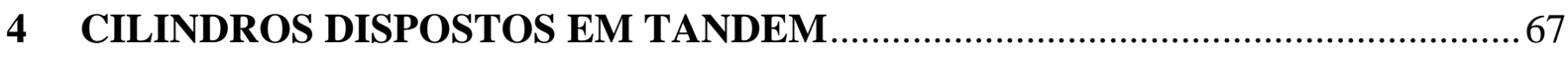

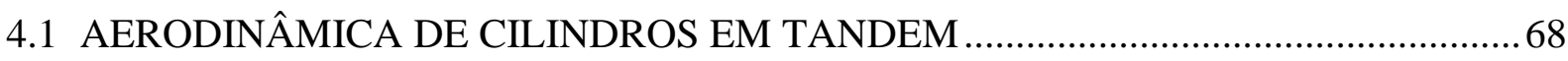

4.2 MODELO COMPUTACIONAL E CAMPO FLUIDODINÂMICO .................................69

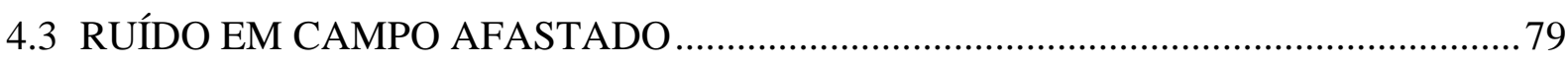

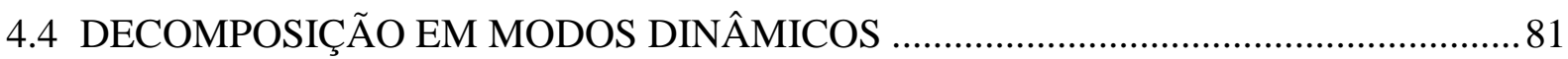

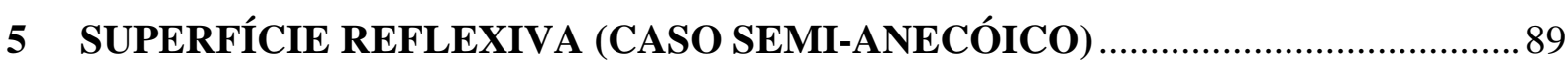

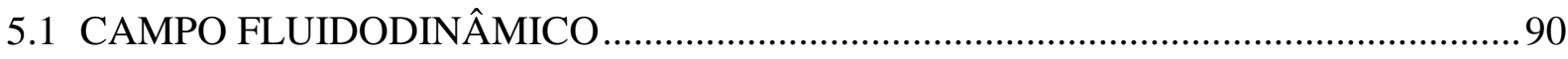

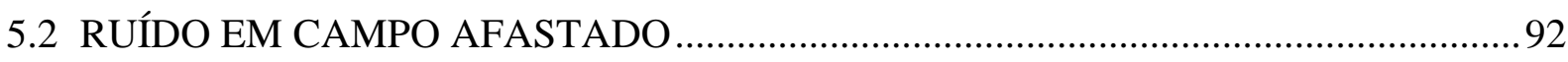

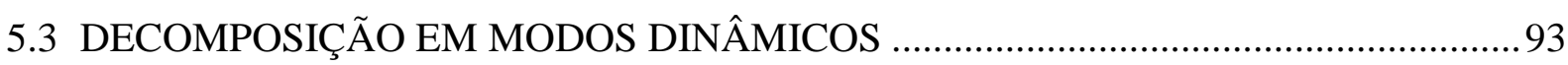

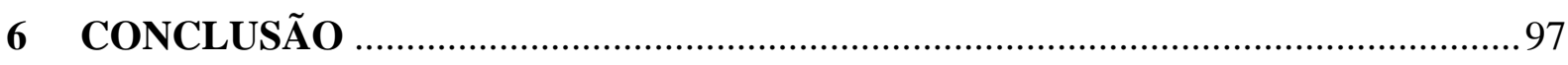

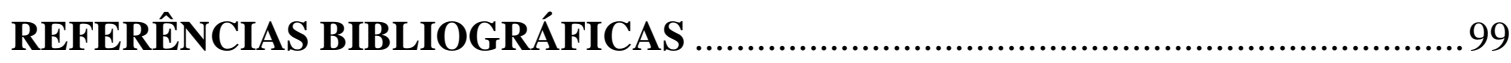

APÊNDICE A - CAMPO FLUIDODINÂMICO: CASO ANECÓICO.....................107

APÊNDICE B - CAMPO FLUIDODINÂMICO: CILINDROS EM TANDEM ......111

APÊNDICE C - CAMPO FLUIDODINÂMICO: CASO SEMI-ANECÓICO ........123 



\section{INTRODUÇÃO}

O desempenho de ruídos e vibrações é um critério relevante na validação de automóveis e está diretamente associada a percepção de refino e qualidade do projeto, uma vez que a exposição prolongada a níveis elevados desses parâmetros induz estresse e fadiga nos ocupantes. O tema de estudo Ruídos, Vibrações e Aspereza mais conhecido pelo acrônimo em inglês NVH (Noise, Vibration and Harshness) é responsável por definir requisitos, aferir e modificar as características de ruídos e vibrações de veículos e tem se tornado mais importante em decorrência da crescente exigência dos consumidores (WANG, 2010).

Wang (2010) cita que o ruído audível com frequência entre $20 \mathrm{~Hz}$ e 20 kHz observado pelos ocupantes de um automóvel é dividido em dois grupos: o primeiro deles é o ruído estrutural, ou do inglês structure-borne noise, transmitido pela estrutura do veículo; e o segundo é o ruído aéreo, ou airborne noise, transmitido unicamente pelo ar.

As três principais fontes de ruído (estrutural e aéreo) em automóveis são o conjunto motopropulsor, os pneus e o escoamento de ar ao redor do veículo. O balanço das fontes que constituem o ruído interno total depende da velocidade e da carga instantânea no conjunto motopropulsor. Quando em velocidade de cruzeiro constante, próximas dos $80 \mathrm{~km} / \mathrm{h}$, o ruído é resultado da rodagem e da aerodinâmica, sendo o ruído aerodinâmico predominante em velocidades acima dos $110 \mathrm{~km} / \mathrm{h}$. Em acelerações através das marchas todas as fontes são relevantes e, quando o veículo está parado e em marcha lenta, o conjunto motopropulsor é a fonte dominante (FAHY; WALKER, 2004).

Dentre todos os sistemas de um automóvel de passeio, o ruído aerodinâmico foi o item mais reclamado em pesquisas de satisfação com consumidores entre os anos de 1987 e 2014, sendo superado em 2015 por reclamações relacionadas ao sistema de infoentretenimento (OETTLE; SIMS-WILLIAMS, 2017).

Fatores como a geometria do veículo e de componentes externos (retrovisores, maçanetas, limpadores de para-brisa, rack de teto, etc.), espessura dos vidros, guarnições, cavidades abertas (teto solar, vidros abertos, vãos ao redor das portas ...) e isolamento acústico determinam o nível de pressão sonora no habitáculo (OETTLE; SIMS-WILLIAMS, 2017).

Segundo Karbon e Dietschi (2005) racks de teto são acessórios comuns que além da função primária de sustentar cargas, muitas vezes são utilizados como elementos estéticos, vide exemplo mostrado na Figura 1. Dependente da geometria e das configurações de fixação o ruído radiado por esses acessórios pode apresentar características tonais (aeolian tones) em adição ao ruído de banda larga. 


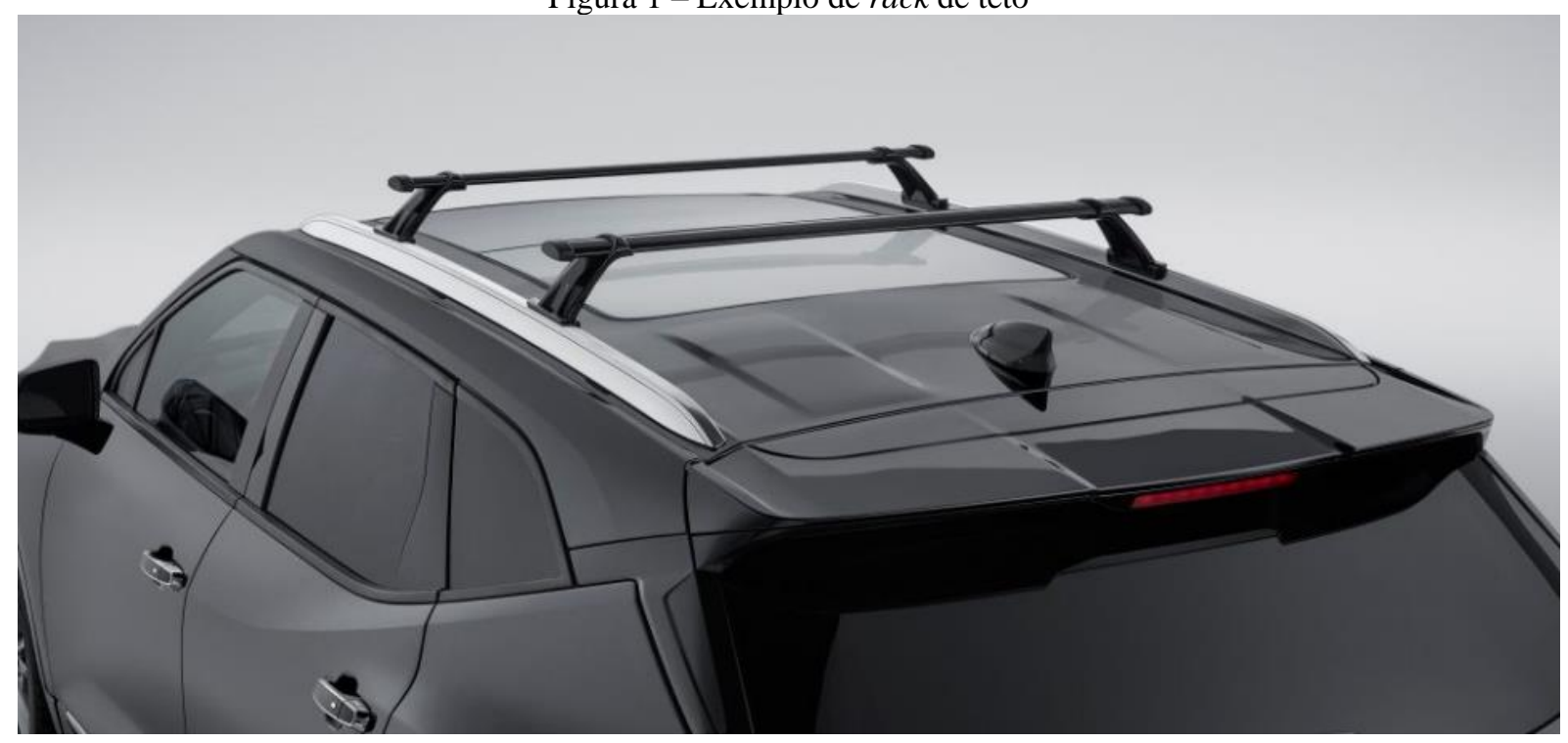

Fonte: Chevrolet (2020).

Entende-se como ruído de banda larga o ruído cuja análise espectral possui energia distribuída em uma ampla faixa de frequências. Já os tonais são definidos segundo a norma ISO 1996-2:2007, como possuindo uma determinada banda do espectro de frequência proeminente em relação às bandas adjacentes por um certo valor em decibéis $(\mathrm{dB})$ que depende da frequência central da banda de maior energia. Tonais com frequência fundamental $\left(f_{0}\right)$ também podem manifestar-se com níveis de intensidade progressivamente menores em frequências harmônicas múltiplas inteiras da frequência fundamental $\left(2 f_{0}, 3 f_{0}, 4 f_{0} ..\right)$ como o caso dos aeolian tones.

A natureza tonal do ruído radiado por racks de teto é resultado da emissão de vórtices fortemente correlacionados nas barras transversais. Conhecendo-se o número Strouhal $(S t)$ da geometria das barras é possível determinar o valor da frequência fundamental $\left(f_{0}\right)$ para diferentes velocidades de cruzeiro (WANG, 2010).

Massarotti (2017) cita que a presença de ruídos tonais durante a condução de um automóvel é inaceitável e representa um dos problemas mais críticos para o desempenho aeroacústico de um veículo.

Com a tendência de eletrificação da frota mundial, o desenvolvimento da aeroacústica tornou-se um desafio importante na indústria automotiva. Uma vez que os motores elétricos possuem características de emissão de ruído diferentes das observadas nos motores à combustão, o balanço entre as fontes sonoras é alterado e, dependendo da intensidade sonora destas fontes, o ruído aerodinâmico pode sobressair-se em velocidades de cruzeiro mais baixas, aumentando a importância das técnicas de predição e concepção do desempenho aeroacústico veicular. 


\subsection{JUSTIFICATIVA}

O desenvolvimento de um automóvel dura anos e compreende etapas que vão desde os estudos avançados na fase conceitual até o início da produção. Durante o amadurecimento ou refino do projeto a geometria do veículo sofre modificações a fim de atender às necessidades estéticas e aos requisitos de engenharia, sendo a evolução do custo e da facilidade de modificação ao longo do cronograma de desenvolvimento detalhada na Figura 2. Nota-se que as curvas são inversamente proporcionais e que na fase de conceituação é onde há maior facilidade de modificação da geometria com menor custo atrelado.

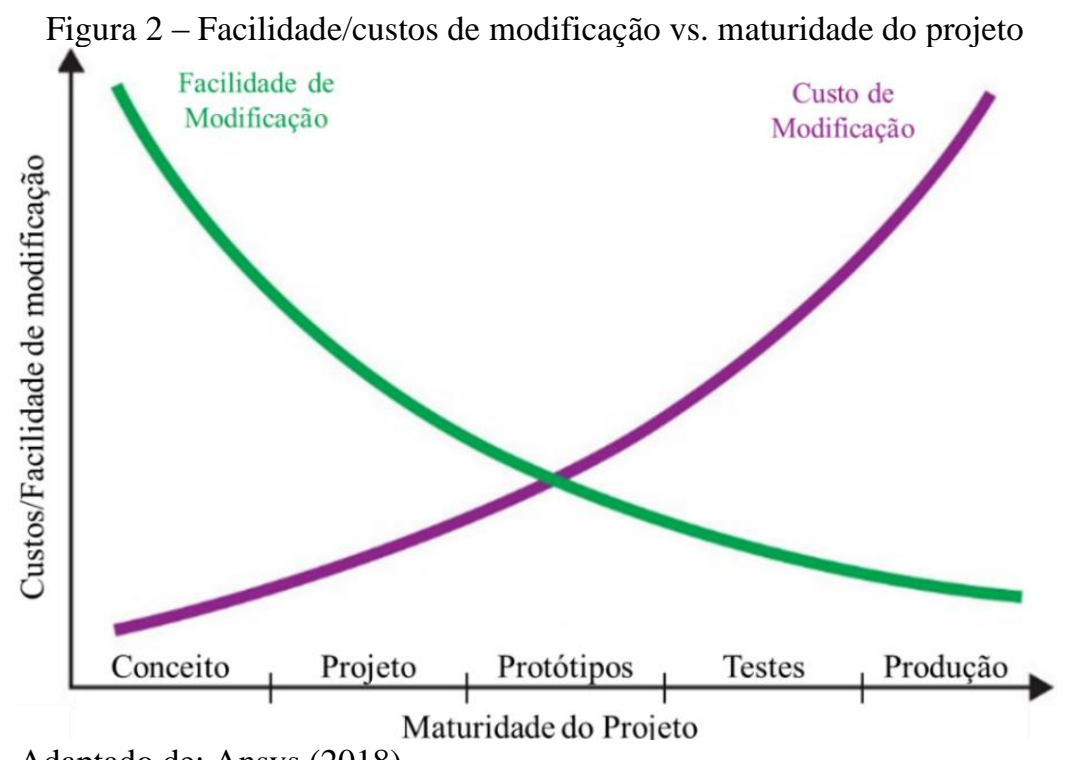

Adaptado de: Ansys (2018).

Historicamente, a aferição e comprovação do desempenho aeroacústico era realizado apenas em testes com protótipos em túnel de vento, porém, com o desenvolvimento da capacidade computacional e dos métodos numéricos de aeroacústica, tornou-se possível avaliar o ruído aerodinâmico ainda nas fases iniciais do projeto.

As técnicas computacionais viabilizam a concepção de geometrias com menor ruído de banda larga e nível de tonais mitigados antes mesmo da construção do primeiro protótipo, reduzindo a necessidade de testes, encurtando o tempo de projeto e otimizando os custos.

Ciente do retorno financeiro, da velocidade de resposta e da facilidade de implementação das modificações nas fases iniciais, propõe-se realizar simulações com modelos numéricos de cilindros submetidos ao escoamento de ar transversal, similarmente ao escoamento de ar ao redor das barras transversais de racks de teto. Os cilindros foram escolhidos por serem geometrias extensivamente estudadas e possuírem vasta documentação técnica disponível. 


\subsection{OBJETIVOS}

O objetivo desta investigação é analisar, empregando-se um método híbrido de aeroacústica computacional, o ruído radiado por barras prismáticas submetidas ao escoamento de ar transversal com baixo número de $\operatorname{Mach}(M \approx 0,06)$.

Como objetivos específicos listam-se:

a) Avaliar a eficácia do método híbrido de aeroacústica computacional utilizando os métodos de Lattice Boltzmann e a analogia acústica de Ffowcs-Williams \& Hawkings na solução do ruído radiado por um cilindro sujeito ao escoamento transversal de ar em condições que simulam um túnel de vento anecóico (Figura 3a);

b) Analisar o ruído aerodinâmico radiado por cilindros alinhados ou em tandem com três diferentes separações na direção do escoamento (Figura 3b);

c) Avaliar como a presença de uma superfície planar reflexiva no campo fluidodinâmico próximo interfere nos resultados do ruído calculado em campo afastado (Figura 3c);

d) Comparar as estruturas fluidodinâmicas coerentes provenientes da análise de Decomposição em Modos Dinâmicos (DMD) com as obtidas mediante análise do histórico temporal das flutuações de pressão com filtro passa-banda aplicado nas frequências de interesse e comprovar a relevância destas ferramentas na solução de problemas de engenharia.

Figura 3 - Esquema ilustrativo dos casos simulados

a) × Campo afastado

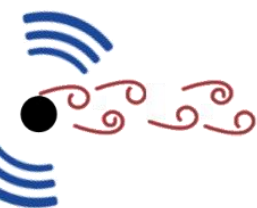

b) $\times$ Campo afastado

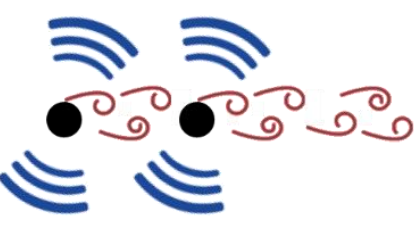

c)

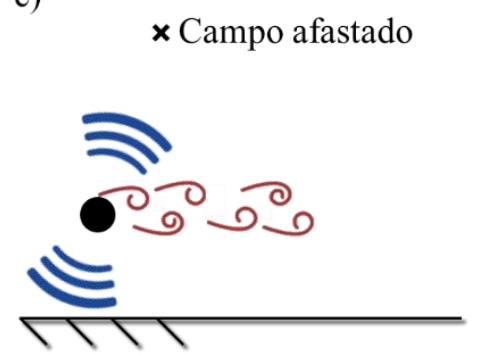

\subsection{ESTRUTURA DA DISSERTAÇÃO}

Além da introdução esta dissertação é dividida em outros cinco capítulos:

- Capítulo 2 apresenta uma breve introdução aos conceitos de aeroacústica computacional além de uma revisão bibliográfica dos métodos de Lattice-Boltzmann, analogia acústica de Ffowcs Williams \& Hawkings e Decomposição em Modos Dinâmicos. 
Complementarmente, expõem-se particularidades do software comercial de dinâmica dos fluídos PowerFLOW;

- Capítulo 3 constata a eficácia dos métodos computacionais escolhidos para o cálculo do ruído em campo afastado no caso de um cilindro sujeito a escoamento de ar transversal com número de Mach $(M \approx 0,06)$ simulando um túnel de vento anecóico;

- Capítulo 4 estende o uso do modelo validado no capítulo 3 para o caso de cilindros de diâmetro $(d)$ alinhados na direção do escoamento com três diferentes separações medidas de centro a centro $(L)$ sendo elas: $L / d=1,0,2,5$ e 4,0;

- Capítulo 5 verifica a influência no cálculo do ruído em campo afastado devido a presença de uma superfície plana, reflexiva, paralela ao escoamento e distante $100 \mathrm{~mm}$ do centro do cilindro do capítulo 3;

- Capítulo 6 apresenta a conclusão da dissertação e as principais contribuições do presente estudo; 


\section{FUNDAMENTAÇÃO TEÓRICA}

Este capítulo é dedicado à abordagem dos principais conceitos físicos e matemáticos utilizados como ferramentas no cumprimento dos objetivos enunciados. São explanados conceitos de aeroacústica computacional, dos métodos de Lattice-Boltzmann e analogia acústica de Ffowcs Williams e Hawkings, assim como a Decomposição em Modos Dinâmicos (DMD). Adicionalmente, expõe-se particularidades da implementação comercial dos métodos supracitados nos softwares PowerFLOW e PowerACOUSTICS. São citadas diversas publicações científicas que servem de referência aos que desejarem aprofundar os conceitos nas metodologias aqui apresentadas.

\subsection{AEROACÚSTICA COMPUTACIONAL}

Aeroacústica é a ciência que abrange conceitos de fluidodinâmica e acústica com o objetivo de elucidar os mecanismos de geração e propagação do ruído radiado devido ao escoamento de ar ao redor de corpos rombudos (ruído aerodinâmico). Dois fenômenos que resultam em ondas sonoras são: a movimentação relativa entre fluido e superfície sólida e a turbulência. Uma pequena parcela da energia do escoamento turbulento do campo próximo é convertida em ondas sonoras que se propagam até o campo afastado (meio quiescente) (ANSELMET; MATTEI, 2016; HOWE, 2003; WAGNER; HÜTTL; SAGGAUT, 2007).

Historicamente o estudo da aeroacústica era limitado aos métodos analíticos e experimentais, porém, com o amadurecimento das técnicas de Dinâmica dos Fluidos Computacional (Computational Fluid Dynamics - CFD) aliado ao crescimento do poder computacional, tornou-se possível o desenvolvimento da metodologia conhecida como Aeroacústica Computacional (Computational Aeroacoustics - CAA) que consiste em utilizar técnicas e códigos computacionais no cálculo do ruído aerodinâmico (WAGNER; HÜTTL; SAGGAUT, 2007).

O método direto (Direct Noise Computation - DNC) consiste em resolver por meio de simulações computacionais, de forma direta e completa, as equações acopladas de NavierStokes em todo o domínio de interesse, desde o campo próximo até o campo afastado, combinando em uma única solução, o escoamento turbulento e o campo sonoro.

Em escoamentos com baixo número de Mach $(M)$ a velocidade e o comprimento da onda sonora irradiada são geralmente muito maiores que a velocidade do escoamento e o comprimento característico das estruturas turbilhonares presentes no escoamento respectivamente (WAGNER; HÜTTL; SAGGAUT, 2007; GLEGG; DEVENPORT, 2017). 
Tal disparidade nas escalas de comprimento e velocidade tornam o método DNC custoso computacionalmente, pois exige um domínio de cálculo com grandes dimensões (propagação das ondas até o campo afastado) e discretização espaço-temporal muito refinada (solução das menores escalas do escoamento turbulento). Outro fator que dificulta o uso do método direto é a difusão numérica, que pode acarretar em dissipação significativa da energia inerente às pequenas flutuações acústicas antes mesmo destas propagarem-se até o receptor em campo afastado (GLEGG; DEVENPORT, 2017; WAGNER; HÜTTL; SAGGAUT, 2007).

Com o propósito de reduzir o esforço computacional é conveniente resolver separadamente os fenômenos de geração e propagação do ruído aerodinâmico (o que se denomina método híbrido), onde a solução não-estacionária de uma simulação CFD serve como fonte para um código de cálculo do ruído propagado (WAGNER; HÜTTL; SAGGAUT, 2007, ORSELLI, 2012).

Orselli (2012) e Wagner; Hüttl e Saggaut (2007) descrevem alguns dos métodos híbridos disponíveis, dentre eles o método baseado na analogia acústica de Ffowcs-Williams e Hawkings (FW-H), que consiste em integrar as fontes sonoras de um dado campo fluidodinâmico próximo a fim de obter o ruído em um campo afastado.

Diversos códigos CFD podem ser utilizados na solução do campo fluidodinâmico que serve de entrada para o cálculo do ruído em campo afastado, sendo os métodos fundamentados na solução numérica das equações de Navier-Stokes (NS) frequentemente utilizados. As formulações e particularidades nas tratativas de turbulência dos códigos NS são encontradas em textos como os de Maliska (2014), Versteeg e Malalasekera (2007), Zienkiewicz, Taylor e Nithiarasu (2014), Colonius e Lele (2004) dentre outros citados por Orselli (2012).

Nas décadas de 70 e 80 uma nova classe de modelos emergiu como alternativa aos tradicionais métodos embasados nas equações NS. Com origens na teoria cinética microscópica, essa nova classe de modelos possui equacionamento simples capaz de descrever escoamentos complexos. Um dos primeiros métodos a seguir tal metodologia é o Lattice GasCellular Automata (LGCA) que serviu de base para outros modelos como o Lattice-Boltzmann.

Os pioneiros do LGCA foram Hardy, Pomeau e Pazzis (1973) com o modelo intitulado HPP que consiste em distribuir partículas fictícias microscópicas nos vértices de um reticulado quadrangular e iterativamente redistribuí-las por meio da aplicação dos operadores propagação e colisão a fim de obter a fluidodinâmica do sistema. Uma das desvantagens do HPP é que a geometria básica do reticulado (quadrilátero) não possui simetrias suficientes para satisfazer as equações de continuidade e produz turbilhões de formato quadrado (AIDUN; CLAUSEN, 2010; CHEN; DOOLEN, 1998; HARDY; POMEAU; PAZZIS, 1973; SUCCI, 2001). 
Reconhecendo a importância da quantidade de simetrias do reticulado, Frisch, Hasslacher e Pomeau (1986) propuseram o método conhecido como FHP formado por um reticulado triangular em que cada vértice possui seis vizinhos fornecendo assim simetrias suficientes para garantir a invariância rotacional das equações de NS, permitindo com que seus autores fossem os primeiros a obter as equações de Navier-Stokes partindo das equações do método LGCA (AIDUN; CLAUSEN, 2010; CHEN; DOOLEN, 1998; FRISCH; HASSLACHER; POMEAU, 1986; SUCCI, 2001).

A principal vantagem do modelo FHP é que ele possui operações puramente booleanas e livres de arredondamentos, com capacidade de paralelização tecnicamente ilimitada. Sua principal desvantagem é o erro estatístico associado à esta natureza booleana das operações e à intensa atividade molecular dos fluidos, que resulta em uma flutuação constante dos valores macroscópicos das variáveis fluidodinâmicas, mesmo quando o sistema encontra-se em equilíbrio (KRÜGER et al., 2017; SUCCI, 2001).

Proposto por McNamara e Zanetti (1988), o método de Lattice-Boltzmann (LatticeBoltzmann Method - LBM) surgiu como uma alternativa bem-sucedida de contornar o erro estatístico oriundo do seu principal antecessor, o método FHP. Com equacionamento fundamentado na teoria cinética da mesoescala e na equação de Boltzmann (física estatística), o método descreve a dinâmica macroscópica como o resultado do comportamento coletivo de conjuntos de partículas microscópicas através da aplicação de operações de colisão e propagação (AIDUN; CLAUSEN, 2010; CHEN; DOOLEN, 1998; MARIÉ; RICOT; SAGAUT, 2008; MCNAMARA; ZANETTI, 1988; SUCCI, 2001).

Devido ao avanço da computação de alto desempenho (High-Performance Computing - HPC) e à grande capacidade de paralelização do LBM, o método vem apresentando bons resultados na solução de casos complexos, inclusive no ramo da aeroacústica computacional, como mostrado em Marié; Ricot e Sagaut (2008), Brès, Wessels e Noelting (2010), Casalino, Hazir e Mann (2017) e Casalino et al. (2014).

Tomando como base os fatos aqui expostos e as características dos escoamentos investigados neste trabalho $(M \cong 0,06)$, optou-se por utilizar o método híbrido de aeroacústica computacional resolvendo o escoamento via método de Lattice-Boltzmann e o campo sonoro ao longe via método de Ffowcs Williams e Hawkings. Os códigos comerciais PowerFLOW e PowerACOUSTICS possuem rotinas de LBM e FW-H implementadas e foram selecionados no cumprimento dos objetivos declarados. 


\subsection{LATTICE GAS-CELLULAR AUTOMATA}

Historicamente o método de Lattice-Boltzmann evoluiu do método Lattice GasCellular Automata, porém, outra maneira de obter as equações do LBM é derivá-las diretamente da equação de Boltzmann. A primeira conduta de obtenção é favorável ao aprendizado, pois utiliza dos mesmos formalismos matemáticos do LGCA que corroboram à compreensão da física intrínseca ao LBM (GUO; SHU, 2013; SUCCI, 2018).

Os pioneiros na técnica LGCA foram Hardy, Pomeau e Pazzis que propuseram, em 1973, o modelo HPP, que consiste em distribuir partículas fictícias em um reticulado quadrangular no qual as partículas são livres para movimentar-se e colidirem respeitando as leis de conservação em nível molecular (GUO; SHU, 2013; KRÜGER et al., 2017; SUCCI, 2001).

Apesar de satisfazer as equações de conservação, o modelo HPP, diferente das equações de Navier-Stokes, falha em garantir a invariância rotacional (anisotropia) devido ao baixo número de simetrias do reticulado quadrangular. A dinâmica microscópica coletiva não reproduz com fidelidade a hidrodinâmica macroscópica resultando nos turbilhões "quadrados" citados anteriormente (SUCCI, 2001; GUO; SHU, 2013).

Frisch, Hasslacher e Pomeau reconheceram a importância do número de simetrias do reticulado e propuseram, em 1986, o método FHP, formado por um reticulado triangular com simetria hexagonal capaz de assegurar a isotropia e, pela primeira vez, as equações de NavierStokes foram recuperadas corretamente partindo das equações de um método com origem na teoria cinética molecular (CHEN; DOLLEN, 1998; SUCCI, 2018).

Uma célula de cálculo hexagonal utilizada no FHP é formada por um nó central e seis nós vizinhos (célula de 6-bits: $b=6$ ) identificados pelo índice $i(i=1,2, \ldots, b)$, conforme ilustrado na Figura 4 (SUCCI, 2018; FRISCH; HASSLACHER; POMEAU, 1986).

Figura 4 - Representação gráfica de uma célula hexagonal do reticulado triangular do método FHP

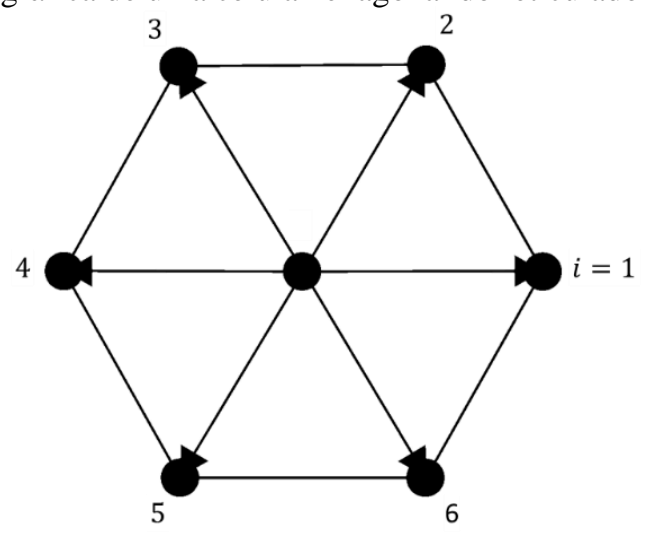

Adaptado de: Succi (2018) 
Cada nó do reticulado pode ou não conter uma partícula, introduzindo assim o conceito da booleana de ocupação $\left(n_{i}\right)$, sendo que $n_{i}(\vec{x}, t)=1$ significa a presença de partícula no nó de posição $\vec{x}$ no instante de tempo $t$ e $n_{i}(\vec{x}, t)=0$ indica ausência de partícula (CHEN; DOOLEN, 1998; SUCCI, 2018).

Guo e Shu (2013), Succi (2001) e Wolf-Gladrow (2000) citam outras propriedades importantes da formulação FHP:

a) todas as partículas possuem a mesma massa $(m=1)$;

b) espaço e tempo são discretos ( $\Delta \vec{x}$ - distância entre os nós lattice units e $\Delta t$ - incremento temporal);

c) cada partícula move-se na direção do vizinho mais próximo apontado pelo vetor velocidade $\vec{c}_{i}$ (lattice velocities) sendo $\left|\vec{c}_{i}\right|=1$ em qualquer direção $i$

d) não é permitido mais de uma partícula em um mesmo nó movendo-se na mesma direção (princípio da exclusão).

A maneira como as moléculas se movimentam em cada incremento de tempo $\Delta t$ é regida por duas leis que representam a evolução temporal das booleanas de ocupação $n_{i}$. A primeira delas é conhecida como propagação ou free-streaming, um operador linear que determina a movimentação de uma partícula com posição $\vec{x}$ e vetor velocidade $\vec{c}_{i}(i=$ $1,2,3, \ldots, b)$ para seu vizinho no instante de tempo $t+\Delta t$. A segunda é uma lei de colisão estritamente local, que define como as partículas serão redistribuídas caso duas ou mais se encontrarem com vetores velocidades concorrentes em uma mesma célula de cálculo e em um mesmo instante de tempo (CHOPARD; DROZ, 1998; KRÜGER et al., 2017; SUCCI, 2018).

Sabendo que a distância entre dois nós adjacentes é dada por $\Delta \vec{x}=\vec{c}_{i} \Delta t$, escreve-se a equação da propagação:

$$
n_{i}\left(\vec{x}+\vec{c}_{i} \Delta t, t+\Delta t\right)=n_{i}(\vec{x}, t)
$$

A equação (2.1) expressa que uma partícula chegando ao nó $\vec{x}$ no instante de tempo $t$ seguirá na direção apontada por seu vetor velocidade $\vec{c}_{i}$, adentrará o nó $\vec{x}+\vec{c}_{i} \Delta t$ no instante de tempo $t+\Delta t$ e permanecerá em linha reta até que um evento de colisão altere a direção do seu vetor velocidade (CHOPARD; DROZ, 1998).

Uma vez que as partículas se encontrem na mesma célula, elas colidem e podem sofrer uma rotação de $\pi / 6$ na direção de seu vetor velocidade, redistribuindo-se para uma das seis direções possíveis, de forma a obedecer às leis da conservação (CHOPARD; DROZ, 1998). 
O evento de colisão $\left(C_{i}\right)$ altera as booleanas de ocupação $n_{i}$ de uma determinada célula:

$$
n_{i}(\vec{x}, t)+C_{i}
$$

A eq. (2.2) expressa o número de partículas com velocidade $\vec{c}_{i}$ que serão mantidas na direção $i$ após a colisão (CHOPARD; DROZ, 1998).

Das equações (2.1) e (2.2) pode-se escrever a equação geral do método LGCA como:

$$
n_{i}\left(\vec{x}+\vec{c}_{i} \Delta t, t+\Delta t\right)=n_{i}(\vec{x}, t)+C_{i}
$$

O evento de colisão é estritamente local e calculado em cada célula individualmente, sendo o modelo mais simples conhecido como FHP-I no qual são consideradas apenas a colisão frontal entre duas partículas e a colisão entre três partículas conforme ilustra a Figura 5. A colisão frontal pode resultar em dois estados pós colisão sendo que cada um deles possui a mesma probabilidade $(q)$ de ocorrer e são escolhidos de forma aleatória pelo algoritmo (GUO; SHU, 2013; SUCCI, 2018, CHOPARD; DROZ, 1998; FRISCH et al., 1987).

Figura 5 - Colisão frontal entre duas partículas (esquerda) colisão simétrica entre três partículas (direita)

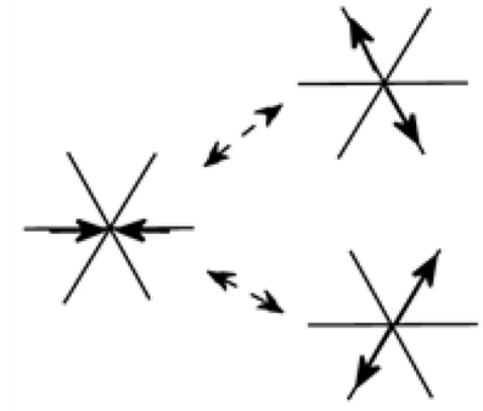

Adaptado de: Guo e Shu (2013)

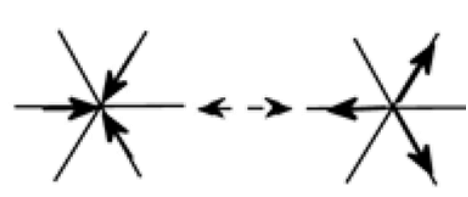

No caso do operador colisão do modelo FHP-I, duas grandezas dependentes do estado inicial na célula de cálculo determinam qual colisão ocorrerá na célula $\vec{x}$ sendo, $D_{i}$ para colisão frontal e $T_{i}$ para colisão tripla:

$$
\begin{gathered}
D_{i}=n_{i} n_{i+3}\left(1-n_{i+1}\right)\left(1-n_{i+2}\right)\left(1-n_{i+4}\right)\left(1-n_{i+5}\right) \\
T_{i}=n_{i} n_{i+2} n_{i+4}\left(1-n_{i+1}\right)\left(1-n_{i+3}\right)\left(1-n_{i+5}\right)
\end{gathered}
$$

O valor $D_{i}=1$ indica que a colisão frontal ocorrerá e as partículas serão rotacionadas com um ângulo de $\pi / 6$ para a esquerda ou para a direita, ambas com a mesma probabilidade $q$ 
de ocorrer. O número de partículas deixadas na posição $n_{i}$ e direção $\vec{c}_{i}$ é dada por $n_{i}-D_{i}$ e o número de partículas que surgirão nas outras direções é dada por:

$$
q D_{i-1}+(1-q) D_{i+1}
$$

Realizando o mesmo quando $T_{i}=1$ e somando as contribuições de $D_{i}$ e $T_{i}$, pode-se escrever o operador colisão do modelo FHP-I como:

$$
C_{i}=-D_{i}+q D_{i-1}+(1-q) D_{i+1}-T_{i}+T_{i+3}
$$

Substituindo (2.7) em (2.3) obtém-se a equação completa da microdinâmica FHP-I:

$$
n_{i}\left(\vec{x}+\vec{c}_{i} \Delta t, t+\Delta t\right)=n_{i}(\vec{x}, t)-D_{i}+q D_{i-1}+(1-q) D_{i+1}-T_{i}+T_{i+3}
$$

Uma variante do método FHP-I que considera a possibilidade de presença de partículas em repouso no nó central das células ( 7 booleanas $n_{i}$ por célula, 7 bits) é o método FHP-III, que, adicionalmente, conta com um operador colisão "saturado" capaz de modelar todas as formas de colisão possíveis para cada estado pré-colisão $n_{i}$ (D`HUMIÈRES; LALLEMAND, 1987; FRISCH et al., 1987).

As variáveis macroscópicas de massa específica $\rho(\vec{x}, t)$ e quantidade de movimento $\rho \vec{u}(\vec{x}, t)$ são obtidas utilizando a média de conjunto $N_{i}(\vec{x}, t)=\left\langle n_{i}(\vec{x}, t)\right\rangle$ da booleana microscópica de ocupação como mostra a eq. (2.9) (CHOPARD;DROZ, 1998):

$$
\rho(\vec{x}, t)=\sum_{i} N_{i}(\vec{x}, t) ; \rho(\vec{x}, t) \vec{u}(\vec{x}, t)=\sum_{i}^{n} \vec{c}_{i} N_{i}(\vec{x}, t)
$$

em que, $\vec{u}$ é o campo de velocidades do escoamento.

Durante a evolução temporal do método LGCA, as partículas movimentam-se continuamente para dentro e para fora das células de cálculo, o que promove intensa flutuação nos resultados das variáveis macroscópicas e origina o erro estatístico. Por realizar a média de conjunto, a eq. (2.9) reduz, mas não elimina os efeitos de tal flutuação nos resultados (GUO; SHU, 2013; KRÜGER et al., 2017). 
Duas outras desvantagens do método LGCA citadas por Succi (2018) são: a limitação quanto ao número de Reynolds, que é controlada pelo número máximo de colisões por incremento temporal que o modelo é capaz de realizar e, a complexidade exponencial do operador colisão quanto ao número de estados possíveis $(b)$ nas células de cálculo do reticulado.

O número de Reynolds $(R e)$ limite para uma determinada solução dependerá do parâmetro de modelo $\left(R^{*}\right)$, do número de Mach $(M)$ do escoamento e da quantidade de reticulados por unidade de comprimento $(N)$ da malha, sendo:

$$
R e=R^{*} M N
$$

onde, $R^{*}=g \cdot \Delta \vec{x} / l_{u}$ sendo $g=(D / D+2)(1-2 d / 1-d), d=\rho / b, \quad D$ o número de dimensões, $\Delta \vec{x}$ a distância entre dois nós adjacentes e $l_{u}$ o caminho médio percorrido entre duas colisões consecutivas (mean-free path). Essencialmente $R^{*}$ é controlado pela razão $\Delta \vec{x} / l_{u}$ e uma das maneiras de incrementar o valor de $R^{*}$ é fazer $\Delta \vec{x}>l_{u}$ (SUCCI, 2018).

O modelo FHP-I atinge $R^{*} \approx 0,4$ indicando que uma colisão acontece a cada 2,5 incrementos de tempo e após muita pesquisa, no fim dos anos 80 , o maior valor de $R^{*}$ possível era $R^{*}=13$. Como exemplo da limitação quanto ao número de Reynolds dos modelos LGCA, para uma configuração onde $M=0,2$ e $N=1000$, tem-se $R e=80$ para o modelo FHP-I; e $R e=2600$ para o modelo em que $R^{*}=13$. Succi (2018) cita ainda que o esforço computacional requerido para resolver o campo fluidodinâmico via LGCA é diretamente proporcional a $R^{* 4}$ (SUCCI, 2018; WOLF-GLADROW, 2000).

Em se tratando da complexidade do operador colisão, sabe-se que o número de estados possíveis em uma célula de cálculo é proporcional a $2^{b}$, sendo $b$ o número de bits de uma célula de cálculo. Em um reticulado bidimensional FHP-I $(b=6)$ tem-se que cada célula de cálculo possui $2^{6}=64$ estados possíveis. Já em um reticulado tridimensional com reticulado de 24 bits ( $b=24$ ) cada célula possui $2^{24} \approx 16,8$ milhões de estados possíveis e requerem ainda maior poder computacional (SUCCI, 2018).

\subsection{MÉTODO DE LATTICE-BOLTZMANN}

A principal contribuição de McNamara e Zanetti (1988) para contornar o erro estatístico e originar o LBM foi concentrar-se na dinâmica de um conjunto ou população de 
partículas em vez de tratar a dinâmica de cada molécula individualmente, introduzindo assim a função distribuição $f_{i}$ escrita como:

$$
f_{i}(\vec{x}, t)=\left\langle n_{i}\right\rangle
$$

onde, \langle\rangle indica média do conjunto (SUCCI, 2018).

Considerando que não há interação molecular entre as partículas entrando em uma colisão e que não há forças externas atuando no sistema a eq. (2.3) pode ser reescrita como em (2.12) para obter a função geral de evolução temporal do LBM:

$$
f_{i}\left(\vec{x}+\vec{c}_{i} \Delta t, t+\Delta t\right)=f_{i}(\vec{x}, t)+\Omega_{i}(\vec{x}, t)
$$

em que, $\vec{c}_{i}$ é o vetor velocidade na direção $i, \Delta t$ é o incremento temporal, $\vec{x}$ é o vetor posição e $\Omega_{i}(\vec{x}, t)$ o operador colisão do LBM (CHEN; DOOLEN, 1998; SUCCI, 2018).

As variáveis macroscópicas de massa específica $\rho(\vec{x}, t)$ e quantidade de movimento $\rho \vec{u}(\vec{x}, t)$ são obtidas similarmente ao método LGCA por:

$$
\rho(\vec{x}, t)=\sum_{i} f_{i}(\vec{x}, t) ; \rho(\vec{x}, t) \vec{u}(\vec{x}, t)=\sum_{i}^{n} \vec{c}_{i} f_{i}(\vec{x}, t)
$$

Ao proceder dessa maneira McNamara e Zanetti (1988) contornaram o erro estatístico e mantiveram as principais vantagens do LGCA: a facilidade de implementação e a elevada capacidade de paralelização computacional. Contudo, o operador colisão carrega a complexidade de seu antecessor e com um agravante: por realizar a média das booleanas de ocupação $n_{i}(\vec{x}, t)$, o método está sujeito aos erros de truncamento e consequentemente substitui as operações puramente booleanas por operações com ponto flutuante demandando ainda mais poder computacional para resolver a colisão, fato que dificulta e quase inviabiliza sua aplicação em casos tridimensionais (SUCCI, 2018).

Mesmo com tais desvantagens o método de Lattice-Boltzmann possui características importantes na descrição da dinâmica macroscópica de fluidos que o tornaram atraente para a comunidade científica. Uma parcela importante dos estudos posteriores ao de McNamara e Zanetti (1988) concentrou esforços em simplificar o operador colisão e reduzir o poder computacional necessário na aplicação do método tridimensional. 
Higuera e Jiménez (1989) propuseram que para baixos números de Knudsen $(K n)$ e de Mach $(M)$, a função distribuição $f_{i}$ pode ser expandida ao redor do equilíbrio local como sendo:

$$
f_{i}=f_{i}^{e}+f_{i}^{n e}
$$

onde $f_{i}^{e}$ é a parcela de $f_{i}$ em equilíbrio e $f_{i}^{\text {ne }}$, a parcela de não-equilíbrio.

Succi (2018) aborda com detalhes as manipulações matemáticas impostas por Higuera e Jiménez (1989) à eq. (2.14) que deram origem ao novo operador colisão simplificado, denominado operador colisão linear ou operador quasilinear:

$$
\Omega_{i}=A_{i j}\left(f_{j}-f_{j}^{e}\right)
$$

onde, $A_{i j} \equiv \partial \Omega_{i}\left(f^{e}\right) / \partial f_{j}$ é a matriz distribuição que determina a taxa de distribuição entre as direções $i$ e $j$.

O uso do operado colisão quasilinear de Higuera e Jiménez reduz significativamente a complexidade do operador colisão da ordem $O\left(2^{b}\right)$ para $O\left(b^{2}\right)$ propriedade que por si só não viabilizou a simulação em três dimensões, porém, forneceu boa base para a pesquisa do LBM tridimensional (SUCCI, 2018).

Utilizando o conceito do operador colisão de Bhatnagar, Gross e Krook (1954) onde as populações são aproximadas ao equilíbrio à uma taxa $\tau$ (tempo de relaxação), Qian, D`Humières e Lallemand (1992) propuseram o modelo Lattice BGK (LBGK) em que o operador colisão é escrito como:

$$
\Omega_{i}=-\frac{1}{\tau}\left(f_{i}-f_{i}^{e}\right)
$$

onde a solução da eq. (2.16) deve satisfazer as leis de conservação de massa e quantidade de movimento e para isso a função $f_{i}^{e}$ pode ser escrita até a ordem $O\left(\vec{u}^{2}\right)$ como proposto por Qian, D’Humières e Lallemand (1992) em (2.17):

$$
f_{i}^{e}(\vec{x}, t)=w_{i} \rho\left(1+\frac{\vec{u} \cdot \vec{c}_{i}}{c_{S}^{2}}+\frac{\left(\vec{u} \cdot \vec{c}_{i}\right)^{2}}{2 c_{s}^{4}}-\frac{\vec{u} \cdot \vec{u}}{2 c_{s}^{2}}\right)
$$

sendo, $w_{i}$ o fator ponderação, $\rho$ a massa específica local, $c_{s}$ Lattice-Sound Speed e $\vec{u}$ é o campo de velocidades do escoamento. 
Qian, D‘Humières e Lallemand (1992) demonstraram soluções da eq. (2.17) que originaram uma família de modelos denominada por eles como $D n Q b$ onde $n$ indica o número de dimensões e $b$ o número de velocidades de cada célula de cálculo. Os parâmetros de (2.17) para três dos modelos $D n Q b$ encontram-se compilados na Tabela 1:

Tabela 1 - Parâmetros de diferentes modelos $D n Q b$

\begin{tabular}{|c|c|c|c|c|}
\hline Modelo & Representação Gráfica & Velocidade $\left(c_{i}\right)$ & Fator $\left(w_{i}\right)$ & $\left(c_{s}^{2}\right)$ \\
\hline D1Q3 & $\longrightarrow 1$ & $\begin{array}{c}0 \\
\pm 1\end{array}$ & $\begin{array}{l}2 / 3 \\
1 / 6\end{array}$ & $1 / 3$ \\
\hline D2Q9 & $\rrbracket^{5}$ & $\begin{array}{c}(0,0) \\
( \pm 1,0),(0, \pm 1) \\
( \pm 1, \pm 1)\end{array}$ & $\begin{array}{l}4 / 9 \\
1 / 9 \\
1 / 36\end{array}$ & $1 / 3$ \\
\hline & 8 & & & \\
\hline D3Q19 & 15 & $\begin{array}{c}(0,0,0) \\
( \pm 1,0,0),(0, \pm 1,0),(0,0, \pm 1) \\
( \pm 1, \pm 1,0),( \pm 1,0, \pm 1),(0, \pm 1, \pm 1)\end{array}$ & $\begin{array}{l}1 / 3 \\
1 / 18 \\
1 / 36\end{array}$ & $1 / 3$ \\
\hline
\end{tabular}

Adaptado de: Guo e Shu (2013) e Krüger et al. (2017)

O operador colisão BGK é totalmente independente do LGCA e seu uso eleva a eficiência computacional do método de Lattice-Boltzmann simplificando sua implementação. Essas vantagens, aliadas à elevada capacidade de paralelização, tornam o LBGK um dos modelos LBM mais utilizados na simulação de fenômenos fluidodinâmicos (CHEN; DOOLEN, 1998; GUO; SHU, 2013 KRÜGER et al., 2017).

Uma desvantagem do LBGK é que a expansão que resulta na equação para $f_{i}^{e}$ é valida apenas para pequenos números de Mach $(M)$, tornando o método capaz de aproximar as equações de Navier-Stokes até o limite da incompressibilidade, sendo o erro proporcional a $M^{2}$ (CHEN; DOOLEN, 1998; REIDER;STERLING, 1995).

Estudos mostram que essa característica pode ser superada utilizando diferentes técnicas como as expansões de alta ordem $O>\left(\vec{u}^{2}\right)$ com base em polinômios de Hermite capaz de aproximar as equações de Navier-Stokes para casos transônicos (SHAN; YUAN; CHEN, 2006) ou com metodologias hibridas LBM/Diferenças Finitas (NIE; SHAN; CHEN, 2009) capazes de aproximar as equações de Navier-Stokes em casos supersônicos. 


\subsection{O CÓDIGO COMERCIAL POWERFLOW}

PowerFLOW é um código comercial de Lattice-Boltzmann desenvolvido pela Exa Corporation na década de 90 e implementado com base nas equações LBGK que aproxima a função distribuição de equilíbrio utilizando:

$$
f_{i}^{e}(\vec{x}, t)=w_{i} \rho\left(1+\frac{\vec{u} \cdot \vec{c}_{i}}{T_{L}}+\frac{\left(\vec{u} \cdot \vec{c}_{i}\right)^{2}}{2 T_{L}{ }^{2}}-\frac{\vec{u} \cdot \vec{u}}{2 T_{L}}+\frac{\left(\vec{u} \cdot \vec{c}_{i}\right)^{3}}{6 T_{L}{ }^{3}}-\frac{\vec{u} \cdot \vec{c}_{i}}{2 T_{L}{ }^{2}} \vec{u}^{2}\right)
$$

onde os termos são comuns aos da eq. (2.17) exceto pelo termo Lattice-temperature $\left(T_{L}\right)$, que tem valor pré-estabelecido como $1 / 3$ em simulações isotérmicas. O modelo tridimensional utilizado é o D3Q19, com simetrias suficientes para garantir a isotropia das equações de NavierStokes, e os valores dos termos restantes são os mesmos já mostrados na Tabela 1 (KOTAPATI et al., 2009; SATTI, et al., 2008).

Satti (2008) cita que a equação de estado resultante obedece a lei dos gases perfeitos, $p=\rho T$ e a viscosidade cinemática do fluído $\left(v_{0}\right)$ é relacionada com a taxa de relaxação $\tau$, por:

$$
v_{0}=(\tau-1 / 2) T_{L}
$$

As equações (2.12), (2.16), (2.18) e (2.19) formam o método base implementado no software em que as variáveis macroscópicas são obtidas via (2.13) (KOTAPATI et al., 2009; SATTI, et al., 2008).

O código permite que o usuário escolha qual método de simulação utilizar: o método direto ou o método com modelagem de turbulência. Recomenda-se o método direto para casos onde $R e<10^{4}$ pois o nível de discretização requerida para resolver todas as escalas relevantes é refinado e proporcional a $R e^{-3 / 4}$ na região de escoamento livre e $y^{+} \sim 1$ nas paredes. Para $R e>10^{4}$ o poder computacional exigido torna o método direto inviável e desse modo a modelagem de turbulência é a metodologia recomendada (EXA CORPORATION, 2017b).

O PowerFLOW possui implementado em seu código o modelo de turbulência Very Large Eddy Simulation (VLES) que utiliza um filtro espacial para separar as maiores das menores escalas sendo as maiores resolvidas e as menores (escalas de sub-malha ou sub-filtro) modeladas através das equações $k-\varepsilon$ do grupo de renormalização (RNG $k$ - $\varepsilon$ ) com modificações de propriedade intelectual do desenvolvedor para atingir a precisão VLES necessária (EXA CORPORATION, 2017b). 
Chen et al. (2003) mostram que a maneira de introduzir um modelo de turbulência no método LGBK é substituir em (2.16) o tempo de relaxação $(\tau)$ por um tempo de relaxação efetivo $\left(\tau_{e f f}\right)$ que considera o efeito médio das pequenas escalas (modeladas) sob as maiores escalas (resolvidas) e que descreve consistentemente a dinâmica das flutuações turbulentas.

Satti et al. (2008), Kotapati et al. (2009) e Li et al. (2015) citam que o tempo de relaxação efetivo implementado no PowerFLOW é escrito como:

$$
\tau_{e f f}=\tau+C_{\mu} \frac{k^{2} / \varepsilon}{T_{L}\left(1+\tilde{\eta}^{2}\right)^{1 / 2}}
$$

onde $C_{\mu}$ é uma constante, $\tilde{\eta}$ é uma equação proprietária e resultante da combinação dos parâmetros local strain $(\eta=k|S| / \varepsilon)$, local vorticity $\left(\eta_{\omega}=k\left|\Omega^{*}\right| / \varepsilon\right)$ e local helicity, sendo $S$ o gradiente de velocidade local (não apenas a taxa de deformação), $\Omega^{*}$ é a vorticidade local e $k$ $\varepsilon$ são as equações modificadas do modelo RNG $k-\varepsilon$ descritas em de Satti et al. (2008), Kotapati et al. (2009) e Li et al. (2015).

O software possui implementada uma função de parede que reduz a demanda por discretização nas regiões onde há o desenvolvimento de camada limite em simulações com modelagem de turbulência. Tal função é descrita por um modelo de perfil de velocidades acoplado a um modelo de gradiente de pressão (EXA CORPORATION, 2017b). Kotapati et al. (2008) mencionam que a modelagem acoplada é importante para predizer corretamente o ponto de separação da camada limite.

Kotapati et al. (2008) também mostram que a função de parede do PowerFLOW é dividida em três partes, sendo que a primeira descreve a subcamada viscosa $\left(y^{+}<5\right)$, a segunda descreve a camada amortecida ou de transição $\left(5<y^{+}<35\right)$ e a terceira descreve a região turbulenta logarítmica $\left(y^{+}>35\right)$, definidas como:

$$
u^{+}=\left\{\begin{array}{lr}
y^{+} & y^{+}<5 \\
g\left(y^{+}\right) & 5<y^{+}<35 \\
(1 / \kappa) \log \left(y^{+}\right)+C_{1} & y^{+}>35
\end{array}\right.
$$

onde $y^{+}$é a distância adimensional da parede $y^{+}=u_{\tau} y / v, u_{\tau}$ é a velocidade de atrito $u_{\tau}=$ $\tau_{w} / \rho, y$ é a distância da parede, $v$ é a viscosidade cinemática, $\tau_{w}$ é a tensão de cisalhamento, $\rho$ é a massa específica, $u^{+}$é a velocidade adimensional paralela à parede $u^{+}=u / u_{\tau}, u$ é a velocidade, $g\left(y^{+}\right)$é uma equação proprietária, $\kappa$ é a constante de Von-Kármán $(\sim 0,40)$ e $C_{1}$ é uma constante (EXA CORPORATION, 2013). 
Uma vez analisadas as principais características da formulação do método de LatticeBoltzmann implementado no PowerFLOW torna-se importante mencionar algumas particularidades do código:

a) O software é preparado para manipular geometrias complexas e arbitrárias gerando automaticamente a malha cartesiana utilizada para resolver as equações de LatticeBoltzmann (LI et al., 2015);

b) O usuário pode criar regiões de malha refinada, conhecidas como Variable Resolution (VR), que subdividem o domínio de cálculo em regiões menores com células de cálculo mais refinadas em seu interior, possibilitando maior detalhamento nas regiões de interesse. As células de cálculo são indeformáveis de formato quadrado (2D) ou cúbico (3D) (EXA CORPORATION, 2017b);

c) As VRs são contadas da mais grosseira para a mais refinada. A título de exemplo, a VR0 possui células de cálculo maiores que as da VR1, sendo o grau de refino sempre na proporção 2, ou seja, as células da VR0 são duas vezes maiores que as da VR1 e assim por diante (EXA CORPORATION, 2017a). Cabe ao usuário definir a dimensão da menor célula do modelo, a quantidade e a geometria das VRs que serão utilizadas.

d) O código é intrinsecamente transiente e o incremento temporal (timestep) é controlado pelo software de acordo com os parâmetros característicos do caso simulado, como a dimensão da menor célula de cálculo $\left(D_{\min }\right)$ e a temperatura $(T)$ (EXA CORPORATION, 2017a). Os casos abordados nos capítulos seguintes obedecem a formulação:

$$
\text { timestep }[s]=\frac{0,028224 . D_{\min }[m]}{\sqrt{T}[K]}
$$

e) As equações do LBM são resolvidas no VR mais refinado a cada timestep, resultando em uma frequência de atualização igual a 1/timestep sendo que no próximo VR as equações são resolvidas a cada 2 timesteps, assim sendo, a frequência de atualização da região mais refinada é duas vezes maior que a da menos refinada demandando assim maior poder computacional (EXA CORPORATION, 2017a).

\subsection{MONOPOLO, DIPOLO E QUADRUPOLO}

As fontes de ruído aeroacústico possuem características diretivas tridimensionais conhecidas e são classificadas em três formatos, os monopolos, os dipolos e os quadrupolos. 
Os monopolos são definidos como fontes de ruído esféricas ou omnidirecionais que radiam ruído aproximadamente como no caso de uma esfera pulsante, contraindo e expandindo ao longo do tempo sendo a amplitude de flutuação de pressão $p_{r}^{\prime}$ das ondas radiadas função apenas da distância radial $\left(r_{s}\right)$ medida à partir do centro do monopolo, $\left(p_{r}^{\prime}=f\left(r_{s}\right)\right)$. Os dipolos são considerados como dois monopolos de mesma intensidade posicionados próximos um do outro, porém, pulsando com $180^{\circ}$ de defasagem. A amplitude de flutuação de pressão das ondas sonoras emitidas por um dipolo é função do ângulo polar $(\alpha)$ em adição à distância radial $\left(r_{s}\right)$, $\left(p_{r}^{\prime}=f\left(r_{s}, \alpha\right)\right.$. A associação de dois dipolos com mesma intensidade e pulsando com defasagem de $180^{\circ}$ é o que denominada quadrupolo a intensidade de flutuação de pressão das ondas sonoras radiadas por, assim como nos dipolos, é função da distância radial $\left(r_{s}\right)$ e do ângulo polar $(\alpha),\left(p_{r}^{\prime}=f\left(r_{s}, \alpha\right)\right)$. A Figura 6 contém a representação gráfica destas três estruturas (NORTON, KARCZUB, 2003, WANG, 2010).

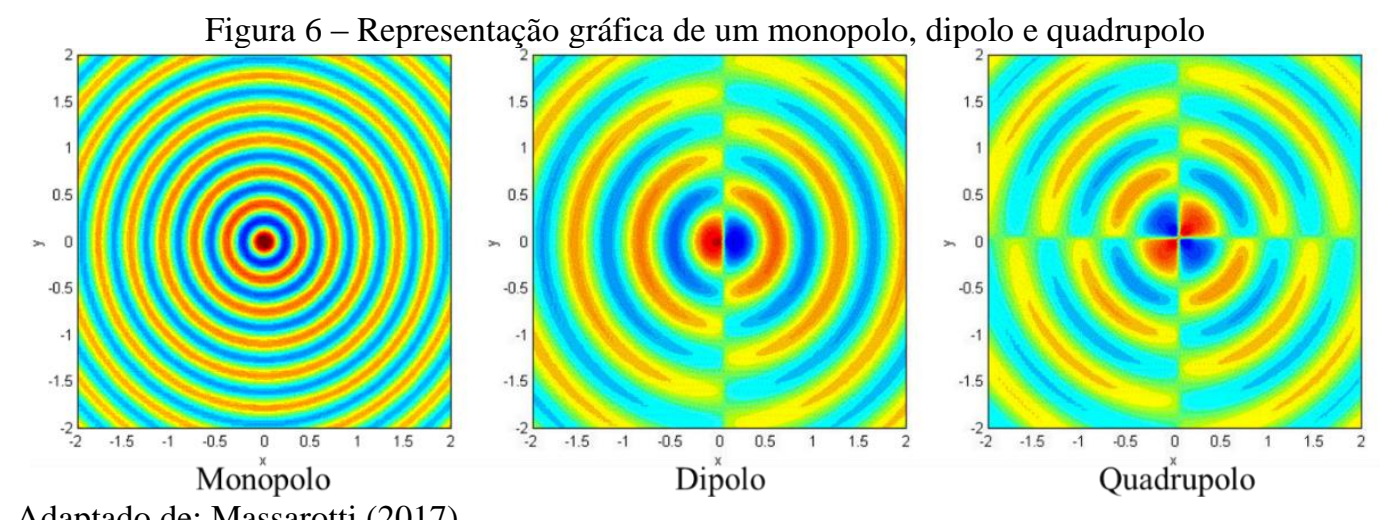

\subsection{ANALOGIA ACÚSTICA DE FFOWCS-WILLIAMS E HAWKINGS}

A técnica pioneira de rearranjar as equações de Navier-Stokes e obter uma equação de onda não homogênea com termo fonte capaz de governar a geração e propagação do ruído aerodinâmico radiado por um escoamento turbulento livre foi desenvolvida por Lighthill (1952, 1954) tornando-o precursor da analogia acústica. Outra grande contribuição da obra de Lighthill $(1952,1954)$ foi que, considerando o comprimento de onda do ruído radiado significativamente maior que a dimensão característica da fonte sonora (fonte acústica compacta) e que o observador encontra-se em campo afastado, o ruído gerado pelo escoamento turbulento livre, como os jatos turbulentos, é equivalente a uma distribuição volumétrica de quadrupolos com intensidade sonora proporcional a oitava potência da velocidade do escoamento (lei da oitava potência de Lighthill) (HOWE, 2003; LARSSON, 2002; LIGHTHILL, 1952, 1954; WAGNER; HÜTTL; SAGGAUT, 2007). 
Curle (1955) estendeu os conceitos de Lighthill e considerou o ruído gerado devido à presença de superfícies sólidas e estacionárias em escoamento turbulento. Considerando fonte sonora compacta e observador em campo afastado, Curle (1955) concluiu que o ruído radiado por superfícies sólidas imersas em um escoamento turbulento é equivalente a uma distribuição de dipolos de superfície com intensidade sonora proporcional à sexta potência da velocidade típica do escoamento. A contribuição acústica dos dipolos em escoamentos com baixo número de Mach é suficientemente maior que a dos quadrupolos a ponto de tornar-se a fonte sonora dominante e o ruído ser considerado como resultado da flutuação das forças que as superfícies sólidas exercem sobre o fluido (CURLE, 1955; HOWE, 2003; LARSSON, 2002; WAGNER; HÜTTL; SAGGAUT, 2007).

Ffowcs-Williams e Hawkings (1969) propuseram um equacionamento ainda mais geral que considera a presença de superfícies sólidas com movimento arbitrário e escoamento turbulento adjacente. A dedução da equação da analogia de Ffowcs-Williams e Hawkings considera o esquema mostrado na Figura 7, em que um volume de fluido $V$ delimitado pela superfície $\Sigma$ é separado em duas regiões (1 e 2) pela superfície $(S)$ impermeável e livre para se movimentar em 2 com velocidade $\vec{v}$ e normal $\vec{n}$ apontando na direção de 1 para 2 . A equação $f=0$ define a superfície $S$ sendo $f<0$ na região interior a $S$ e $f>0$ na região exterior a $S$.

Figura 7 - Esquema utilizado na dedução da equação da analogia de Ffowcs-Williams e Hawkings (FW-H)

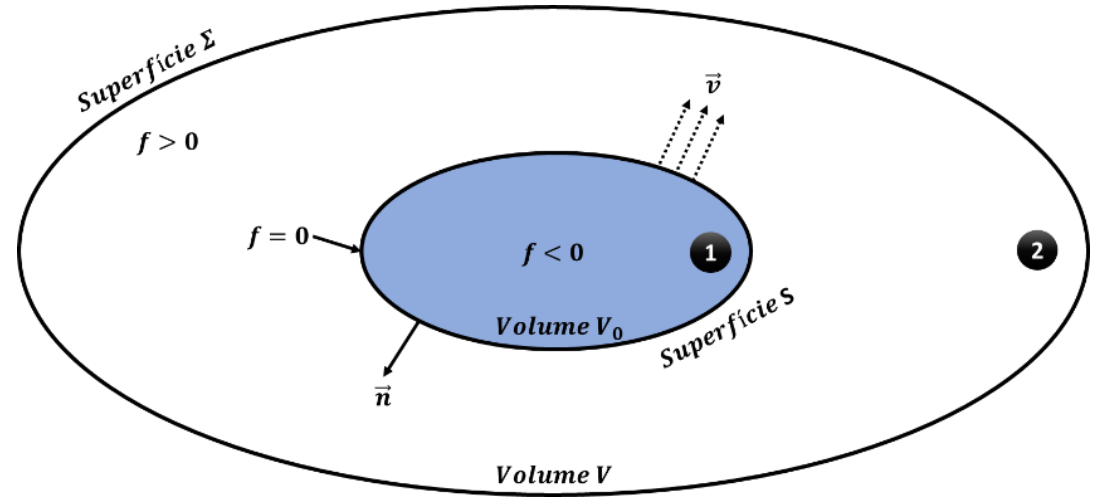

Os detalhes de obtenção da equação de onda da analogia FW-H são descritos no trabalho Ffowcs-Williams e Hawkings (1969), sendo sua forma diferencial escrita como:

$$
\left(\frac{\partial^{2}}{\partial t^{2}}-c^{2} \frac{\partial^{2}}{\partial x_{i}^{2}}\right)\left(\overline{\rho-\rho_{0}}\right)=\frac{\partial^{2} \overline{T_{\imath \jmath}}}{\partial x_{i} \partial x_{j}}-\frac{\partial}{\partial x_{i}}\left(L_{i} \delta(f) \frac{\partial f}{\partial x_{j}}\right)+\frac{\partial}{\partial t}\left(U_{i} \delta(f) \frac{\partial f}{\partial x_{i}}\right)
$$

em que o símbolo $\left(^{-}\right)$indica variável generalizada (associada à função Heaviside), sendo seu valor diferente de zero na região externa a $S$ e igual a zero no interior de $S, \rho$ é a massa específica, $c$ e $\rho_{0}$ são respectivamente os valores da velocidade do som e da massa específica 
no fluido não perturbado, $T_{i j}$ é o tensor de Lighthill $\left(T_{i j}=\rho u_{i} u_{j}+p_{i j}-c^{2}\left(\rho-\rho_{0}\right) \delta_{i j}\right)$, a componente $L_{i}=\left(p_{i j}+\rho u_{i}\left(u_{j}-v_{j}\right)\right)$, a componente $U_{i}=\left(\rho_{0} v_{i}+\rho\left(u_{i}-v_{i}\right)\right.$, as variáveis $u_{i}, u_{j}, v_{i}$ e $v_{j}$ são respectivamente as componentes da velocidade do fluido e da superfície $S$ nas direções $x_{i}$ e $x_{j}$, o tensor $p_{i j}$ é dado em termos da velocidade do escoamento $p_{i j}=p \delta_{i j}+$ $\mu\left(-\partial u_{i} / \partial x_{j}-\partial u_{j} / \partial x_{i}+(2 / 3)\left(\partial u_{k} / \partial x_{k}\right) \delta_{i j}\right), \mu$ é o coeficiente de viscosidade, $p$ a pressão $\delta_{i j}$ é a função delta de Kronecker que vale 0 quando $i \neq j$ e é igual a 1 quando $i=j$ e $\delta(f)$ é a função delta que vale zero em qualquer região exceto onde $f=0$.

O lado esquerdo da eq. (2.23) é exatamente a equação de propagação de onda em meio uniforme e, do lado direito, tem-se os termos fontes. $\mathrm{O}$ primeiro termo fonte equivale à contribuição da distribuição volumétrica de quadrupolos com energia por unidade de volume igual a $T_{i j}$, o segundo termo corresponde à distribuição superficial de dipolos com energia por unidade de área igual a $p_{i j} n_{j}$, e o terceiro termo é a principal contribuição da pesquisa de Ffowcs-Williams e Hawkings, que representa uma distribuição superficial de monopolos que constituem o efeito do deslocamento volumétrico resultante da movimentação da superfície sólida (LIGHTHILL, 1952; CURLE, 1955; FFOWCS-WILLIAMS; HAWKINGS, 1969).

Ffowcs-Williams e Hawkings (1969) mostraram que, considerando a superfície em movimento como rígida e impermeável e as fontes sonoras como compactas, o termo monopolo pode ser substituído por uma distribuição de dipolos e quadrupolos no interior do volume $\left(V_{0}\right)$ e a solução de (2.23) é escrita como:

$$
4 \pi c^{2}\left(\rho-\rho_{0}\right)=\frac{\partial^{2}}{\partial x_{i} \partial x_{j}}\left[\frac{Q_{i j}+\rho_{0} v_{i} v_{j} V_{0}}{r\left|1-M_{r}\right|}\right]-\frac{\partial}{\partial x_{i}}\left[\frac{P_{i}+\rho_{0} \dot{v}_{i} V_{0}}{r\left|1-M_{r}\right|}\right]
$$

sendo $Q_{i j}$ a contribuição de todos os quadrupolos externos, $P_{i}$ a força total exercida pela superfície no fluido, $r$ é a distância da fonte ao observador, $M_{r}$ é a componente do número de Mach da superfície $S$ na direção do observador, $\left|1-M_{r}\right|$ está associado ao efeito Doppler, $\dot{v}_{i}$ é a aceleração de $S$ e os colchetes indicam que os termos são calculados no tempo atrasado $\left(\tau_{r}\right)$, ou seja, no momento em que a onda sonora foi gerada $\tau_{r}=t-r / c$. Os termos $\rho_{0} v_{i} v_{j} V_{0} \mathrm{e}$ $\rho_{0} \dot{v}_{i} V_{0}$ são resultantes da substituição do termo monopolo pela distribuição de dipolos e quadrupolos no interior de $V_{0}$.

Ffowcs-Williams e Hawkings (1969) mostraram que, em escoamento com baixo número de Mach $(M<0,3)$ e fontes sonoras compactas, a eq. (2.24) reduz-se à eq. (2.25), comprovando que os termos dipolares possuem maior importância nessas configurações de escoamento podendo-se desprezar as contribuições do escoamento afastado de superfícies 
sólidas. Uma análise dimensional em (2.25) comprova que a intensidade sonora das fontes dipolares varia com a sexta potência da velocidade característica do escoamento.

$$
4 \pi c^{2}\left(\rho-\rho_{0}\right)=-\frac{\partial}{\partial x_{i}}\left[\frac{P_{i}+\rho_{0} \dot{v}_{i} V_{0}}{r\left|1-M_{r}\right|}\right]
$$

Distintas soluções da eq.(2.23) foram propostas com a finalidade de fornecer resultados otimizados para configurações específicas vide Farassat (2007), Brentner (1997), Brentner e Farassat (2003), Farassat e Casper (2012) e Di Francescantonio (1997). Das diversas formulações FW-H disponíveis, o código comercial PowerACOUSTICS, que é um módulo de aeroacústica do mesmo desenvolvedor do PowerFLOW, utiliza duas soluções distintas da eq. (2.23) para calcular o ruído em campo afastado.

O software PowerACOUSTICS utiliza o histórico temporal das variáveis fluidodinâmicas de pressão, velocidade e massa específica de simulações computacionais como dados de entrada para o cálculo do ruído em campo afastado. Em casos onde as fontes sonoras são móveis (tal qual na certificação do ruído de passagem de automóveis e aeronaves) é utilizada a formulação 1A detalhada na publicação de Farassat e Succi (1980) e para casos onde fontes e observador são estáticos (tal qual em túnel de vento) é empregue uma formulação fundamentada no triângulo de Garrick, similar a demonstrada na publicação de Brès, Pérot e Freed (2010) (EXA CORPORATION, 2016).

A solução original de Ffowcs-Williams e Hawkings (1969) considera superfícies físicas impermeáveis e indeformáveis. Em contrapartida, as formulações implementadas no PowerACOUSTICS, já citadas, permitem considerar as superfícies de coleta de resultados ou de integração como impermeáveis ou permeáveis (porosas), físicas ou fictícias (que não fazem parte da solução do campo fluidodinâmico), coincidentes (on-body) ou não (off-body) com as superfícies físicas do problema. No caso de simulações off-body, a superfície fictícia e permeável deve envolver em seu interior as fontes sonoras relevantes para a caracterização do ruído em campo afastado e a discretização do domínio dentro desse volume deve ser suficiente para calcular as fontes e propagá-las até a superfície porosa. (EXA CORPORATION, 2016).

\subsection{DECOMPOSIÇÃO EM MODOS DINÂMICOS}

A Decomposição em Modos Dinâmicos (Dynamic Mode Decomposition - DMD) foi desenvolvida por Schmid e Sesterhenn (2008) com a finalidade de identificar as características dinâmicas de um conjunto de dados espaço-temporais provenientes de experimentos ou simulações de um determinado sistema. Os modos dinâmicos resultantes da análise DMD 
carregam consigo as características dinâmicas do sistema e, quando oriundos de testes ou simulações de escoamentos turbulentos, representam o comportamento dinâmico dominante ou as estruturas coerentes mais energéticas presentes no escoamento (SCHMID; SESTERHENN, 2008; SCHMID, 2010; KUTZ et al., 2016).

Para obter os modos dinâmicos de um sistema não-linear através da formulação de Schmid e Sesterhenn (2008) é essencial dispor a coletânea de dados experimentais ou numéricos em duas matrizes $\left(X\right.$ e $\left.X^{\prime}\right)$ com dimensões $n$ linhas e $m-1$ colunas, sendo $n$ o número de pontos espaciais monitorados e $m$ o número total de amostras igualmente espaçadas no tempo.

$$
\begin{aligned}
X_{n \times m-1} & =\left[\begin{array}{ccc}
\mid & \mid & \mid \\
x_{1} & \ldots & x_{m-1} \\
\mid & \mid & \mid
\end{array}\right] \\
X_{n \times m-1}^{\prime} & =\left[\begin{array}{ccc}
\mid & \mid & \mid \\
x_{2} & \ldots & x_{m} \\
\mid & \mid & \mid
\end{array}\right]
\end{aligned}
$$

Schmid e Sesterhenn (2008) e Kutz et al. (2016) mencionam que os modos dinâmicos são o resultado da análise de autovalores e autovetores do operador linear $A$ que conecta as matrizes $X$ e $X^{\prime}$ de acordo com a eq. (2.28), sendo que cada autovetor de $A$ representa um modo dinâmico correlacionado com um autovalor particular.

$$
X^{\prime}=A X
$$

Schmid (2010) e Dawson et al. (2016) relatam que, usualmente, em aplicações práticas, $n \gg m$ tornando a análise direta da matriz $A$ impraticável. Schmid (2010) menciona que a técnica DMD é robusta e capaz de obter as características dinâmicas do operador $A$ (autovalores, autovetores, taxa de decaimento, etc.) por meio da aplicação da metodologia detalhada nos parágrafos seguintes, conforme descrito em Kutz et al. (2016).

Primeiramente calcula-se a Decomposição em Valores Singulares (Singular Value Decomposition - SVD) da sequência de dados $X$ :

$$
X=U \Sigma_{s} V_{s}^{*}
$$

onde o símbolo $\left({ }^{*}\right.$ ) denota matriz conjugada transposta e as matrizes $U, V_{S}$ e $\Sigma_{S}$ são respectivamente os vetores singulares à esquerda, os vetores singulares à direita e os valores singulares resultantes da decomposição da matriz $X$. As colunas de $U$ são os modos POD (Proper Orthogonal Decomposition - detalhes em Sirovich, 1987). 
Substituindo a decomposição (2.29) em (2.28) e realizando as devidas manipulações algébricas obtém-se o operador linear $A$ :

$$
A=X^{\prime} V_{s} \Sigma_{s}^{-1} U^{*}
$$

Por meio da projeção da matriz $A$ nos vetores singulares de $U$ (modos POD), conforme descrito em (2.31), é possível obter uma matriz menor e mais eficiente do ponto de vista computacional $(\tilde{A})$ que define um modelo de baixa dimensão do sistema dinâmico descrito nas coordenadas POD.

$$
\tilde{A}=U^{*} A U
$$

Calcula-se então os autovalores e autovetores da matriz $\tilde{A}$ :

$$
\tilde{A} W=W \Lambda,
$$

sendo $W$ os autovetores e $\Lambda$ uma matriz diagonal contendo os autovalores $\lambda_{k}$ de $\tilde{A}$.

Os autovalores e autovetores $A$ são reconstruídos com base nos resultados anteriores, sendo os autovalores dados por $\Lambda$ e os autovetores (modos DMD) são as colunas da matriz $\Phi$ calculada via:

$$
\Phi=X^{\prime} V_{s} \Sigma_{s}^{-1} W
$$

Wang (2017) menciona que a energia de cada modo é obtida por meio do módulo de cada autovetor $\left|\Phi_{i}\right|$ servindo de métrica para identificar as estruturas coerentes dominantes.

Segundo Frederich e Luchtenburg (2011), no domínio do tempo, a frequência $\left(f_{k}\right)[\mathrm{Hz}]$ e a taxa de decaimento ou crescimento $\left(\sigma_{k}\right)$ de um modo DMD são calculadas via:

$$
\begin{gathered}
f_{k}=\operatorname{Im}\left(\ln \left(\lambda_{k}\right)\right) / 2 \pi \Delta t \\
\sigma_{k}=\operatorname{Re}\left(\ln \left(\lambda_{k}\right)\right) / \Delta t
\end{gathered}
$$

em que $\Delta t$ é o incremento de tempo que separa duas medições consecutivas.

Kutz et al. (2016) mencionam que em determinados sistemas dinâmicos, a maior parcela da energia pode concentrar-se nos primeiros modos DMD (Ex.: > 90\% da energia nos 
5 primeiros modos), tornando vantajoso truncar o algoritmo nos primeiros $r$ modos mais energéticos reduzindo significativamente o esforço computacional necessário para realizar a decomposição. A Figura 8 exemplifica os quatro primeiros modos da análise DMD realizada nos resultados de uma simulação DNS do escoamento transversal com $R e=100$ ao redor de um cilindro isolado.

Pretende-se aplicar a metodologia DMD nos resultados das simulações dos capítulos seguintes a fim de identificar e detalhar quais as estruturas coerentes presentes no sistema dinâmico e, adicionalmente, verificar se o método apresenta resultados condizentes com as frequências do ruído radiado dos casos simulados. O software MATLAB foi utilizado na implementação do método.

Figura 8 - Exemplo de modos DMD do escoamento ao redor de um cilindro isolado
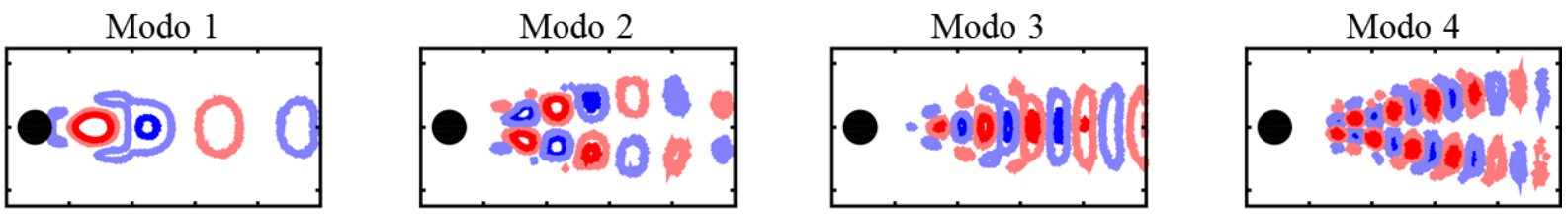

Fonte: Dawson et al. (2016).

\subsection{FILTRO PASSA-BANDA}

Aplicando-se uma análise de Densidade Espectral de Potência (Power Spectral Density - PSD) em uma série temporal, determina-se o espectro de frequências do sinal (CROCKER, 2007).

Segundo Howard e Angus (2017) um filtro é uma técnica de processamento de sinais que separa apenas uma parte da totalidade do espectro de um sinal. O filtro passa-banda (Bandpass Filter - BPF) transmite apenas as contribuições das frequências no interior de uma determinada banda de frequências $(B)$ delimitada pelas frequências de corte superior $\left(f_{c 2}\right)$ e inferior $\left(f_{c 1}\right)$ e rejeita as contribuições do restante do sinal conforme ilustrado na Figura 9 (CROCKER, 2007).

Figura 9 -Diagrama ilustrativo de um filtro passa-banda

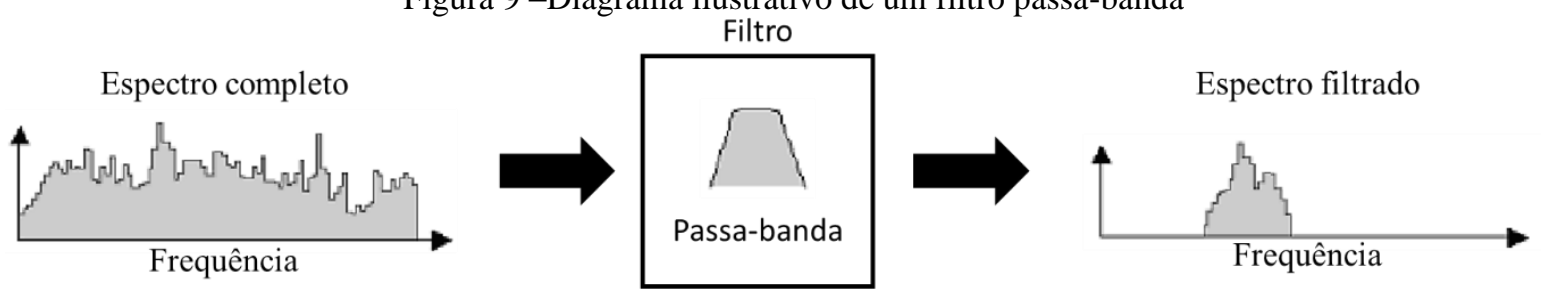

Adaptado de: Crocker (2007). 
A análise do histórico temporal com filtro passa-banda de variáveis fluidodinâmicas, como o campo de pressão total e o campo de velocidades, é utilizada para determinar as estruturas fluidodinâmicas presentes no escoamento em determinadas faixas de frequência. Por meio da análise passa-banda pode-se, também, determinar a escala de comprimento e a natureza das instabilidades presentes na esteira e no campo fluidodinâmico próximo em cada banda de frequência relevante (EXA CORPORATION, 2013). A Figura 10 ilustra a aplicação aeroacústica da análise passa-banda do campo de pressões do escoamento ao redor do perfil NACA 0018 e exemplifica os atributos da metodologia.

Os resultados de análises com filtro passa-banda, aplicadas nos campos de pressão total das simulações dos capítulos seguintes, servirão de comparativo para os resultados obtidos utilizando a metodologia DMD.

Figura 10 - Exemplo de aplicação aeroacústica do filtro passa-banda

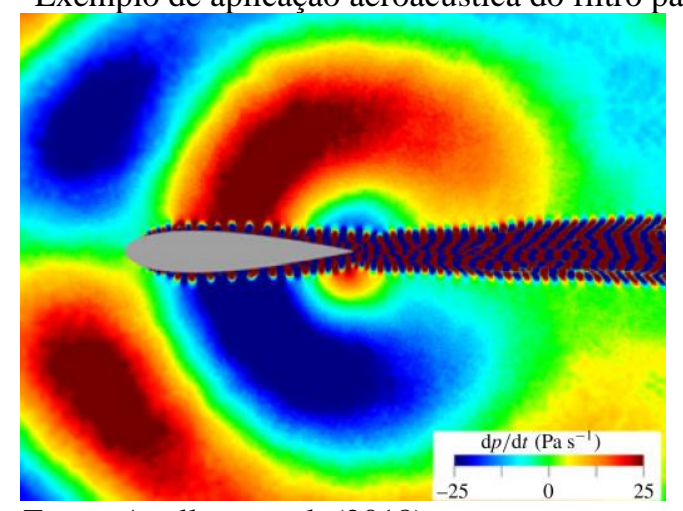

Fonte: Avallone et al. (2018) 


\section{VERIFICAÇÃO DA EFICÁCIA DO MÉTODO HÍBRIDO}

Neste capítulo aborda-se a investigação e a validação numérica do campo fluidodinâmico e do ruído radiado por um cilindro sujeito ao escoamento transversal de ar simulando as condições de um túnel de vento anecóico. Os resultados da simulação aeroacústica híbrida por meio do método de Lattice-Boltzmann e da analogia acústica de Ffowcs-Williams e Hawkings serão avaliados a partir dos resultados experimentais de Casalino e Jacob (2003), Norberg (2003), Zdravkovich (1997) e White (1991). As frequências de interesse oriundas da análise da Densidade Espectral de Potência (Power Spectral Density - PSD) do ruído em campo afastado servirão de parâmetros de entrada para uma análise de Decomposição em Modos Dinâmicos (DMD).

\subsection{DADOS EXPERIMENTAIS DE REFERÊNCIA}

Casalino e Jacob (2003) documentaram em seu trabalho os resultados de um experimento realizado para aferir o ruído radiado por um cilindro de envergadura $l=0,3 \mathrm{~m}$ e diâmetro $d=16 \mathrm{~mm}$ (razão de aspecto $L_{s}=18,75 d$ ) submetido a um escoamento de ar transversal de ar com velocidade $V_{\infty}=20 \mathrm{~m} / \mathrm{s}$ correspondente a $M \approx 0,06$ e $R e=2,2 \times 10^{4}$. Os parâmetros do escoamento na entrada da seção de testes são a massa específica $\rho_{\infty}=$ $1,225 \mathrm{~kg} / \mathrm{m}^{3}$, a viscosidade dinâmica $\mu_{\infty}=1,78 \times 10^{-5} \mathrm{~kg} / \mathrm{m}$. $\mathrm{s}$, a pressão ao longe $p_{\infty}=$ 101.253,6 $\mathrm{Pa}$ e a energia cinética turbulenta inicial de $1 \%$.

O ruído foi medido a uma distância $r=1,38 m(86,25 d)$ do centro do cilindro em diferentes ângulos $\phi$ por meio de um microfone conectado a um pré-amplificador (vide esquema da Figura 11).

Figura 11 - Esquema gráfico do teste realizado por Casalino e Jacob (2003)

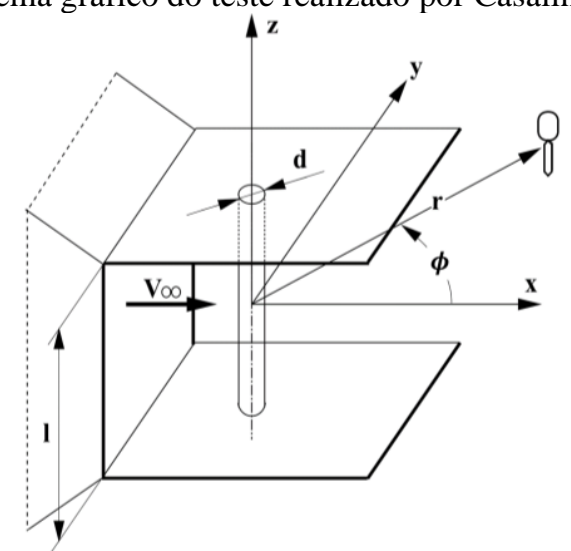

Adaptado de: Casalino e Jacob (2003) 
O equipamento de medição foi configurado para aquisitar o ruído na faixa de frequência de 0 a $6400 \mathrm{~Hz}$ com resolução de $2 \mathrm{~Hz}$. O valor médio do ruído para cada posição de ângulo $\phi$ foi calculado com base nos resultados de 400 medições consecutivas. Na Figura 12 apresentam-se as curvas de Densidade Espectral de Potência (PSD) em função do Número de Strouhal das medições do ruído com o microfone posicionado em $\phi=40^{\circ}$ e $\phi=90^{\circ}$.

Figura 12 - Ruído medido por Casalino \& Jacob (2003) com microfone nas posições $\phi=40^{\circ}$ e $\phi=90^{\circ}$

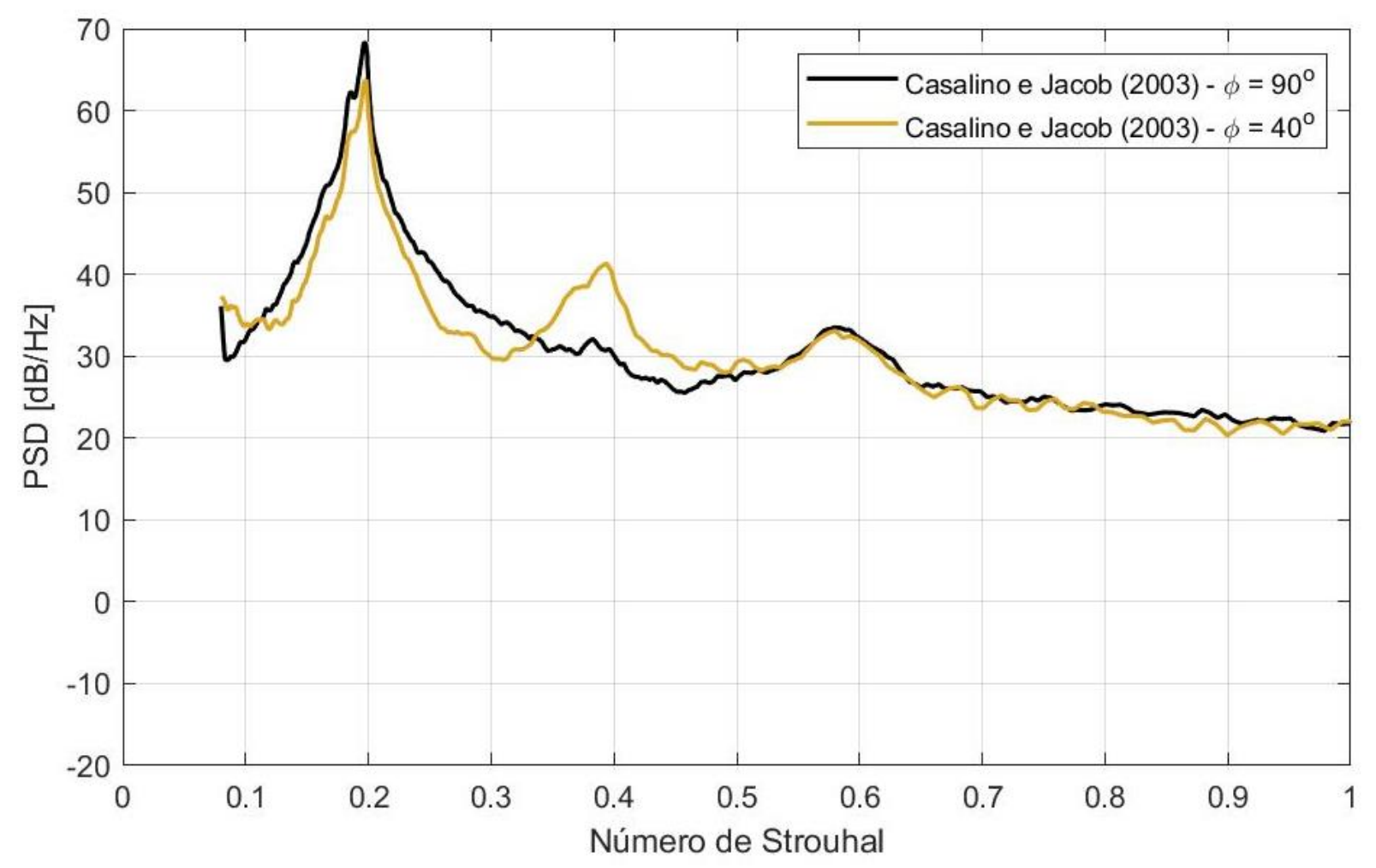

Adaptado de: Casalino e Jacob (2003)

Da equação da analogia acústica de Ffowcs-Williams e Hawkings (1969) tem-se que em escoamentos ao redor de corpos rombudos com baixo número de Mach o ruído é fundamentalmente gerado pelas flutuações de força na parede do cilindro. Nos resultados apresentados no gráfico de ruído do trabalho de Casalino e Jacob (2003) nota-se a ocorrência de três picos. $O$ primeiro deles é centrado na frequência fundamental $f_{0}$ e corresponde ao típico $S t=0,2$ associado à emissão de vórtices alternados que provocam a flutuação da força de sustentação. O segundo pico, ou harmônico em $2 f_{0}$, corresponde ao ruído gerado pela flutuação da força de arrasto. Na frequência igual a $3 f_{0}$ tem-se o harmônico também associado à flutuação da força de sustentação. A ocorrência do harmônico em $2 f_{0}$ é mais bem observada na medição com microfone posicionado em $\phi=40^{\circ}$. 


\subsection{VALIDAÇÃO DO CAMPO FLUIDODINÂMICO}

Um modelo de aeroacústica computacional foi configurado utilizando o pacote comercial PowerFLOW com o objetivo de reproduzir numericamente o ruído radiado por um cilindro em túnel de vento anecóico comparando-o com os dados experimentais de Casalino e Jacob (2003).

A Figura 13 mostra um esquema do modelo computacional que consiste em um cilindro de diâmetro $d=16 \mathrm{~mm}$ em um túnel de vento virtual com dimensões de $276 d$ de comprimento, $240 d$ de altura e razão de aspecto $L_{s}=5,7 d$ escolhidas para adequar o tempo de solução ao poder computacional disponível. Uma região de absorção acústica (Sponge zone) de largura $45 d$, na qual o software aumenta consideravelmente a viscosidade do fluido, foi adicionada para absorver as ondas sonoras refletidas pelas paredes e/ou condições de contorno com o intuito de reduzir o ruído de fundo do túnel de vento e também para evitar a contaminação dos resultados por fontes sonoras não físicas ou espúrias.

Figura 13 - Esquema do modelo computacional

$276 d$

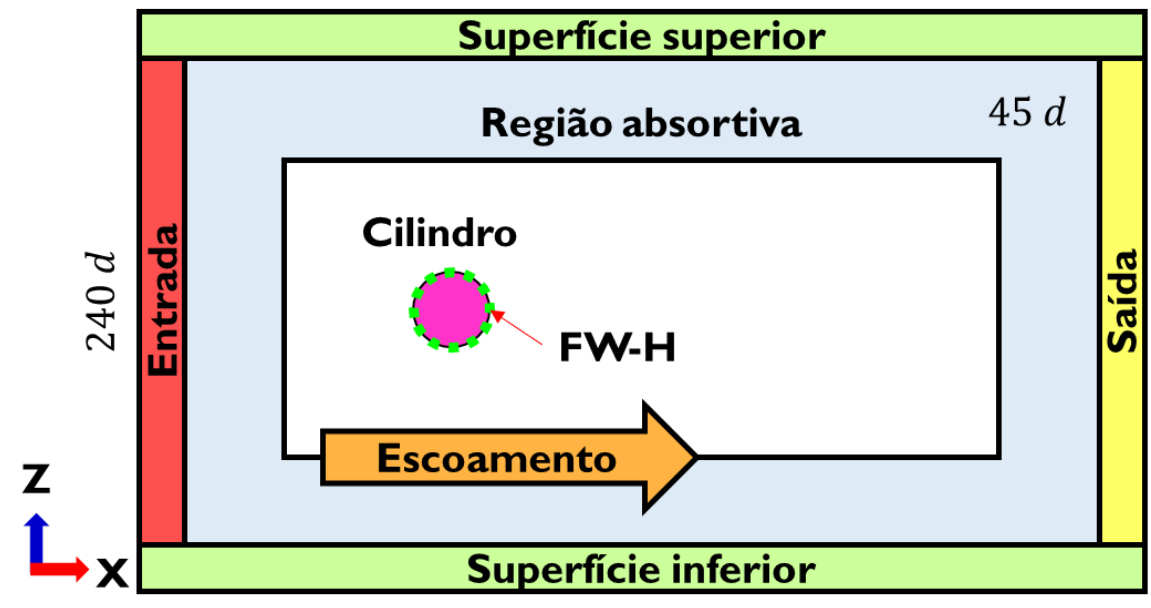

As condições de contorno de entrada, saída e superfícies superior e inferior são do tipo velocidade na direção x de $20 \mathrm{~m} / \mathrm{s}$ e pressão ao longe de $101.253,6 \mathrm{~Pa}$ com escala de turbulência inicial de $5 \mathrm{~mm}$ e intensidade de turbulência de $1 \%$. Na parede do cilindro foi aplicada a condição de contorno de parede Standard wall na qual a velocidade do fluido na superfície é igual a zero. As laterais do domínio são do tipo periódicas e dessa forma tenta-se aproximar ao resultado de um cilindro infinito evitando assim o efeito de ponta e possíveis interações com paredes laterais. Uma superfície permeável, fictícia e coincidente com a parede do cilindro foi adicionada para coletar os dados utilizados no cálculo do ruído via FW-H. 
Para simular o equivalente a 150 ciclos completos de emissão de vórtices (ou 0,6 s do escoamento real) foi utilizado um timestep de $1,478 \times 10^{-7} s$ ou $1 / 27.000$ do período de emissão de vórtices totalizando aproximadamente 4.060.000 iterações. A massa específica empregada é de $1,225 \mathrm{~kg} / \mathrm{m}^{3}$ e a viscosidade cinemática igual a $1,455 \times 10^{-5} \mathrm{~m}^{2} / \mathrm{s}$. O número de Reynolds da simulação é igual a $2,2 \times 10^{4}$ (regime subcrítico), e com isso espera-se camada limite laminar até a separação e transição para a turbulência na camada cisalhante. De acordo com os parâmetros escolhidos, a velocidade do som resultante no escoamento livre é de $340,3 \mathrm{~m} / \mathrm{s}$.

Os dados do escoamento foram coletados ao longo de toda a simulação, contudo apenas os últimos 125 períodos de emissão de vórtices $(0,5 s)$ foram considerados no cálculo do ruído e demais variáveis. Para obter as respostas finais foram necessárias 91 horas de cálculos computacionais realizados por 288 núcleos de processamento em um cluster de processamento da General Motors (GM).

Grandezas fluidodinâmicas como o comprimento de formação de vórtices $\left(\ell_{f}\right)$, os valores médios $\left(^{-}\right)$e eficazes $\left({ }^{-}\right)$dos coeficientes de arrasto $\left(C_{d}\right)$ e sustentação $\left(C_{l}\right)$, o ângulo de separação da camada limite $(\theta)$, o número de Strouhal $(S t)$ e as curvas dos coeficientes de pressão $\left(C_{p}\right)$ e atrito $\left(C_{f}\right)$ foram escolhidas para avaliar a qualidade dos resultados no campo fluidodinâmico.

Antes de apresentar maiores detalhes do modelamento numérico é importante alinhar a nomenclatura utilizada no PowerFLOW para a descrição da malha tridimensional. Conforme ilustra a Figura 14, o reticulado é composto pelos voxels, que são os elementos tridimensionais básicos. Os surfels são elementos superficiais planos originados da intersecção de um voxel com a superfície da geometria em estudo, no caso, o cilindro (EXA CORPORATION, 2017).

Figura 14 - Nomenclatura dos elementos superficiais e volumétricos de um modelo construído no PowerFLOW

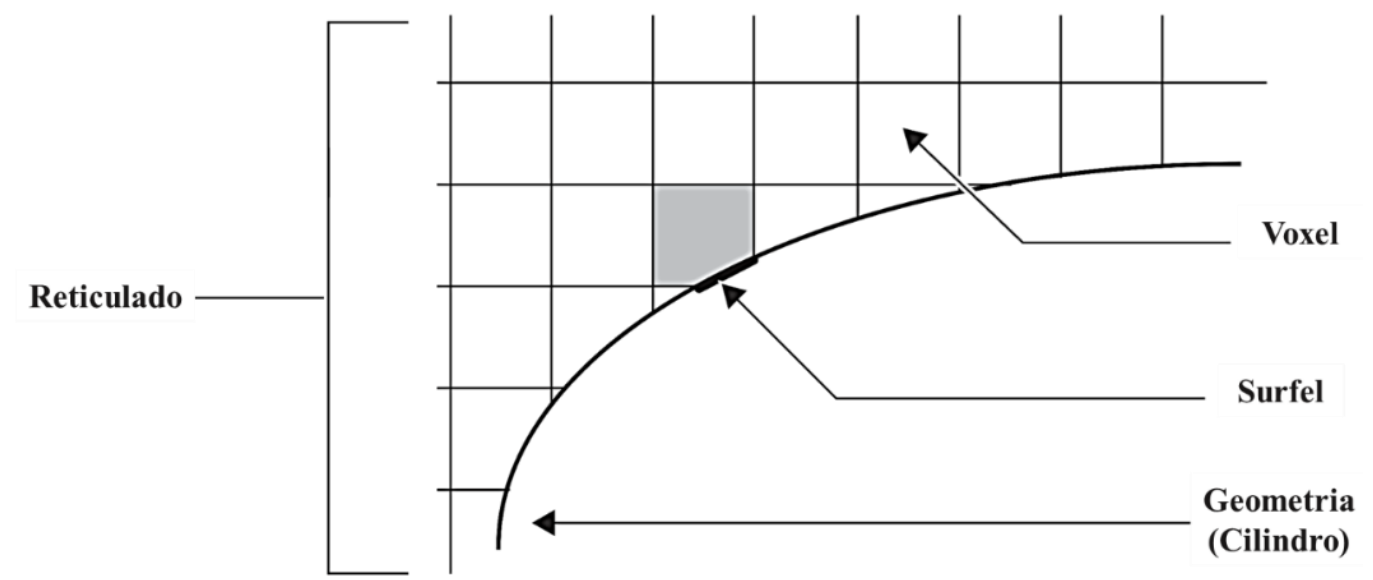


O passo inicial na verificação da acurácia de um modelo computacional é realizar uma análise de sensibilidade de malha. A Tabela 2 mostra o histórico dos resultados para discretizações com diferentes graus de refino. As malhas de 1 a 3 foram utilizadas para testar a sensibilidade volumétrica do modelo, já a malha 4 foi utilizada para testar a sensibilidade do refino superficial do cilindro sendo que a malha de número 5 apresentou resultados coerentes com a literatura.

Os dados de referência para os coeficientes de arrasto médio $\left(\overline{C_{d}}\right)$ e RMS $\left(\widehat{C_{d}}\right)$, para o valor RMS do coeficiente de sustentação $\left(\widehat{C}_{l}\right)$ e para o número de Strouhal $(S t)$ foram retirados respectivamente dos trabalhos de Zdravkovich (1997), Norberg (2003) e Schewe (1983).

Tabela 2 - Análise de sensibilidade de malha

\begin{tabular}{|c|c|c|c|c|c|c|c|}
\hline Malha \# & Resolução & Voxels & Surfels & $\overline{C_{d}}$ & $\widehat{C_{d}}$ & $\widehat{C_{l}}$ & $S t$ \\
\hline \multirow{2}{*}{ Ref. } & \multirow{2}{*}{ - } & \multirow{2}{*}{ - } & \multirow[b]{2}{*}{ 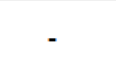 } & Zdravkovich (1997) & Zdravkovich (1997) & Norberg (2003) & Schewe (1983) \\
\hline & & & & $1,14 \sim 1,23$ & $0,050 \sim 0,165$ & $0,458 \sim 0,496$ & 0,200 \\
\hline 1 & 160 & 16.776 .010 & 753.232 & 0,93 & 0,024 & 0,128 & 0,232 \\
\hline 2 & 160 & 19.404 .874 & 753.232 & 1,10 & 0,066 & 0,388 & 0,228 \\
\hline 3 & 160 & 36.812 .586 & 753.232 & 1,32 & 0,069 & 0,479 & 0,225 \\
\hline 4 & 160 & 36.785 .958 & 632.295 & 1,28 & 0,070 & 0,429 & 0,224 \\
\hline 5 & 180 & 46.286 .740 & 1.511 .914 & 1,20 & 0,077 & 0,462 & 0,198 \\
\hline
\end{tabular}

O modelo \#5 possui aproximadamente 46 milhões de voxels e 1,5 milhões de surfels e com resolução de 180 voxels por comprimento característico, resultando em um voxel mais refinado com dimensão igual a 0,0889 $\mathrm{mm}$. O $y^{+}$deste modelo é de aproximadamente 8,5. Devido aos valores de $R e$ e $y^{+}$faz-se necessário utilizar modelagem de turbulência (VLES) com função de parede para melhor capturar a camada limite e as estruturas turbilhonares no escoamento livre.

Ao todo 10 regiões de refino (Variable Resolution - VR) foram criadas, sendo elas contadas de 0 a 9 . Todas possuem formato retangular, exceto as detalhadas na Figura 15.

Figura 15 - Detalhamento das regiões de refino ao redor do cilindro

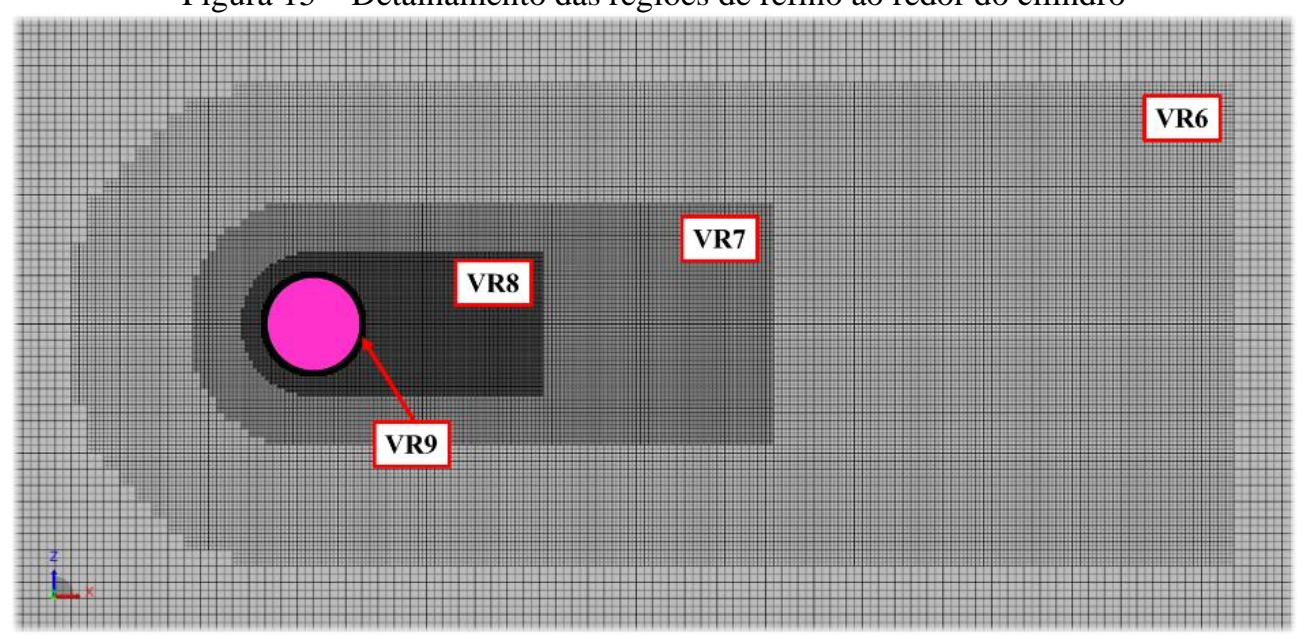


A análise da convergência física do modelo computacional associado à malha \#5 é apresentada na Tabela 3. O valor de referência do ângulo de separação $(\theta)$ para camada limite laminar foi retirado de White (1991) e a referência para o comprimento de formação de vórtices $\left(\ell_{f}\right)$, que determina a distância ao longo da esteira entre o ponto central do cilindro e o ponto onde a flutuação da velocidade na direção do escoamento é máxima, foi retirado do trabalho de Norberg (1998).

Tabela 3 - Resultados fluidodinâmicos compilados para a simulação da malha \#5

\begin{tabular}{ccccccc}
\hline Malha \# & $\overline{C_{d}}$ & $\widehat{C_{d}}$ & $\widehat{C}_{l}$ & $S t$ & $\ell_{f} / d$ & $\theta$ \\
\hline \multirow{2}{*}{ Ref. } & Zdravkovich (1997) & Zdravkovich (1997) & Norberg (2003) & Schewe (1983) & Norberg (1998) & White (1991) \\
& $1,14 \sim 1,23$ & $0,050 \sim 0,165$ & $0,458 \sim 0,496$ & 0,200 & 1,30 & $80 \sim 83^{\circ}$ \\
5 & 1,20 & 0,077 & 0,462 & 0,198 & 1,14 & $86^{\circ}$ \\
\hline
\end{tabular}

Por apresentar resultados coerentes com a literatura o modelo \#5 foi selecionado como padrão para os estudos apresentados neste e nos próximos capítulos. Daqui em diante o modelo supracitado será referenciado como Caso Anecóico.

Na Figura 16 encontra-se o gráfico do coeficiente de pressão $\left(C_{p}\right)$ ao longo da parede do cilindro onde, $\theta=0^{\circ}$ é o ponto de estagnação frontal e $\theta=180^{\circ}$ o ponto mais à jusante. Os dados numéricos obtidos via LBM são comparados com os dados experimentais disponíveis no paper de Igarashi (1981). Os valores absolutos são similares até aproximadamente $\theta=60^{\circ}$ e a partir desse ponto os dados numéricos são ligeiramente superiores aos experimentais. Em ambos os casos o gradiente de pressão favorável atua no cilindro até próximo de $\theta=70^{\circ}$, ponto no qual o gradiente de pressão se torna adverso e persiste por uma extensão maior no caso numérico resultando em um ângulo de separação da camada limite mais à jusante $\left(86^{\circ}\right)$ se comparado ao caso experimental $\left(\sim 80^{\circ}\right)$.

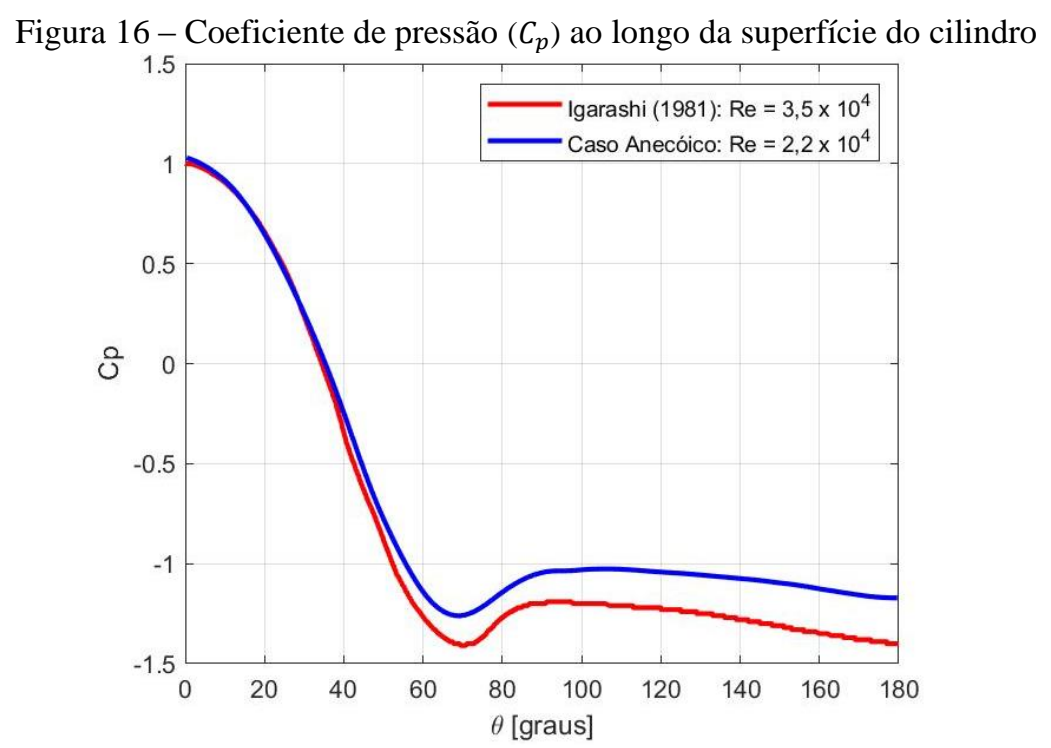


O gráfico apresentado na Figura 17 refere-se ao resultado do coeficiente de atrito na superfície do cilindro e é comparado ao dado de Achenbach (1968). O resultado da simulação é semelhante ao experimental até o ponto que marca a separação da camada limite $\left(C_{f}=0\right)$ onde o gradiente de velocidade é nulo. Posterior ao descolamento os valores experimentais são superiores aos simulados.

Figura 17 - Coeficiente de atrito $\left(C_{f}\right)$ ao longo da superfície do cilindro

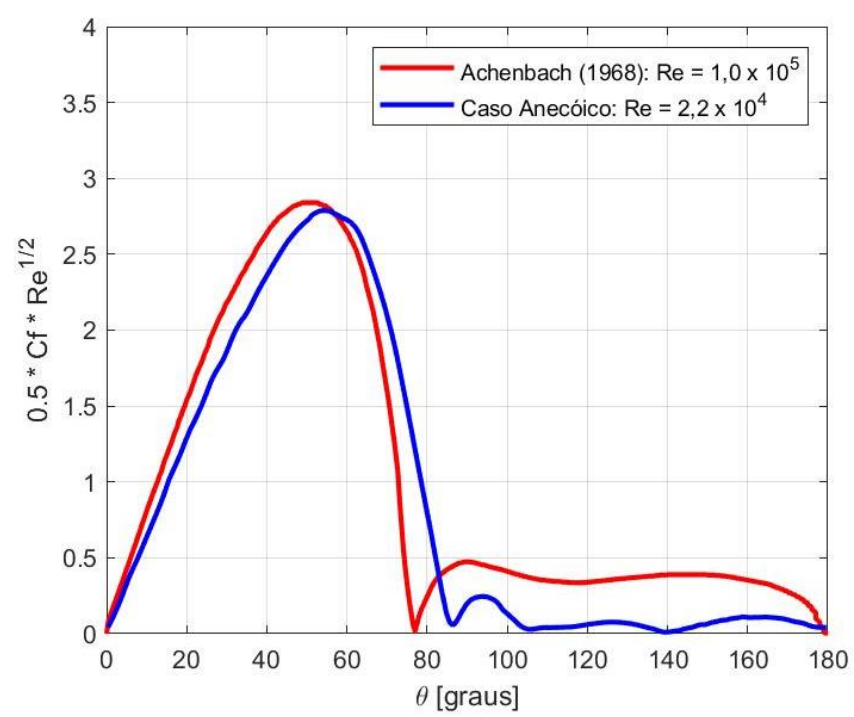

Outro parâmetro importante para simulações de aeroacústica é o valor eficaz da flutuação de pressão na parede do cilindro $\left(C_{p}{ }^{\prime}\right)$, pois, segundo a formulação da analogia acústica de FW-H o nível do ruído radiado devido a um escoamento de ar com baixo número de Mach $(M<0,3)$ ao redor de um corpo rombudo é correlacionado ao valor da flutuação de pressão na parede do objeto em estudo. Na Figura 18 encontram-se os dados numéricos via LBM e os dados experimentais de Igarashi (1981) onde é possível notar que o primeiro pico do valor eficaz da flutuação de pressão na parede do cilindro ocorre próximo ao ponto de separação da camada limite que, após separada, origina a camada cisalhante que dará origem a um vórtice. O escoamento reverso originado por esse fenômeno readere na superfície posterior do cilindro e descola-se novamente próximo a $\theta=160^{\circ}$ (segundo pico). A simulação foi capaz de capturar o primeiro pico com boa precisão em frequência e amplitude, já o segundo pico relacionado ao descolamento do escoamento reverso apresentou valor inferior ao do teste. Diferença que pode ser explicada pelas divergências no número de Reynolds $(R e)$, ângulo $\theta$ de separação da camada limite, comprimento de formação de vórtices $\ell_{f}$ e razão de aspecto $\left(L_{s}\right)$ entre o teste de Igarashi (1981) e a simulação. 
Figura 18 - Valor eficaz da flutuação da pressão ao longo da superfície do cilindro $\left(C_{p}{ }^{\prime}\right)$

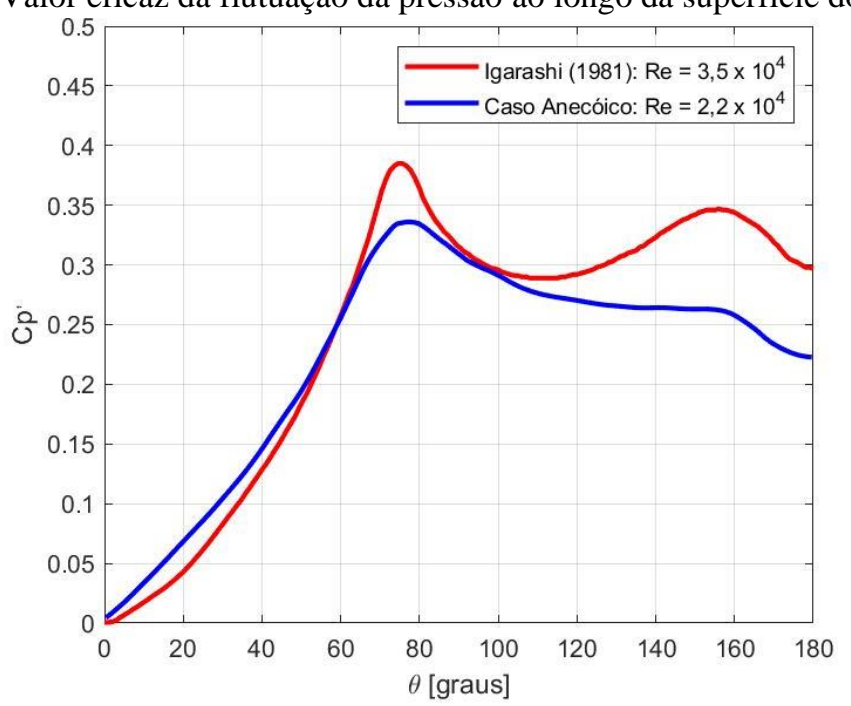

O histórico temporal dos coeficientes de arrasto $\left(C_{d}\right)$ e sustentação $\left(C_{l}\right)$ são apresentados na Figura 19. Os valores médio e RMS do coeficiente de arrasto são respectivamente 1,2 e 0,077 e o RMS do coeficiente de sustentação é 0,46. A amplitude harmônica de oscilação do sinal no tempo de $C_{l}$ é resultado da multiplicação do valor eficaz por $\sqrt{2}$ obtendo assim um valor de 0,65 . Para quantificar a ordem de grandeza com que os picos do histórico temporal do coeficiente de sustentação variam em relação a amplitude do sinal é adequado calcular a média das amplitudes dos 10 maiores e dos 10 menores picos positivos no intervalo de tempo entre 0,15s e 0,6s e compará-las com a amplitude do sinal. Essa análise indica que a média de oscilação dos dez maiores picos é 0,89 ou 137\% da amplitude do sinal e a média dos dez menores é 0,32 ou 49\% desta mesma amplitude.

Os pontos em verde na Figura 19 indicam os ciclos de emissão de vórtices que serão utilizados para caracterizar o escoamento ao redor do cilindro.

Figura 19 - Histórico temporal dos coeficientes de arrasto $\left(C_{d}\right)$ e sustentação $\left(C_{l}\right)$ para o Caso Anecóico

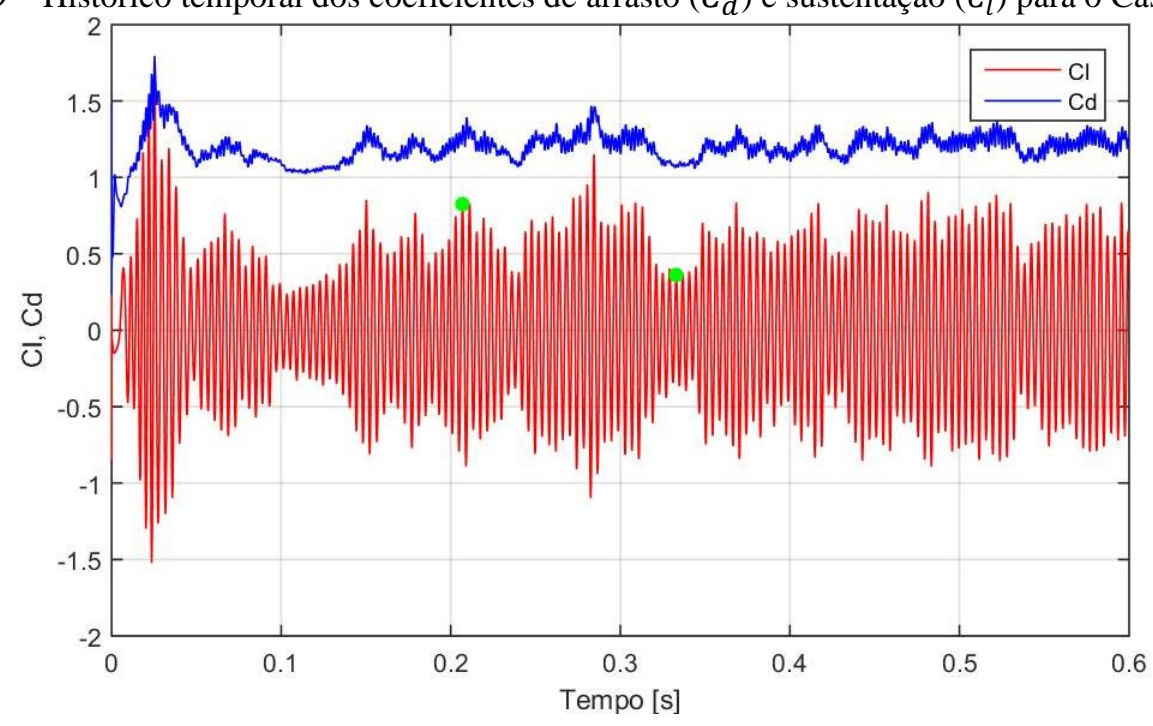


O primeiro pico foi escolhido por representar uma oscilação com amplitude aproximadamente igual a média dos dez maiores picos e o segundo por corresponder a média dos dez menores picos. Os períodos completos de emissão de vórtice dos instantes selecionados foram discretizados em nove pontos conforme Figura 20 onde a posição de número 3 corresponde ao instante assinalado.

Figura 20 - Nomenclatura das posições para caracterização do escoamento

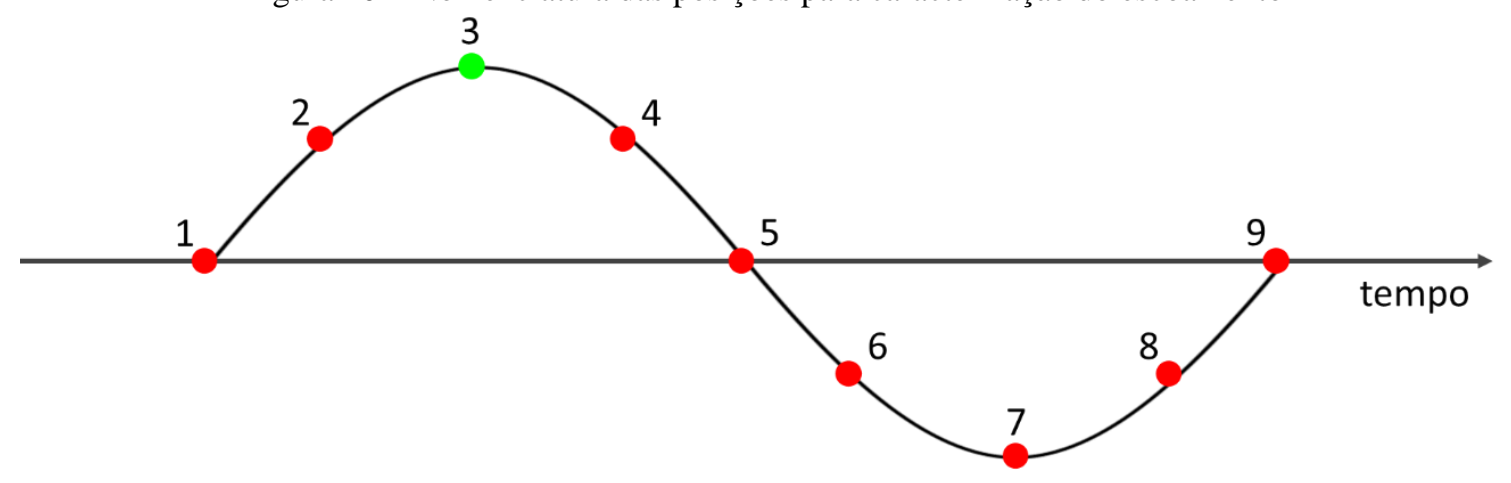

Para ilustrar o escoamento serão apresentadas figuras de contornos de velocidade total e vorticidade no sentido do comprimento do cilindro $(\circlearrowright+)$ para o ponto 3. As ilustrações dos campos escalares para os demais pontos encontram-se no APÊNDICE A e representam o desenvolvimento temporal do escoamento de ar ao redor do cilindro. O plano paralelo ao escoamento é coincidente com o ponto médio do cilindro foi escolhido como referência para geração das imagens aqui apresentadas sendo as figuras que ilustram o comportamento do escoamento para os dois picos do Caso Anecóico mostradas a seguir:

Figura 21 - Contorno de magnitude de velocidade para o maior pico

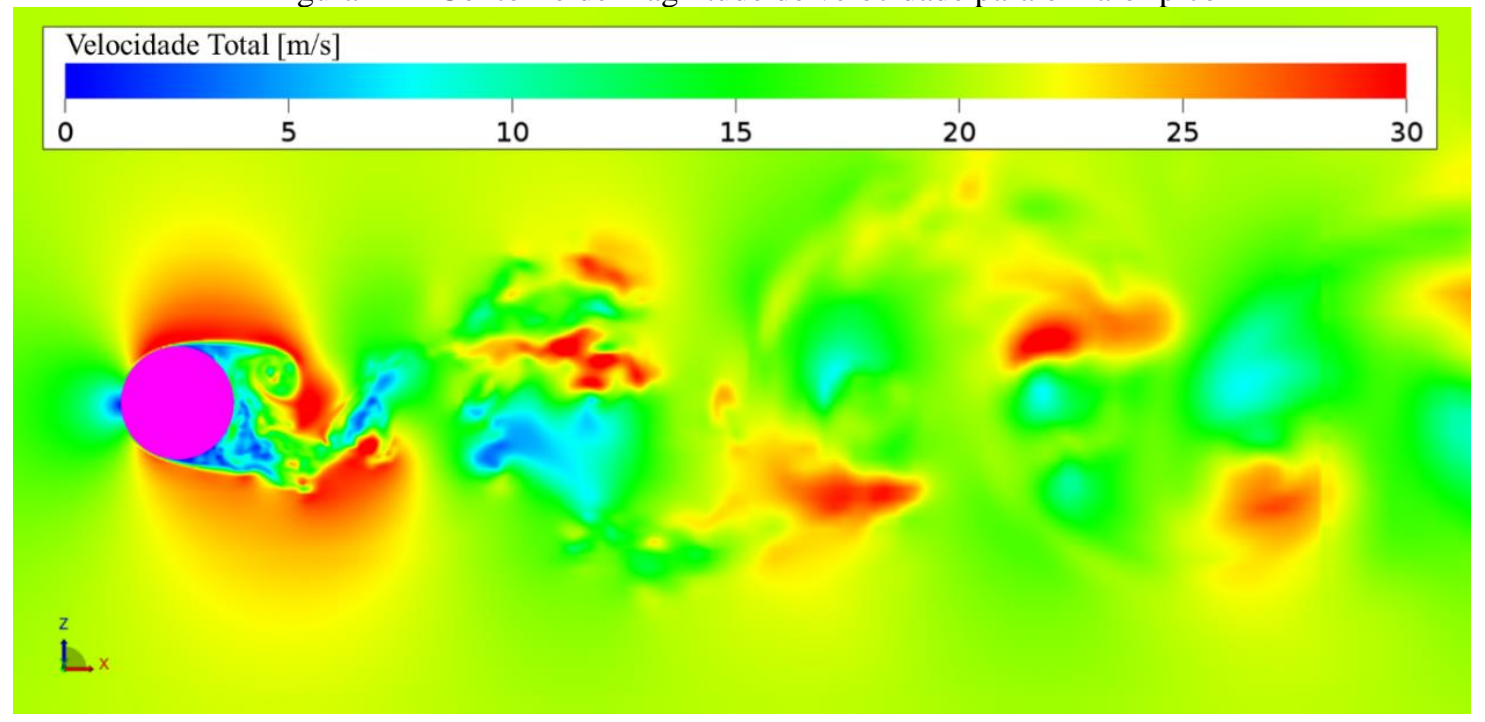


Figura 22 - Contorno de magnitude de velocidade para o menor pico

\begin{tabular}{|l|lllll|}
\hline \multicolumn{2}{|c|}{ Velocidade Total $[\mathrm{m} / \mathrm{s}]$} & & & & \\
\hline \\
\hline
\end{tabular}

Figura 23 - Contorno de vorticidade para o maior pico

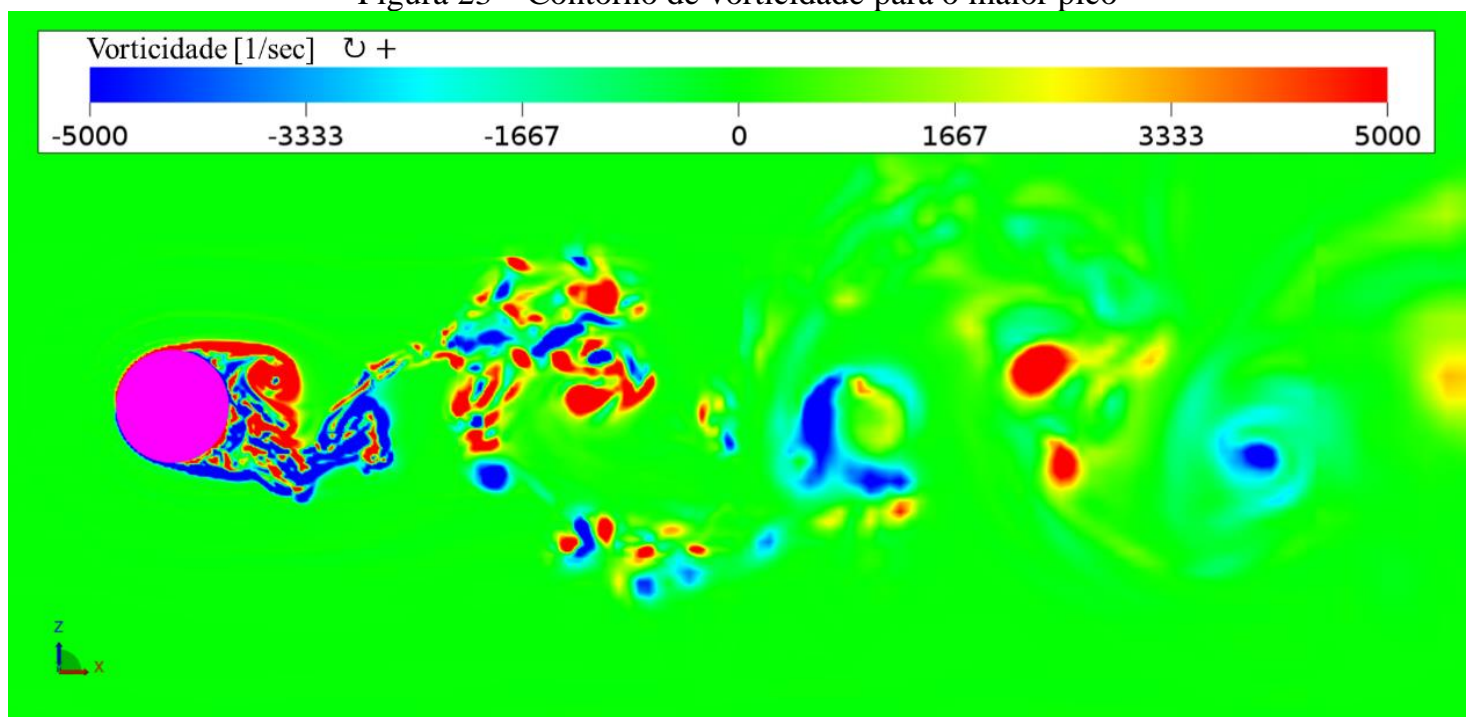

Figura 24 - Contorno de vorticidade para o menor pico

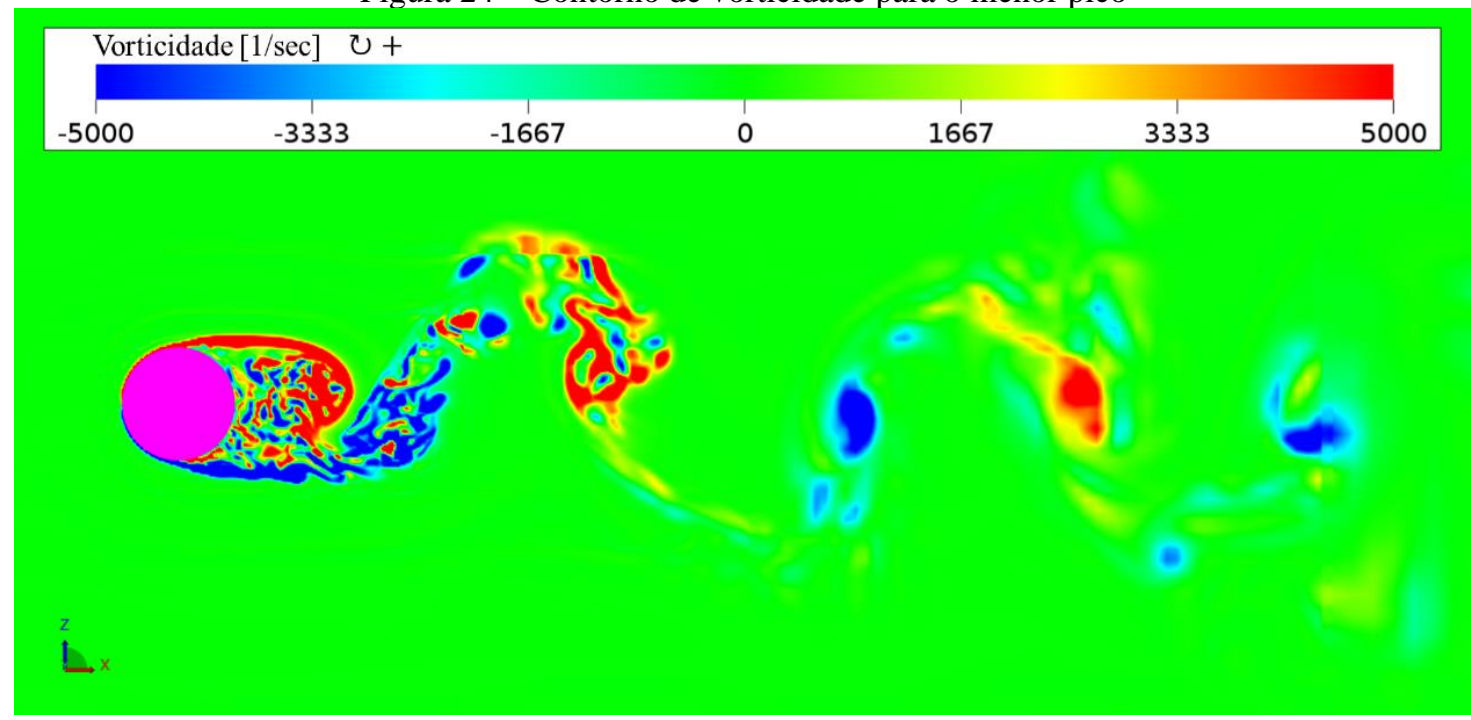


Analisando as Figuras 21, 22, 23 e 24 nota-se que o comprimento de formação de vórtices é qualitativamente diferente nos dois instantes de tempo selecionados. No primeiro pico, em que a amplitude de oscilação é equivalente à média dos dez maiores picos, tem-se no plano central do cilindro um enrolamento da camada cisalhante mais próximo ao cilindro do que no segundo pico. Outra característica importante verificada é que nessa faixa $R e$ a transição para a turbulência ocorre na camada cisalhante, assim como descrito por Zdravkovich (1997), o que explica a existência de pequenas escalas turbulentas na formação dos vórtices.

Blevins (2001) cita que a estrutura de emissão de vórtices não é bidimensional, estacionária e harmônica, mas que a modulação nas forças de sustentação e arrasto é resultado da tridimensionalidade do escoamento destacada na Figura 25.

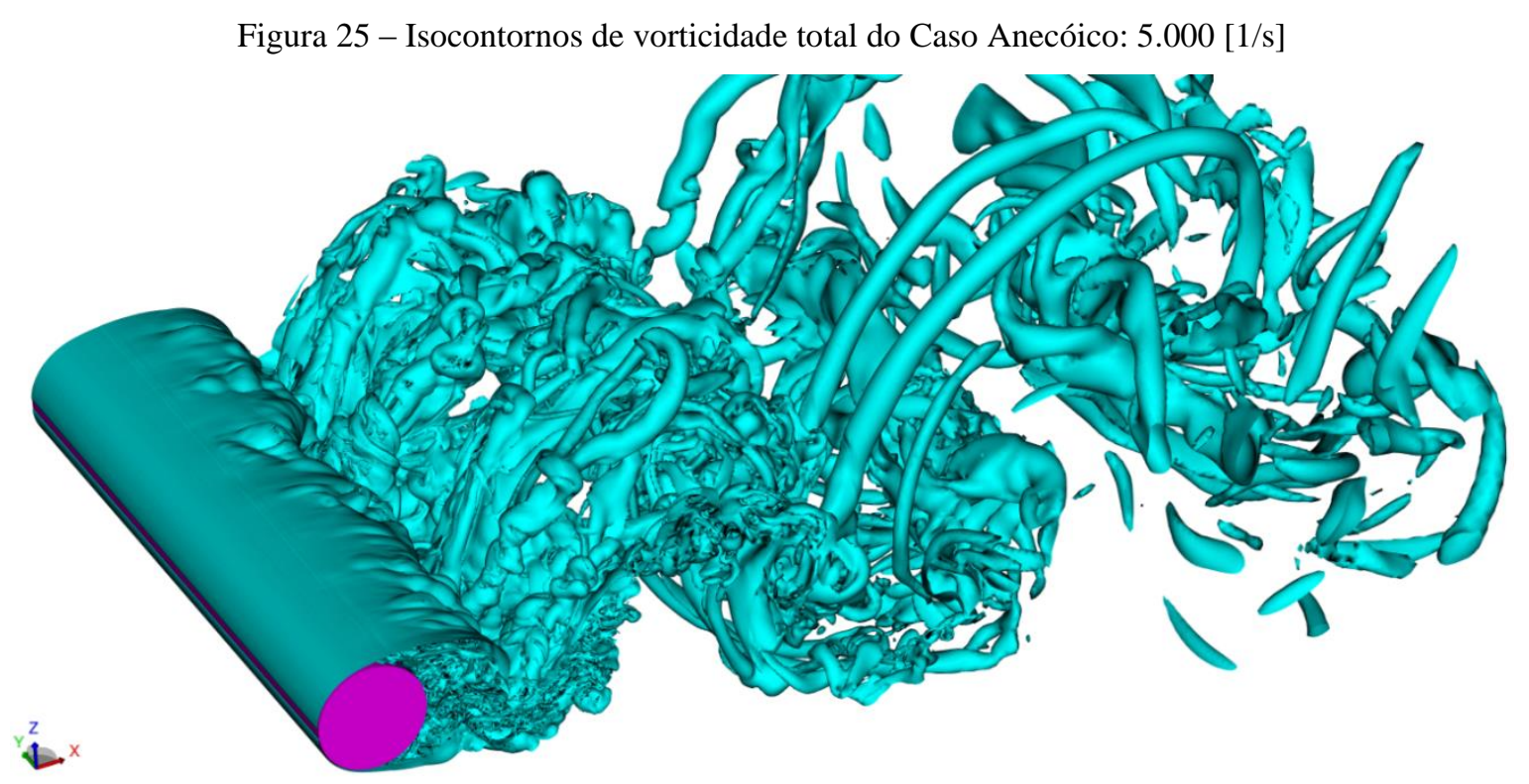

Realizou-se uma análise de Densidade Espectral de Potência (PSD) nos dados temporais dos coeficientes de sustentação $C_{l}$ e arrasto $C_{d}$ com o intuito de analisar seu conteúdo em frequência e confirmar que o espectro desses dois sinais podem ser correlacionados com o ruído radiado pelo cilindro sujeito a escoamento com $M<0,3$. Os resultados das PSDs de ambos os sinais realizadas para os 0,5s finais da simulação são apresentados na Figura 26.

Para $S t=0,198\left(f_{0}\right)$ encontra-se a maior amplitude da PSD de $C_{l}$ que é exatamente o valor do número de Strouhal mostrado na Tabela 3 correspondente ao valor típico associado à emissão de vórtices de um cilindro. O harmônico com pico centrado em $S t=0,396\left(2 f_{0}\right)$ é associado ao histórico temporal do coeficiente de arrasto. O fato do número de Strouhal deste harmônico ser o dobro do pico em $f_{0}$ deve-se ao fato de que em cada ciclo de emissão de 
vórtices observa-se uma oscilação completa no valor da força de sustentação e duas oscilações completas no valor da força de arrasto. Ainda na Figura 26 nota-se que o harmônico em $S t=$ $0,594\left(3 f_{0}\right)$ é também associado à flutuação do coeficiente de sustentação.

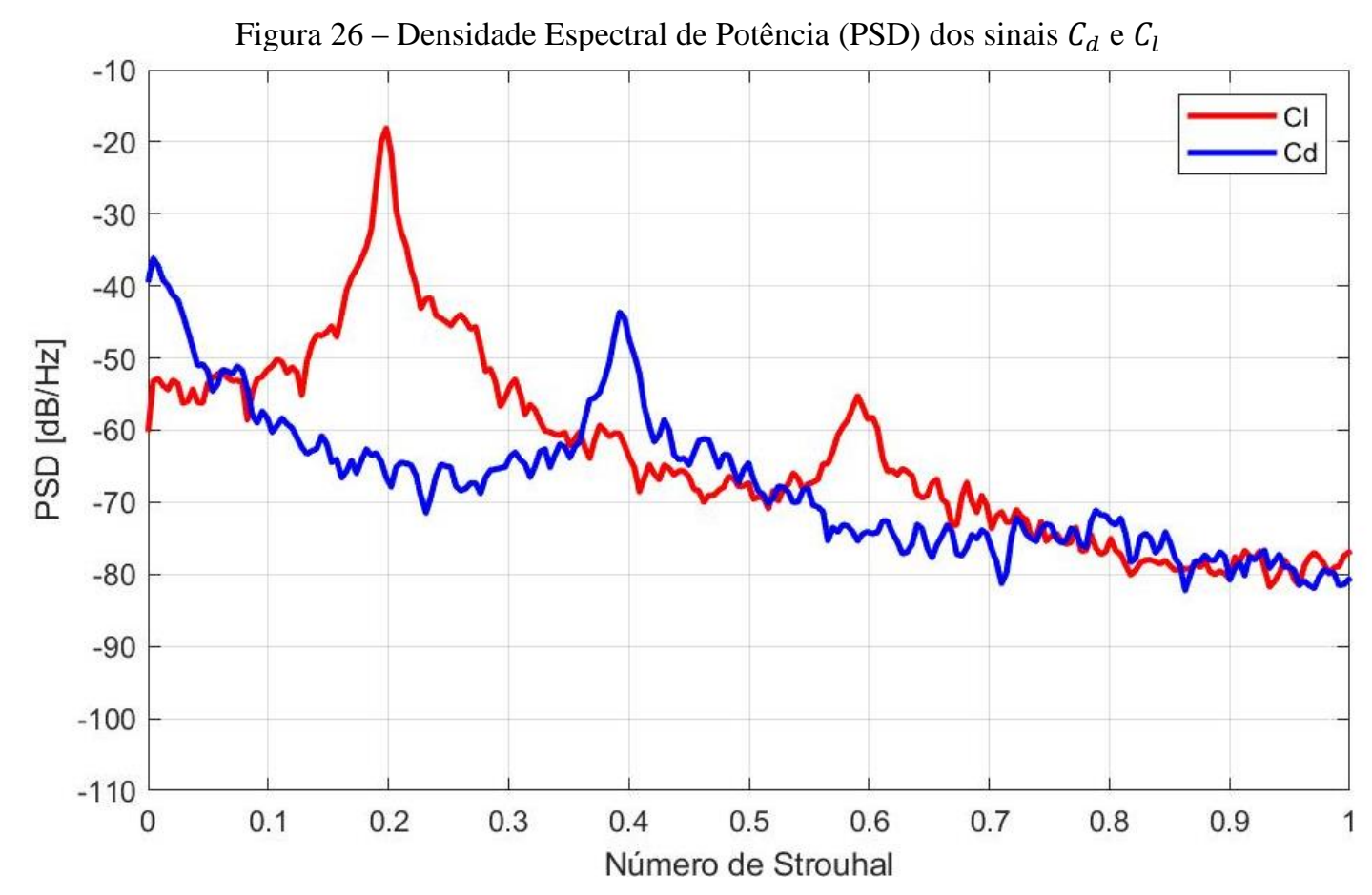

3.3 VALIDAÇÃO DO RUÍDO EM CAMPO AFASTADO

A frequência de aquisição das variáveis fluidodinâmicas utilizadas no cálculo do ruído em campo afastado é de $52.860 \mathrm{~Hz}$ sendo o tempo total de simulação foi escolhido para que após os $0,1 \mathrm{~s}$ iniciais da simulação, ocorressem ao menos 5 ciclos completos de emissão de vórtices na frequência de $10 \mathrm{~Hz}$. Tal escolha resulta em uma curva de densidade espectral de ruído com frequência mínima de $2 \mathrm{~Hz}$, máxima de $13210 \mathrm{~Hz}$ (frequência de Nyquist = 4) e resolução de 2Hz. As frequências de interesse são $S t=0,2(250 \mathrm{~Hz}), S t=0,4(500 \mathrm{~Hz})$ e $S t=$ 0,6 $(750 \mathrm{~Hz})$ e fundamentado nisso decidiu-se apresentar as curvas de PSD [dB/Hz] em função do número de Strouhal de $S t=0$ até $S t=1(1250 \mathrm{~Hz})$, valor que abrange todas as frequências relevantes do estudo.

Foi aplicada a formulação porosa de FW-H via software PowerACOUSTICS nos dados coletados em uma superfície fictícia e permeável coincidente com a superfície do cilindro durante os 0,5 s finais da simulação com o intuito de calcular o ruído ao longe em uma distância de $86,25 d$ do centro do cilindro nas posições $\phi=90^{\circ}$ e $\phi=40^{\circ}$. O resultado da PSD calculada com técnica de janelamento Hanning (50\% de overlap) do ruído em $\phi=90^{\circ}$ do Caso Anecóico comparada ao resultado do teste de Casalino e Jacob (2003) é mostrada na Figura 27. 


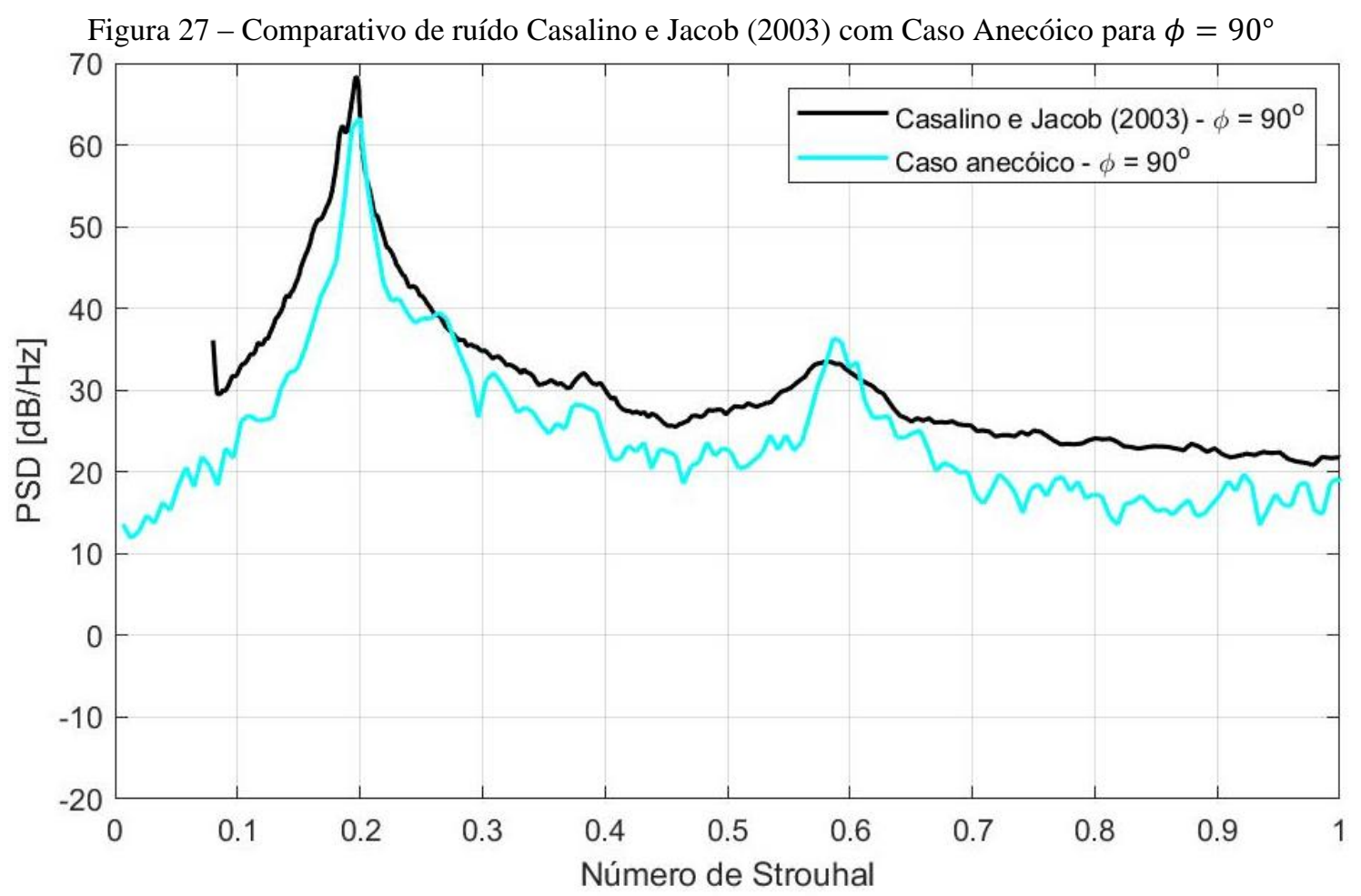

Uma leitura detalhada do gráfico permite concluir que os tonais $f_{0}$ e $3 f_{0}$ foram capturados pelo método LBM + FW-H. O valor de número de Strouhal resultante da simulação foi de 0,198 contra 0,200 do experimento, resultando em uma precisão em frequência de $99 \%$. A amplitude do pico nessa mesma frequência é de $62,9 \mathrm{~dB} / \mathrm{Hz}$ contra $68 \mathrm{~dB} / \mathrm{Hz}$ do teste resultando em $92,5 \%$ de precisão em amplitude. Não foi observado pico proeminente na faixa de frequência correspondente ao harmônico $2 f_{0}$ e a amplitude em PSD nas demais frequências estão em média 5 dB/Hz abaixo da curva de referência extraída de Casalino \& Jacob (2003).

A amplitude da curva simulada é inferior a curva do experimento de referência pois a envergadura do cilindro simulado $\left(L_{s}=5,7 d\right)$ é inferior ao comprimento do cilindro testado $(18,75 d)$. Orselli (2012) cita o método de correção acústica de Kato (1993) elaborado para corrigir a amplitude da curva de ruído quando a largura do domínio da simulação é menor que o comprimento total do objeto em estudo. Duas curvas extraídas da tese de Orselli (2012) serão utilizadas para evidenciar o potencial do método de Kato (1993) em corrigir a curva de ruído obtida na simulação de modelos reduzidos. As curvas escolhidas foram as do caso $F_{x y z}$ com razão de aspecto $L_{s} / d=3,0$ com e sem correção de Kato (1993) e são comparadas ao resultado do teste de Casalino e Jacob (2003) na Figura 28.

$\mathrm{Na}$ análise da Figura 28 verifica-se que na frequência fundamental $f_{0}$ o valor somado a curva original foi em torno de $15 \mathrm{~dB} / \mathrm{Hz}$, sendo que nas demais frequências somaram-se aproximadamente $8 \mathrm{~dB} / \mathrm{Hz}$. Orselli (2012) fez o mesmo para o caso $M_{x y z}$ com razão de aspecto 
$L_{s} / d=6,0$ e os valores de correção calculados por ele foram $8,92 \mathrm{~dB} / \mathrm{Hz}$ para frequências no entorno de $f_{0}$ e $4,95 \mathrm{~dB} / \mathrm{Hz}$ para as demais. Nota-se que quanto maior a largura do domínio, menores são os valores das correções de Kato (1993).

Figura 28 - Comparativo dos dados com e sem correção de Kato de Orselli (2012) Ls/d = 3

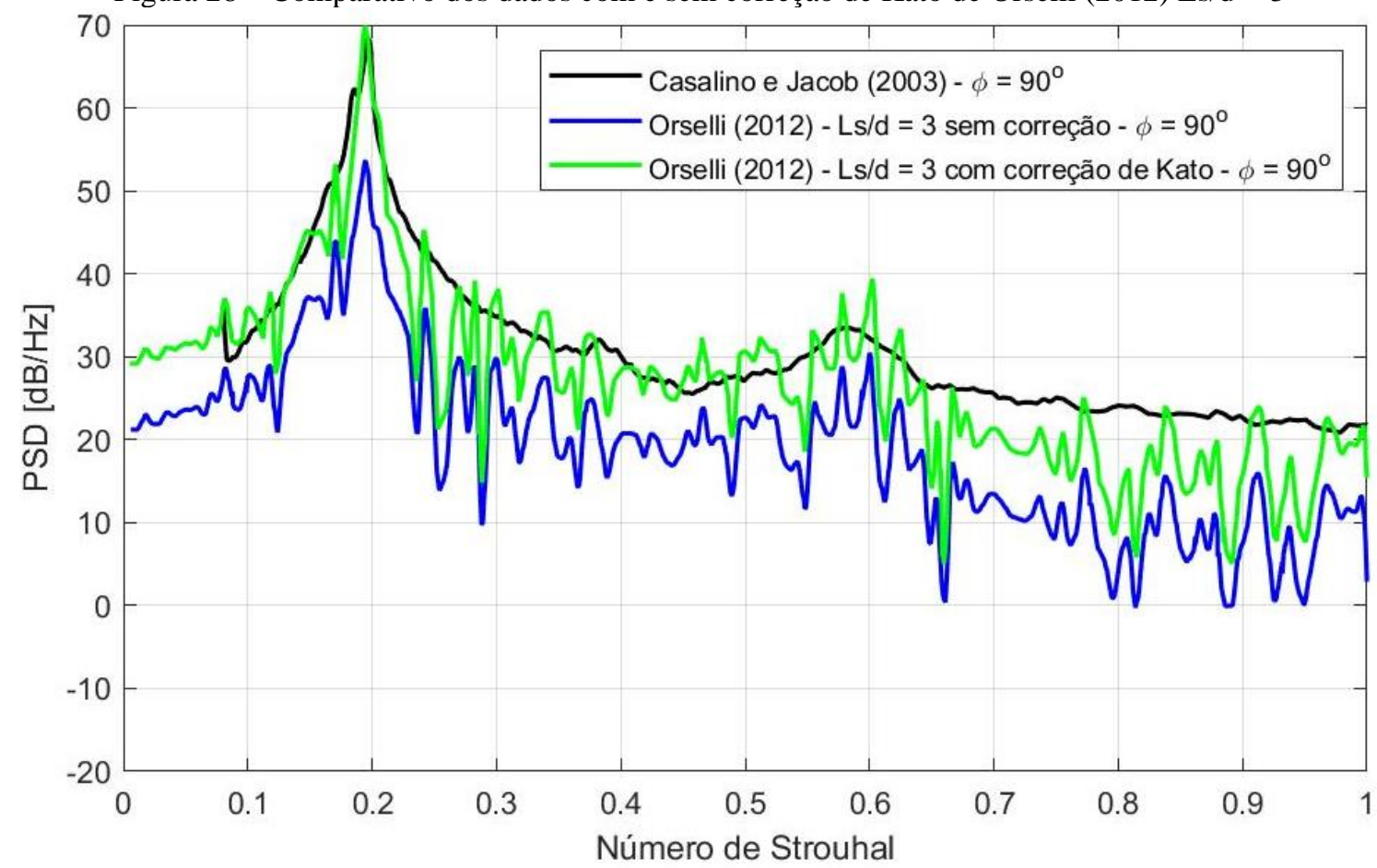

Adaptado de: Orselli (2012) e Casalino e Jabob (2003)

Realizar o cálculo da correção de Kato não é parte integrante desse trabalho, porém, com os dados mostrados anteriormente pode-se concluir que os dados obtidos na simulação de aeroacústica computacional híbrida via LBM + FW-H apresenta resultados de amplitude satisfatórios quando comparados aos resultados do teste de Casalino e Jacob (2003).

A não captura do harmônico $2 f_{0}$ no cálculo do ruído via analogia acústica de FW-H para a posição $\phi=90^{\circ}$ ocorre pois o dipolo associado à flutuação da força de arrasto possui direções principais perpendiculares à reta que liga o centro do cilindro ao ponto do cálculo do ruído sendo o mesmo observado nas medições de Casalino e Jacob (2003). Para demonstrar a capacidade do método LBM + FW-H em capturar este harmônico, compara-se na Figura 29 os dados do teste de Casalino e Jacob (2003) e os resultados do Caso Anecóico para $\phi=40^{\circ}$.

O pico em $2 f_{0}$ e $S t=0,394$ resultou em $98,5 \%$ de correlação quando comparado ao teste de referência com $S t=0,4$. Para melhorar a acurácia em amplitude basta aplicar a correção de Kato (1993) aos dados simulados assim como no caso $\phi=90^{\circ}$. 
Figura 29 - Comparativo de ruído Casalino e Jacob (2003) com Caso Anecóico para $\theta=40^{\circ}$

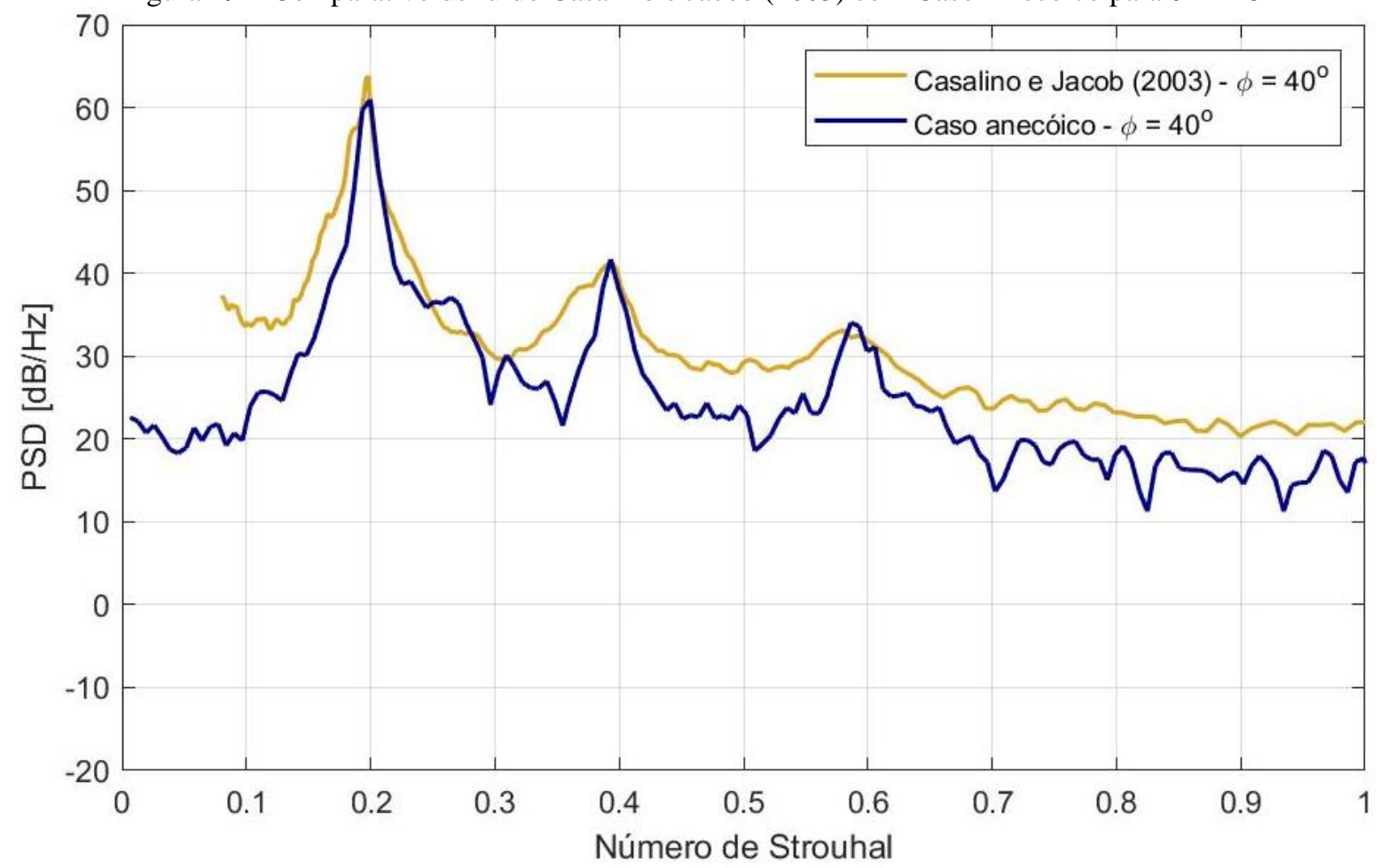

\subsection{DECOMPOSIÇÃO EM MODOS DINÂMICOS}

Uma análise de Decomposição em Modos Dinâmicos (DMD) foi conduzida com o intuito de caracterizar as estruturas fluidodinâmicas coerentes associadas às frequências dos três principais picos do ruído em campo afastado $\left(f_{0}, 2 f_{0}\right.$ e $\left.3 f_{0}\right)$. Para isso, um código adaptado do trabalho de Kutz et. al. (2016) foi escrito em MATLAB e utilizado para extrair os modos dinâmicos do histórico temporal de pressão na região próxima ao cilindro.

Para calcular os modos dinâmicos do escoamento utiliza-se os dados temporais do campo de pressão total em 57.600 pontos dispostos de forma retangular ao redor do cilindro. A janela de medição possui nove diâmetros de comprimento e quatro diâmetros de altura, sendo 360 pontos ao longo do comprimento e 160 pontos na altura. Os sinais possuem duração de 35 ciclos de emissão de vórtices na frequência $f_{0}$ ou $0,14 s$ e resolução de aproximadamente 24 medições consecutivas por período ou um timestep $\Delta t=1,7 \times 10^{-4} \mathrm{~s}$.

As estruturas coerentes resultantes da análise DMD serão comparadas com as estruturas instantâneas provenientes da análise do histórico temporal do campo de pressão total com filtro passa-banda (bandpass filter - BPF) aplicado nas frequências de interesse. As duas metodologias servem como ferramentas na solução de problemas e contribuem para o entendimento da natureza das instabilidades e para isolar os efeitos ocasionados pelos diferentes modos de oscilação presentes no escoamento. 
O resultado da análise DMD foi truncado nos cem primeiros modos dinâmicos e o gráfico da taxa de crescimento/decaimento $\left(\sigma_{k}\right)$ em função do número de Strouhal de cada modo é mostrado na Figura 30, sendo os modos de interesse associadas a $f_{0}, 2 f_{0}$ e $3 f_{0}$ marcados pelas setas verdes.

Figura 30 - Taxa de decaimento vs. número de Strouhal dos modos DMD do Caso Anecóico

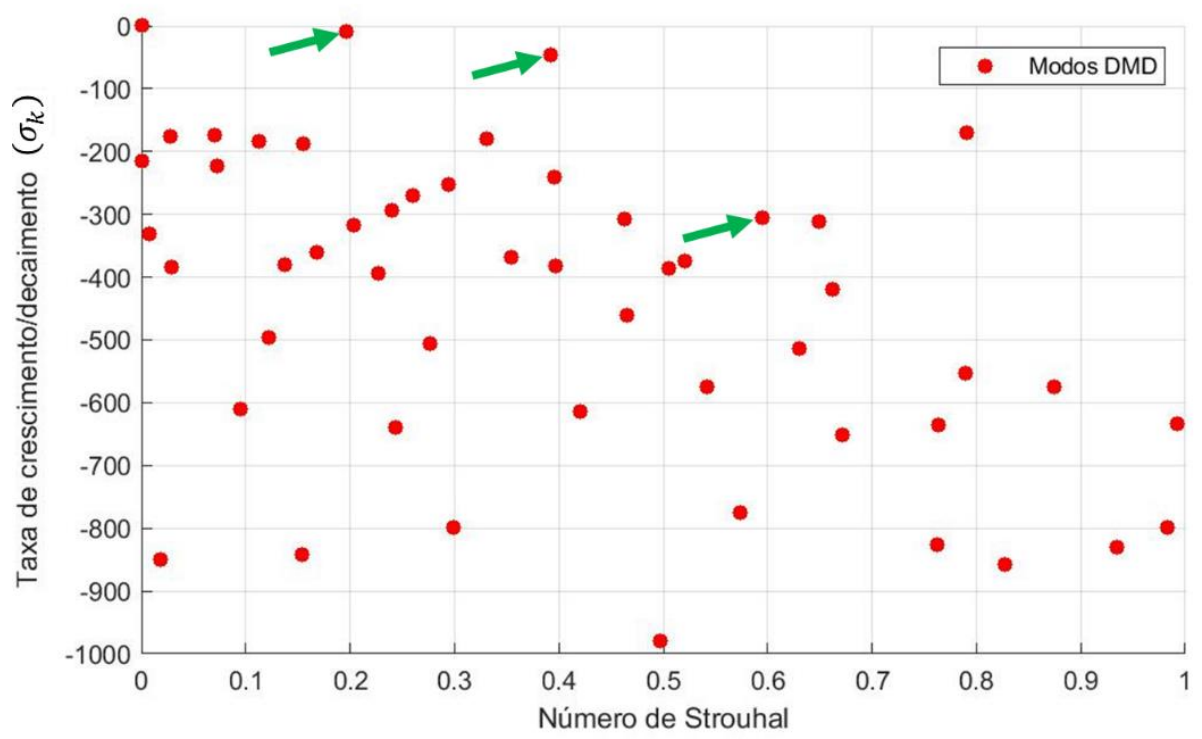

Os comparativos são mostrados nas Figuras 31, 32 e 33, nas quais as ilustrações superiores representam os modos DMD complexos, sendo que a imagem da esquerda é a representação da parte real do modo e está adiantada em 90 graus da parte imaginária (imagem da direita). A imagem inferior é o resultado da análise passa-banda na mesma frequência do modo DMD apresentado.

Nota-se nas figuras dos modos dinâmicos das frequências $f_{0}$ e $3 f_{0}$ que existe a alternância entre autovalores positivos (contornos vermelhos) e negativos (contornos azuis) acima e abaixo do cilindro sendo este um comportamento semelhante ao modo de um dipolo emitido pela flutuação da força de sustentação. Esse comportamento de alternância não é tão claro em $3 f_{0}$, pois está associado à outras dinâmicas mais complexas. Uma vez que as escalas foram mantidas constata-se que as estruturas coerentes no modo $3 f_{0}$ são menores que no modo $f_{0}$. Já o modo $2 f_{0}$ apresenta autovalores positivos e negativos alternados na direção do escoamento, típico de um modo relativo à flutuação da força de arrasto, sendo as dimensões das estruturas coerentes intermediárias às dos outros dois modos. A completa visualização da estrutura do dipolo exige uma janela de medição proporcional ao comprimento de onda da frequência de interesse demandando grande poder computacional e, por este motivo, a janela de cálculo foca apenas na região próxima ao cilindro. 
A representação das estruturas coerentes dos modos DMD estão em concordância com a análise Band-Pass nas três frequências de interesse, demonstrando a capacidade da Decomposição em Modos Dinâmicos em servir como ferramenta de análise do escoamento.

Figura 31 - Modo DMD (superiores) e Band-Pass (Inferior) para a frequência $f_{0}$
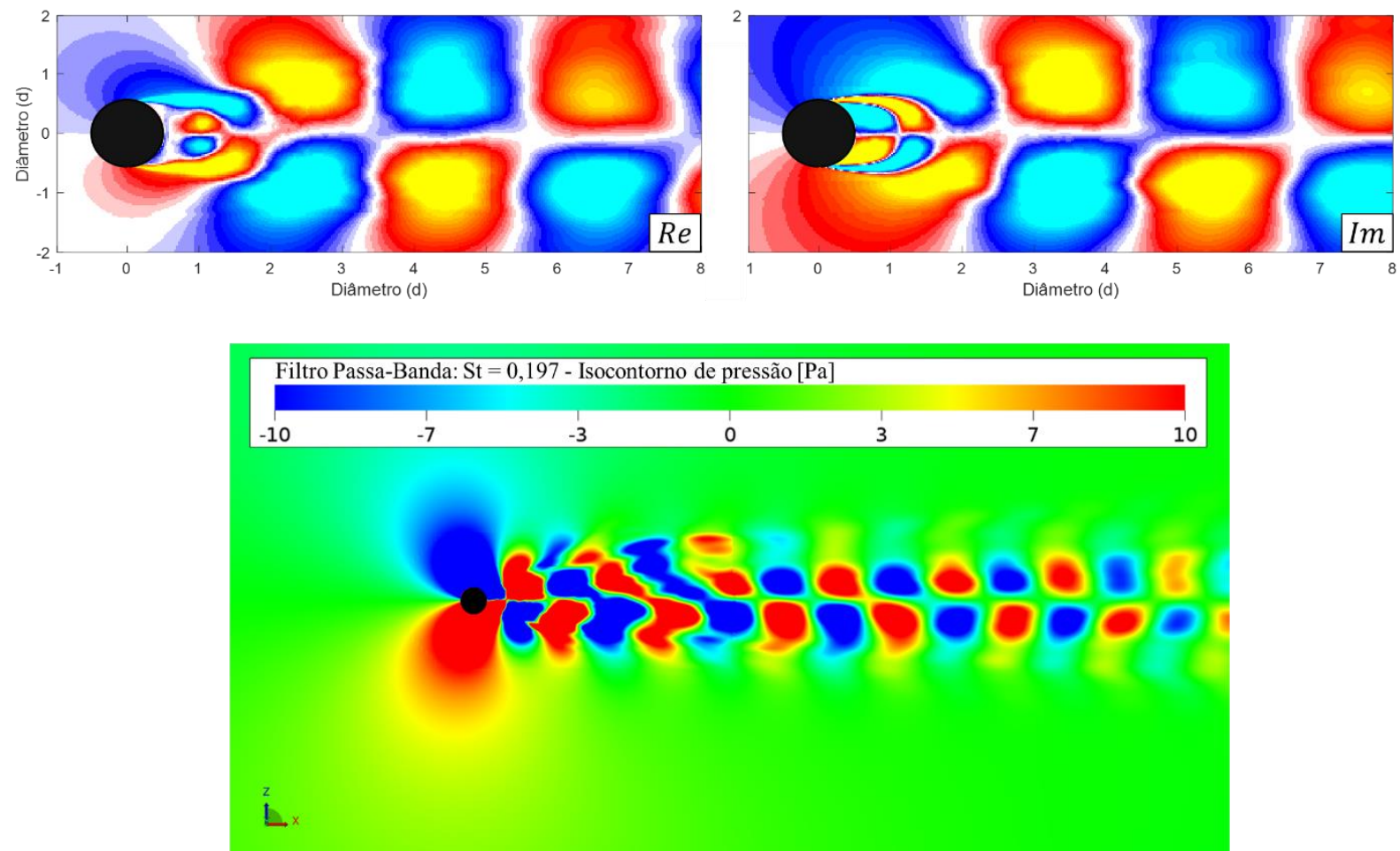

Figura 32 - Modo DMD (superiores) e Band-Pass (Inferior) para a frequência $2 f_{0}$
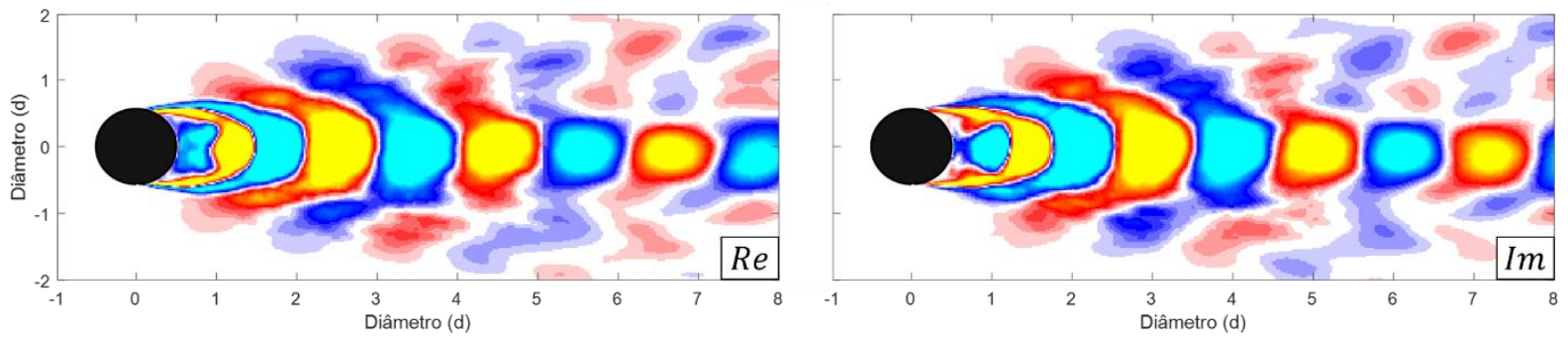

\begin{tabular}{|ccccccc|}
\multicolumn{5}{l}{ Filtro Passa-Banda: $\mathrm{St}=0,393$} & - Isocontorno de pressão [Pa] \\
\hline-10 & -7 & -3 & 0 & 3 & 7 & 10
\end{tabular}


Figura 33 - Modo DMD (superiores) e Band-Pass (Inferior) para a frequência $3 f_{0}$
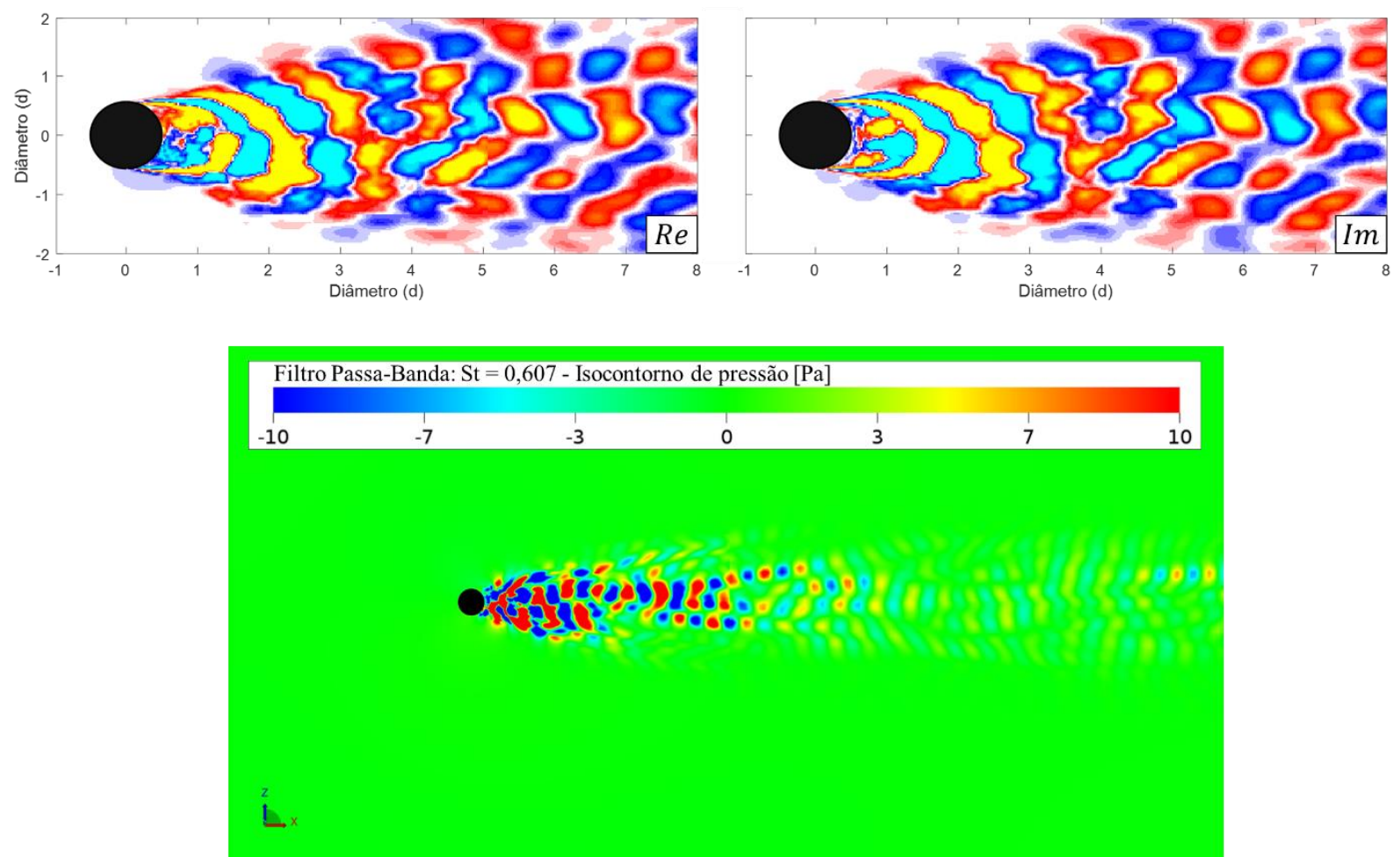

Os resultados indicam que o modelo proposto gera resultados satisfatórios para o estudo da aeroacústica de corpos rombudos sujeitos a escoamento de ar com baixo número de Mach, que é uma configuração comumente encontrada na indústria automotiva. A metodologia abordada é valiosa para o desenvolvimento de barras de teto transversais, antenas, retrovisores e apêndices aerodinâmicos se aplicada ainda nos estágios iniciais do projeto onde os custos de modificações são reduzidos e há maior flexibilidade na implementação de modificações geométricas nos componentes. Complementarmente, o método serve como ferramenta de análise e solução de problemas em produtos já existentes. 


\section{CILINDROS DISPOSTOS EM TANDEM}

Além da função estética, racks de teto fornecem estrutura para a montagem de acessórios destinados ao transporte de objetos sendo que alguns desses acessórios são fabricados com barras cilíndricas alinhadas na direção do escoamento, ou em tandem, como no caso do bagageiro mostrado na Figura 34. A interferência aerodinâmica dessa configuração é complexa e difere em vários aspectos do escoamento transversal ao redor de um único cilindro isolado. Um modelo simplificado, e utilizado com frequência no estudo de bancos de cilindros arranjados em linha, é o de dois cilindros separados por uma distância $L$ medida de centro a centro e dispostos em tandem como detalhado na Figura 35.

Com base nisso optou-se por realizar simulações computacionais no modelo simplificado com o intuito de investigar e detalhar o escoamento e o ruído radiado por um par de cilindros arranjados em linha.

\section{Figura 34 - Exemplo de bagageiro gradeado}

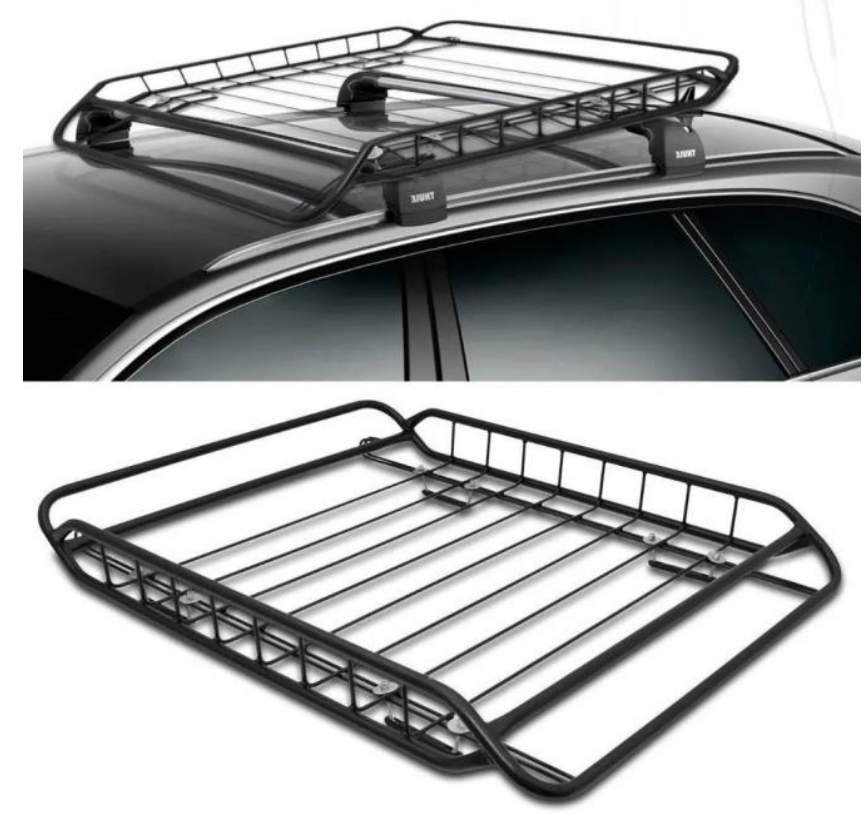

Fonte: Projecar (2020).

Figura 35 - Detalhes do modelo simplificado de um banco de cilindros arranjados em linha

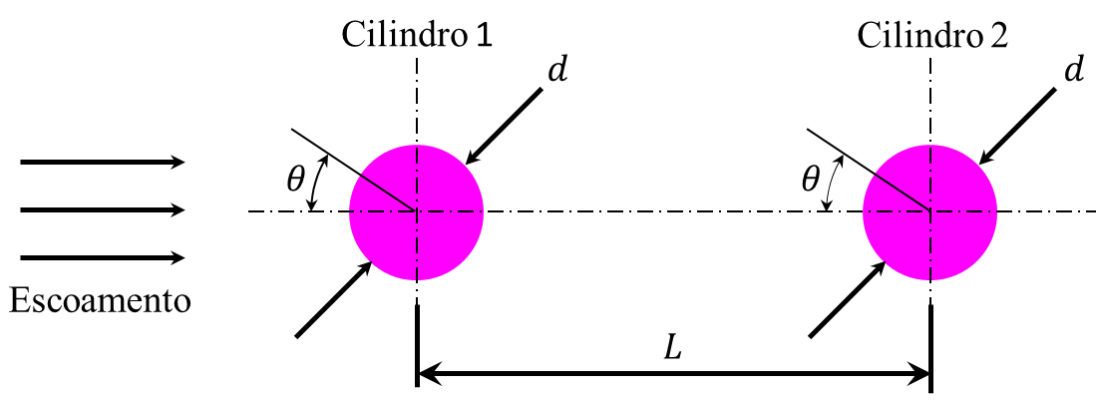




\subsection{AERODINÂMICA DE CILINDROS EM TANDEM}

Ljungkrona, Norberg e Sundén (1991) e Igarashi (1981) descrevem com detalhes a aerodinâmica de dois cilindros em tandem e mostram que variáveis fluidodinâmicas como coeficientes de arrasto e sustentação, coeficiente de pressão e número de Strouhal dependem da relação $L / d$, de $R e$ e da intensidade de turbulência no escoamento livre $(T u)$.

O diagrama proposto por Igarashi (1981) e demonstrado na Figura 36 mostra uma classificação do escoamento quanto ao número de Reynolds e o parâmetro $L / d$.

Figura 36 - Classificação do escoamento segundo número de Reynolds e parâmetro $L / d$
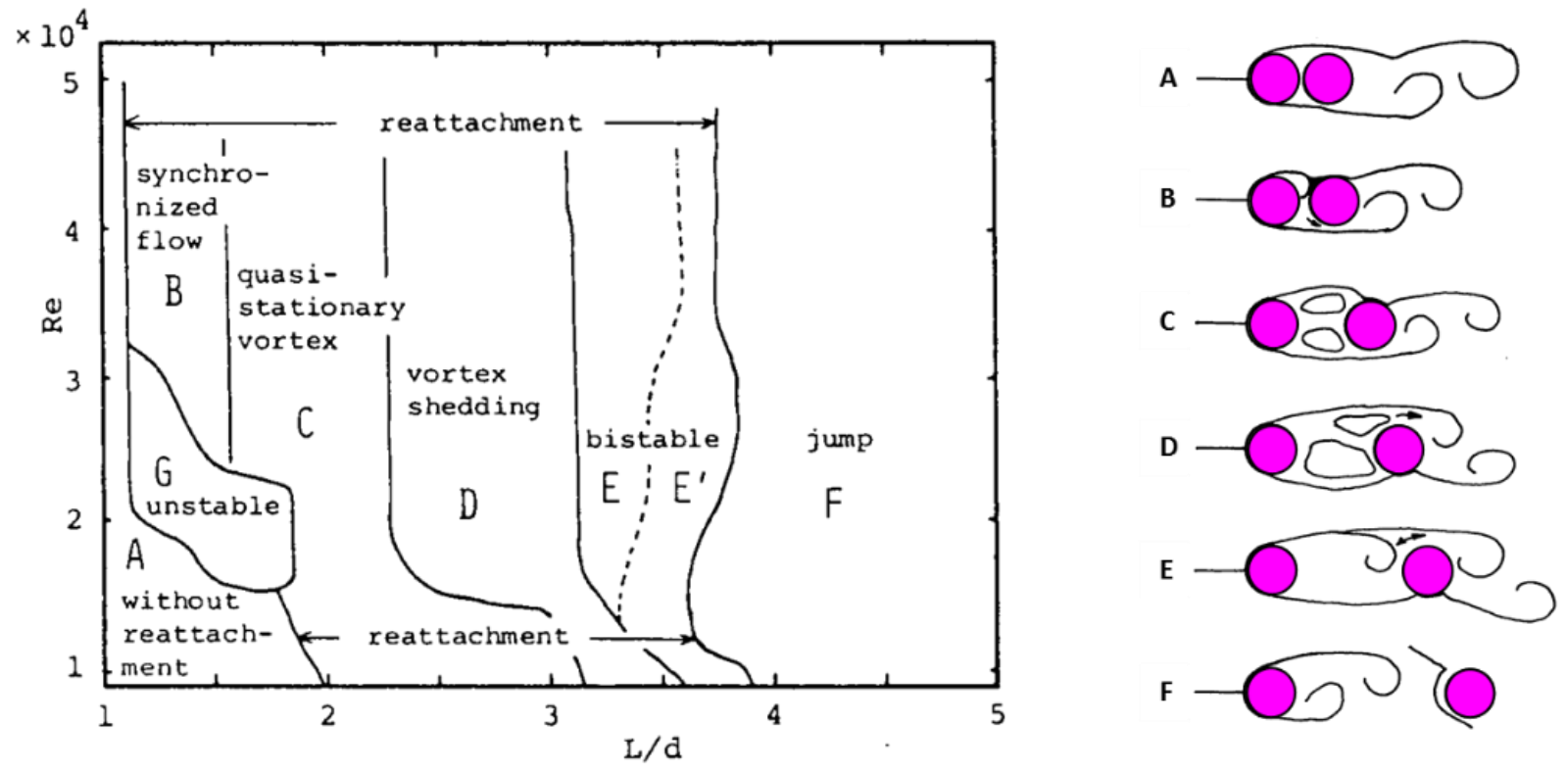

Adaptado de: Igarashi (1981).

Segundo Igarashi (1981) o padrão A é caracterizado pela formação e desprendimento de vórtices à jusante do segundo cilindro sem indícios de recolamento da camada cisalhante do primeiro cilindro no cilindro 2 , daí o nome without reattachment. Os padrões $\mathrm{B}, \mathrm{C}, \mathrm{D}$ e E possuem uma característica em comum que é o recolamento da camada cisalhante no segundo cilindro e são denominados reattachment. No padrão B há um sincronismo da formação de vórtices na camada cisalhante na esteira próxima ao cilindro 2 sendo a frequência de emissão de vórtices aproximadamente constante e independe da velocidade no escoamento incidente. $\mathrm{O}$ padrão C é determinado pela formação de dois vórtices estacionários no espaço que separa os cilindros, sendo que no padrão D esses mesmos vórtices tornam-se instáveis e a emissão de vórtices acontece de forma intermitente. Os padrões E e E' determinam a região de transição entre os padrões D e F em que os vórtices do cilindro 1 formam-se intermitentemente ora na 
frente, ora atrás do cilindro 2, sendo que o padrão sustenta-se por um intervalo de tempo maior em E'. No padrão F há formação e desprendimento de vórtices no espaço entre os cilindros e vórtices desprendidos atingem o segundo cilindro originando um escoamento complexo denominado jump. No experimento de Igarashi (1981) a transição de reattachment para jump acontece na separação intitulada como crítica onde $L / d \approx 3,53$, mas sabe-se que ela é fortemente dependente de $\operatorname{Re}$ (Assi et al., 2010).

Este efeito de interferência aerodinâmica entre os dois cilindros induz grandes flutuações de pressão no cilindro à jusante que, inclusive, podem excitar o fenômeno de WIV - Wake-Induced Vibration, descrito por Assi et al (2010, 2013).

Ljungkrona, Norberg e Sundén (1991) citam que os coeficientes $C_{p}$ e $C_{p}^{\prime}$ do segundo cilindro são fortemente dependentes da intensidade de turbulência no escoamento livre $(T u)$ e do parâmetro $L / d$ diferente do observado no primeiro cilindro que até a separação crítica não sofre influência desses fatores e, para $L / d$ maiores que a separação crítica, apresenta resultados similares ao do escoamento ao redor de um único cilindro. Outra observação importante do estudo de Ljungkrona, Norberg e Sundén (1991) é que a separação crítica diminui de 3,53 para 2,5 quando a intensidade de turbulência no escoamento livre é aumentada de $0,1 \%$ para 1,4\%.

Considerado os fatos anteriores e o diagrama da Figura 36 optou-se por realizar três simulações de cilindros dispostos em tandem com diferentes separações: Caso $1-L / d=1,0$, Caso $2-L / d=2,5$ e Caso $3-L / d=4,0$. As variáveis fluidodinâmicas monitoradas são as mesmas da simulação do Caso Anecóico.

Os trabalhos de Igarashi (1981) e Ljungkrona, Norberg e Sundén (1991) servirão de referência para os casos simulados neste capítulo. As curvas e valores de referência serão apresentados junto aos resultados das simulações.

\subsection{MODELO COMPUTACIONAL E CAMPO FLUIDODINÂMICO}

O modelo numérico validado no capítulo anterior $(T u=1,0 \%)$ foi modicado de forma a contemplar um segundo cilindro de diâmetro $d=16 \mathrm{~mm}$, como mostra a Figura 37. As dimensões do túnel anecóico não foram modificadas e apenas as distribuições das VRs próximas aos cilindros (VR9 até VR6) foram alteradas para melhor capturar os pontos de separação das camadas limites, recolamento das camadas cisalhantes e a formação e emissão de vórtices no espaço entre os cilindros e após o cilindro 2, como ilustra a Figura 38. 
Figura 37 - Detalhamento do modelo computacional

$276 d$

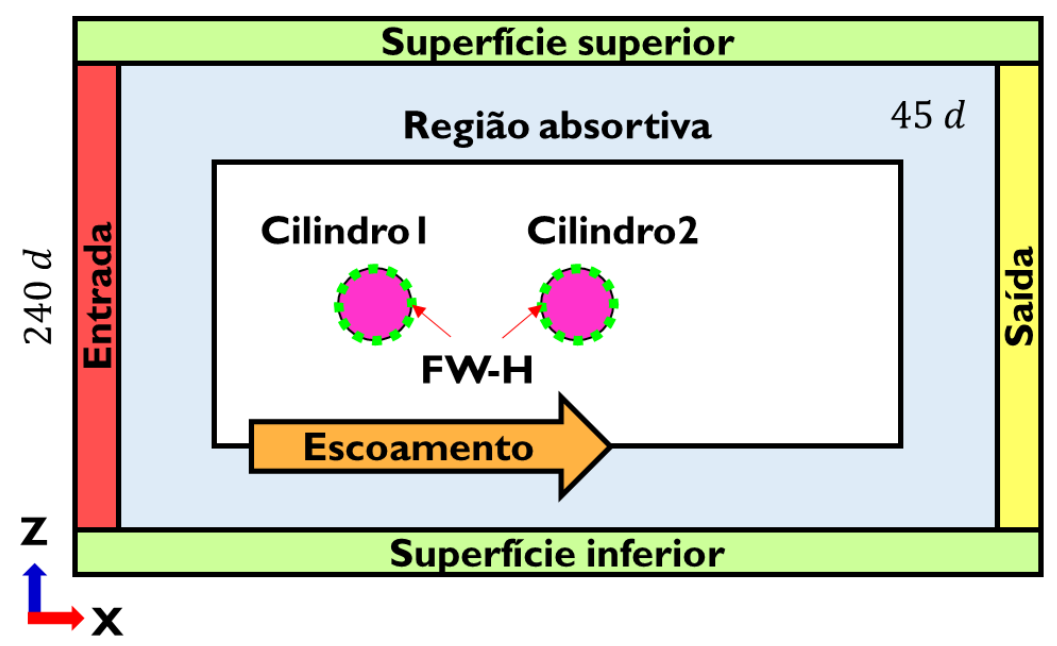

Figura 38 - Detalhamento das regiões de refino ao redor dos cilindros

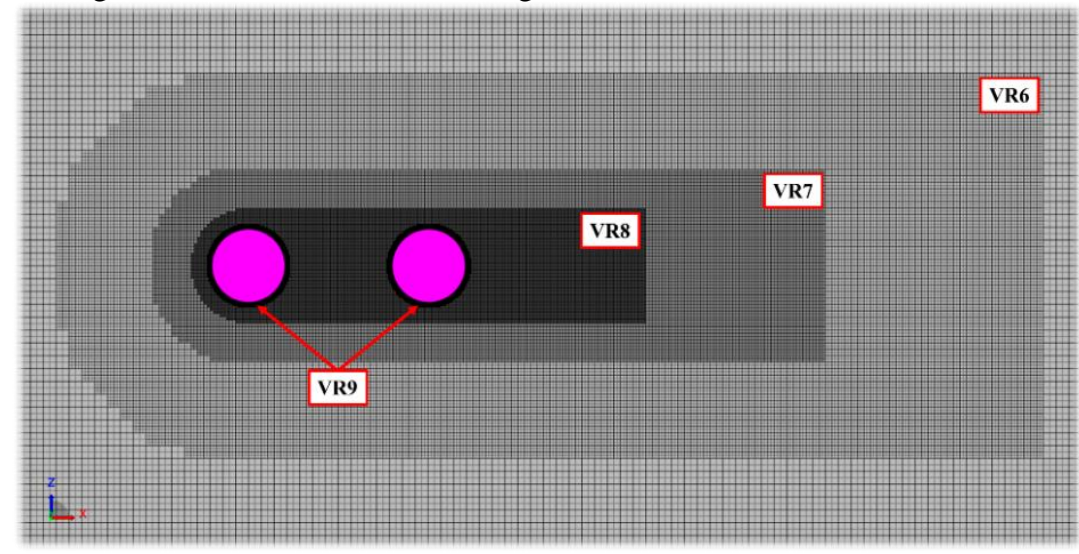

As estatísticas das malhas geradas os resultados do coeficiente de arrasto médio $\left(\overline{C_{d}}\right)$ e número de Strouhal (St) para as simulações dos três casos propostos são compilados nas tabelas a seguir:

Tabela 4 - Estatísticas das malhas geradas

\begin{tabular}{lcccccc}
\hline$L / d$ & Resolução & Cilindro 1: $y+$ & Cilindro 2: $y+$ & Voxels & Surfels & Horas de processamento \\
\hline 1,0 & 180,0 & 8,64 & 5,24 & 61.176 .212 & 3.023 .095 & 147,7 \\
2,5 & 180,0 & 8,15 & 5,31 & 73.426 .324 & 3.023 .105 & 155,4 \\
4,0 & 180,0 & 8,34 & 5,82 & 83.260 .820 & 3.023 .100 & 164,8 \\
\hline
\end{tabular}

Tabela 5 - Coeficiente de arrasto $\left(\overline{C_{d}}\right)$

Cilindro 1

\begin{tabular}{cccc}
\hline \multirow{2}{*}{$L / d$} & $\begin{array}{c}\text { Igarashi(1981) } \\
\operatorname{Re}=3,5 \times 10^{4}\end{array}$ & $\begin{array}{c}\text { Ljungkrona (1991) } \\
\mathrm{Re}=2,0 \times 10^{4}\end{array}$ & $\begin{array}{c}\text { Simulação } \\
\mathrm{Re}=2,2 \times 10^{4}\end{array}$ \\
\hline 1,0 & 1,10 & - & 1,09 \\
2,5 & 0,94 & 0,84 & 0,89 \\
4,0 & 1,30 & 1,19 & 1,19 \\
\hline
\end{tabular}

\begin{tabular}{ccc}
\multicolumn{3}{c}{ Cilindro 2 } \\
\hline Igarashi (1981) & Ljungkrona (1991) & Simulação \\
$\operatorname{Re}=3,5 \times 10^{4}$ & $\operatorname{Re}=2,0 \times 10^{4}$ & $\mathrm{Re}=2,2 \times 10^{4}$ \\
\hline$-0,66$ & - & $-0,54$ \\
$-0,26$ & $-0,24$ & $-0,41$ \\
0,43 & 0,40 & 0,39 \\
\hline
\end{tabular}


Tabela 6 - Número de Strouhal $(S t)$

\begin{tabular}{cccc}
\hline \multirow{2}{*}{$L / d$} & $\begin{array}{c}\text { Igarashi(1981) } \\
\mathrm{Re}=3,5 \times 10^{4}\end{array}$ & $\begin{array}{c}\text { Ljungkrona (1991) } \\
\mathrm{Re}=2,0 \times 10^{4}\end{array}$ & $\begin{array}{c}\text { Simulação } \\
\mathrm{Re}=2,2 \times 10^{4}\end{array}$ \\
\hline 1,0 & 0,276 & - & 0,276 \\
2,5 & 0,157 & 0,146 & 0,165 \\
4,0 & 0,191 & 0,179 & 0,171 \\
\hline
\end{tabular}

Quando comparadas ao Caso Anecóico as estatísticas da Tabela 4 indicam que o tempo de processamento aumentou de 91 para uma média de 156 horas como consequência da adição da nova região VR9 ao redor do segundo cilindro e também pelo alongamento das VRs 6 a 8.

A análise da Tabela 5 mostra que os modelo com separações $L / d=1,0$ e $L / d=2,5$ capturaram o efeito de sucção do segundo cilindro (arrasto negativo) esperado em escoamentos dos padrões without reattachment e reattachment, já na separação $L / d=4,0$ observaram-se valores referentes ao comportamento jump (arrasto positivo ou empuxo). Os resultados do coeficiente de arrasto $\overline{C_{d}}$ estão em concordância com os experimentos de referência exceto, pelo caso $L / d=2,5$ em que o efeito de sucção no segundo cilindro é $58 \%$ maior que os obtidos por Igarashi (1981) e Ljungkrona, Norberg e Sundén (1991), diferença esta que pode ser explicada pela sensibilidade do caso $L / d=2,5$ quanto ao número de Reynolds e a distância de separação entre os dois cilindros. Em escoamentos ao redor de um único cilindro na faixa de $R e$ transicional, Zdravckovich (1997) e Norberg (2003) mostram que pequenas diferenças em fatores como rugosidade do cilindro, intensidade de turbulência no escoamento livre e razão de aspecto resultam em variações consideráveis nos valores médios dos coeficientes de arrasto e sustentação entre diferentes testes. Adicionalmente na configuração $L / d=2,5$, Ljungkrona, Norberg e Sundén (1991) e Igarashi (1981) demonstram que pequenas alterações nesses mesmos parâmetros alteram o valor da separação crítica, promovendo divergências significativas no valor do coeficiente de arrasto.

Nota-se na Tabela 6 que o número de Strouhal das simulações para $L / d=1,0$ e $L / d=2,5$ aproximaram-se dos resultados de Igarashi (1981) já o $S t$ do caso com separação $L / d=4,0$ aproximou-se do resultado de Ljungkrona, Norberg e Sundén (1991), sendo os erros inferiores a $5 \%$.

A seguir apresentam-se os resultados do coeficiente de pressão $\left(C_{p}\right)$ e do valor eficaz da flutuação de pressão na parede do cilindro $\left(C_{p}^{\prime}\right)$. As curvas de referência utilizadas nos comparativos são as de Igarashi (1981) com Tu =0,6\% e $R e=3,5 \times 10^{4}$ e as de Ljungkrona, Norberg e Sundén (1991) com $T u=1,4 \%$ e $R e=2,0 \times 10^{4}$, exceto para os gráficos do caso $L / d=2,5$ em que utilizaram-se os dados de Ljungkrona, Norberg e Sundén (1991) com intensidade de turbulência $0,1 \%$ pois, no teste com $T u=1,4 \%$, o escoamento apresentou 
comportamento jump diferente do padrão reattachment do experimento de Igarashi (1981) e da simulação via PowerFLOW.

Figura 39 - Coeficiente de pressão $\left(C_{p}\right)$ nos cilindros 1 e 2 da configuração $L / d=1,0$

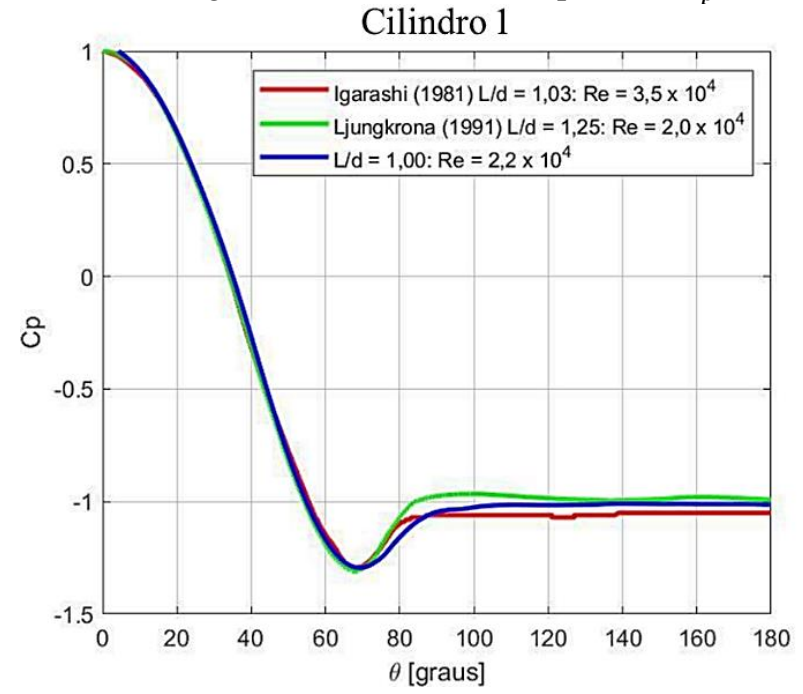

Cilindro 2

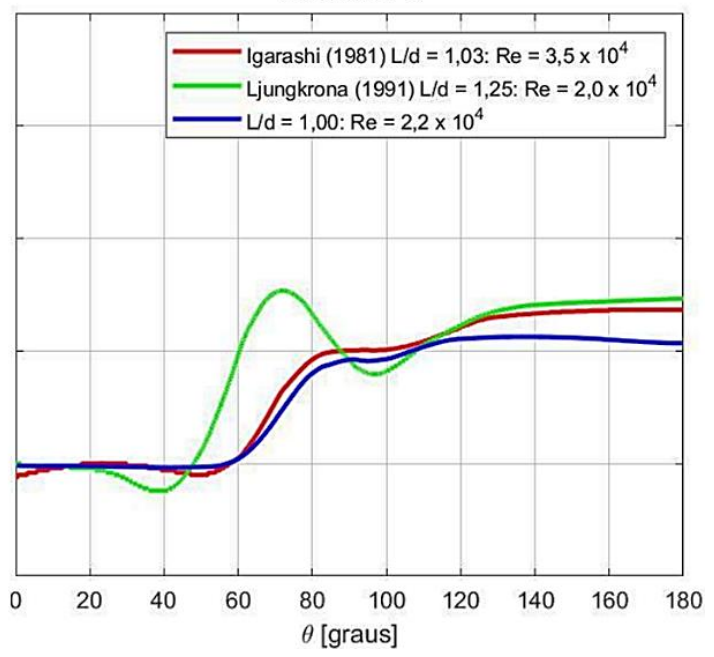

Figura 40 - Coeficiente de pressão $\left(C_{p}\right)$ nos cilindros 1 e 2 da configuração $L / d=2,5$

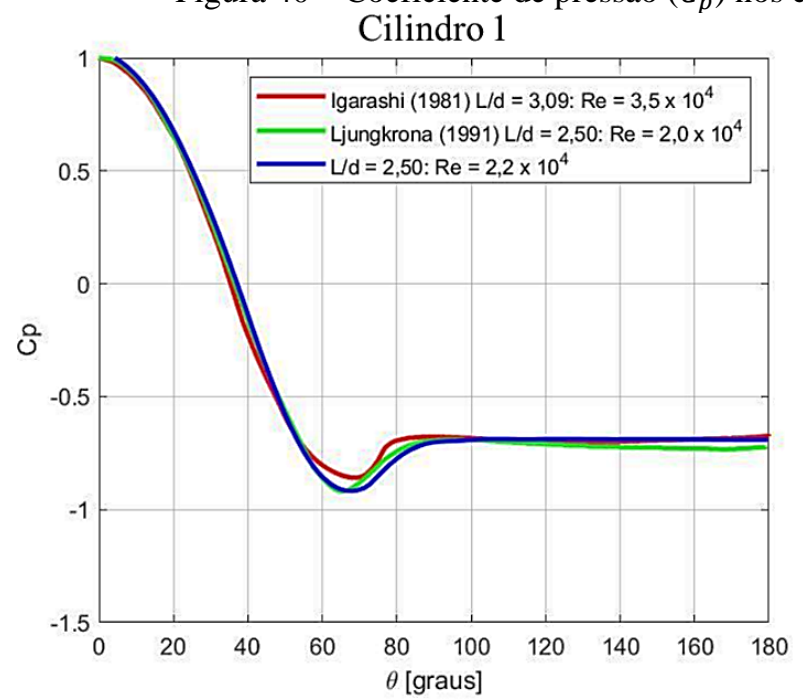
Cilindro 2

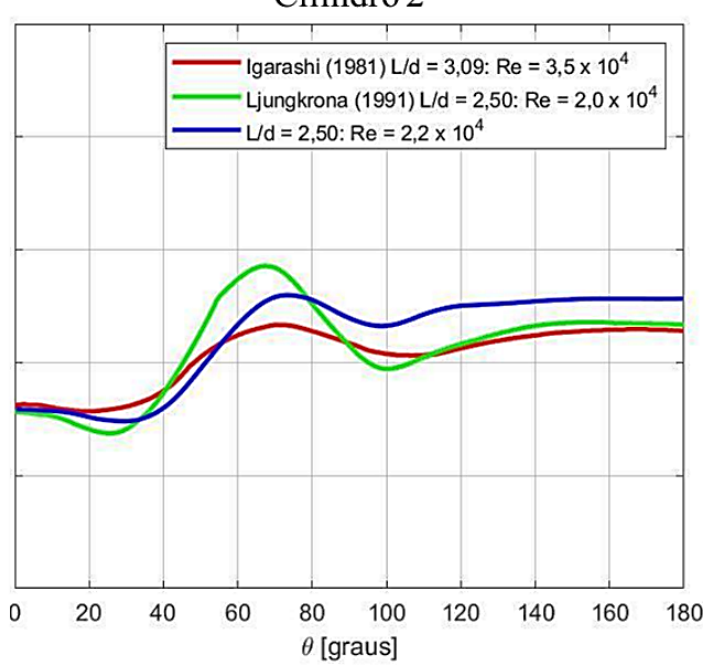

Figura 41 - Coeficiente de pressão $\left(C_{p}\right)$ nos cilindros 1 e 2 da configuração $L / d=4,0$

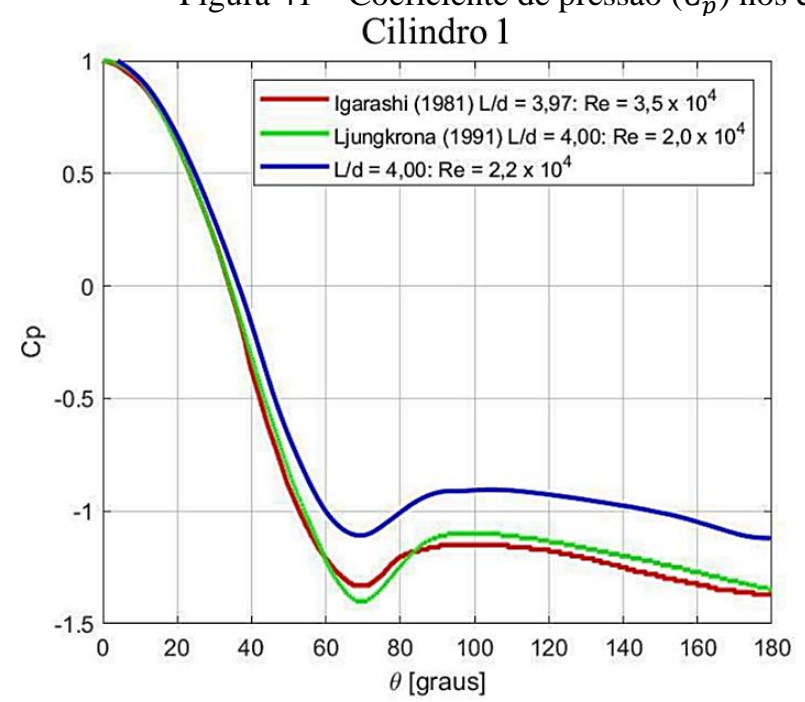
Cilindro 2

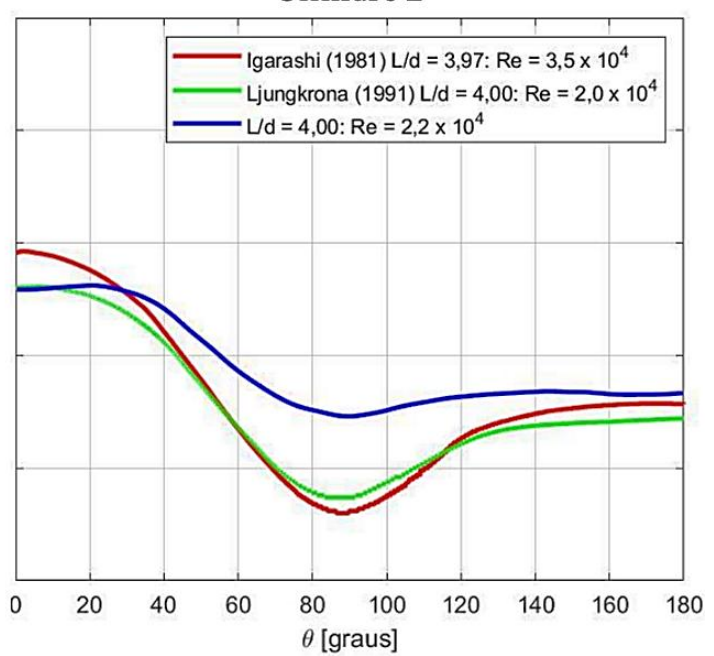


As curvas de $C_{p}$ mostram boa correlação com os dados de referência tanto em valor absoluto como nos ângulos de descolamento da camada limite e de recolamento da camada cisalhante. Para a separação $L / d=1,0$ os dois cilindros comportam-se como um corpo afilado, sendo que a camada limite descola no primeiro cilindro em um ângulo $\theta \approx 80^{\circ}$ e não há indícios de recolamento da camada cisalhante em ambos os cilindros assim como encontrado por Igarashi (1981). No caso $L / d=2,5$ o valor de $C_{p}$ no primeiro cilindro é maior que no primeiro caso e a camada limite descola no primeiro cilindro em $\theta \approx 80^{\circ}$ e volta a recolar no ponto de máximo da curva do cilindro 2 curva em $\theta \approx 70^{\circ}$. Já na separação $L / d=4,0$ o cilindro 1 comporta-se como um cilindro único e a curva do cilindro 2 evidencia que o padrão de escoamento é do tipo jump. A seguir apresentam-se as curvas do coeficiente de atrito $\left(C_{f}\right)$ na parede dos cilindros a fim de auxiliar na localização dos pontos de descolamento e recolamento das camadas limites e cisalhantes nos cilindros 1 e 2 .

Figura 42 - Coeficiente de atrito $\left(C_{f}\right)$ ao longo das superfícies dos cilindros 1 e 2 da configuração $L / d=1,0$
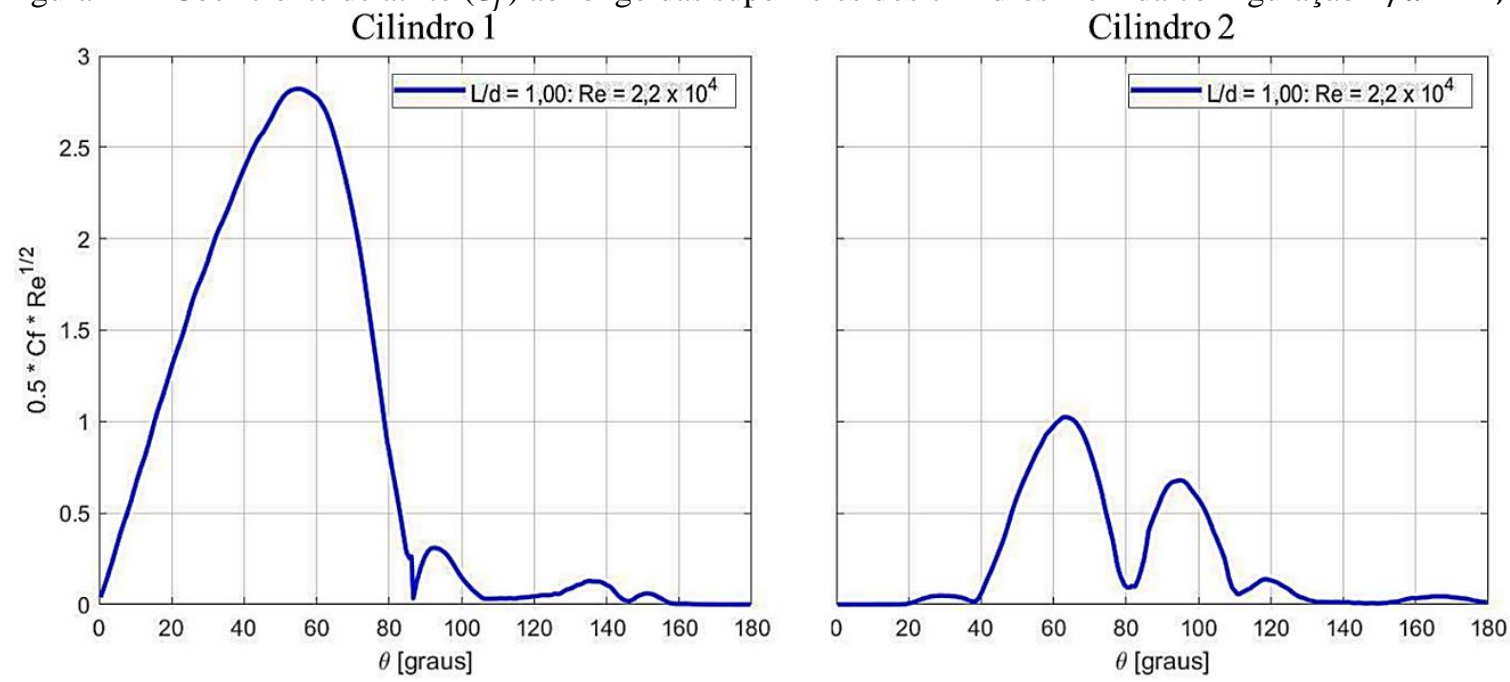

Figura 43 - Coeficiente de atrito $\left(C_{f}\right)$ ao longo das superfícies dos cilindros 1 e 2 da configuração $L / d=2,5$
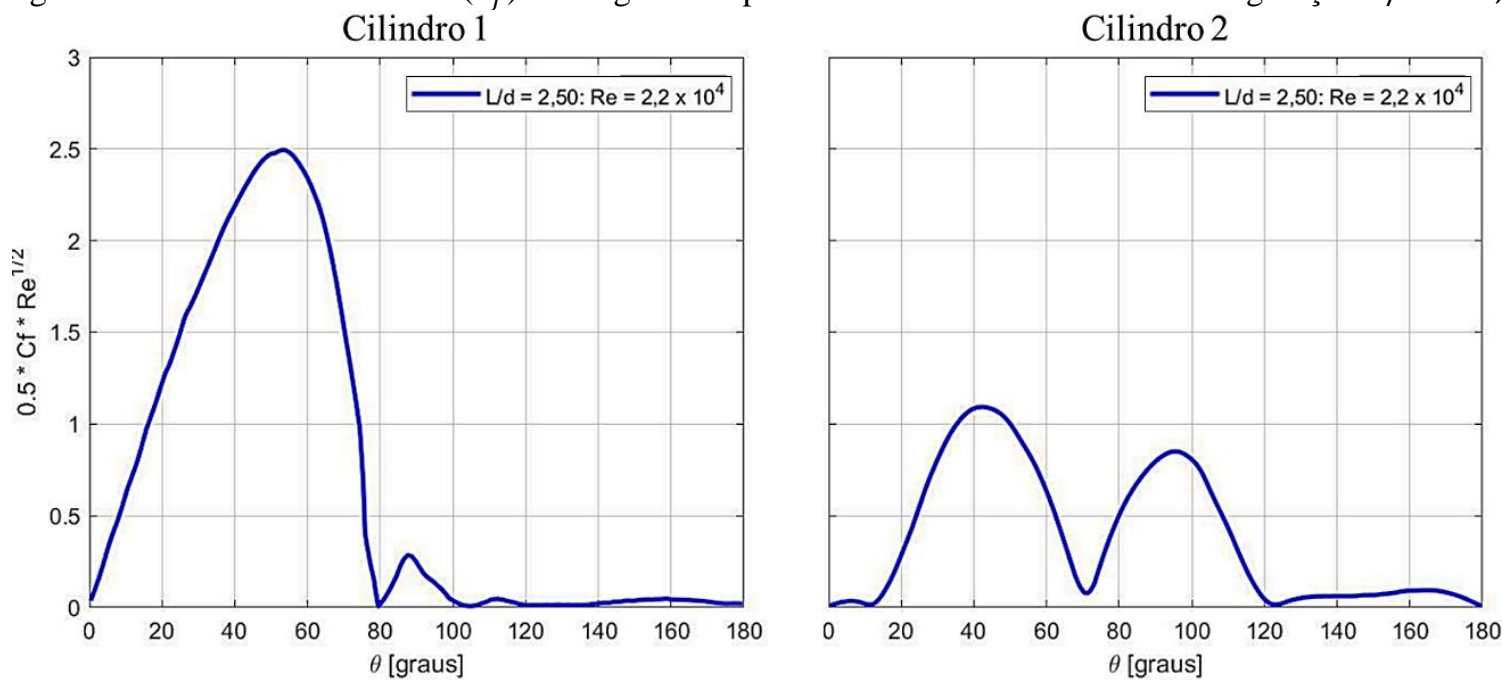
Figura 44 - Coeficiente de atrito $\left(C_{f}\right)$ ao longo das superfícies dos cilindros 1 e 2 da configuração $L / d=4,0$ Cilindro 1

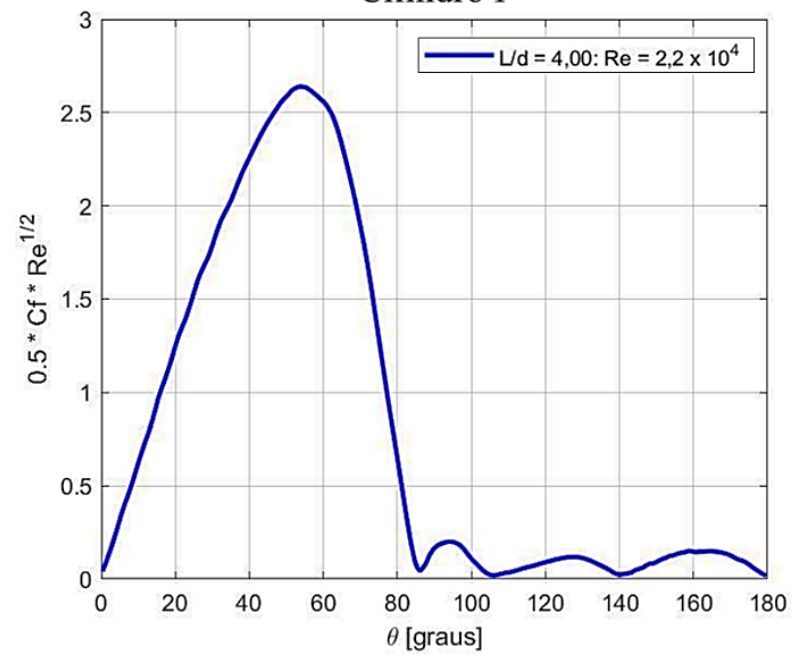

Cilindro 2

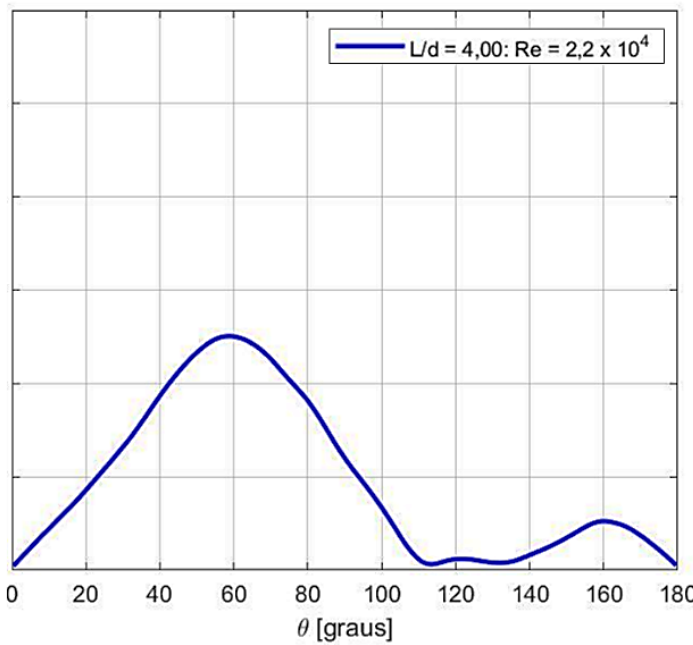

Os comparativos de $C_{p}^{\prime}$ dos testes e das simulações mostram que, antes da separação crítica, o valor eficaz da flutuação de pressão na parede do cilindro 1 é consideravelmente menor que no caso $L / d=4$ no qual o primeiro pico no cilindro à montante acontece nas proximidades do ponto de descolamento da camada limite $\left(\theta \approx 80^{\circ}\right)$ e o segundo pico acontece na região onde o escoamento reverso descola-se novamente em $\theta \approx 160^{\circ}$. Já para o cilindro 2 nota-se que os valores de $C_{p}^{\prime}$ variam significativamente com o incremento do parâmetro $L / d$ sendo a curva $C_{p}^{\prime}$ do caso $L / d=4,0$ a maior observada. Ainda nos gráficos do segundo cilindro nota-se que o primeiro pico acontece pouco antes do ponto de recolamento da camada cisalhante no segundo cilindro e o pico posterior acontece na região de descolamento da camada limite. Em todos os comparativos de $C_{p}^{\prime}$ houve melhor aproximação dos resultados numéricos com as curvas dos experimentos de Ljungkrona, Norberg e Sundén (1991).

Figura 45 - Valor eficaz da flutuação de pressão $\left(C_{p}^{\prime}\right)$ nos cilindros 1 e 2 da configuração $L / d=1,0$

Cilindro 1

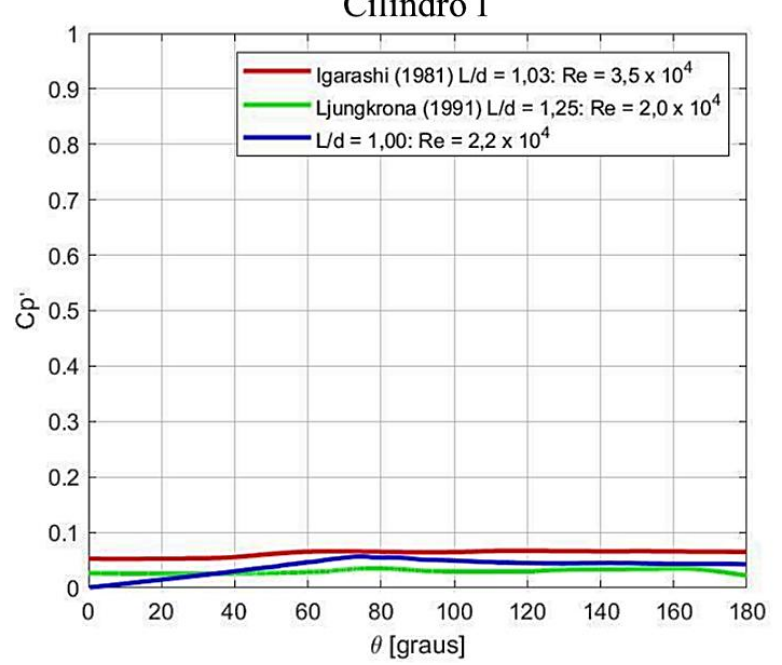

Cilindro 2

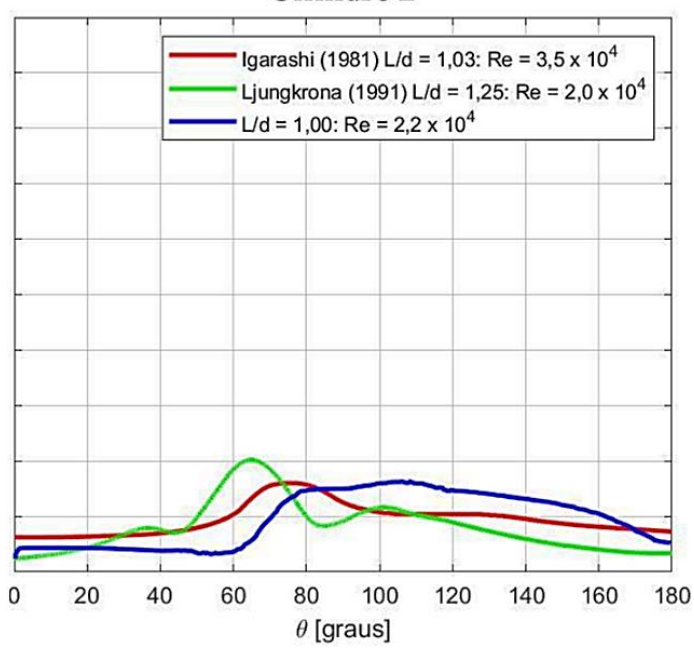


Figura 46 - Valor eficaz da flutuação de pressão $\left(C_{p}^{\prime}\right)$ nos cilindros 1 e 2 da configuração $L / d=2,5$
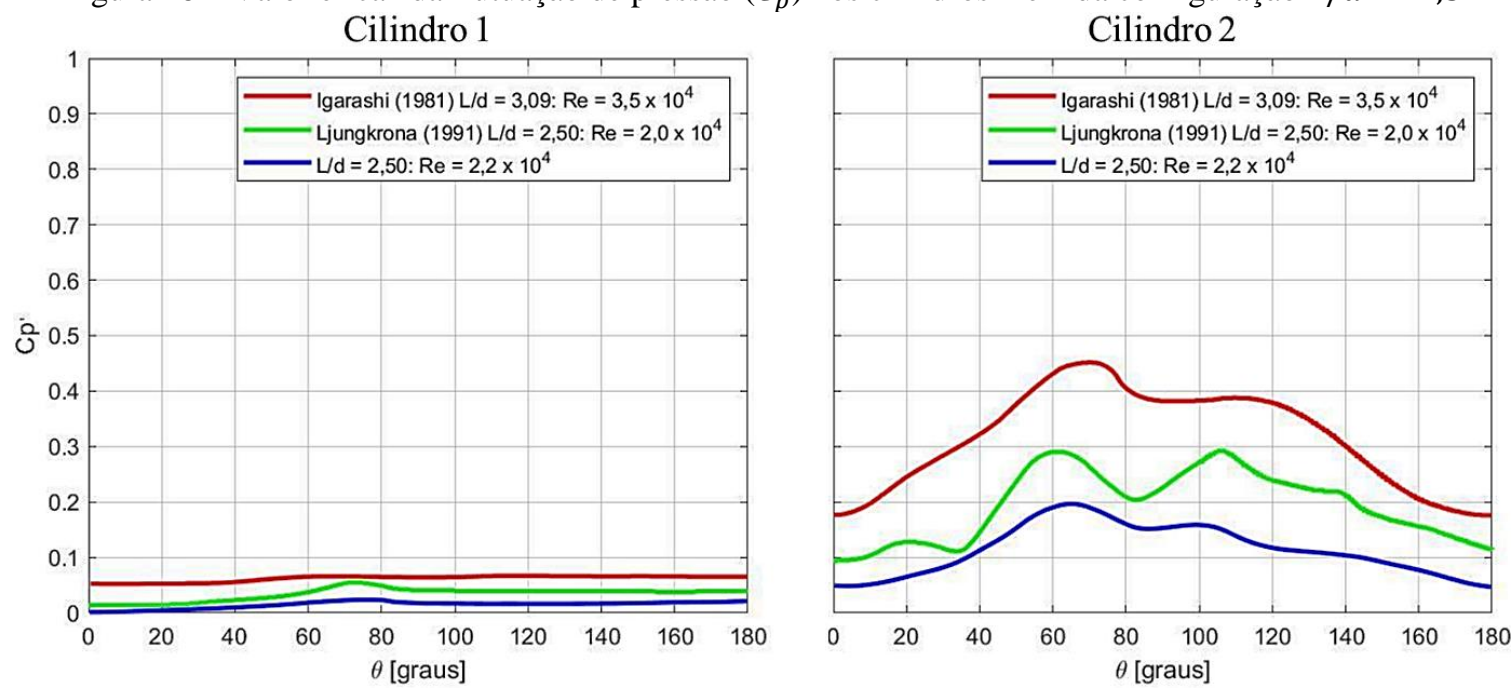

Figura 47 - Valor eficaz da flutuação de pressão $\left(C_{p}^{\prime}\right)$ nos cilindros 1 e 2 da configuração $L / d=4,0$.

Cilindro 1

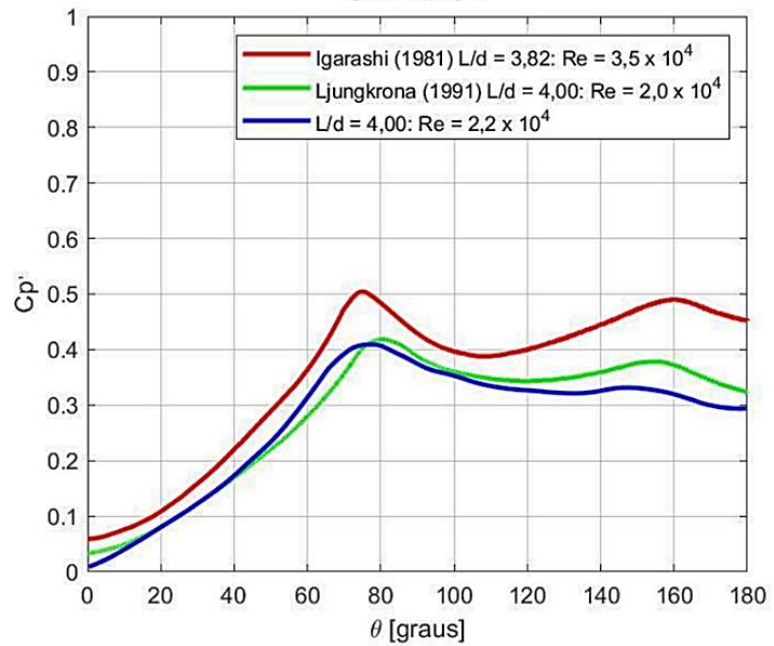

Cilindro 2

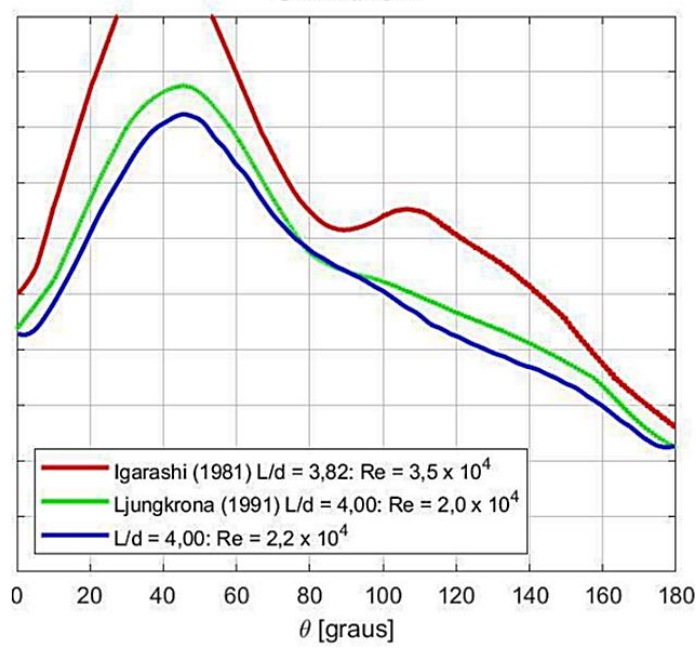

Nota: Escala de $C_{p}^{\prime}$ truncada em $C_{p}^{\prime}=1$ para permitir melhor comparação entre os gráficos.

Por apresentar maior amplitude de oscilação optou-se por apresentar a seguir os dados temporais dos coeficientes de sustentação $\left(C_{l}\right)$ e arrasto $\left(C_{d}\right)$ no segundo cilindro juntamente com a indicação dos pontos que representam a média dos dez maiores e menores picos de oscilação de $C_{l}$ (em verde) para os três casos em estudo.

Figura 48 - Histórico temporal dos coeficientes $C_{l}$ e $C_{d}$ para o segundo cilindro do caso $L / d=1,0$

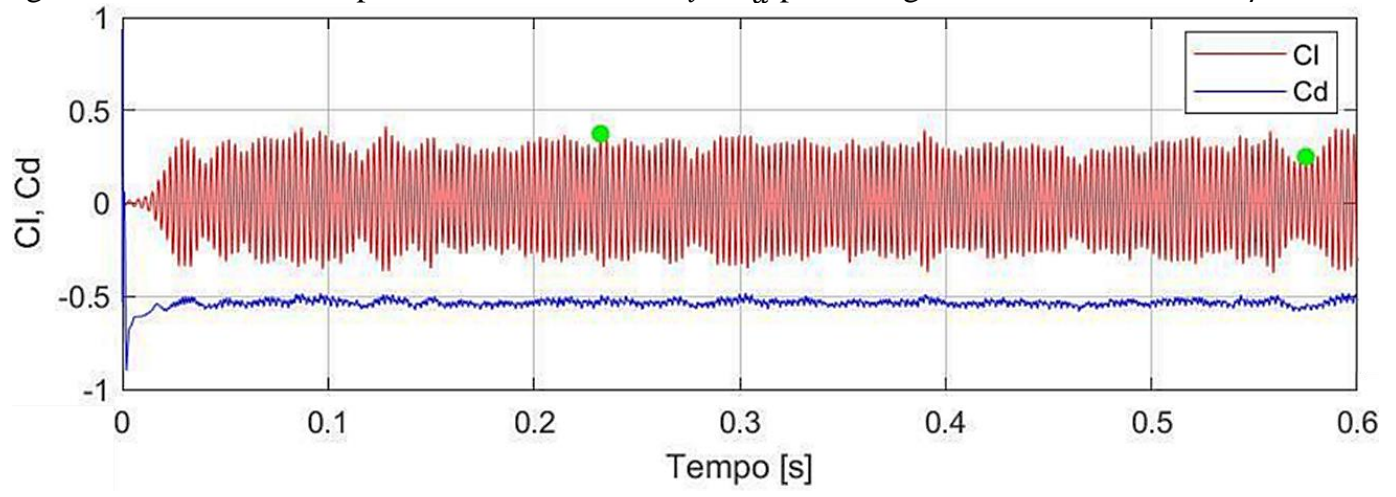


Figura 49 - Histórico temporal dos coeficientes $C_{l}$ e $C_{d}$ para o segundo cilindro do caso $L / d=2,5$

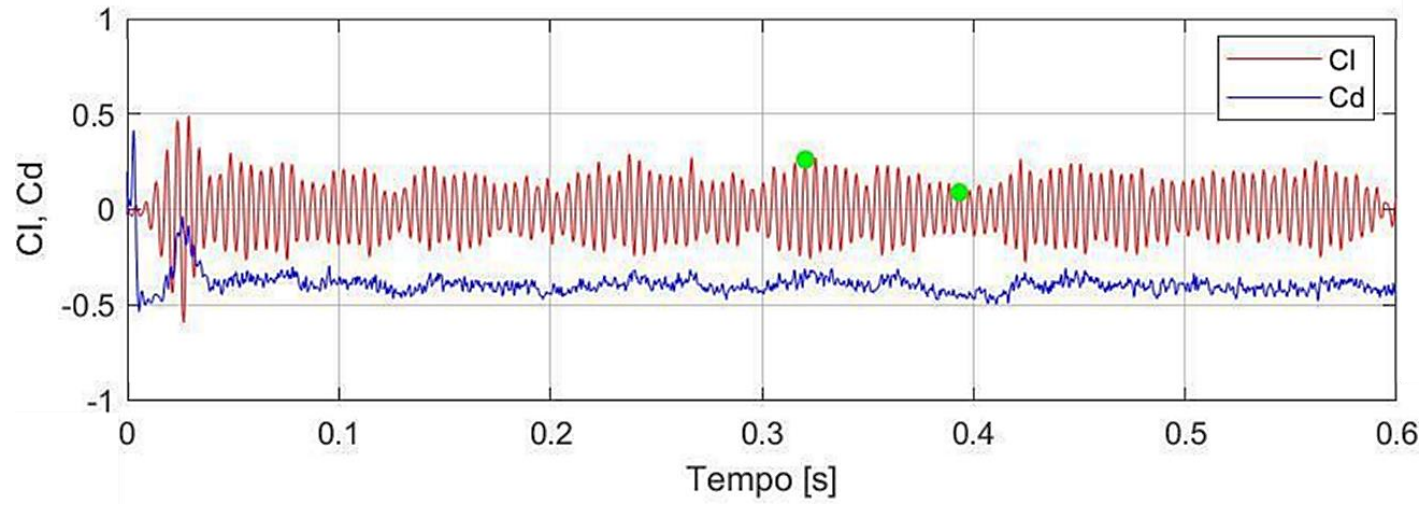

Figura 50 - Histórico temporal dos coeficientes $C_{l}$ e $C_{d}$ para o segundo cilindro do caso $L / d=4,0$

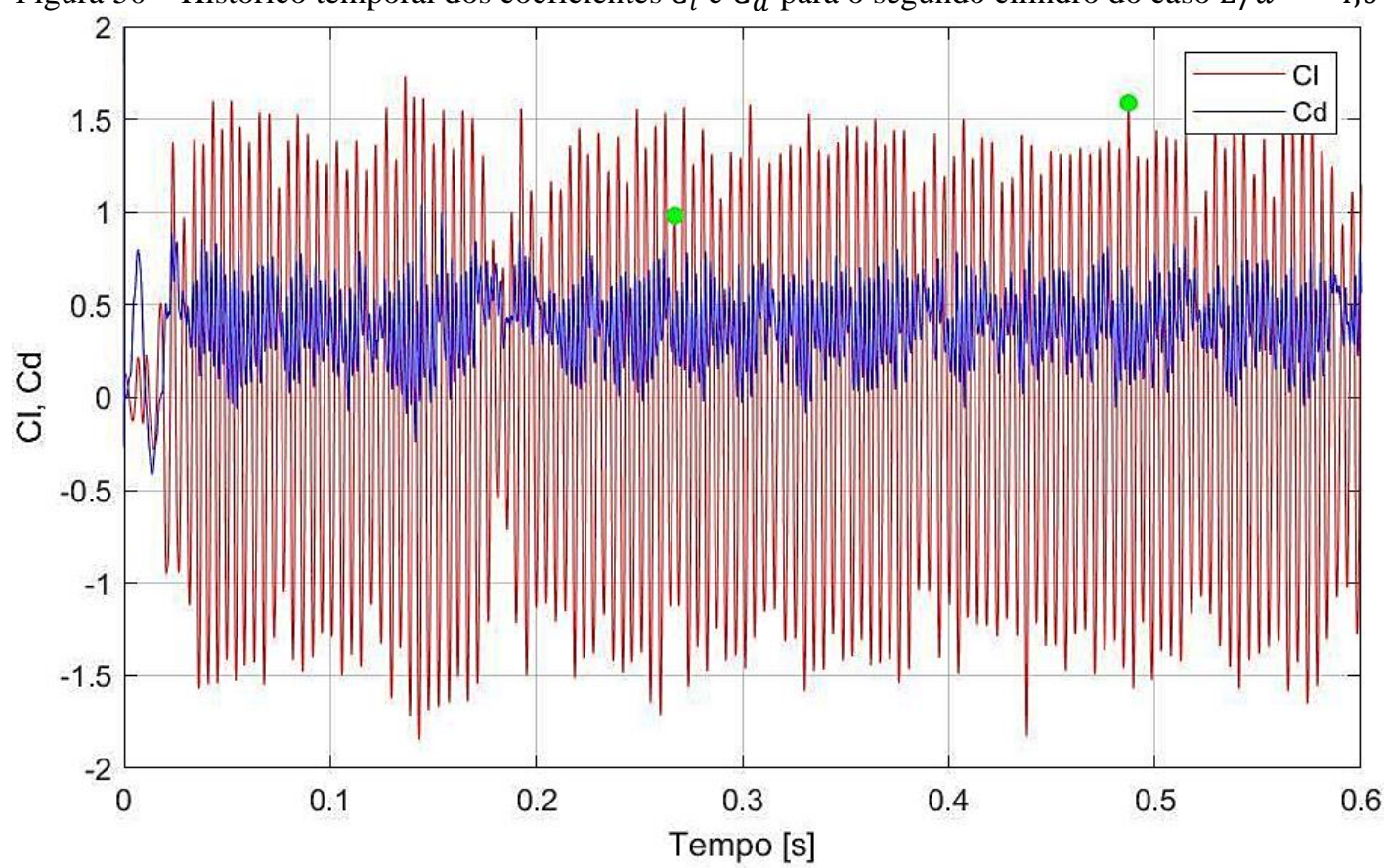

Nota-se que a amplitude de flutuação de $C_{L}$ no segundo cilindro no caso $L / d=4,0$ é muito maior que as $L / d$ devido à presença de uma esteira desenvolvida no espaço entre os dois cilindros.

Assim como na simulação do Caso Anecóico o período completo de emissão de vórtice de cada um dos instantes destacados com um símbolo verde nas figuras acima foi discretizado em nove instantes, sendo a posição de número 3 correspondente ao instante de tempo selecionado (detalhes vide Figura 20). Os resultados de vorticidade no sentido do comprimento do cilindro $(\circlearrowright+)$ para a posição 3 do maior pico das três simulações serão mostrados a seguir e os demais pontos encontram-se ilustrados no APÊNDICE B, juntamente com os contornos de magnitude de velocidade, representando o desenvolvimento temporal do escoamento de ar ao redor dos cilindros. O plano paralelo à corrente de ar e coincidente com o ponto médio do comprimento dos cilindros foi escolhido como referência na coleta dos resultados. 
Figura 51 - Contorno de vorticidade maior pico: $L / d=1,0$

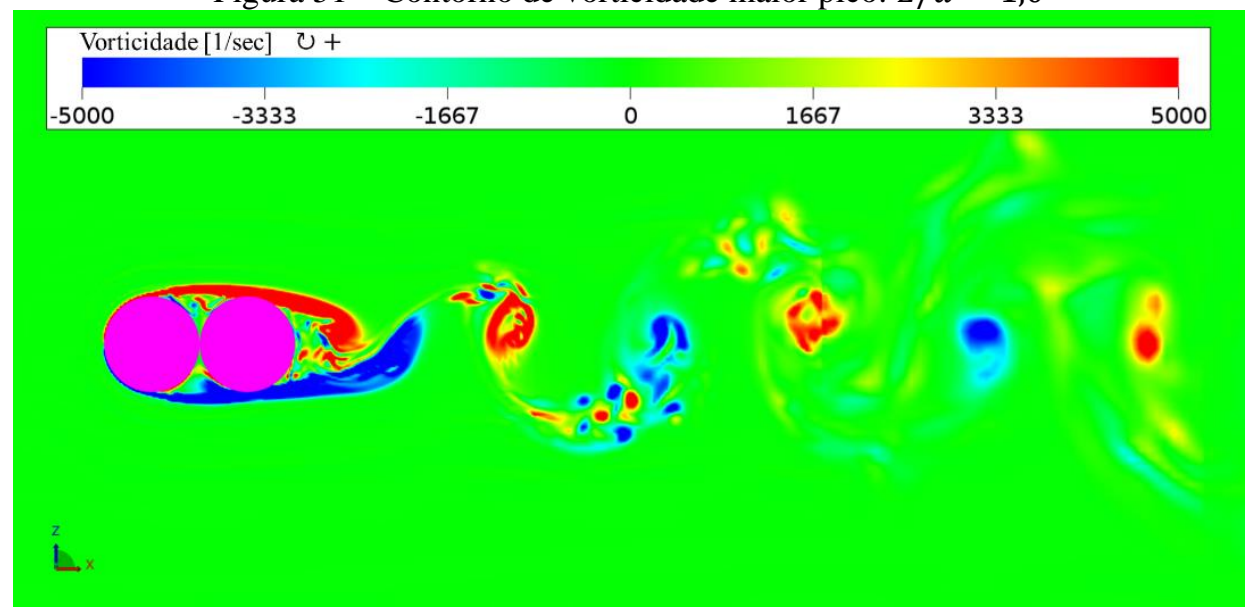

Figura 52 - Contorno de vorticidade maior pico: $L / d=2,5$

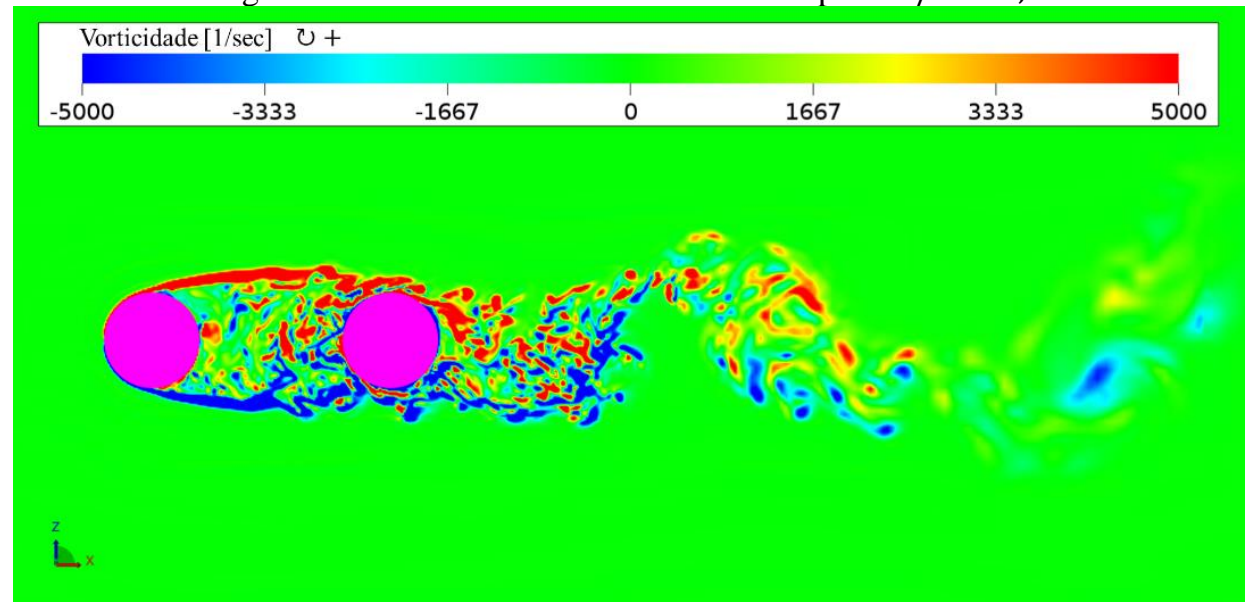

Figura 53 - Contorno de vorticidade maior pico: $L / d=4,0$

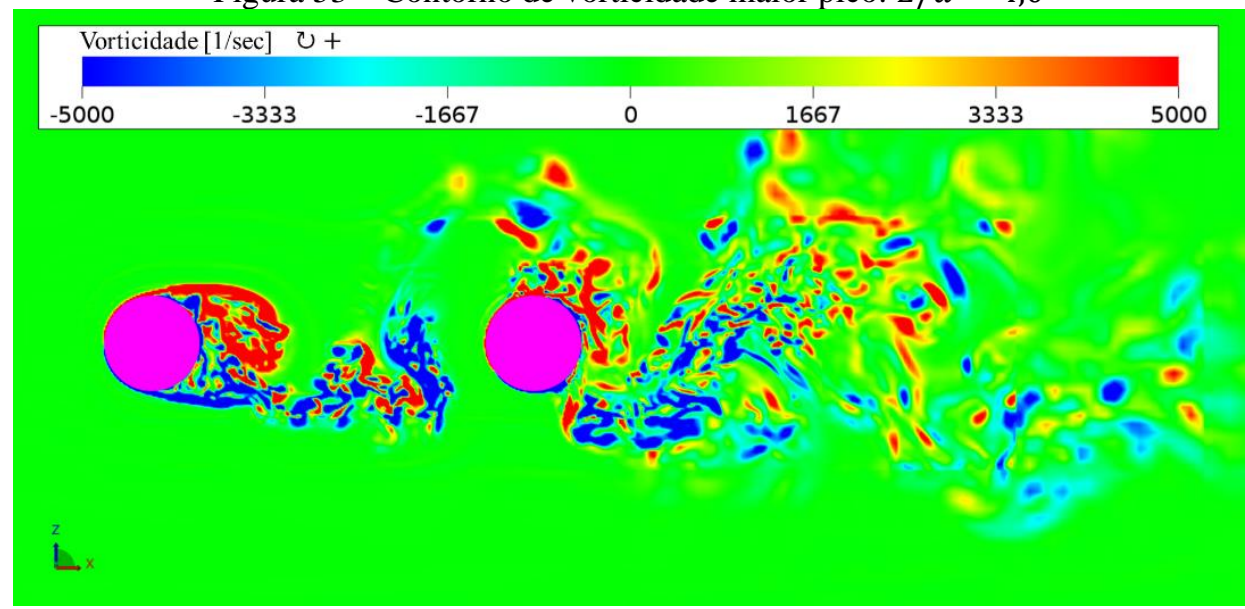

Analisando os resultados do caso $L / d=1,0$ nota-se que o conjunto se comporta como um corpo rombudo mais alongado e a transição para a turbulência acontece na esteira. $\mathrm{O}$ contraste entre os resultados do menor e maior pico correspondentes ao caso $L / d=2,5$ evidenciam o padrão típico do escoamento reattachment, que apresenta vórtices estacionários entre os cilindros com recolamento de camada cisalhante no segundo cilindro, além da emissão 
de vórtices à jusante do cilindro 2. As figuras referentes ao caso $L / d=4,0$ mostram o comportamento de escoamento jump em que o cilindro 1 comporta-se como um cilindro único e emite vórtices que se desprendem no espaço entre os cilindros e atingem o cilindro 2 resultando em um escoamento complexo.

As Figuras 54, 55 e 56 mostram os resultados da análise de densidade espectral de potência dos sinais $C_{d}$ e $C_{l}$ dos $0,5 \mathrm{~s}$ finais da simulação que serão utilizadas para confirmar que o espectro desses dois sinais podem ser correlacionados com o ruído radiado pelos cilindros sujeitos à escoamento transversal com baixo número de Mach $(M<0,3)$. Nos resultados dos três casos avaliados nota-se um acoplamento do conteúdo de frequência dos históricos temporais dos coeficientes de sustentação e arrasto nos cilindros 1 e 2 . Os resultados indicam a ocorrência de picos centrados em $f_{0}$ nos mesmos números de Strouhal descritos na Tabela 6 e que são relacionados com a flutuação da força de sustentação. Na separação $L / d=1,0$ notase a ocorrência dos harmônicos em $2 f_{0}$ (flutuação da força de arrasto) e $3 f_{0}$ (flutuação da força de sustentação). Já no caso $L / d=2,5$ não há evidências de harmônicos e no caso $L / d=4,0$, além dos harmônicos já mencionados, nas PSDs do cilindro à jusante surge também um harmônico em $4 f_{0}$ devido à flutuação da força de arrasto.

Figura 54 - Densidade Espectral de Potência (PSD) dos sinais $C_{d}$ e $C_{l}: L / d=1,0$
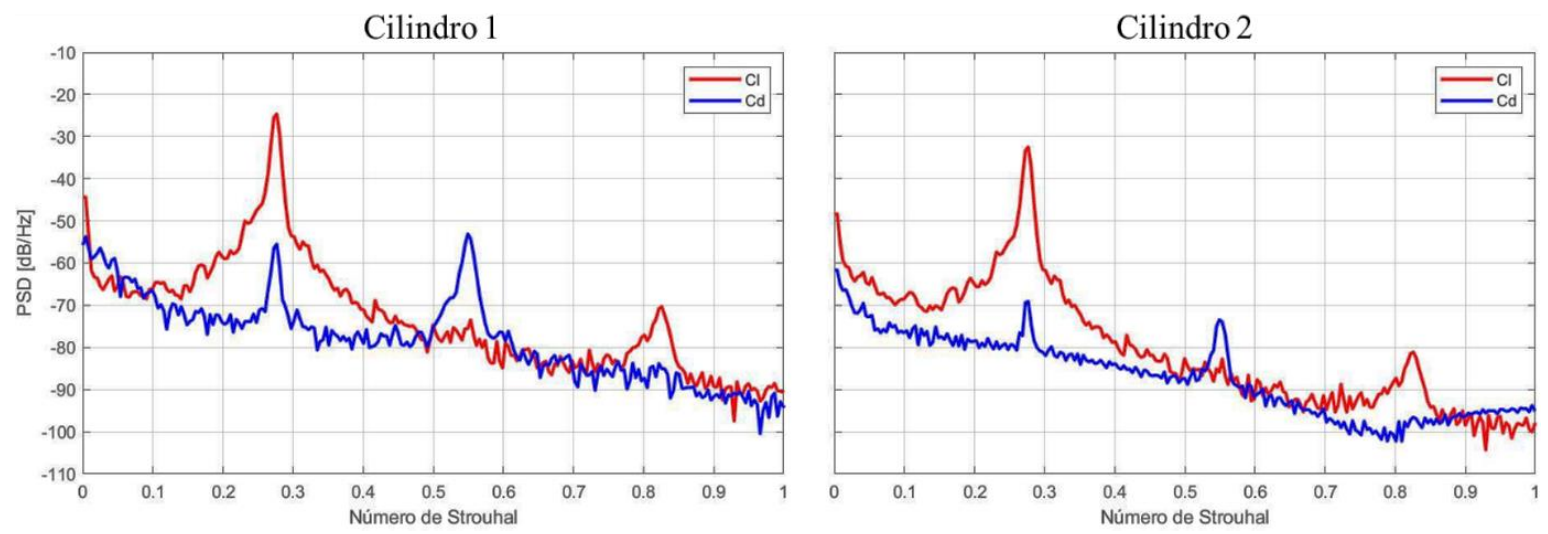

Figura 55 - Densidade Espectral de Potência (PSD) dos sinais $C_{d}$ e $C_{l}: L / d=2,5$
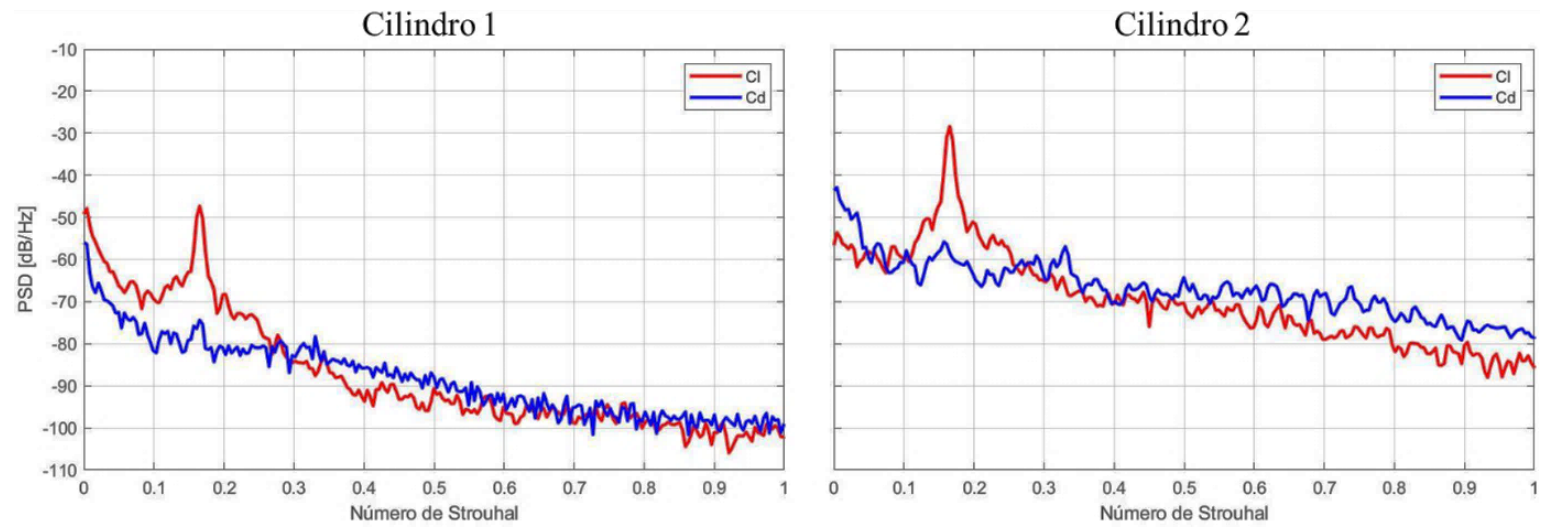
Figura 56 - Densidade Espectral de Potência (PSD) dos sinais $C_{d}$ e $C_{l}: L / d=4,0$
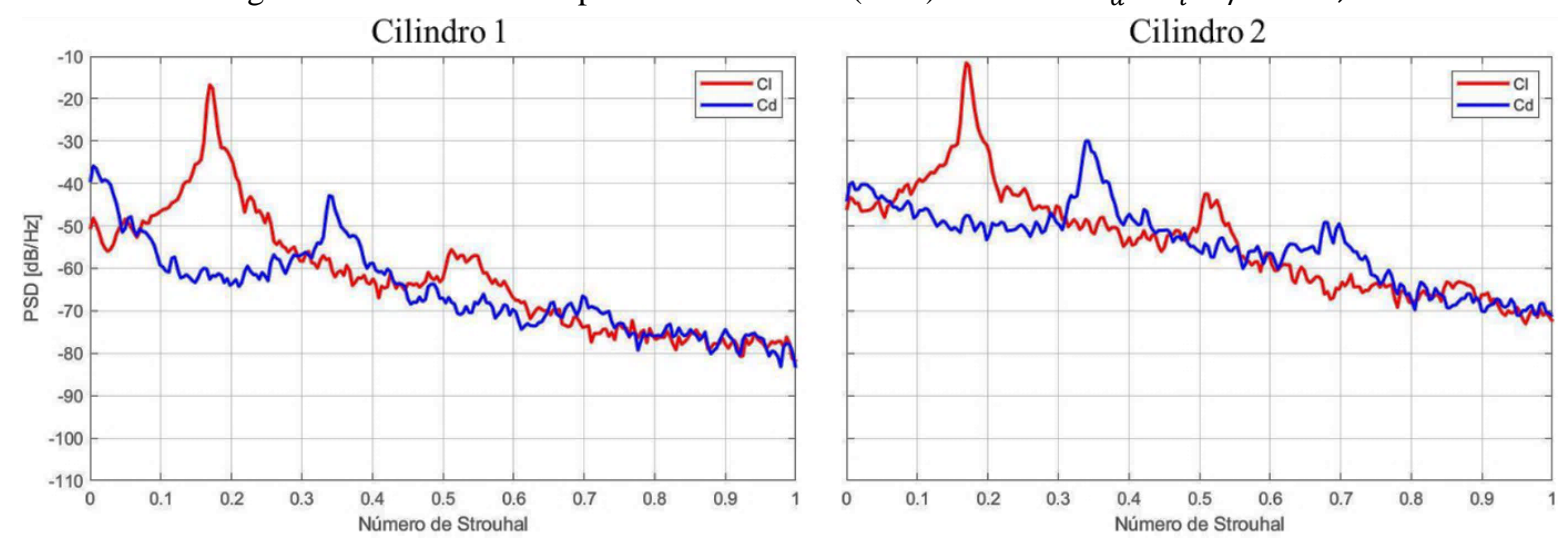

\subsection{RUÍDO EM CAMPO AFASTADO}

As configurações para o cálculo do ruído em campo afastado são as mesmas utilizadas na simulação do Caso Anecóico exceto pelo fato de ter sido adicionada uma nova superfície fictícia e permeável coincidente com o segundo cilindro. O tempo total de coleta de dados é igual a $0,5 \mathrm{~s}$ e com isso as curvas de densidade espectral de potência do ruído apresentam frequência mínima de $2 \mathrm{~Hz}$, máxima de $13210 \mathrm{~Hz}$ e resolução de $2 \mathrm{~Hz}$. As frequências de interesse variam entre $S t=0,171$ e $S t=0,837$ e por esse motivo decidiu-se apresentar as curvas de PSD [dB/Hz] em função do número de Strouhal de $S t=0$ até $S t=1(1250 \mathrm{~Hz})$.

A formulação porosa de FW-H foi utilizada e o ruído calculado por meio do software PowerACOUSTICS com microfone posicionado a uma distância 86,25 $d$ do centro do cilindro 1 nas posições $\phi=90^{\circ}$ e $\phi=40^{\circ}$. As curvas de densidade espectral de potência do ruído total (calculado utilizando ambas superfícies permeáveis simultaneamente) e as contribuições individuais de cada cilindro (calculadas separadamente utilizando a superfícies permeável que envolve cada cilindro) foram geradas aplicando-se técnica de janelamento Hanning com 50\% de overlap sendo os resultados mostrados nas figuras a seguir:

Figura 57 - Ruído em campo afastado $(86,25 d)$ caso $L / d=1,0$
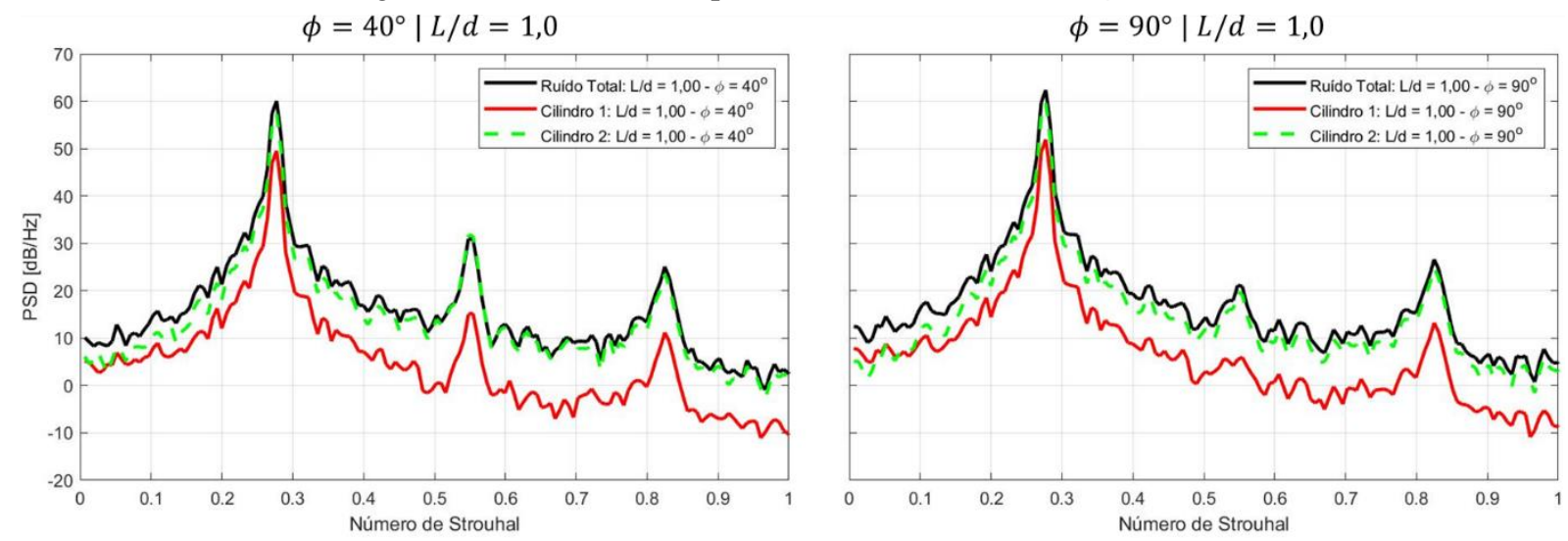
Figura 58 - Ruído em campo afastado $(86,25 d)$ caso $L / d=2,5$
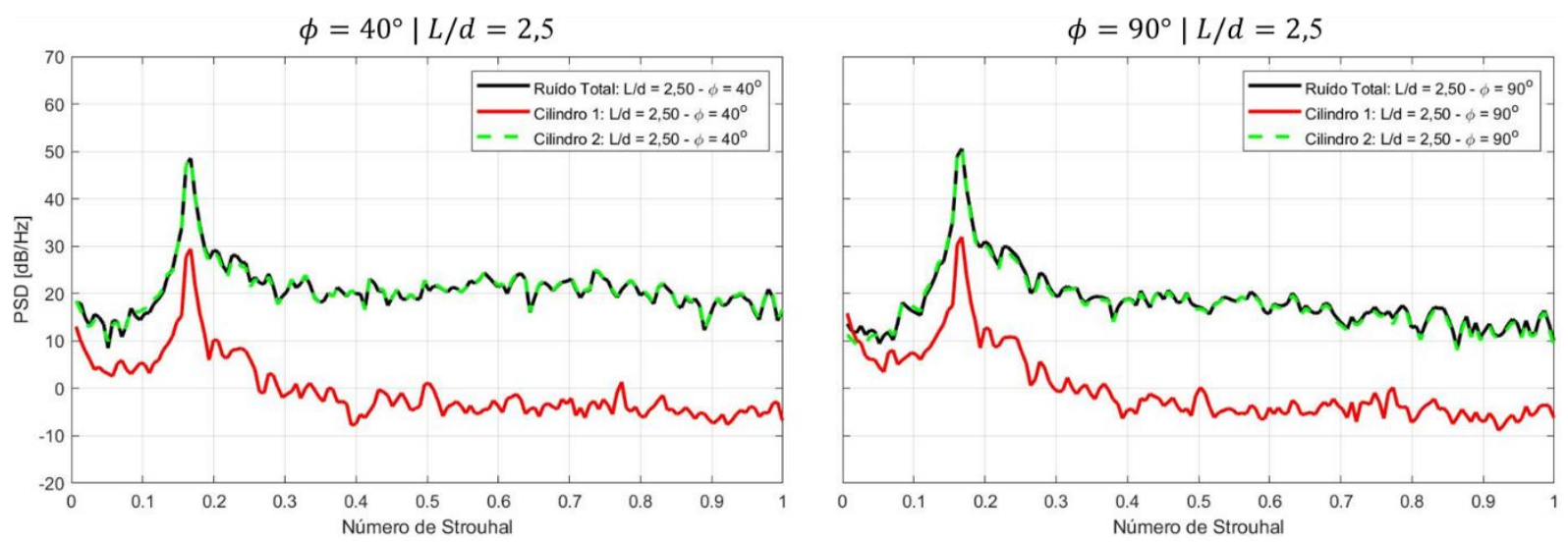

Figura 59 - Ruído em campo afastado $(86,25 d)$ caso $L / d=4,0$
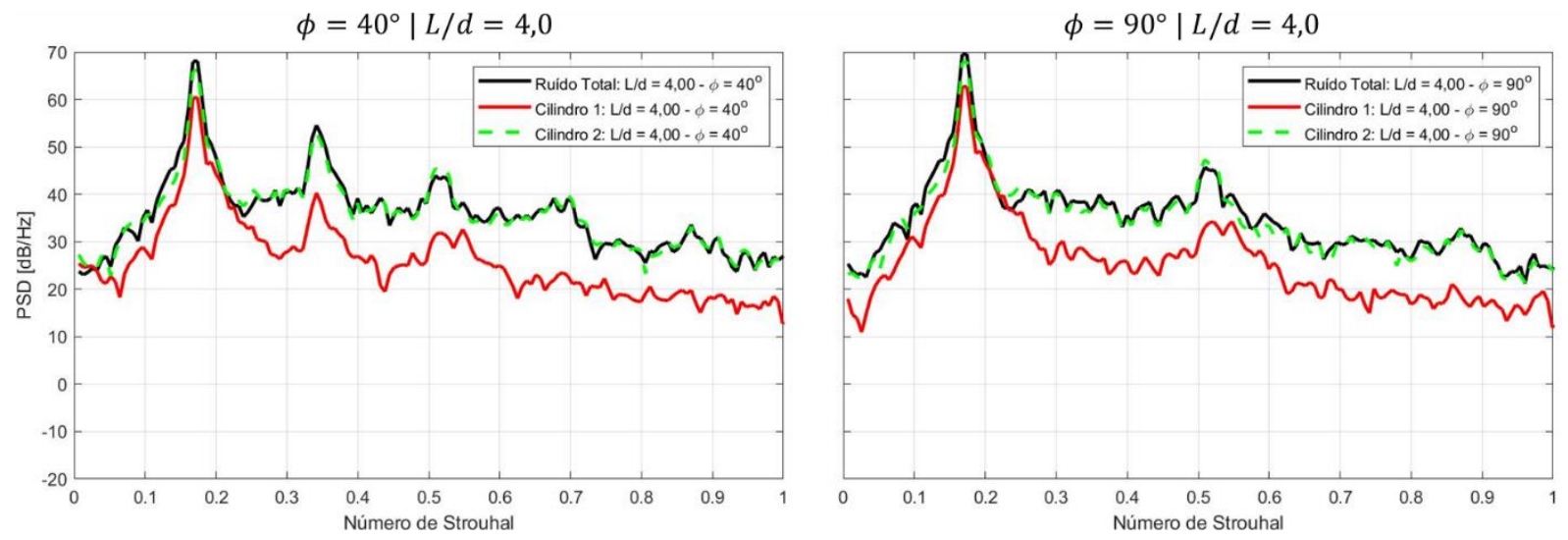

As curvas PSD mostram que nos três casos simulados o ruído total em campo afastado é dominado pela contribuição do cilindro mais à jusante. Associando os resultados da análise espectral de potência com o histórico temporal de oscilação dos coeficientes $C_{l}$ e $C_{d}$ no segundo cilindro, nota-se que na configuração de cilindros arranjados em tandem sujeitos ao escoamento com baixo número de Mach $(M<0,3)$, as hipóteses simplificadoras que resultam na eq. (2.25) produzem resultados condizentes com a flutuação de $C_{l}$ e $C_{d}$, reafirmando que, nessas configurações de escoamento, o ruído aerodinâmico é proporcional à flutuação das forças atuantes nas superfícies submersas.

$\mathrm{Na}$ separação $L / d=1,0$ verifica-se a ocorrência do pico correlacionado com a flutuação da força de sustentação em $f_{0} \operatorname{com} S t=0,276$ e dois harmônicos em $2 f_{0}$ e $3 f_{0}$. No caso $L / d=2,5$, nota-se apenas a presença do pico em $f_{0} \operatorname{com} S t=0,165$. Em $L / d=4,0$, além do pico em $f_{0} \operatorname{com} S t=0,171$, notam-se três harmônicos em $2 f_{0}, 3 f_{0}$ e $4 f_{0}$. A ocorrência dos harmônicos em $2 f_{0}$ e $4 f_{0}$, relacionados com a flutuação da força de arrasto nos cilindros 1 e 2, foi mais bem capturada com o microfone posicionado em $\phi=40^{\circ}$ nos três casos simulados. A frequência dos picos em $f_{0}$ apresentaram erros menores que $5 \%$ quando comparados aos experimentos de Ljungkrona, Norberg e Sundén (1991) e Igarashi (1981). 
As amplitudes dos picos $f_{0}$ das curvas de densidade espectral de potência dos casos simulados mostram boa correlação com a amplitude de oscilação temporal da força de sustentação no segundo cilindro. O pico é mais elevado na simulação com separação $L / d=$ 4,0 seguido pela amplitude do pico da simulação com $L / d=1,0$ sendo o de menor amplitude o da simulação com separação $L / d=2,5$.

As flutuações das forças de sustentação e arrasto no segundo cilindro são mais elevadas do que as no cilindro 1, corroborando para a conclusão de que a emissão de ruído do cilindro à jusante domina o ruído total em campo afastado. Isto deve-se ao fato de as estruturas turbilhonares provenientes do primeiro cilindro colidirem com a superfície do segundo cilindro.

A metodologia LBM + FW-H mostrou-se capaz de descrever, com acurácia de ao menos 95\%, a frequência dos picos de interesse e o PowerFLOW demonstrou versatilidade devido ao baixo número de ajustes implementados na malha volumétrica para transformar o modelo do Caso Anecóico com um cilindro isolado nos modelos de dois cilindros dispostos em tandem.

\subsection{DECOMPOSIÇÃO EM MODOS DINÂMICOS}

O software PowerFLOW controla o passo de tempo das simulações de acordo com a dimensão da menor célula de cálculo (eq. 2.22) e, uma vez que as configurações de malha das simulações dos dois cilindros alinhados são as mesmas do Caso Anecóico, o timestep permanece inalterado e pode-se utilizar o código de decomposição em modos dinâmicos implementado em MATLAB para o Caso Anecóico na análise DMD das simulações dos cilindros em tandem.

Conforme mencionado, o resultado do ruído da separação $L / d=1,0$ possui três picos de interesse que encontram-se identificados pelas setas em verde no gráfico da taxa de crescimento ou decaimento $\left(\sigma_{k}\right)$ em função de $S t$ da análise DMD, mostrado na Figura 60.

As Figuras 61 e 63 das frequências $f_{0}$ e $3 f_{0}$ para $L / d=1,0$ demonstram o comportamento similar ao do dipolo associado à oscilação da força de sustentação. Porém, quando comparado ao Caso Anecóico, nota-se que a formação do dipolo acontece à jusante do segundo cilindro, mostrando que o segundo cilindro é o principal contribuidor para o ruído total calculado em campo afastado. Já a Figura 62 da frequência $2 f_{0}$ mostra o padrão de dipolo associado à força de arrasto. Como no Caso Anecóico, nota-se que as estruturas coerentes são menores quão maior for a frequência. 
Na simulação do caso $L / d=1,0$, o arranjo de cilindros comporta-se como um corpo rombudo mais alongado e as estruturas coerentes do modo DMD são mais bem definidas que na simulação do Caso Anecóico. Isto mostra que, para análises de decomposição em modos dinâmicos de escoamentos turbulentos com elevado número de Reynolds, o uso de um maior número de pontos na janela de medição faz-se necessário para descrever, com definição, as estruturas coerentes.

Figura 60 - Taxa de decaimento vs. número de Strouhal dos modos DMD do caso $L / d=1,0$

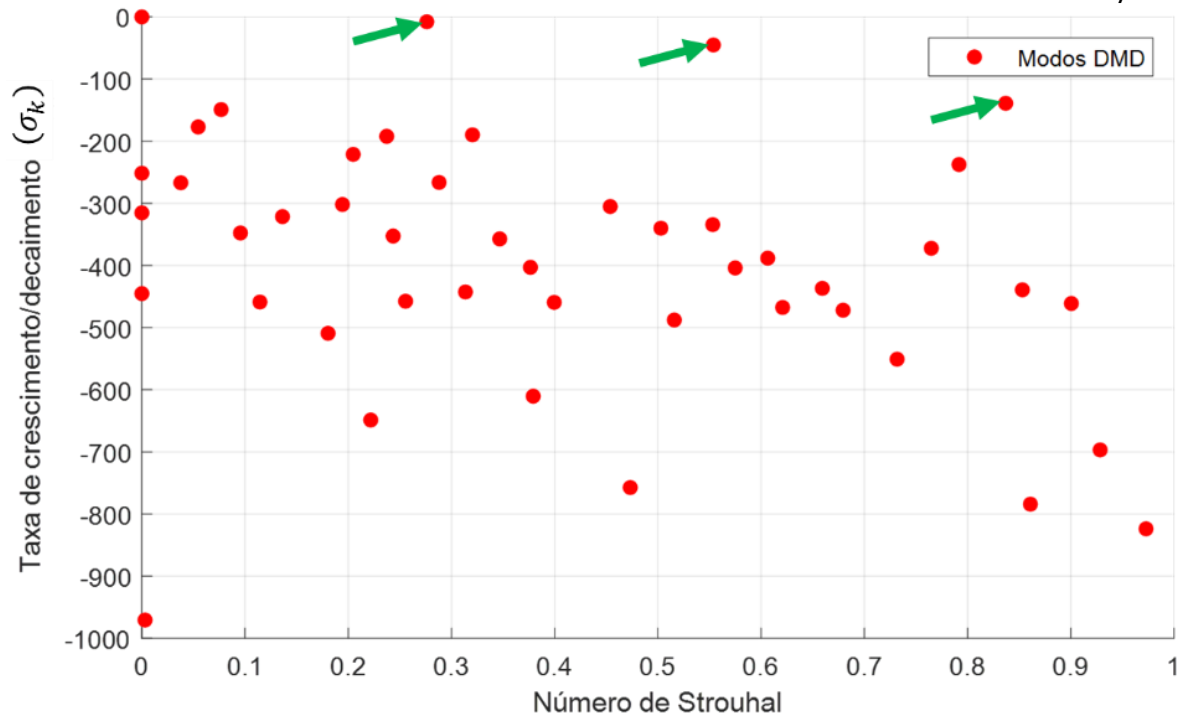

Figura 61 - Modo DMD (superiores) e Band-Pass (Inferior) para a frequência $f_{0}$ do caso $L / d=1,0$
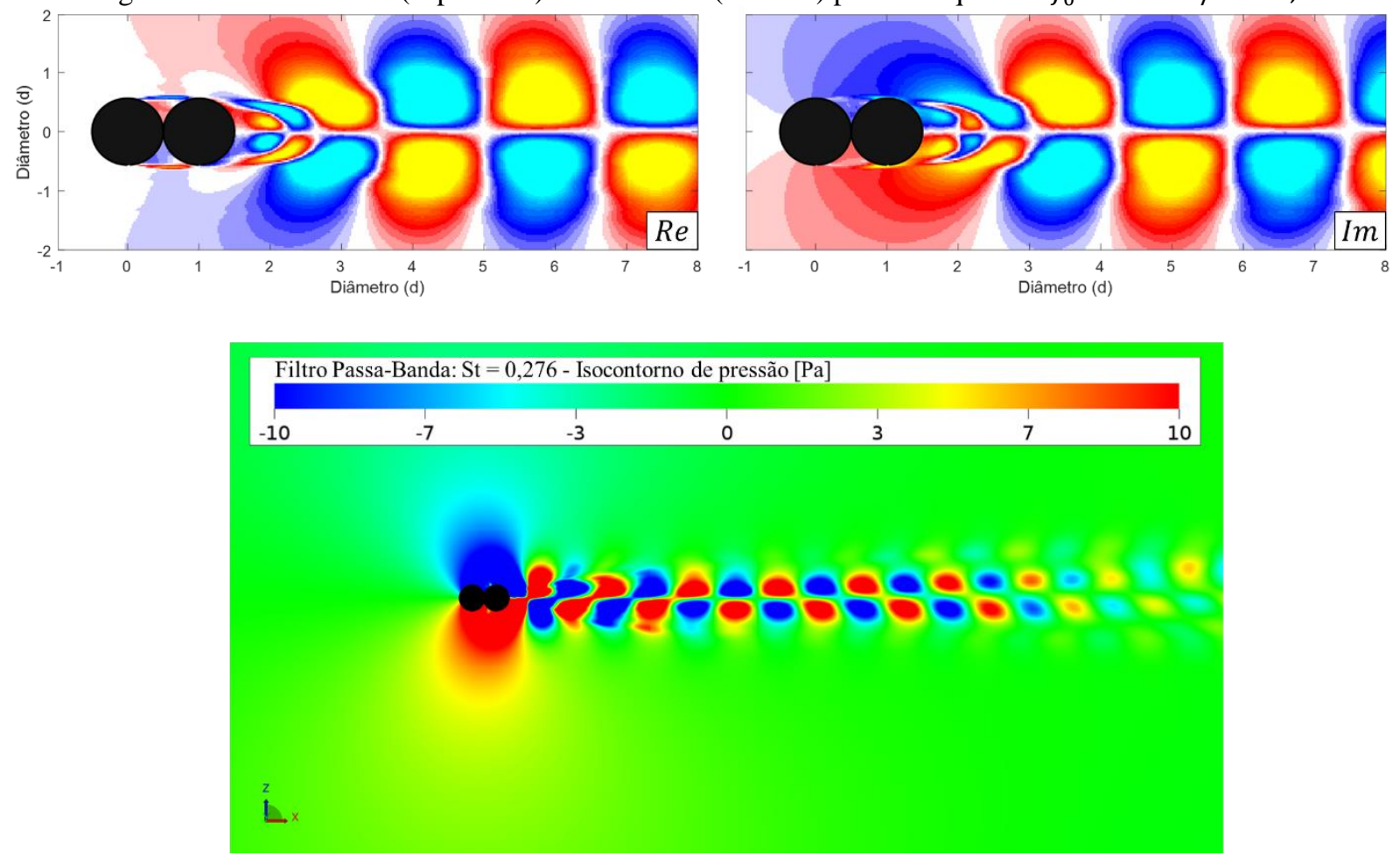
Figura 62 - Modo DMD (superiores) e Band-Pass (Inferior) para a frequência $2 f_{0}$ do caso $L / d=1,0$
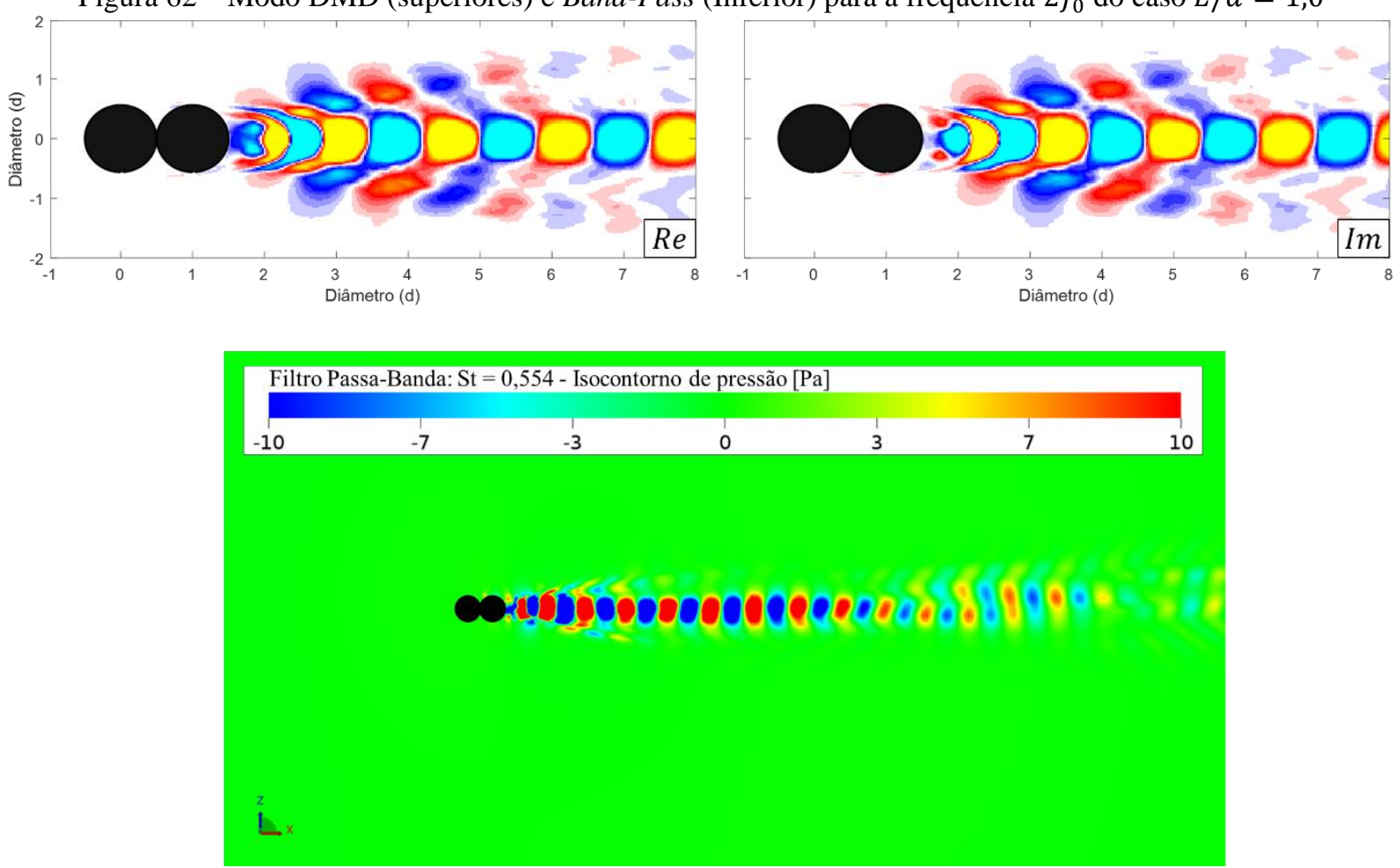

Figura 63 - Modo DMD (superiores) e Band-Pass (Inferior) para a frequência $3 f_{0}$ do caso $L / d=1,0$
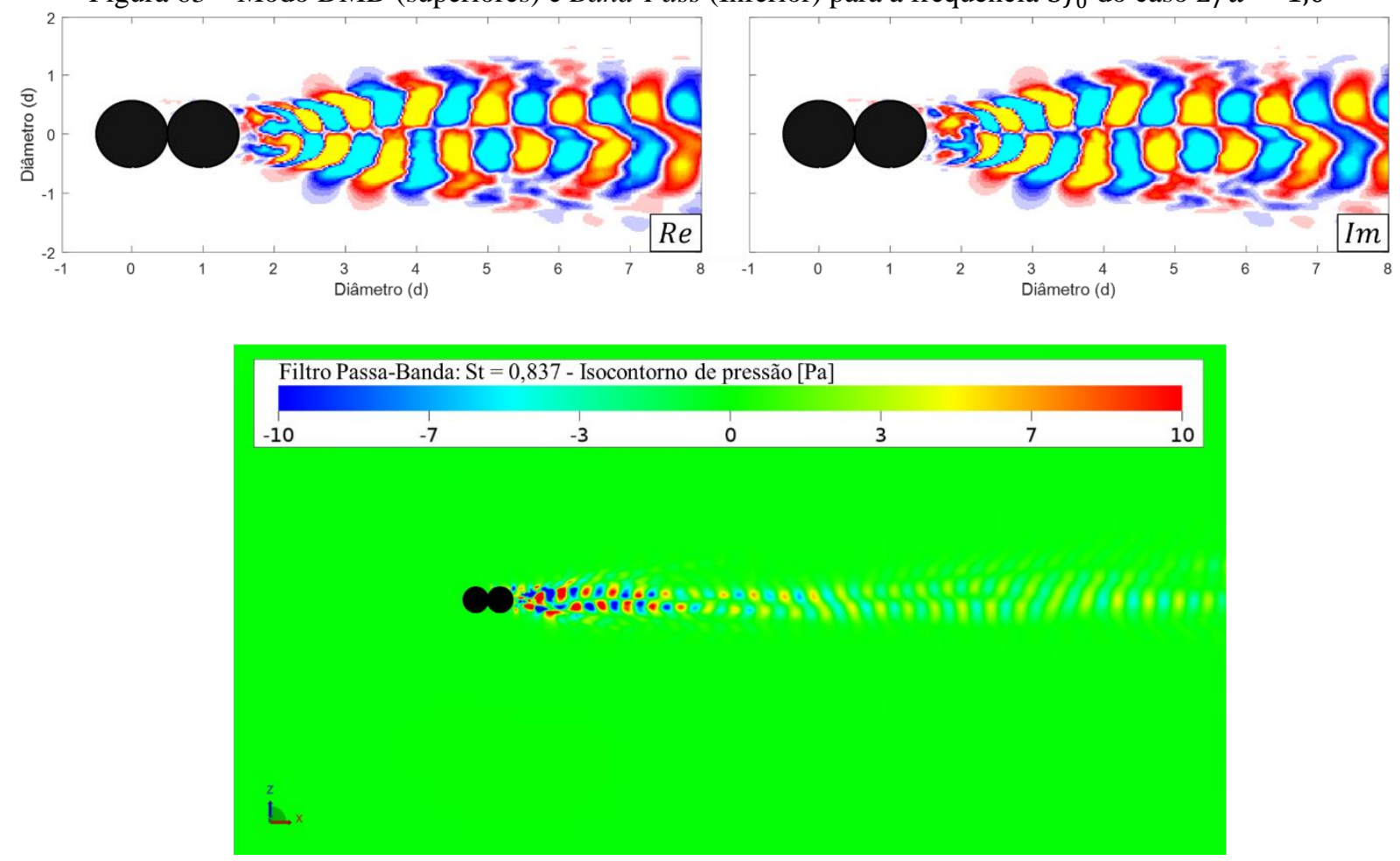

O ruído do caso $L / d=2,5$ possui apenas um pico na frequência $f_{0}$ relacionado com a flutuação da força de sustentação. O modo DMD associado a essa frequência é marcado pela seta verde na Figura 64. 
Figura 64 - Taxa de decaimento vs. número de Strouhal dos modos DMD do caso $L / d=2,5$

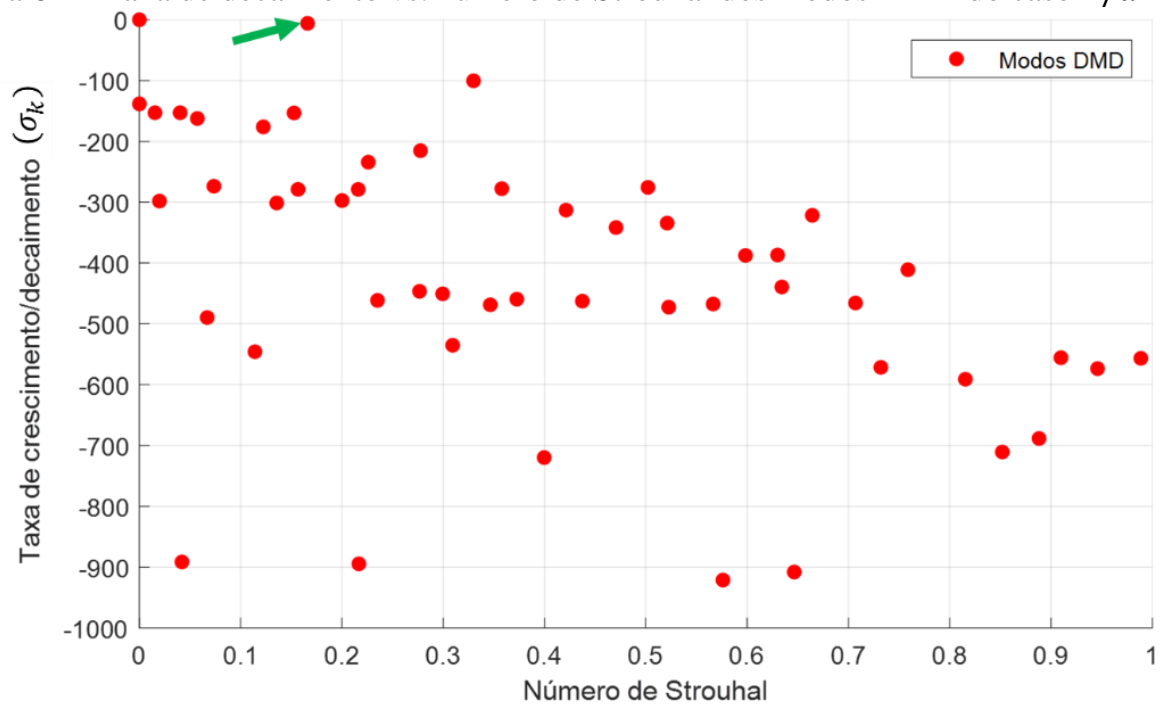

Figura 65 - Modo DMD (superiores) e Band-Pass (Inferior) para a frequência $f_{0}$ do caso $L / d=2,5$
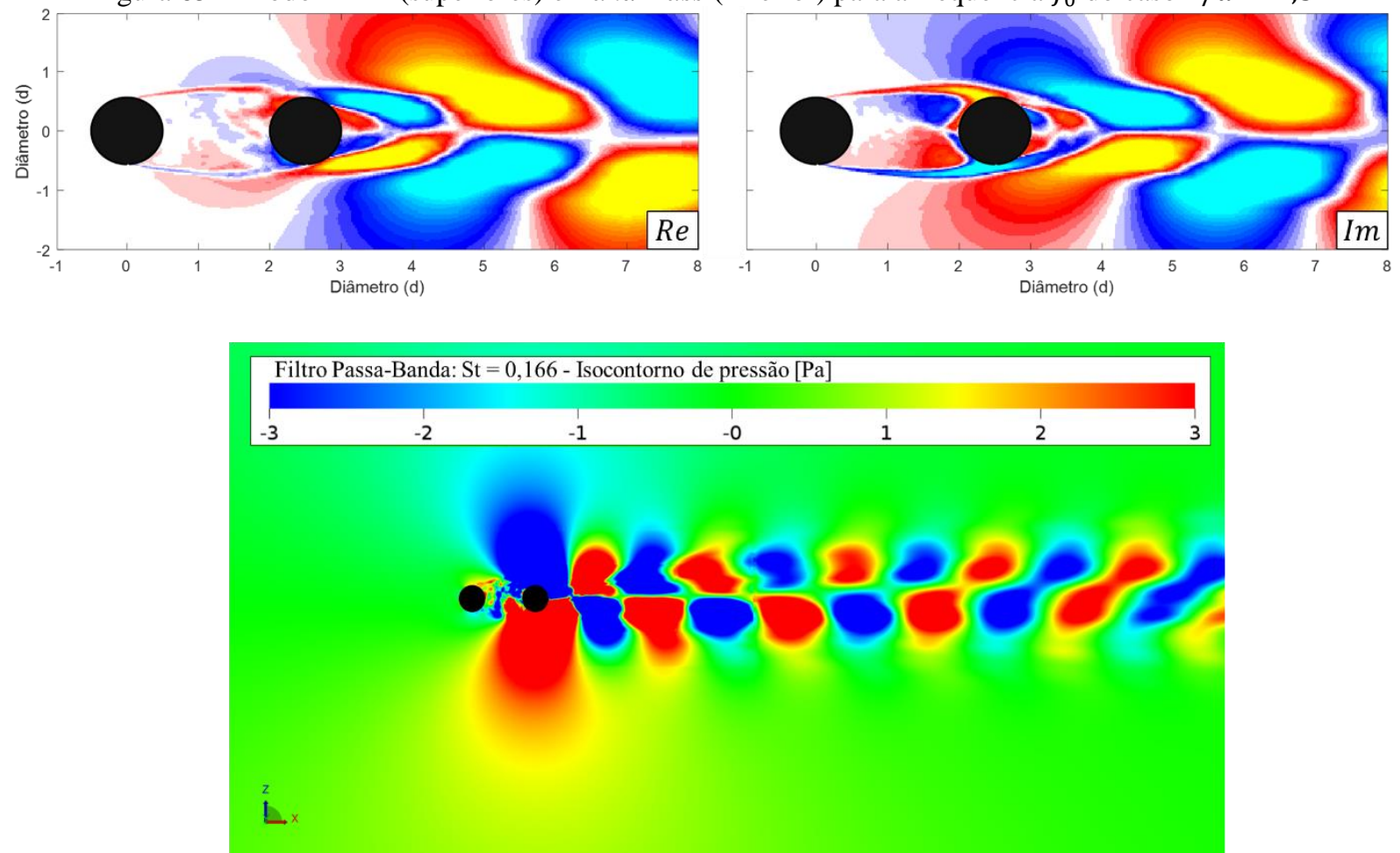

O modo DMD em $S t=0,166$ do espaçamento $L / d=2,5$ mostra com detalhes a estrutura reattached descrita no trabalho de Igarashi (1981). Nota-se a ocorrência de duas estruturas estacionárias entre os dois cilindros, o recolamento da camada cisalhante no segundo cilindro, além da emissão de vórtices à jusante do cilindro 2. Assim, como no caso dos cilindros com separação $L / d=1,0$, o dipolo é centrado no segundo cilindro, sendo dele a principal contribuição para o ruído total em campo afastado. O fundo de escala do campo de pressão na análise passa-banda foi ajustado para demonstrar com clareza as estruturas do caso em questão 
e mostra que a amplitude de oscilação de pressão nessa frequência é menor que a observada na separação $L / d=1,0$.

Apesar de não ocorrer pico de amplitude de ruído na frequência correspondente ao harmônico $2 f_{0}$, nota-se na análise de DMD que há um modo dinâmico nesta frequência e por esse motivo, optou-se por mostrar na Figura 66, a estrutura coerente correspondente ao modo em $2 f_{0}$ em que capturou-se a estrutura associada à flutuação da força de arrasto.

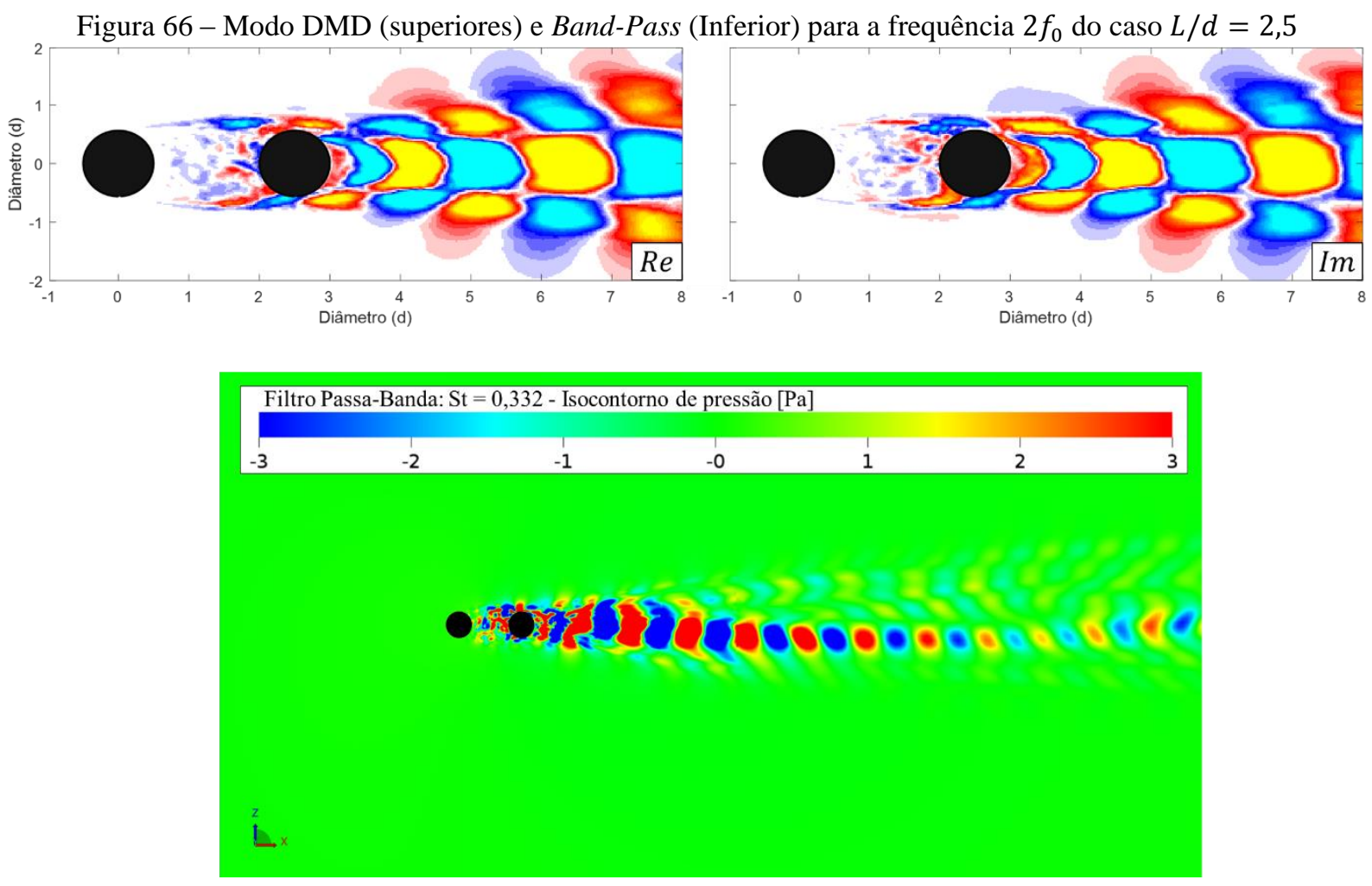

Os quatro picos do caso com separação $L / d=4,0$ são marcados pelas setas verdes na Figura 67. Nas Figuras 68, 69, 70 e 71 apresentam-se as estruturas coerentes dos modos de interesse do escoamento do tipo jump, descrito por Igarashi (1981), no qual há formação e desprendimento de vórtices desenvolvidos no espaço entre os cilindros, resultando em um escoamento complexo ao redor do cilindro 2.

O fundo de escala do campo de pressão da análise band-pass foi ajustada de forma a melhor definir as estruturas coerentes dos quatro modos. Das imagens relativas à frequência $f_{0}$, nota-se que há a ocorrência de um dipolo em cada cilindro com certa defasagem, sendo o dipolo do cilindro mais à jusante o dipolo de maior intensidade. Nota-se a formação de estruturas características da oscilação de força de sustentação nas frequências $f_{0}$ e $3 f_{0}$ e estruturas 
características da oscilação da força de arrasto nas frequências em $2 f_{0}$ e $4 f_{0}$. Assim como nos casos anteriores a amplitude das oscilações é menor quanto maior for a frequência do modo.

A análise DMD mostrou-se capaz de determinar com clareza as estruturas coerentes, mesmo em escoamentos complexos, ao exemplo do escoamento com separação $L / d=4,0$.

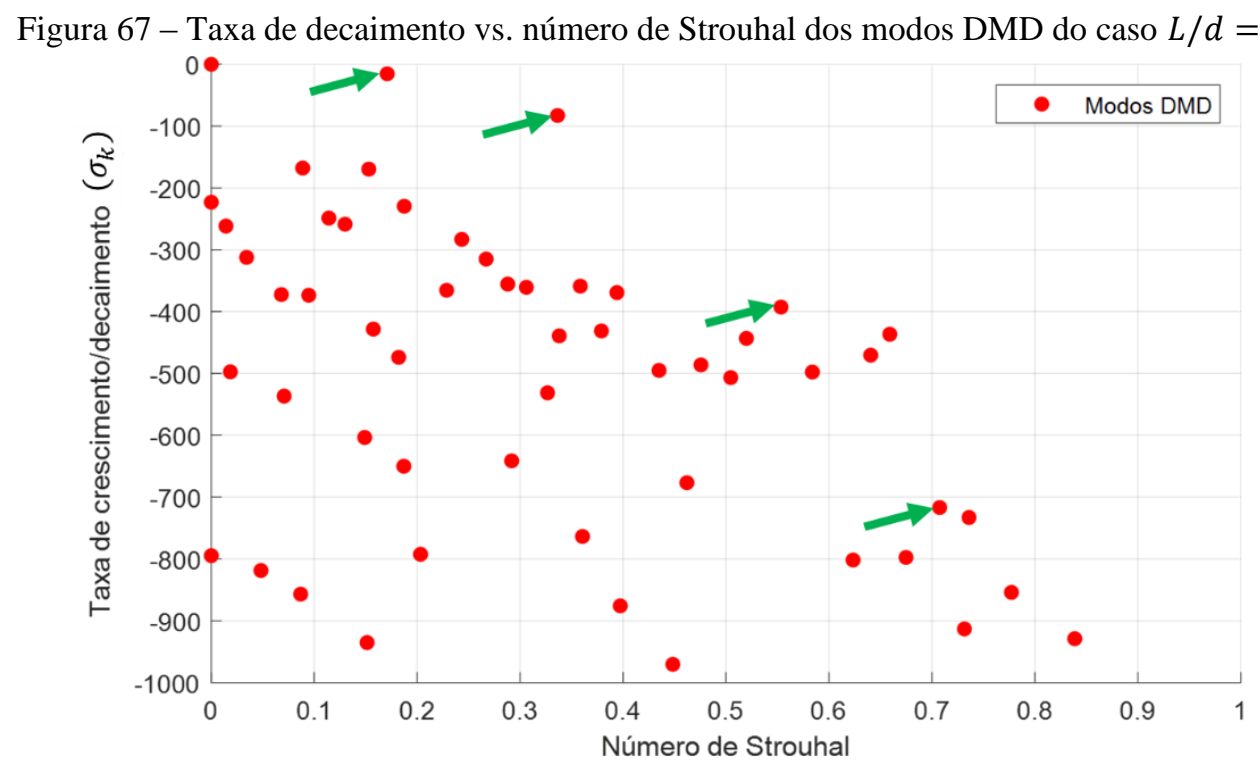

Figura 68 - Modo DMD (superiores) e Band-Pass (Inferior) para a frequência $f_{0}$ do caso $L / d=4,0$
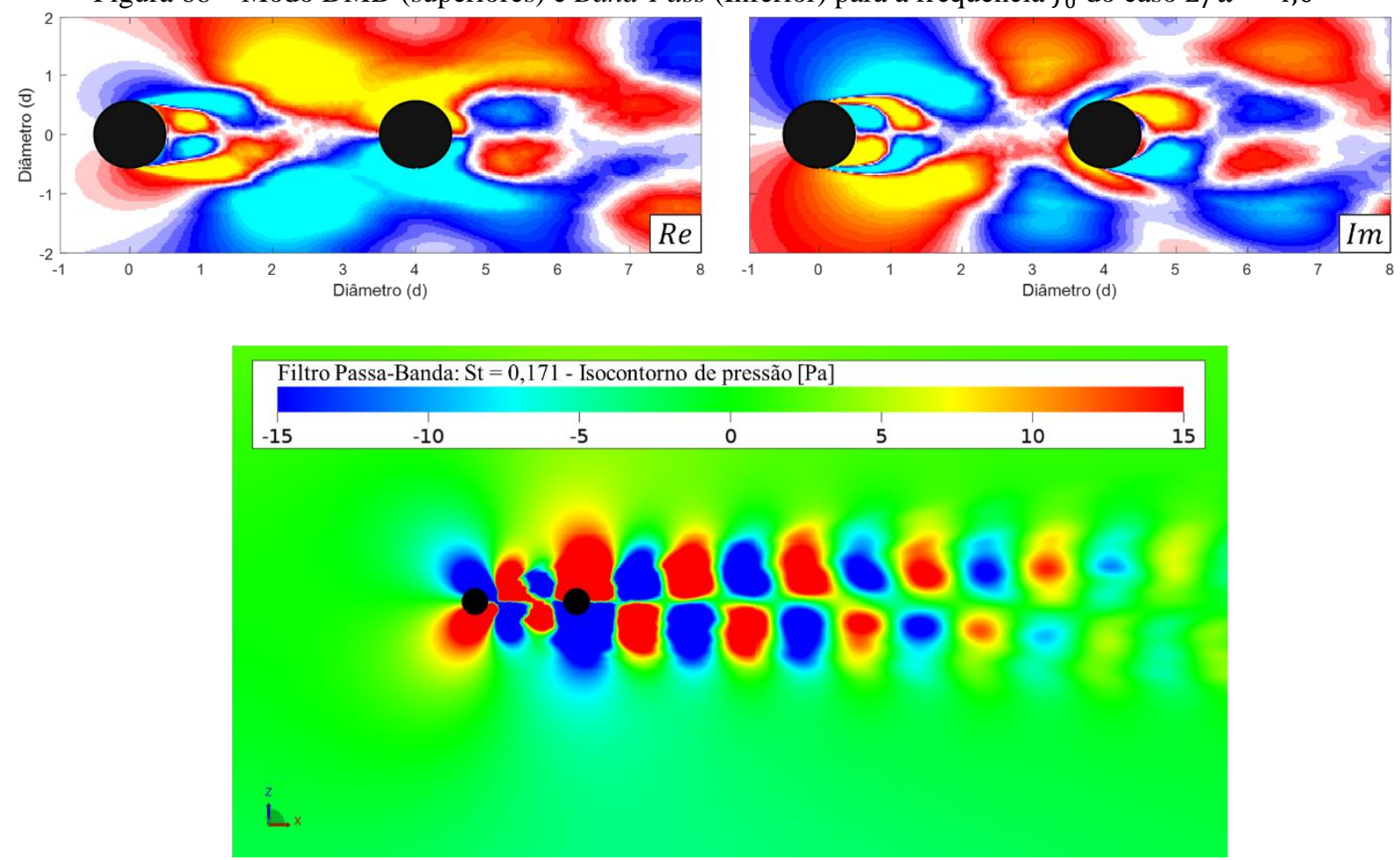
Figura 69 - Modo DMD (superiores) e Band-Pass (Inferior) para a frequência $2 f_{0}$ do caso $L / d=4,0$
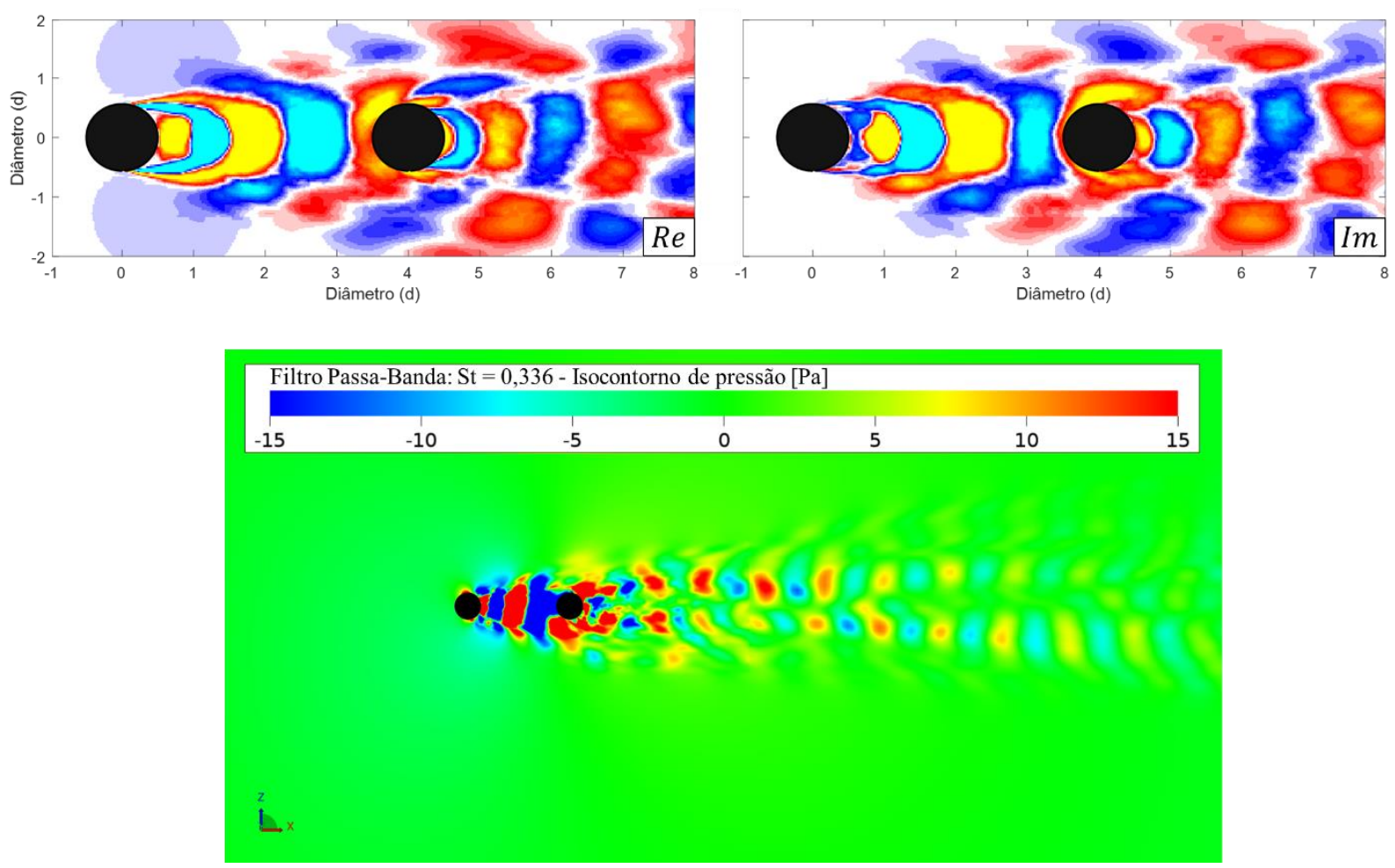

Figura 70 - Modo DMD (superiores) e Band-Pass (Inferior) para a frequência $3 f_{0}$ do caso $L / d=4,0$
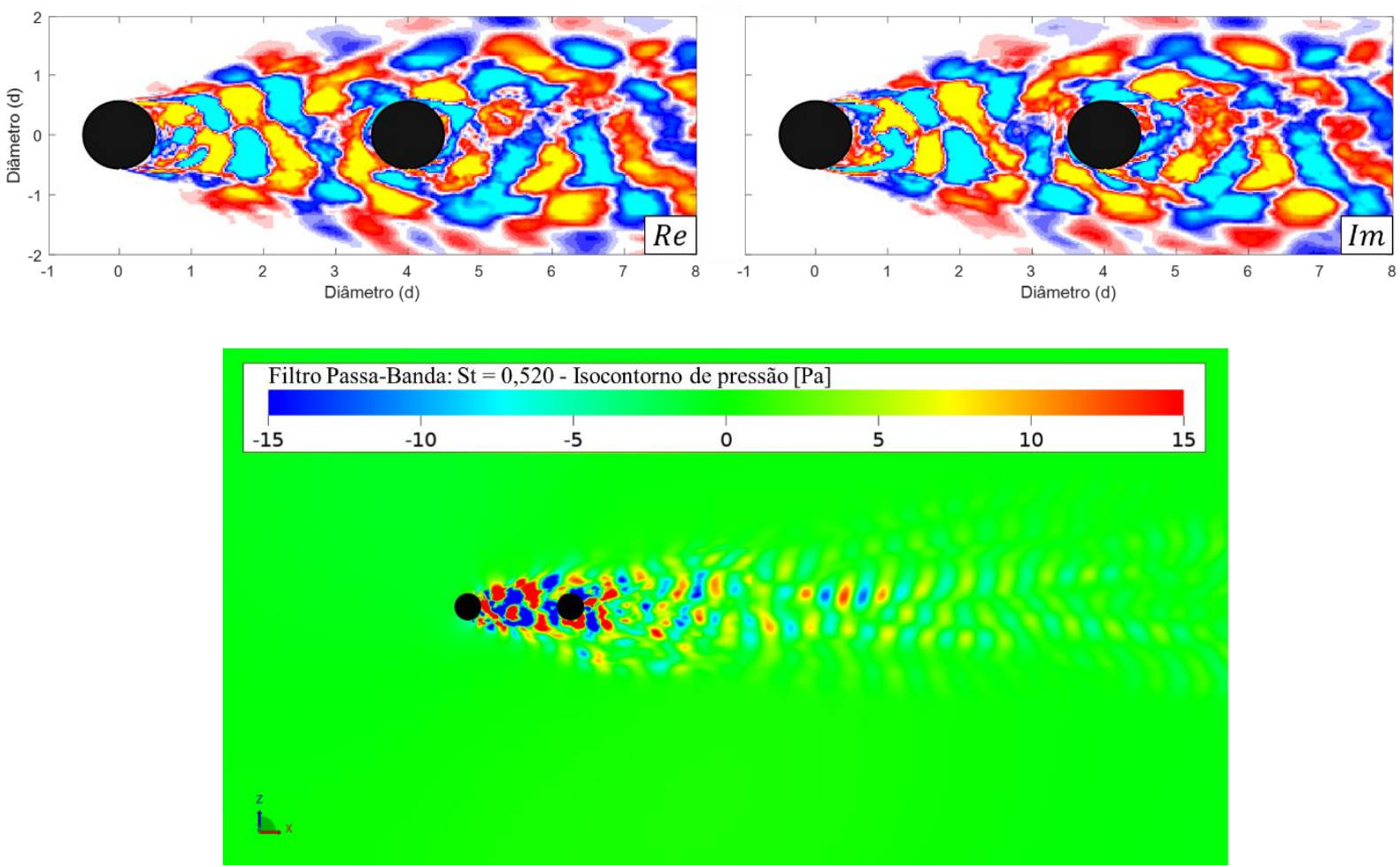
Figura 71 - Modo DMD (superiores) e Band-Pass (Inferior) para a frequência $4 f_{0}$ do caso $L / d=4,0$
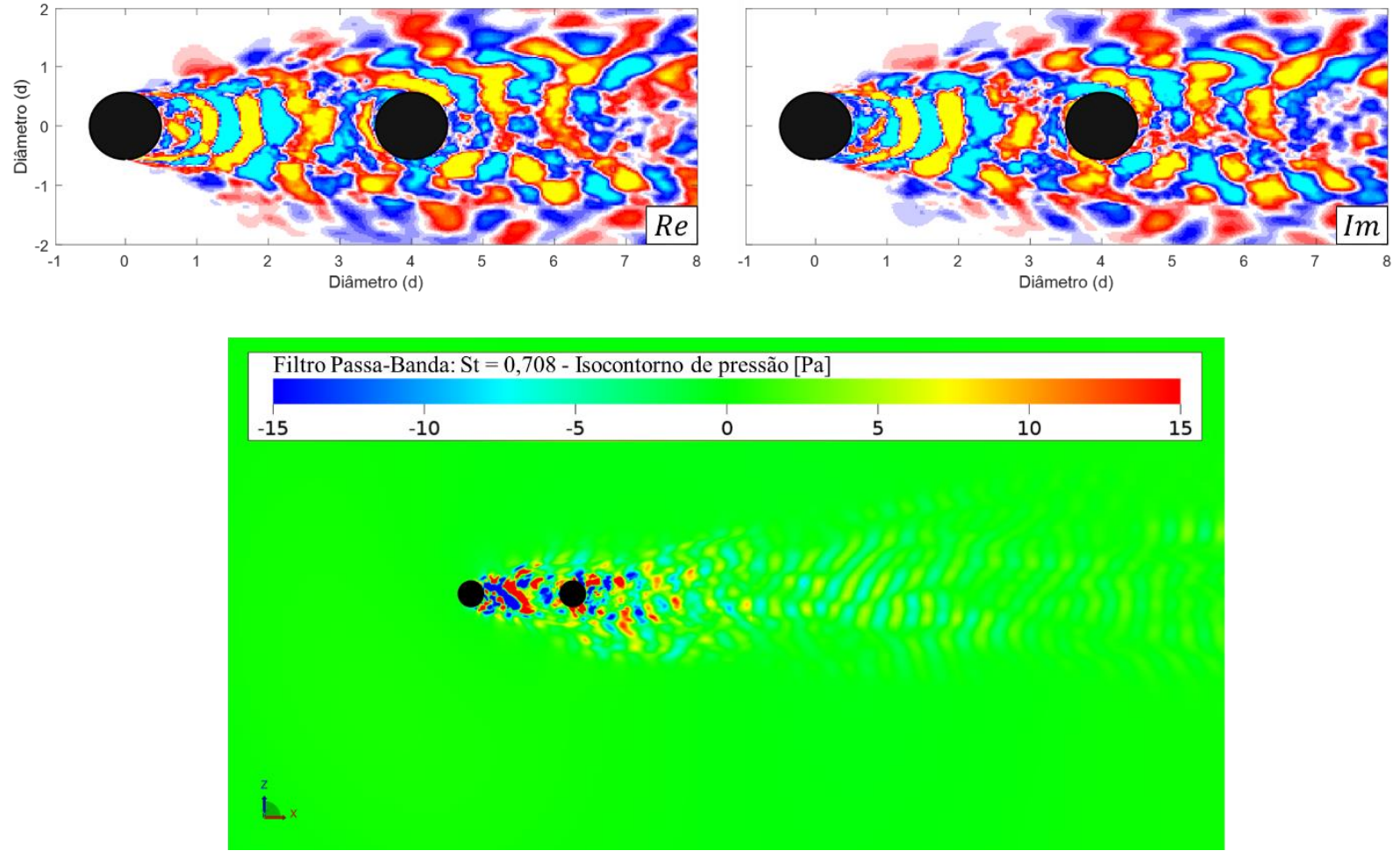


\section{SUPERFÍCIE REFLEXIVA (CASO SEMI-ANECÓICO)}

A simulação realizada no capítulo 3 considerou um domínio simulando um túnel de vento anecóico. No entanto, em aplicações reais da indústria automotiva, as barras transversais são dispostas em média $100 \mathrm{~mm}$ acima do teto do veículo. Para simular esta condição de montagem, neste capítulo, considera-se que a superfície inferior do túnel de vento situa-se próxima ao cilindro (caso Semi-anecóico) e, como consequência, as ondas sonoras geradas e refletidas por essa superfície passam a integrar o cálculo do ruído (detalhes construtivos vide Figura 72). A camada absortiva foi mantida nas regiões entre as condições de contorno de entrada, saída, superfície superior e o cilindro a fim de absorver as ondas sonoras refletidas por essas paredes, para reduzir o ruído de fundo do túnel de vento e evitar a contaminação dos resultados por fontes sonoras não físicas ou espúrias.

Figura 72 - Esboço do modelo computacional

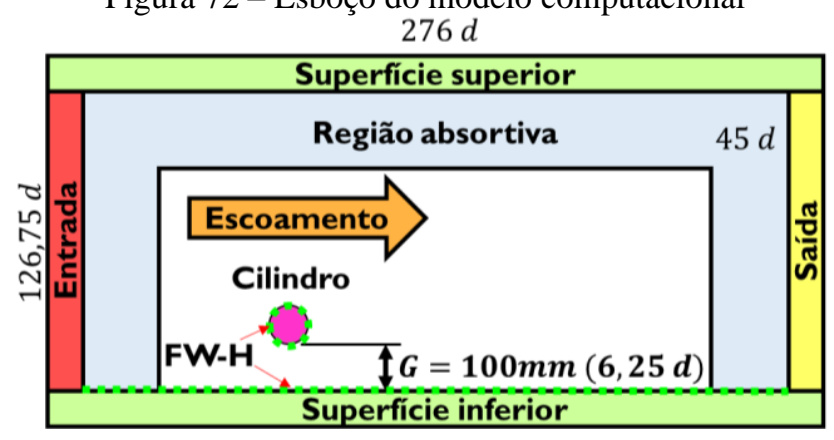

A região próxima ao cilindro é detalhada na Figura 73 e mostra as principais modificações realizadas a fim de contemplar a nova fonte sonora considerada. É possível notar que uma VR foi adicionada próxima à parede inferior do domínio com a mesma resolução da VR5, resultando em um $y^{+} \approx 45$. A equação de parede implementada no código PowerFLOW captura efeitos de camada limite sem separação para $y^{+}$até próximo de 300.

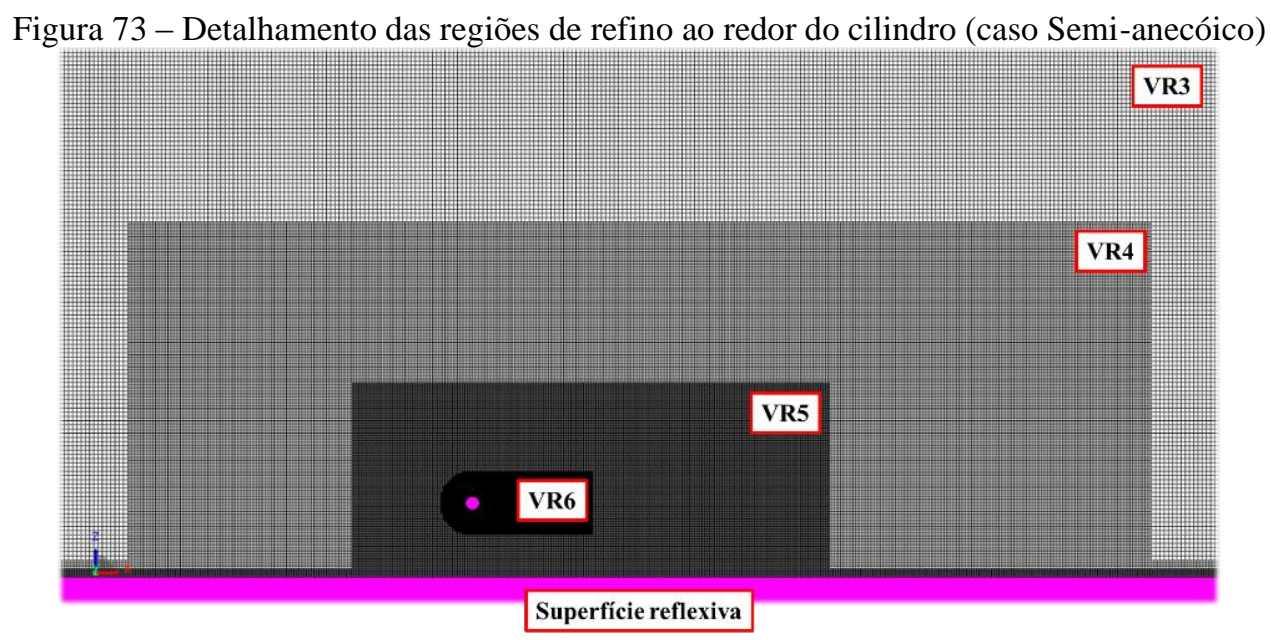


O cálculo do ruído em campo afastado (com microfone posicionado 86,25 $d$ acima do cilindro) do caso semi-anecóico é realizado via formulação porosa do método de FfowcsWilliams e Hawkings considerando os dados coletados em duas superfícies fictícias e permeáveis, sendo a primeira coincidente com o cilindro e a segunda coincidente com a parede inferior do túnel.

Para fins comparativos, adicionalmente, considera-se uma segunda metodologia de reflexão, a formulação do método FW-H com algoritmo proprietário de reflexão planar (disponível no software PowerACOUSTICS), que mimetiza matematicamente os efeitos de superfícies reflexivas sem a necessidade de incluí-las "fisicamente" no domínio de cálculo. Aplicar-se-á tal formulação nos resultados do capítulo 3 (denomina-se aqui como caso Reflexivo Virtual) a fim de comparar estes resultados com os das simulações dos Casos Anecóico e Semi-anecóico. Em tal formulação, a contribuição das ondas refletidas pelo plano "virtual" que, em seguida, incidem no microfone é resultado das ponderações das pressões das ondas incidentes pelo fator $\sqrt{R}$, sendo $R$ o coeficiente de reflexão da superfície (EXA CORPORATION, 2016). Kinsler et al. (2000) descrevem um método similar que, além do coeficiente de reflexão $R$, também considera o efeito do ângulo de incidência da onda refletida.

\subsection{CAMPO FLUIDODINÂMICO}

Estudos como os de Bearman e Zdravkovich (1978), Grass et al. (1984) e Raven et al. (1985) mostram que a influência de uma placa plana posicionada paralela ao escoamento e próxima ao cilindro com distância $G>2 d$ não interfere com a esteira em formação. Dessa forma, espera-se que a topologia do escoamento ao redor do corpo rombudo do caso Semianecóico $(G \approx 6,25 d)$ seja equivalente ao do Caso Anecóico. Os resultados das grandezas fluidodinâmicas importantes para caracterizar o escoamento do caso Semi-anecóico são compilados na Tabela 7 e são devidamente comparados aos resultados do Caso Anecóico e aos dados experimentais de referência, evidenciando a não influência da placa plana no escoamento próximo ao cilindro.

Tabela 7 - Resultados fluidodinâmicos compilados para o caso Semi-anecóico

\begin{tabular}{ccccccc}
\hline Malha \# & $\overline{C_{d}}$ & $\widehat{C_{d}}$ & $\widehat{C}_{l}$ & $S t$ & $\ell_{f} / d$ & $\theta$ \\
\hline Ref. & Zdravkovich (1997) & Zdravkovich (1997) & Norberg (2003) & Schewe (1983) & Norberg (1998) & White $(1991)$ \\
Caso & $1,14 \sim 1,23$ & $0,050 \sim 0,165$ & $0,458 \sim 0,496$ & 0,200 & 1,30 & $80 \sim 83^{\circ}$ \\
$\begin{array}{c}\text { Anecóico } \\
\text { Caso }\end{array}$ & 1,20 & 0,077 & 0,462 & 0,198 & 1,14 & $86^{\circ}$ \\
Semi-anecóico & 1,20 & 0,073 & 0,454 & 0,200 & 1,15 & $86^{\circ}$ \\
\hline
\end{tabular}


O histórico temporal dos coeficientes de sustentação $\left(C_{l}\right)$ e arrasto $\left(C_{d}\right)$ e os dois instantes de tempo que representam o valor médio com que os 10 maiores e 10 menores picos positivos variam em relação a amplitude do sinal (marcados pelos símbolos em verde) são mostrados na Figura 74. As figuras da discretização temporal (vide Figura 20) que mostram a evolução completa dos dois ciclos de emissão de vórtices apontados em verde na Figura 74 encontram-se no APÊNDICE C. O resultado da análise de Densidade Espectral de Potência dos sinais $C_{d}$ e $C_{l}$ são mostrados na Figura 75.

Figura 74 - Histórico temporal dos coeficientes de arrasto $\left(C_{d}\right)$ e sustentação $\left(C_{l}\right)$ para o Caso Semi-anecóico

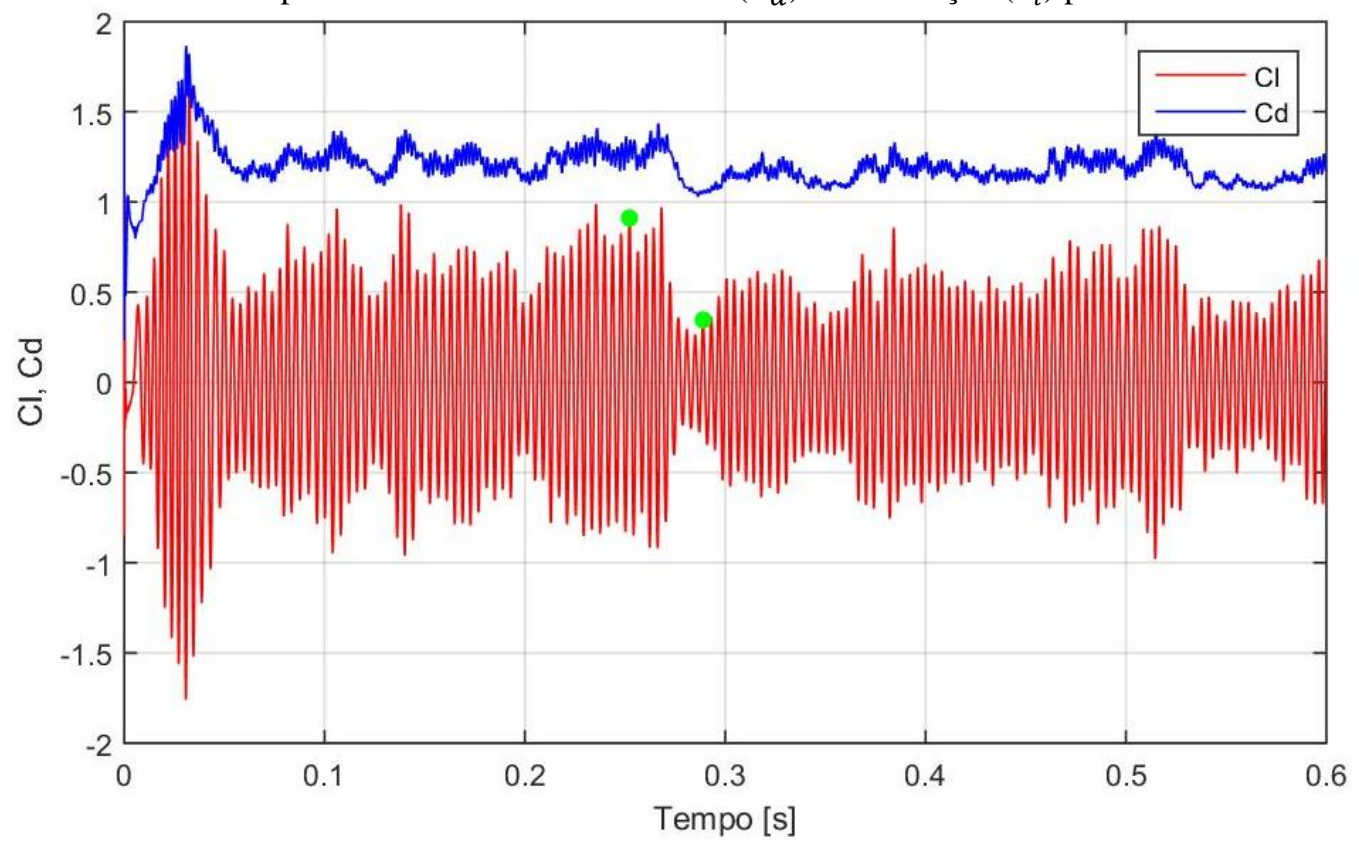

Figura 75 - Densidade Espectral de Potência (PSD) dos sinais $C_{d}$ e $C_{l}$

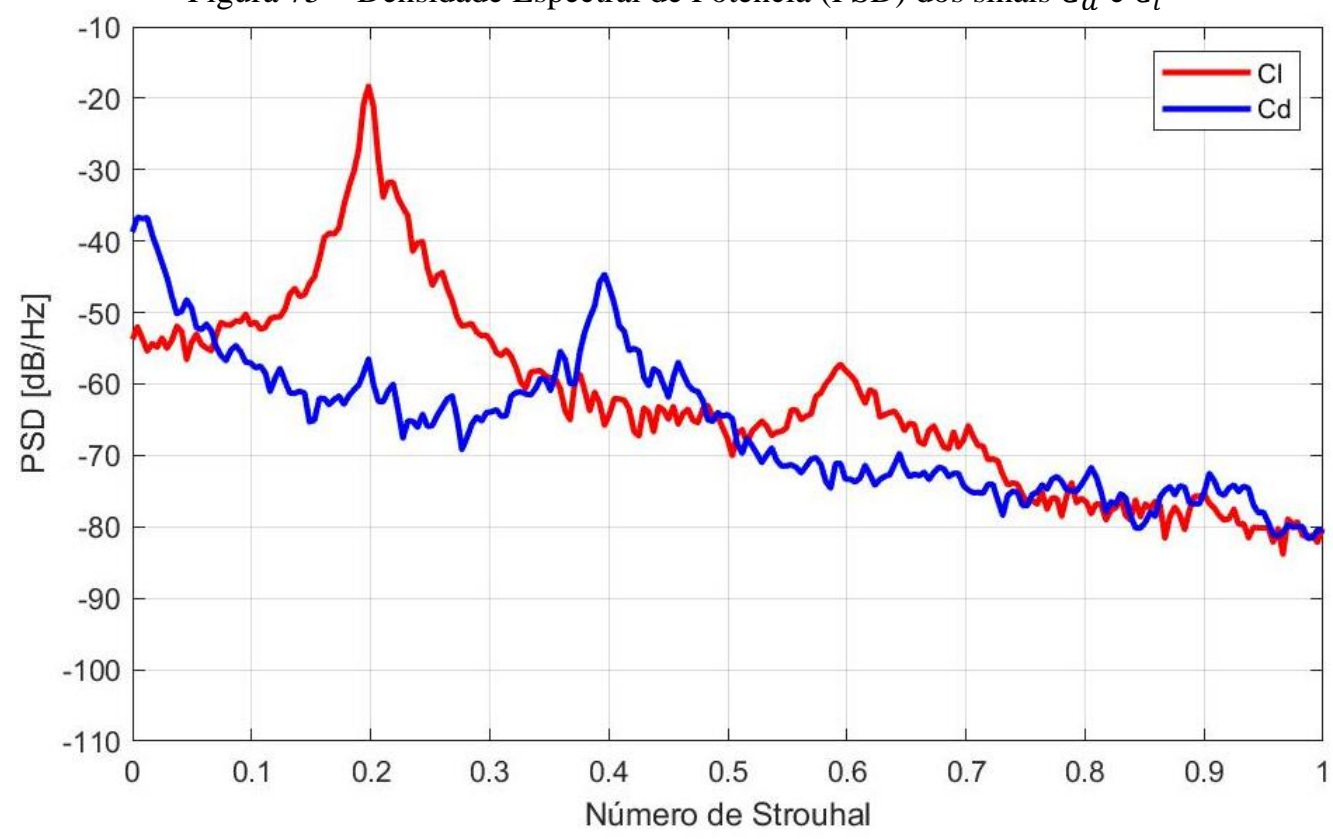


Como esperado, a PSD mostra que os picos em $f_{0}$ e $3 f_{0}$ estão correlacionados com a flutuação da força de sustentação, enquanto o pico em $2 f_{0}$ com a flutuação da força de arrasto. Comparando ao Caso Anecóico, as amplitudes dos picos são discretamente menores e a amplitude da PSD de $C_{l}$ é ligeiramente superior para $S t>0,3$, fazendo com que o pico em $3 f_{0}$ não ficasse tão demarcado como no Caso Anecóico.

\subsection{RUÍDO EM CAMPO AFASTADO}

Pelo fato do escoamento desenvolver-se com $M<0,3$ e pelas hipóteses simplificadoras que resultaram na eq. (2.25), pode-se monitorar os dados transientes em superfícies fictícias, permeáveis e coincidentes com as superfícies de interesse e desprezar as fontes sonoras presentes no volume. O ruído em campo afastado, para microfones posicionados em $86,25 d$ a $\phi=40^{\circ}$ e $\phi=90^{\circ}$, foi calculado aplicando a formulação porosa de FW-H nos dados de flutuação de pressão coletados ao longo dos 125 ciclos finais de emissão de vórtices na frequência $f_{0}$, nas superfícies fictícias coincidentes com a parede do cilindro e com a superfície inferior do túnel de vento.

As curvas de PSD $[\mathrm{dB} / \mathrm{Hz}]$ em função de $S t$ do ruído em campo afastado serão apresentadas até $S t=1$ com resolução suficiente para descrever os picos na faixa de frequências de interesse. O software PowerACOUSTICS foi utilizado para tal finalidade e o resultado das PSDs calculadas com técnica de janelamento Hanning (50\% de overlap) dos casos propostos anteriormente serão apresentadas para $\phi=90^{\circ}$ na Figura 76 e para $\phi=40^{\circ}$ na Figura 77.

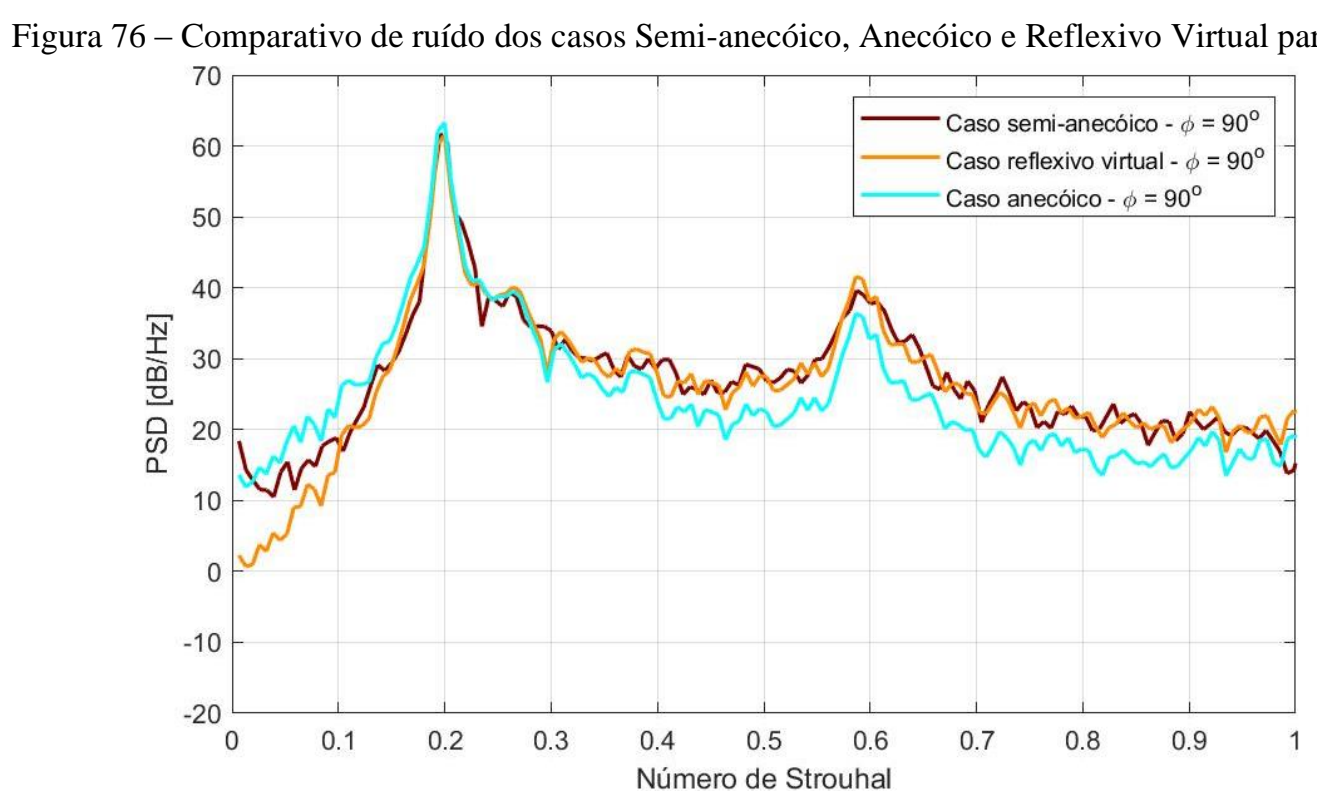


Figura 77 - Comparativo de ruído dos casos Semi-anecóico, Anecóico e Reflexivo Virtual para $\phi=40^{\circ}$

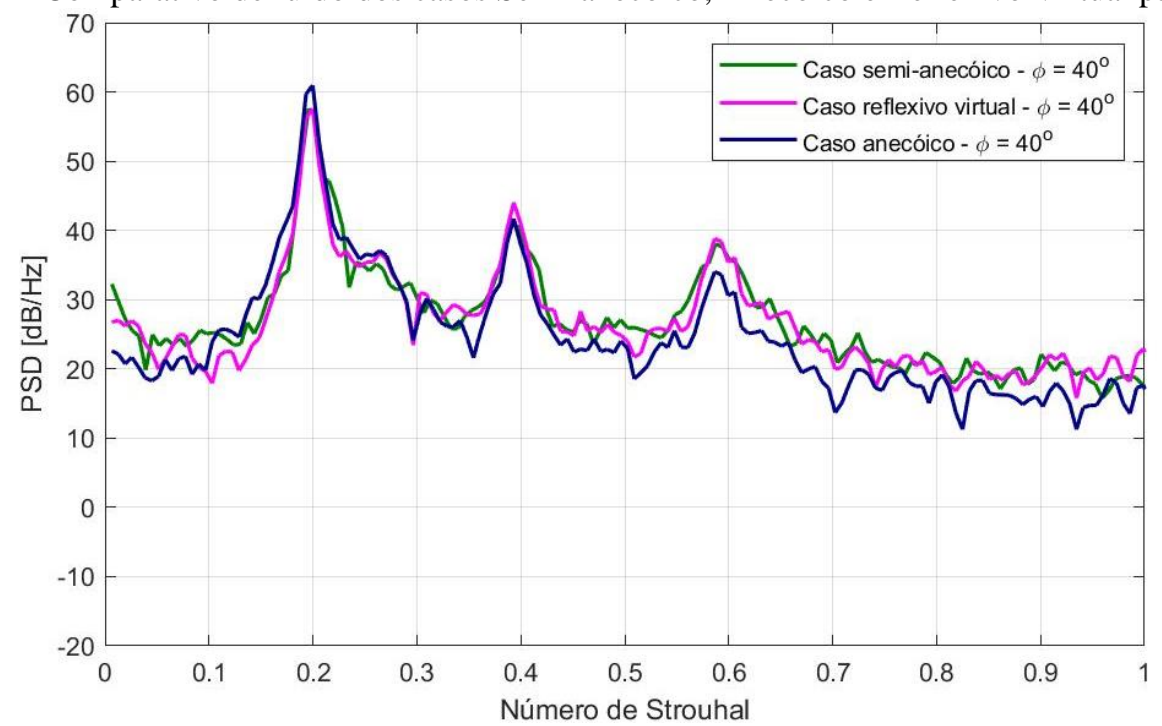

Analisando os comparativos anteriores é possível notar que a frequência dos harmônicos não foi alterada e que as diferenças se concentram na amplitude das curvas apresentadas. A presença da superfície planar reflexiva distante $6,25 d$ do centro do cilindro possui influência apenas no ruído em campo afastado. Os picos em $f_{0}$ dos casos Semi-anecóico e Reflexivo Virtual ficaram em média $4 \mathrm{~dB} / \mathrm{Hz}$ menores que os do Caso Anecóico. Já nas frequências $2 f_{0}$ e $3 f_{0}$ os picos ficaram respectivamente $2 \mathrm{~dB} / \mathrm{Hz}$ e $4 \mathrm{~dB} / \mathrm{Hz}$ maiores que a referência. Para frequências maiores que $S t=0,3$ as metodologias empregues apresentaram amplitude maior que o Caso Anecóico $(\sim 3 \mathrm{~dB} / \mathrm{Hz})$; e nas frequências abaixo de $S t=0,15$ pode-se observar, na posição $\phi=90^{\circ}$, que o caso Reflexivo Virtual apresentou amplitude até $5 \mathrm{~dB} / \mathrm{Hz}$ menor que o Caso Anecóico, o que não foi notado para a curva do caso Semi-anecóico. Complementando para $S t<0,15$ e $\phi=40^{\circ}$ nota-se que os modelos em estudo apresentaram amplitude até $3 \mathrm{~dB} / \mathrm{Hz}$ maior que o Caso Anecóico.

\subsection{DECOMPOSIÇÃO EM MODOS DINÂMICOS}

Assim como na análise DMD dos cilindros em tandem utilizou-se o mesmo código MATLAB do Caso Anecóico. Os três modos de interesse são marcados pelas setas verdes no gráfico da taxa de crescimento ou decaimento $\left(\sigma_{k}\right)$ em função de $S t$ da análise DMD mostrado na Figura 78.

As estruturas coerentes de cada modo são detalhadas nas Figuras 79, 80 e 81 e nota-se que, apesar da condição de contorno reflexiva, as formas modais não divergem das encontradas na análise do Caso Anecóico, sendo a principal diferença o fato da porção inferior do dipolo 
relacionado com a flutuação da força de sustentação estender-se na direção da parede inferior do túnel de vento.

A decomposição em modos dinâmicos associada à análise passa-banda fornece dados importantes para o entendimento do campo fluidodinâmico e das estruturas coerentes dominantes nas frequências que concentram a maior parcela da energia sonora que propaga-se até o observador em campo afastado. Esta análise prova ser uma ferramenta relevante na solução de problemas que auxilia o usuário determinar quais regiões da geometria requerem maior atenção quando o intuito é reduzir a intensidade ou eliminar tonais do ruído radiado.

Figura 78 - Taxa de decaimento vs. número de Strouhal dos modos DMD do caso Semi-anecóico

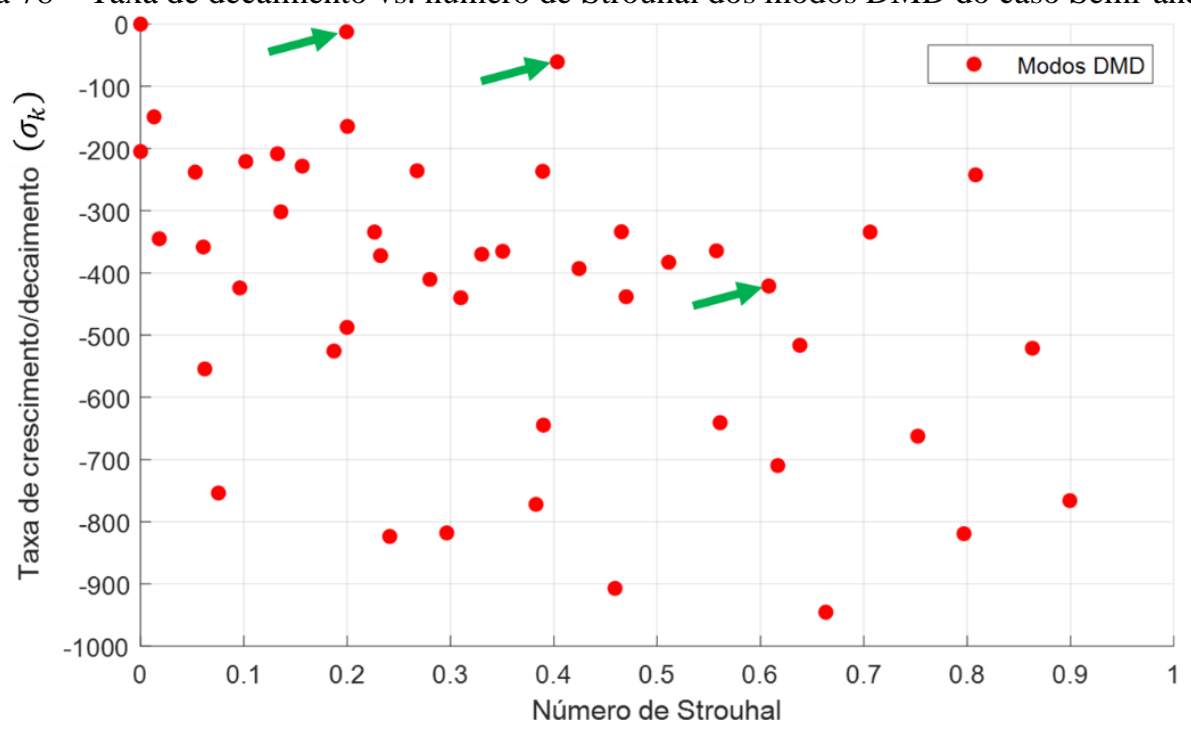

Figura 79 - Modo DMD (superiores) e Band-Pass (Inferior) para a frequência $f_{0}$ do caso Semi-anecóico
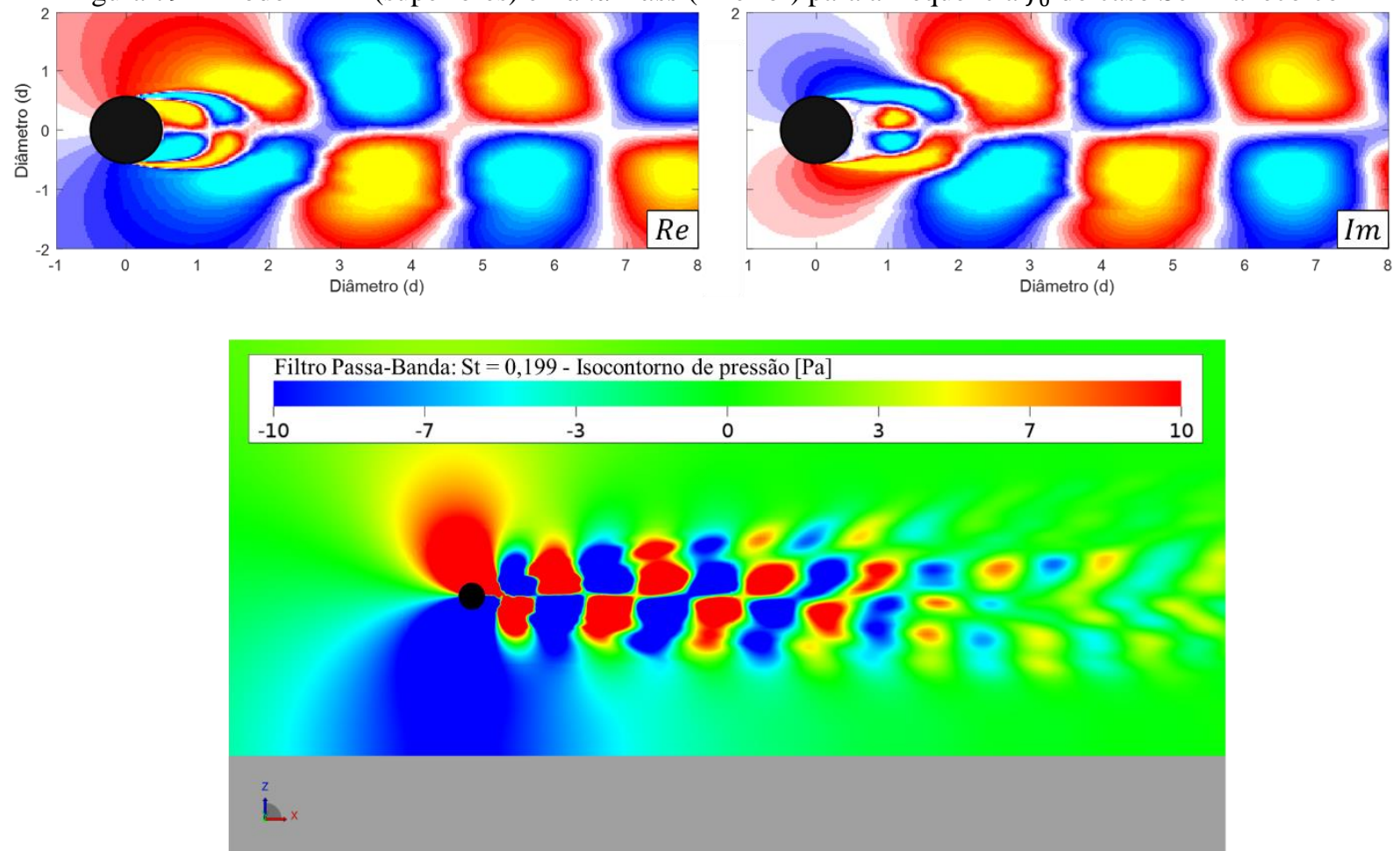

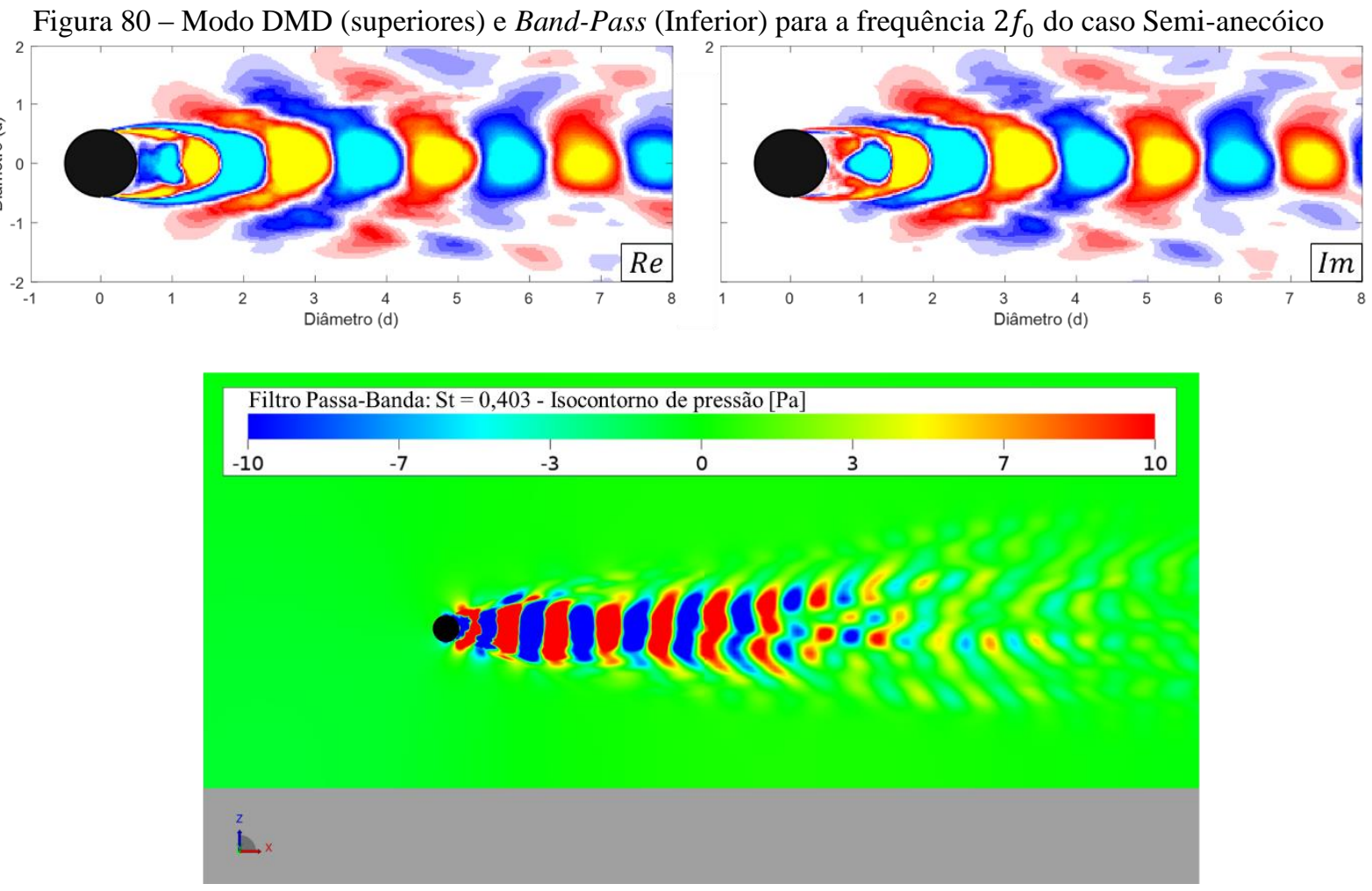

Figura 81 - Modo DMD (superiores) e Band-Pass (Inferior) para a frequência $3 f_{0}$ do caso Semi-anecóico
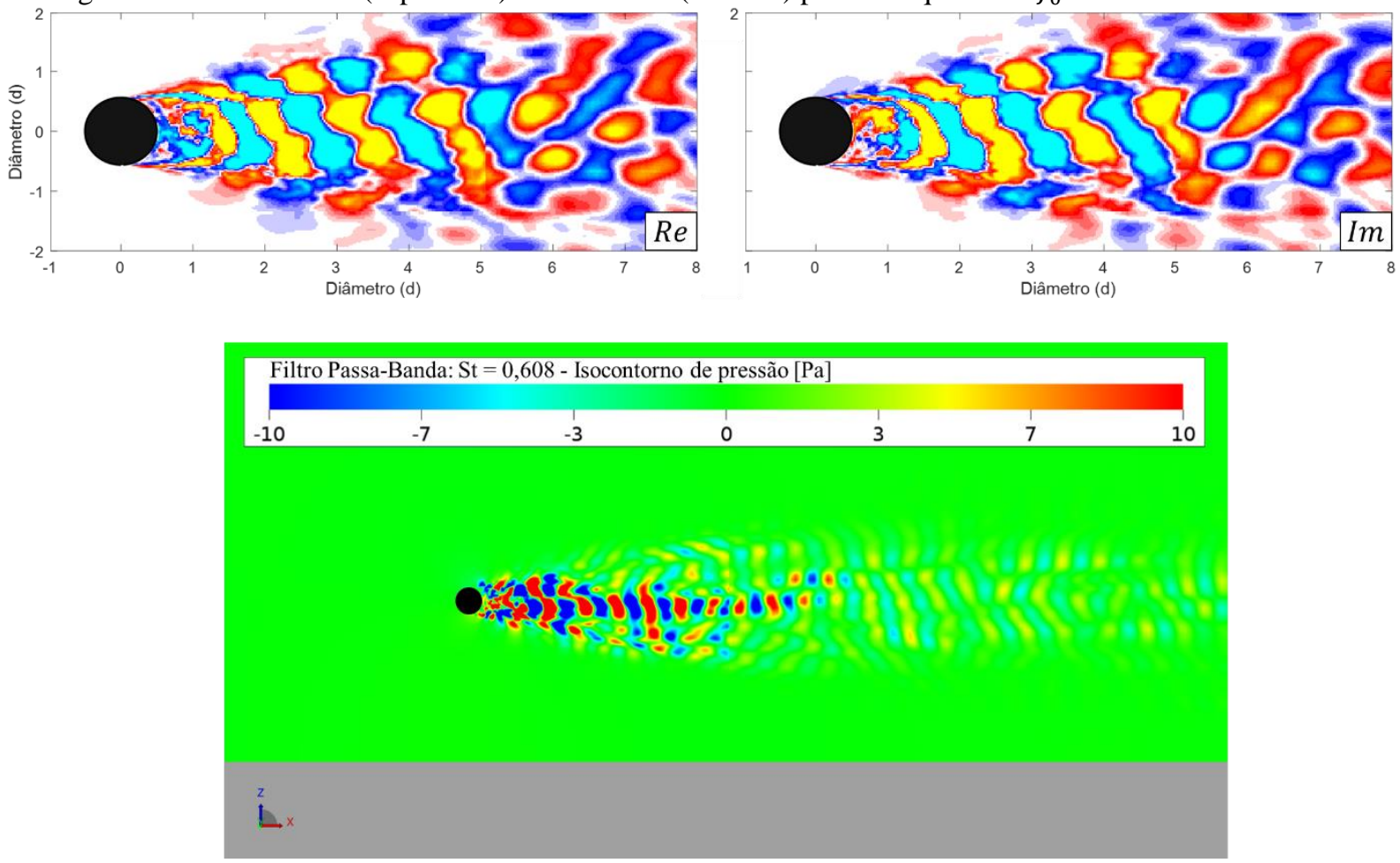

Conclui-se que, para barras transversais distantes $100 \mathrm{~mm}$ de uma superfície reflexiva paralela ao escoamento, a esteira desenvolvida à jusante da barra não sofre interferência do escoamento na superfície adjacente. A principal influência concentra-se na amplitude do ruído 
em campo afastado que foi aumentado, em média, $3 \mathrm{~dB} / \mathrm{Hz}$ na faixa de frequências em estudo. Não houve alterações no conteúdo em frequência ou o surgimento de novos tons no sinal calculado para microfones em campo afastado posicionados a 86,25 $d$ e ângulos $\phi=40^{\circ} \mathrm{e}$ $\phi=90^{\circ}$. O método de reflexão virtual disponível no código PowerACOUSTICS produziu resultados condizentes aos do caso Semi-anecóico.

As análises band-pass e DMD do caso Semi-Anecóico assemelham-se com os resultados do Caso Anecóico exceto pelo dipolo associado à flutuação da força de sustentação que tende a ter um de seus polos alongado na direção da superfície próxima.

Tais constatações indicam que simulações de barras transversais instaladas à aproximadamente $100 \mathrm{~mm}$ do teto do veículo, com foco na mitigação de tonais, podem ser realizadas considerando túnel de vento anecóico sem que ocorram alterações nas frequências dos picos do espectro do sinal. Esta consideração é válida apenas se o escoamento desenvolvido no teto do veículo não interferir com o campo fluidodinâmico próximo à barra. 


\section{CONCLUSÃO}

Tendo em vista a importância do ruído aerodinâmico no desempenho de Ruídos, Vibrações e Aspereza (Noise Vibration and Harshness - NVH) de um automóvel e a ligação direta deste com a percepção de qualidade e refino de um projeto realizaram-se simulações computacionais do ruído radiado por cilindros sujeitos ao escoamento transversal de ar com baixo número de Mach $(M \approx 0,06)$ em diferentes configurações.

A análise dos resultados obtidos através do método híbrido de aeroacústica computacional utilizando a modelagem de Lattice-Boltzmann e a analogia acústica de FfowcsWilliams e Hawkings, contribui para o melhor entendimento do ruído emitido por acessórios externos, como os racks de teto. Uma vez que podemos aplicar tal metodologia na análise do ruído radiado por qualquer barra prismática, o estudo favorece a concepção de geometrias de barras transversais com nível de ruído em banda larga ou tonais mitigados ainda nas fases iniciais do projeto e a baixo custo.

Os resultados apresentados no capítulo 3 comprovaram a eficácia do método em calcular o ruído em campo afastado, tanto em amplitude quanto em conteúdo de frequência, para ângulos $\phi$ iguais a $40^{\circ}$ e $90^{\circ}$. A frequência fundamental e as harmônicas do aeolian tone foram capturadas com erros não maiores que $1 \%$. O pico em $2 f_{0}$ fica mais definido com o microfone virtual posicionado em $\phi=40^{\circ}$ devido ao fato da direção principal do dipolo associado à flutuação da força de arrasto ser paralela ao escoamento. A amplitude do sinal do ruído calculado foi inferior ao medido por Casalino e Jacob (2003), pois o comprimento do cilindro simulado corresponde a, aproximadamente, 1/3 do comprimento da barra testada e consequentemente o ruído radiado por ele é menor. Sabe-se que com o uso de técnicas de correção como a de Kato et al. (1993) a correlação em amplitude pode ser alcançada.

No capítulo 4 constatamos a versatilidade do PowerFLOW que, com poucos ajustes implementados na malha volumétrica do modelo do capítulo 3, foi capaz de capturar com precisão de ao menos $95 \%$ a frequência fundamental do ruído tonal radiado por dois cilindros arranjados em tandem com três diferentes separações de centro a centro. Os resultados reforçaram a teoria apresentada no capítulo 2, onde apresentamos o conceito de que, em escoamentos com baixo número de Mach $(M<0,3)$, o ruído radiado é diretamente proporcional à flutuação das forças atuantes nas superfícies submersas. Adicionalmente, verificamos que, nas configurações simuladas, o ruído em campo afastado foi dominado pela contribuição do cilindro mais à jusante. 
Na simulação apresentada no capítulo 5 constatamos que a presença da superfície planar reflexiva distante $6,25 d$ do centro do cilindro, possui influência apenas no ruído em campo afastado, aumentando em média $3 \mathrm{~dB} / \mathrm{Hz}$ a curva de densidade espectral de ruído na faixa de frequências analisada. Não houve alteração na frequência dos picos ou o surgimento de novos tons no espectro do ruído em campo afastado. O algoritmo de superfície reflexiva virtual, implementado no software PowerACOUSTICS, apresentou resultados condizentes com os obtidos na simulação do caso Semi-anecóico de forma que, para os casos onde não há interferência entre o escoamento da superfície planar e o escoamento ao redor do cilindro, o método pode ser utilizado no lugar de considerar fisicamente a superfície reflexiva na solução do escoamento.

A análise do histórico temporal das flutuações de pressão com filtro passa-banda aplicado nas frequências de interesse e a decomposição do escoamento em modos dinâmicos destacaram as estruturas coerentes mais energéticas presentes no escoamento nas frequências de interesse. Verificamos que esta análise pode ser importante na solução de problemas, auxiliando o usuário a identificar regiões com oportunidade de melhoria para mitigar tonais e conceber geometrias otimizadas ainda nas fazes iniciais do projeto.

Com base no que foi apresentado, o presente trabalho forneceu uma análise do ruído radiado por barras prismáticas sujeitas ao escoamento transversal através do método híbrido de aeroacústica computacional utilizando o método de Lattice-Boltzmann que mostrou-se eficaz em aplicações de aerodinâmica e aeroacústica.

Entendemos que todos os objetivos enunciados foram cumpridos e trabalhos futuros podem concentrar-se em analisar o ruído radiado por três ou mais cilindros em tandem. Ou até estudar a assinatura sonora gerada por cilindros em diferentes arranjos como os dispostos lado a lado (side by side) ou em quincôncio (staggered). Outra contribuição importante é a investigação da influência da superfície reflexiva sobre o ruído radiado pelo cilindro em casos com separação $G<2 d$.

Adicionalmente, pode-se analisar a sensibilidade geométrica na atenuação do ruído aerodinâmico radiado por barras prismáticas comuns nas áreas automobilística e aeronáutica (ex: elipse, perfis NACA, etc.) reduzindo a necessidade do uso de dispositivos adicionais que suprimem ou atenuam a amplitude de flutuação das forças periódicas que as superfícies exercem sobre o fluido (por exemplo, dispositivos atenuadores como boundary layer tripping). 


\section{REFERÊNCIAS BIBLIOGRÁFICAS}

AIDUN, C. K.; CLAUSEN, J. R. Lattice-Boltzmann method for complex flows. Annual review of fluid mechanics, n. 42, p. 439-472, 2010.

ANSELMET, F.; MATTEI, P. Acoustics, aeroacoustics and vibrations. 1. ed. London: John Wiley \& Sons, Inc., 2016. 511 p. E-book.

ANSYS. [S. l.], 2018. Disponível em: http://www.ansys-blog.com/wpcontent/uploads/2016/01/10x-Multiplier-chart-1-1024x 770.jpg. Acesso em: 17 jun. 2018.

ASSI, G. R. S. et al. On the wake-induced vibration of tandem circular cylinders: the vortex interaction excitation mechanism. Journal of fluid dynamics, v. 661, p. 365-401, 2010.

ASSI, G. R. S. et al. The role of wake stiffness on the wake-induced vibration of the downstream cylinder of a tandem pair. Journal of fluid dynamics, v. 718, p. 210-245, 2013.

AVALLONE, F. et al. Noise reduction mechanisms of sawtooth and combed-sawtooth trailing-edge serrations. Journal of fluid dynamics, v. 848, p. 560-591, 2018.

BEARMAN, P. W.; ZDRAVKOVICH, M. M. Flow around a circular cylinder near a plane boundary. Journal of fluid mechanics, Great Britain, v. 89, part 1, p. 33-47, 1978.

BHATNAGAR, P. L.; GROSS, E. P.; KROOK, M. A model for collision process in gases: I. small amplitude process in charged and neutral one-component systems. Physical review, v. 94, n. 3, p. 511-525, 1 maio 1954.

BLAKE, W. K. Mechanics of flow-induced sound and vibration: general concepts and elementary sources. United States of America: Academic Press, Inc., 1986. 425 p. v. 1.

BLEVINS, R. D. Flow-induced vibration. 2. ed. Malabar, Florida: Krieger Publishing Company, 2001. 477 p.

BRENTNER, K. S. An efficient and robust method for predicting helicopter rotor high-speed impulsive noise. Journal of sound and vibration, v. 203, n. 1, p. 87-100, 1997.

BRENTNER, K. S.; FARASSAT, F. Modeling aerodynamically generated sound of helicopter rotors. Progress in aerospace sciences, v. 39, n. 2-3, p. 83-120, 2003.

BRÈS, G.; PÉROT, F.; FREED, D. A Ffowcs Williams-Hawkings solver for Lattice-Boltzmann based computational aeroacoustics. In: AIAA/CEAS AEROACOUSTICS CONFERENCE, 16, 2010, Stockholm, Sweden. Proceedings... American institute of aeronautics and astronautics, 2010. 15 p.

BRÈS, G.; WESSELS, M.; NOELTING, S. Tandem cylinder noise predictions using latticeBoltzmann and Ffowcs Williams-Hawkings methods. In: AIAA/CEAS AEROACOUSTICS CONFERENCE, 16, 2010, Stockholm, Sweden. Proceedings... American institute of aeronautics and astronautics, 2010.12 p. 
CASALINO, D. et al. Lattice-Boltzmann aeroacoustic analysis of the LAGOON landing-gear configuration. AIAA Journal, 2014.

CASALINO, D.; HAZIR, A.; MANN, A. Turbofan broadband noise prediction using the lattice-Boltzmann method. AIAA Journal, 2017.

CASALINO, D.; JACOB, M. Prediction of aerodynamic sound from circular rods via spanwise statistical modelling. Journal of sound and vibration, [S.1.], v. 262, n. 4, p. 815844, 8 may. 2003.

CHEN, S.; DOOLEN, G. D. Lattice-Boltzmann method for fluid flows. Annual review of fluid mechanics, n. 30, p. 329-364, 1998.

CHEN, H. et al. Extended Boltzmann kinetic equation for turbulent flows. Science, Washington, DC, USA, v. 301, n. 5633, p. 633-636, 2003.

CHEVROLET. [S. l.], 2020. Disponível em: https://accessories.chevrolet.com/product/roofrack-cross-rail-package-in-black-(for-vehicles-with-sun-roof)84721134 year $=2020 \&$ make $=$ Chevrolet $\&$ model=Blazer. Acesso em: 21 set. 2020 .

CHOPARD, B.; DROZ, M. Cellular automata modeling of physical systems. 1. ed. Cambridge, United Kingdom: Cambridge University Press, 1998. 341 p.

COLONIUS, T.; LELE, S. K. Computational aeroacoustics: progress on nonlinear problems of sound generation. Progress in Aerospace Science, Pasadena, CA, USA, ano 2004, n. 40, p. 345-416, 2004.

CROCKER, M. J. Handbook of noise and vibration control. 1. ed. New Jersey: John Wiley \& Sons, 2007. 1569 p.

CURLE, N. The influence of solid boundaries upon aerodynamic sound. Proceedings of the Royal Society, London, A231, n. 1187, p. 505-514, 20 sep. 1955.

D`HUMIÈRES, D.; LALLEMAND, P. Numerical simulation of hydrodynamics with lattice gas automata in two dimensions. Complex systems, Champaign, IL, v. 1, n. 4, p. 599-632, 1987.

DAWSON, S. T. M. et al. Characterizing and correcting for the effect of sensor noise in the dynamic mode decomposition. Experiments in fluids, v. 57, n. 42, 2016.

DI FRANCESCANTONIO, P. A new boundary integral formulation for the prediction of sound radiation. Journal of Sound and Vibration, [S.1.], v. 202, n. 4, p. 491-509, 15 may. 1997.

EXA CORPORATION. PowerACOUSTICS user guide's. Release 4.1. Burlington: EXA Corporation, 2016.

EXA CORPORATION. PowerCASE ${ }^{\circledR}$ user guide's. Release 5.4. Burlington: EXA Corporation, 2017a. 
EXA CORPORATION. PowerFLOW best practices guide: ExaBP2.0. Burlington: EXA Corporation, 2013.

EXA CORPORATION. PowerFLOW user guide's. Release 5.4. Burlington: EXA Corporation, 2017b.

FAHY, F.; WALKER, J. Advanced applications in acoustics, noise \& vibration. London: Spon Press, 2004. 640 p.

FARASSAT, F.; SUCCI, G. P. A review of propeller discrete frequency noise prediction technology with emphasis on two current methods for time domain calculations. Journal of sound and vibration, v. 71, n. 3, p. 399-419, 1980.

FARASSAT, F. Derivation of formulations 1 and 1 A of Farassat. Hampton, VA, USA: NASA center for aerospace information (CASI), 2007. 25 p.

FARASSAT, F.; CASPER, J. Broadband noise prediction when turbulence simulation is available: Derivation of formulation $2 \mathrm{~B}$ and its statistical analysis. Journal of sound and vibration, v. 331, n. 10, p. 2203-2208, 2012.

FFOWCS WILLIAMS, J. E.; HAWKINGS, D. L. Sound generation by turbulence and surfaces in arbitrary motion. Proceedings of the Royal Society, London, A264, n. 1151, p. 321-342, 08 may 1969.

FREDERICH, O.; LUCHTENBURG, D. M. Modal analysis of complex turbulent flow. In: INTERNATIONAL SYMPOSIUM ON TURBULENCE AND SHEAR FLOW PHENOMENA, 7., 2011, Ottawa. Proceedings... Ottawa: Technische Universität Darmstadt, 2011. p. 6.

FRISCH, U. et al. Lattice gas hydrodynamics in two and three dimensions. Complex systems, Champaign, IL, ano 1987, v. 1, n. 4, p. 649-707, 1987.

FRISCH, U.; HASSLACHER, B.; POMEAU, Y. Lattice-gas automata for the Navier-Stokes equation. Physical review letters, v. 56, n. 14, p. 1505-1508, 1986.

GLEGG, Stewart; DEVENPORT, William. Acoustics of low mach number flows: Fundamentals, analysis, and measurements. United States: Elsevier, 2017. 537 p.

GRASS, A. J. et al. The influence of boundary layer velocity gradients and bed proximity on vortex shedding from free spanning pipelines. Journal of energy resources technology, $v$. 106, p. 70-78, 1984.

GUO, Z.; SHU, C. Advances in computational fluid dynamics: lattice Boltzmann method and its applications in engineering. Singapore: World Scientific Publishing Co. Pte. Ltd., 2013. 404 p. v. 3.

HARDY, J.; POMEAU, Y.; PAZZIS, O. Time evolution of a two-dimensional classical lattice system. Physical review letters, v. 31, n. 5, p. 276-279, 1973. 
HIGUERA, F. J.; JIMÉNEZ, J. Boltzmann approach to lattice gas simulations. Europhysics letters, v. 9, n. 7, p. 663-668, 1989.

HOWARD, D. M.; ANGUS, J. A. S. Acoustics and psychoacoustics. 5. ed. New York: Routledge, 2017. 510 p.

HOWE, M. S. Theory of vortex sound. United Kingdom: Cambridge University Press, 2003. $216 \mathrm{p}$.

IGARASHI, T. Characteristics of the flow around two circular cylinders arranged in tandem: 1st Report. Bulletin of the JSME, v. 24, n. 188, p. 323-331, 1981.

INTERNATIONAL ORGANIZATION FOR STANDARDIZATION. ISO1996-2:2007: Acoustics - description, measurement and assessment of environmental noise - Part 2: Determination of environmental noise levels. 2. ed. Switzerland: ISO, 2007. 40 p.

KARBON, K. J.; DIETSCHI, D. Computational analysis and design to minimize vehicle roof rack wind noise. In: SAE World congress, 2005, Detroit, MI, USA. Proceedings... SAE International, 2005. 8 p.

KATO, C. et al. Numerical prediction of aerodynamic noise radiated from low mach number turbulence wake. Proceedings of 31st Aerospace Sciences Meeting \& Exhibit; 1993 Jan 11-14; Reno, Nevada: Paper AIAA 1993-0145, 1993.

KINSLER, L. E. et al. Fundamentals of acoustics. 4. ed. United States of America: John Wiley \& Sons, 2000. 551 p.

KOTAPATI, R. et al. The lattice-Boltzmann-VLES method for automotive fluid dynamics simulation, a review. In: SYMPOSIUM ON INTERNATIONAL AUTOMOTIVE TECHNOLOGY, 2009, Pune, India. Proceedings... The automotive research association of India, 2009. p. 13.

KRÜGER, T. et al. The lattice Boltzmann method: principles and practice. Switzerland: Springer, 2017. 694 p.

KUTZ, J. N. et al. Dynamic mode decomposition: data-driven modeling of complex systems. United States of America: Society for industrial and applied mathematics, 2016. 234 p.

LARSSON, Johan. Computational aero acoustics for vehicle applications. 2002. 97 p. Thesis (Licentiate in Engineering) - Chalmers University of Technology, Sweden, 2002.

LI, Y. et al. Exploring an LBM-VLES based CFD approach for predictions of aero-thermal flows in generic turbo-machinery devices. In: $51^{\text {st }}$ AIAA/SAE/ASEE Joint propulsion conference, 2015, Orlando, FL, USA. Proceedings... American institute of aeronautics and astronautics, 2015. p. 15.

LIGHTHILL, M. J. On sound generated aerodynamically: I. general theory. Proceedings of the royal society, London, A211, n. 1107, p. 564-587, 20 mar. 1952. 
LIGHTHILL, M. J. On sound generated aerodynamically: II. Turbulence as a source of sound. Proceedings of the royal society, London, A222, n. 1148, p. 1-32, 23 feb 1954.

LJUNGKRONA, L.; NORBERG, C.; SUNDÉN, B. Free-stream turbulence and tube spacing effects on surface pressure fluctuations for two tubes in an in-line arrangement. Journal of fluids and structures, v. 5, n. 6, p. 701-727, 1991.

MASSAROTTI, M. R. Aeroacoustics of Automotive Roof Crossbars. 2017. 127 p. Dissertação (Mestrado em Engenharia Mecânica) - Faculdade de Engenharia Mecânica, Universidade Estadual de Campinas, Campinas, 2017.

MALISKA, C. R. Transferência de calor e mecânica dos fluidos computacional. 2. ed. Rio de Janeiro: LTC, 2014. 453 p.

MARIÉ, S.; RICOT, D.; SAGAUT, P. Comparison between lattice Boltzmann method and Navier-Stokes high order schemes for computational aeroacoustics. Journal of computational physics, n. 228, p. 1056-1070, 2008

MCNAMARA, G. R.; ZANETTI, G. Use of the Boltzmann equation to simulate lattice-gas automata. Physical Review Letters, v. 61, n. 20, p. 2332-2335, 1988.

NIE, X.; SHAN, X.; CHEN, H. Lattice-Boltzmann / finite-difference hybrid simulation of transonic flow. In: $47^{\mathrm{TH}}$ AIAA AEROSPACE SCIENCES MEETING INCLUDING THE NEW HORIZONS FORUM AND AEROSPACE EXPOSITION, 2009, Orlando.

Proceedings... Orlando, FL, USA: AIAA, 2009. p. 8.

NORBERG, C. LDV-measurements in the near wake of a circular cylinder. In: ADVANCES IN UNDERSTANDING OF BLUFF BODY WAKES AND VORTEX-INDUCED VIBRATION, 1998, Washington, DC, USA. Proceedings... Journal of fluids and structures, 1998. p. 12.

NORBERG, C. Fluctuating lift on a circular cylinder: review and new measurements. Journal of fluids and structures, v. 17, n. 1, p. 57-96, 2003.

NORTON, M. P.; KARCZUB, D. G. Fundamentals of noise and vibration analysis for engineers. 2. ed. Cambridge: Cambridge University Press, 2003. 631 p.

OETTLE, N.; SIMS-WILLIAMS, D. Automotive aeroacoustics: an overview. Journal of automobile engineering, v. 231, n. 9, p. 1177-1189, 2017.

ORSELLI, R. M. Investigação numérica de escoamento e ruído gerado em corpos rombudos prismáticos. 2012, 191 p. Tese (Doutorado em Engenharia Mecânica) Universidade de São Paulo, São Paulo, 2012.

PROJECAR. [S. l.], 2020. Disponível em: https://http2.mlstatic.com/bagageiro-maleiro-deteto-gradeado-pequeno-preto-D_Q_NP_699551-MLB27695976316_072018-F.webp. Acesso em: 21 jul. 2020.

QIAN, Y. H.; D‘HUMIÈRES, D.; LALLEMAND, P. Lattice BGK models for Navie-Stokes equation. Europhysics letters, v. 17, n. 6, p. 479-484, 1992. 
RAVEN, P. W. J. Full-scale dynamic testing of submarine pipeline spans. In: ANNUAL OFFSHORE TECHNOLOGY CONFERENCE, 17., 1985, Houston, TX. Proceedings... Houston: Offshore Technology Conference, 1985. p.10.

REIDER, M. B.; STERLING, J. D. Accuracy of discrete-velocity BGK models for the simulation of the incompressible Navier-Stokes equations. Computer and Fluids, Great Britain, v. 24, n. 4, p. 459-467, 1995.

SATTI, R. et al. Simulation of flow over a 3-element airfoil using a lattice-Boltzmann method. In: $46^{\text {th }}$ AIAA AEROSPACE SCIENCES MEETING AND EXHIBIT, 2008, Reno, NV, USA. Proceedings... American institute of aeronautics and astronautics, 2008. p. 15.

SCHMID, P. J.; SESTERHENN, J. Dynamic mode decomposition of numerical and experimental data. In: ANNUAL MEETING OF THE APS DIVISION OF FLUID DYNAMICS, 61st., 2008, San Antonio, Texas. Proceedings... San Antonio: American Physical Society, 2008. p. 208.

SCHIMID, P. J. Dynamic mode decomposition of numerical and experimental data. Journal of fluid mechanics, v. 656, p. 5-28, 2010.

SCHEWE, G. On the force fluctuations acting on a circular cylinder in crossflow from subcritical up to transcritical Reynolds numbers. Journal of fluid mechanics, ano 1985, v. 133, p. 265-285, 1983.

SHAN, X.; YUAN, X.; CHEN, H. Kinetic theory representation of hydrodynamics: a way beyond the Navier-Stokes equation. Journal of fluid mechanics, United Kingdom, v. 550, p. 413-441, 2006.

SIROVICH, L. Turbulence and the dynamics of coherent structures part II: symmetries and transformations. Quarterly of applied mathematics, v. 45, n. 3, p. 573 - 852, 1987.

SUCCI, S. The lattice Boltzmann equation for fluid dynamics and beyond. Oxford: Clarendon Press, 2001. 288 p.

SUCCI, S. The lattice-Boltzmann equation: for complex states of flowing matter. 1. ed. Oxford, United Kingdom: Oxford University Press, 2018. 761 p.

VERSTEEG, H. K.; MALALASEKERA, W. An introduction to computational fluid dynamics: the finite volume method. 2. ed. England: Pearson Education, 2007. 503 p.

WAGNER, C. A.; HÜTTL, T.; SAGAUT, P. (ed.). Large-eddy simulation for acoustics. Cambridge, UK: Cambridge University Press, 2007. 470 p.

WANG, T. Dynamic mode decomposition on LES result of cylinder cascade wake. In: INTERNATIONAL CONFERENCE OF FLUID FLOW, HEAT AND MASS TRANSFER, 4., 2017, Toronto, Canada. Proceedings... Ontario: Avestia Publishing, 2017. 10 p.

WANG, X. Vehicle noise and vibration refinement. 1. ed. Cambridge: Woodhead Publishing Limited, 2010. 434 p. 
WHITE, F. M. Viscous fluid flow. 2. ed. United States of America: McGraw-Hill, 1991.

WOLF-GLADROW, D. A. Lattice-gas cellular automata and lattice Boltzmann models: an introduction. 1. ed. Germany: Springer-Verlag Berlin Heidelberg, 2000. 314 p.

ZDRAVKOVICH, M. M. Flow around circular cylinders: fundamentals. United States of America: Oxford University Press, 1997. 694 p. v. 1.

ZIENKIEWICZ, O. C.; TAYLOR, R. L.; NITHIARASU, P. The finite element method for fluid dynamics. 7. ed. USA: Elsevier, 2014. 544 p. 


\section{APÊNDICE A - CAMPO FLUIDODINÂMICO: CASO ANECÓICO}

Figura 82 - Contorno de magnitude de velocidade do maior pico: Caso Anecóico - Instantes 1 a 9 ilustrados na Figura 20

\begin{tabular}{|lllllll|}
\hline \multicolumn{2}{|l|}{ Velocidade total $[\mathrm{m} / \mathrm{s}]$} & & & & & \\
\hline & 5 & 10 & 15 & 20 & 25 & 30 \\
\hline
\end{tabular}

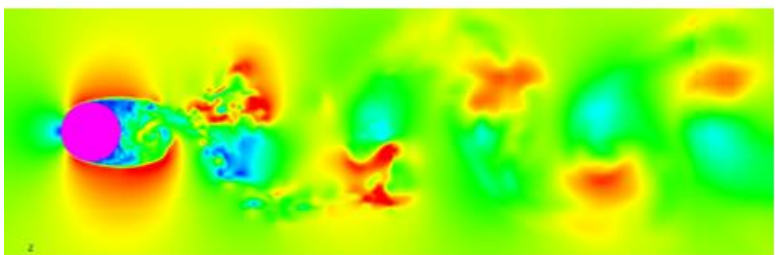

(1)

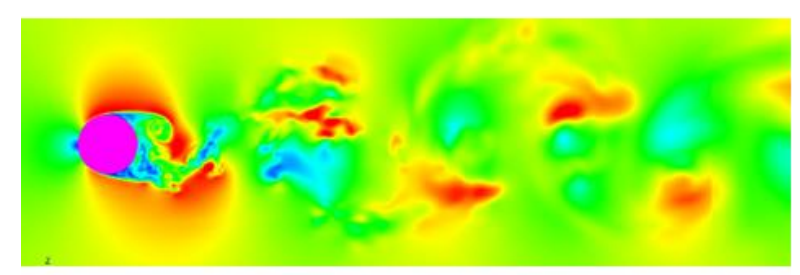

(3)

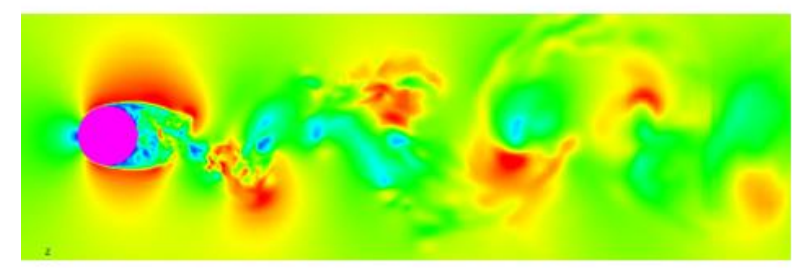

(5)

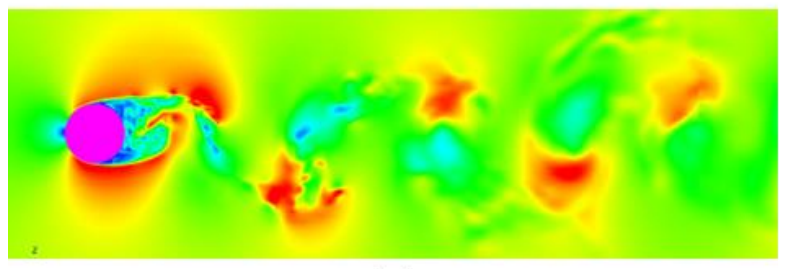

(7)

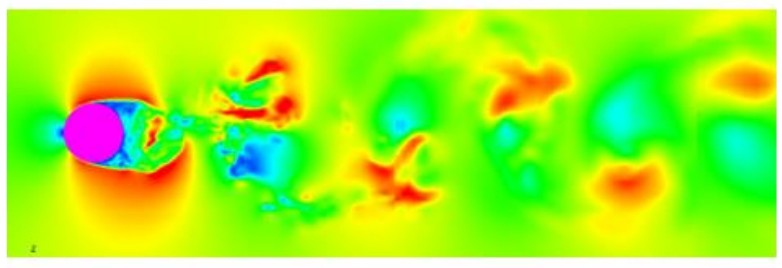

(2)

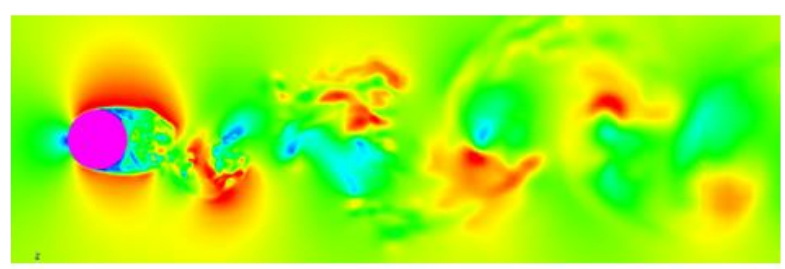

(4)

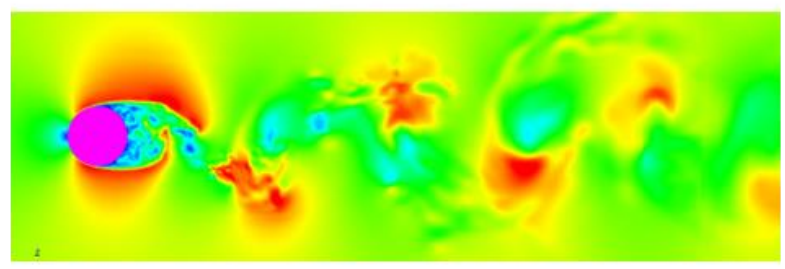

(6)

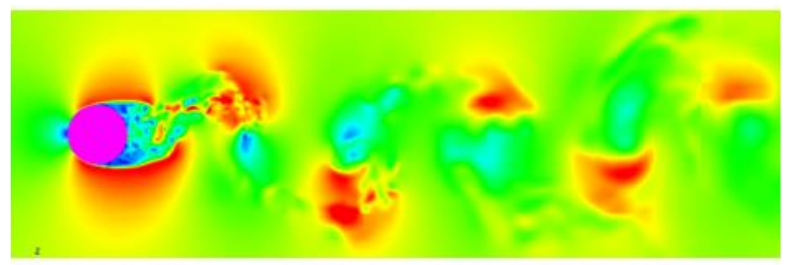

(8)

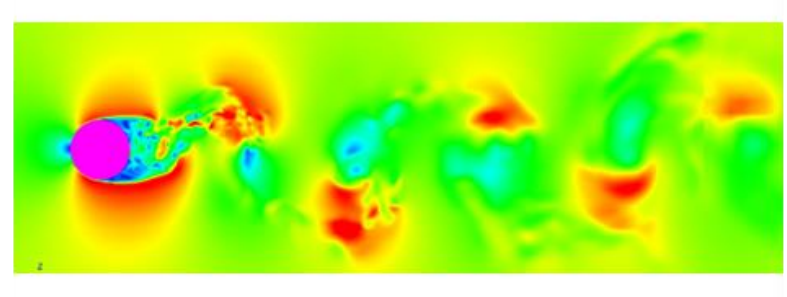

(9) 
Figura 83 - Contorno de magnitude de velocidade do menor pico: Caso Anecóico - Instantes 1 a 9 ilustrados na Figura 20

\begin{tabular}{|lllllll|}
\hline \multicolumn{2}{l}{ Velocidade total $[\mathrm{m} / \mathrm{s}]$} & & & & & \\
\hline & 5 & 10 & 15 & 20 & 25 & 30 \\
\hline
\end{tabular}

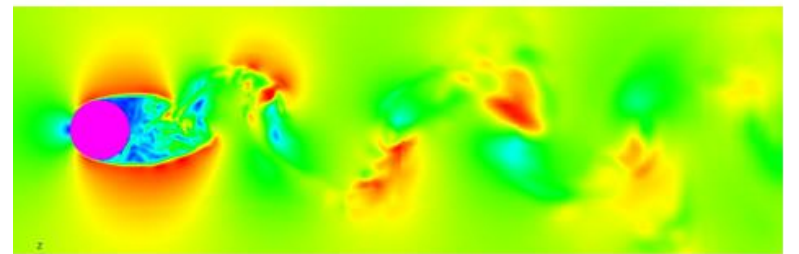

(1)

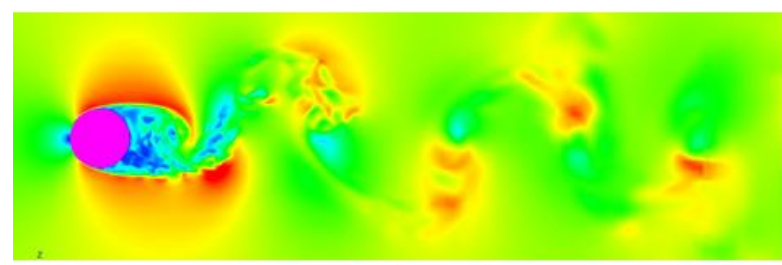

(3)

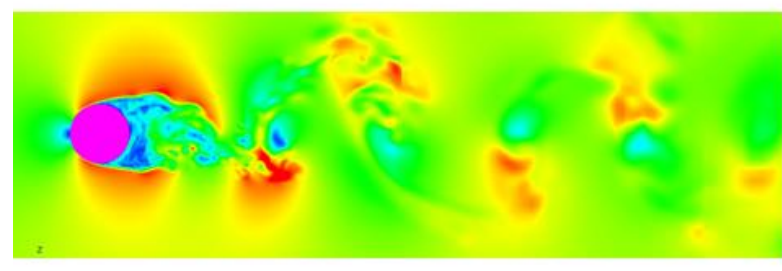

(5)

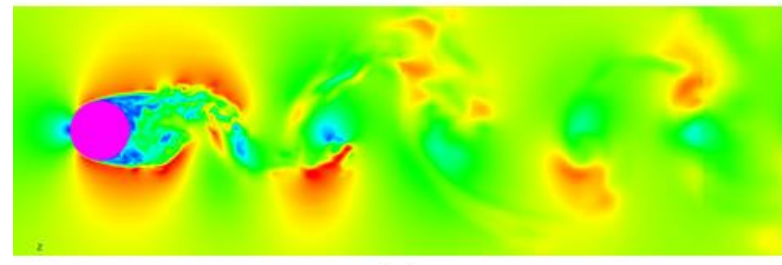

(7)

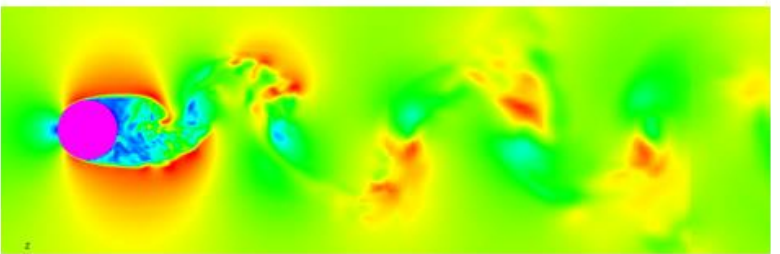

(2)

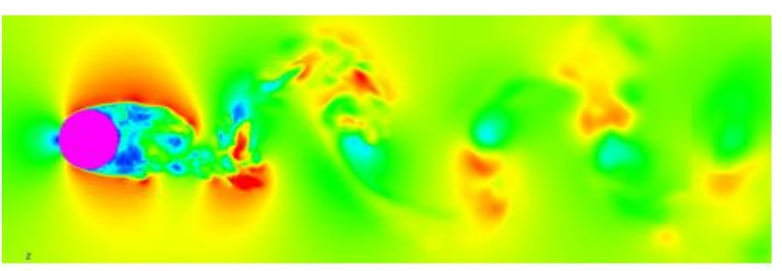

(4)

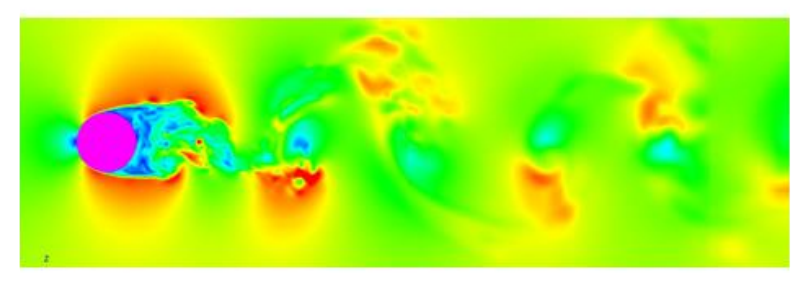

(6)

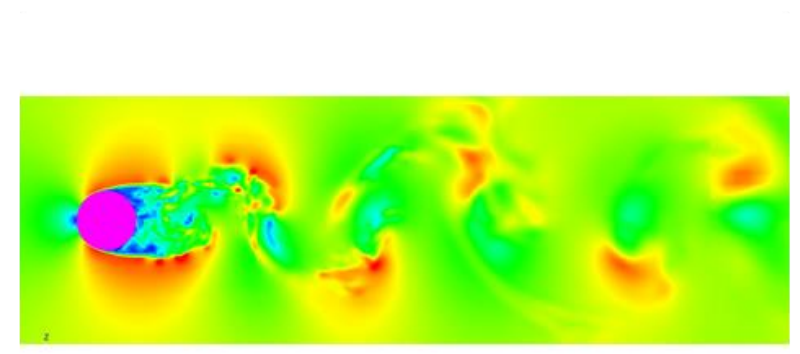

(8)

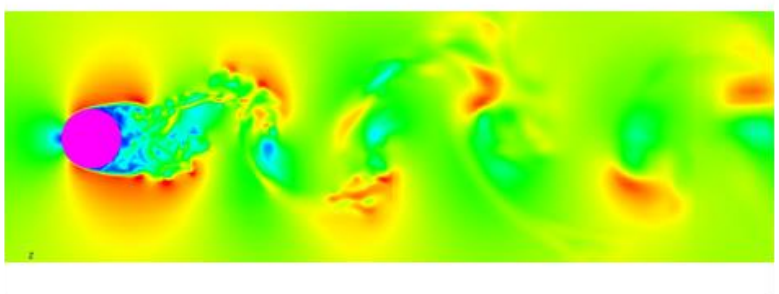

(9) 
Figura 84 - Contorno de vorticidade do maior pico: Caso Anecóico - Instantes 1 a 9 ilustrados na Figura 20

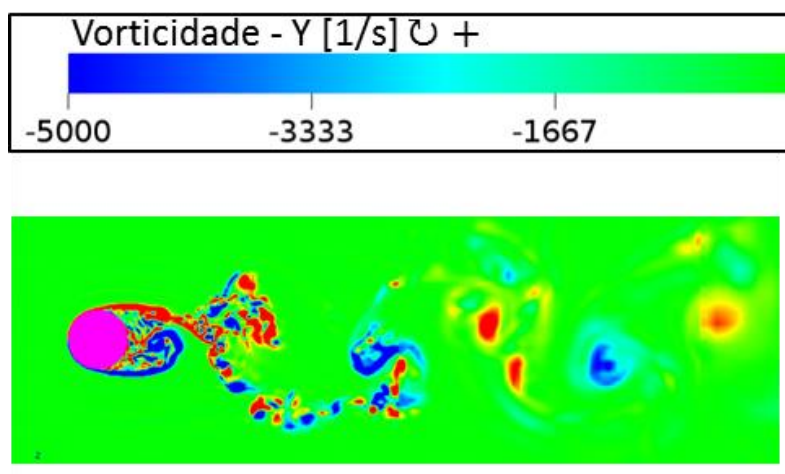

(1)

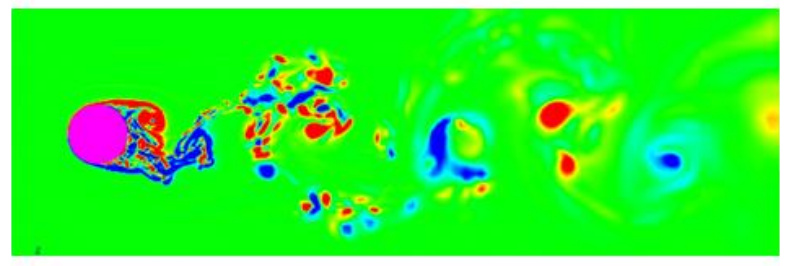

(3)

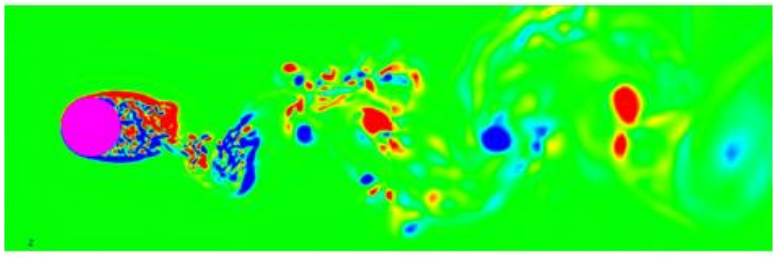

(5)

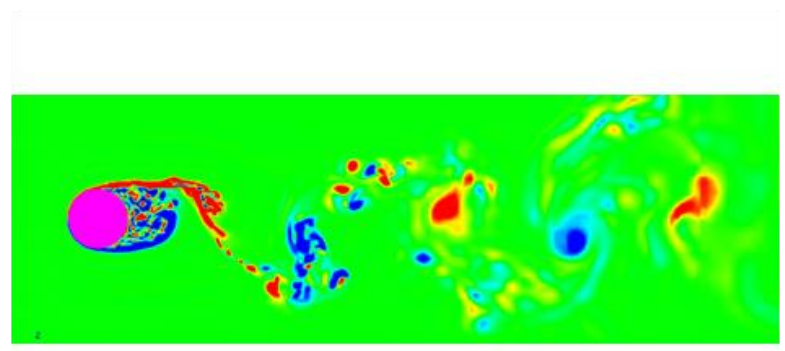

(7)

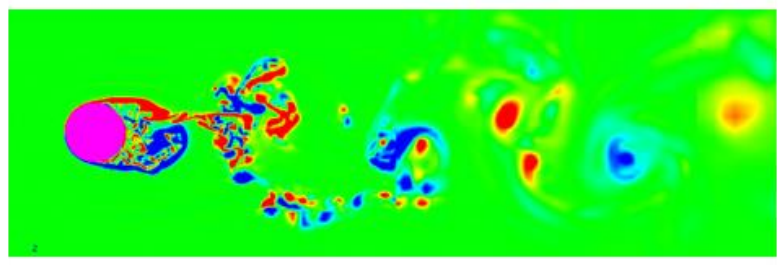

(2)

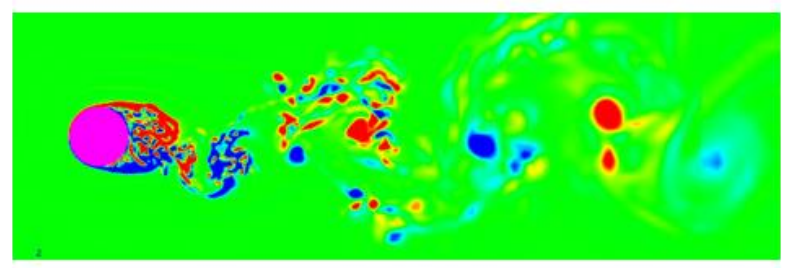

(4)

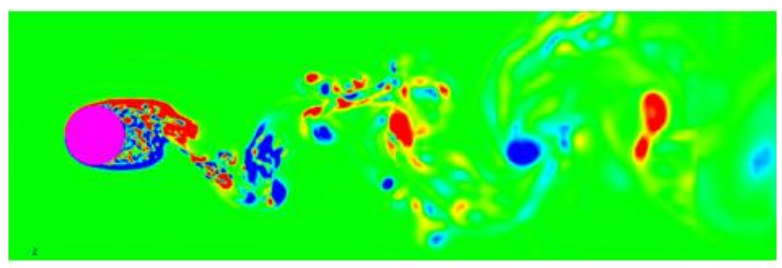

(6)

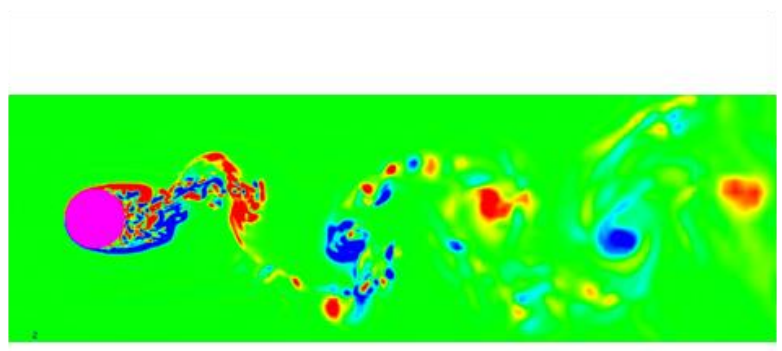

(8)

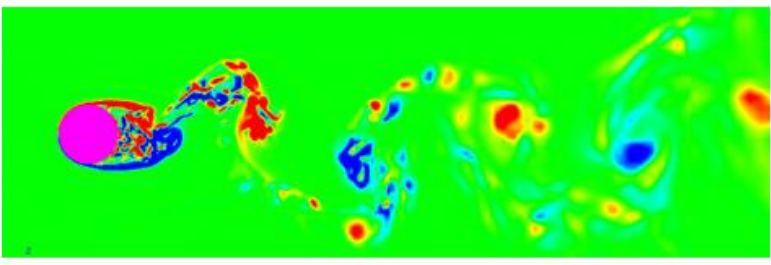

(9) 
Figura 85 - Contorno de vorticidade do menor pico: Caso Anecóico - Instantes 1 a 9 ilustrados na Figura 20

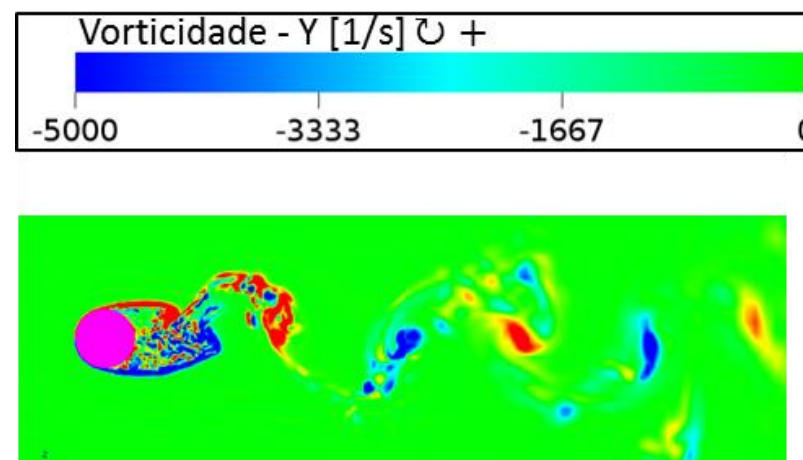

(1)

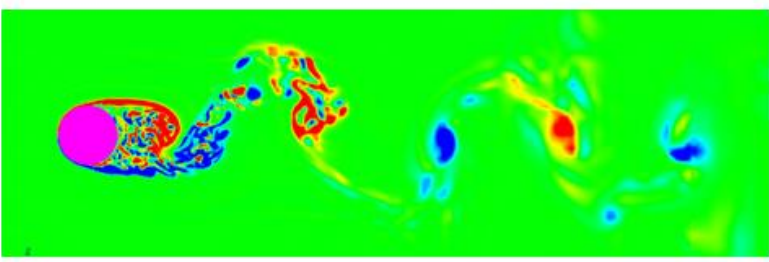

(3)

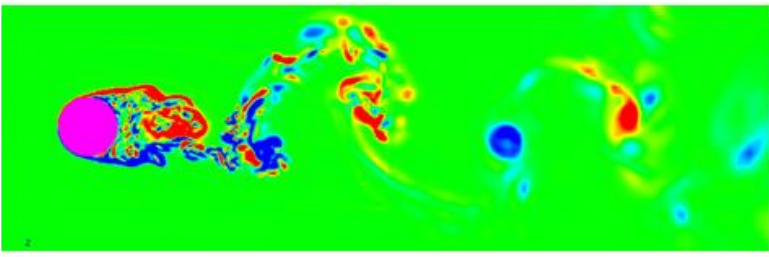

(5)

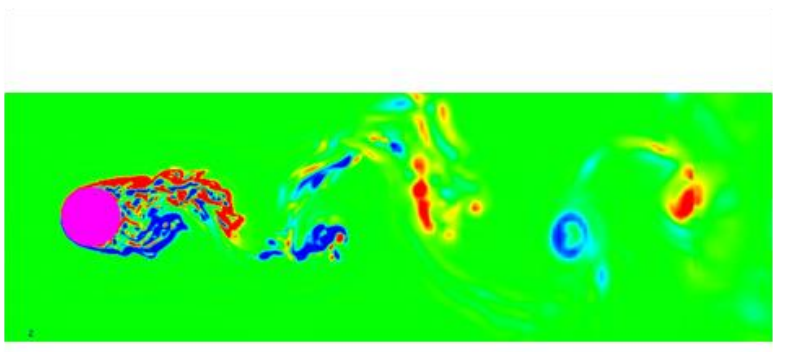

(7)

$0 \quad 1667$

3333 5000

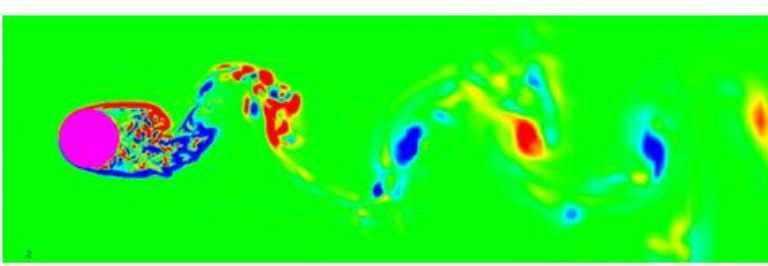

(2)

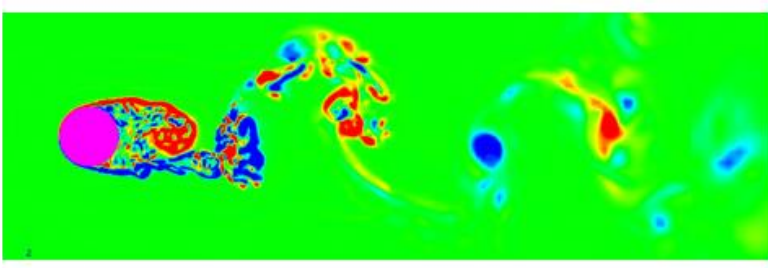

(4)

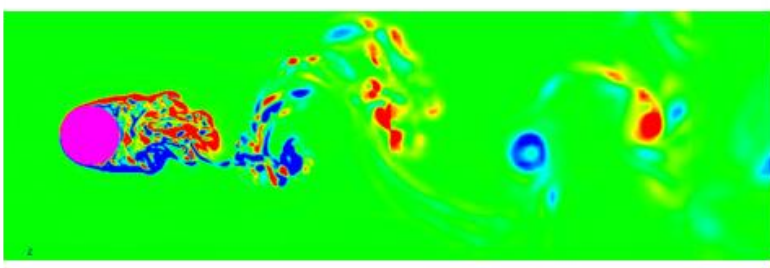

(6)

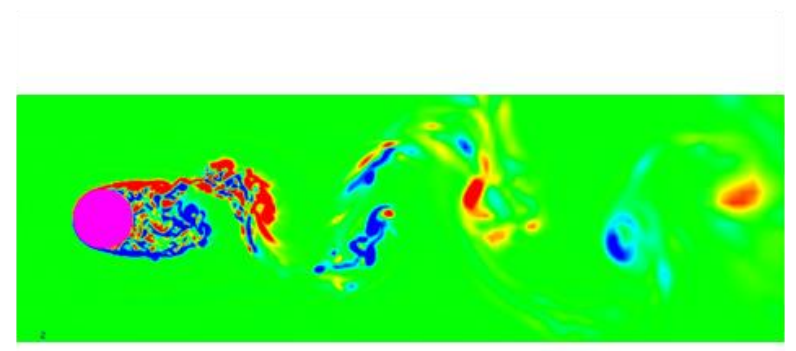

(8)

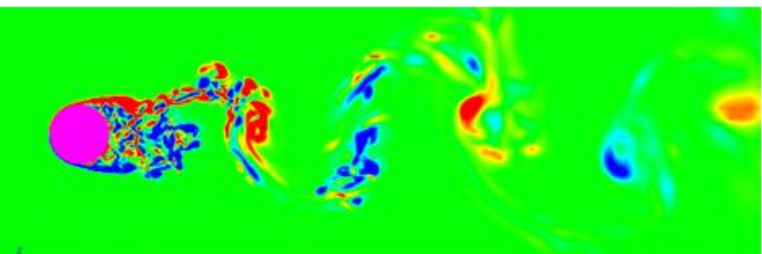

(9) 


\section{APÊNDICE B - CAMPO FLUIDODINÂMICO: CILINDROS EM TANDEM}

Figura 86 - Contorno de magnitude de velocidade do maior pico: caso $L / d=1,0$ - Instantes 1 a 9 ilustrados na

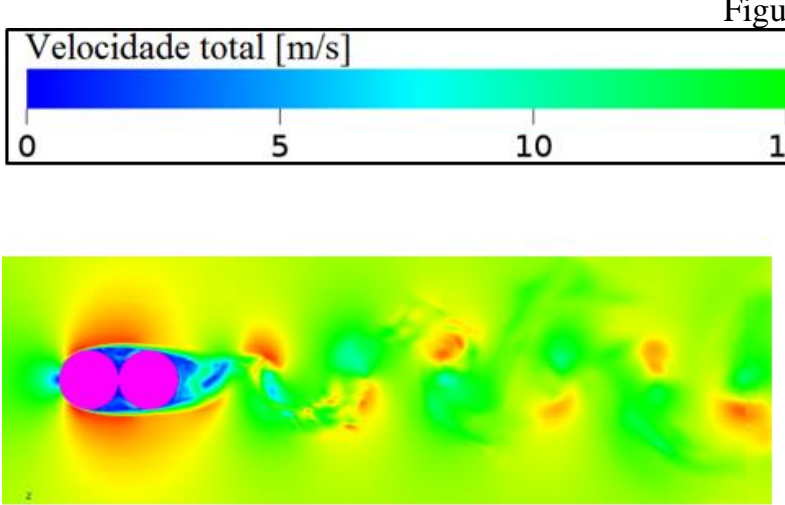

(1)

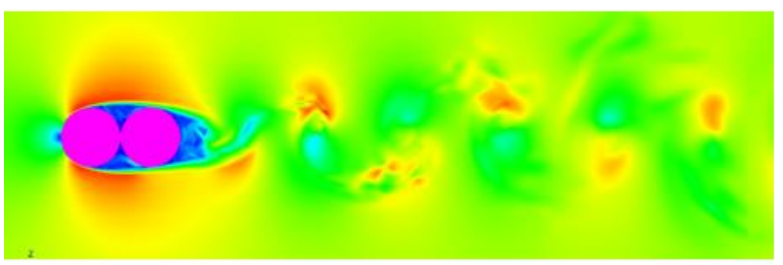

(3)

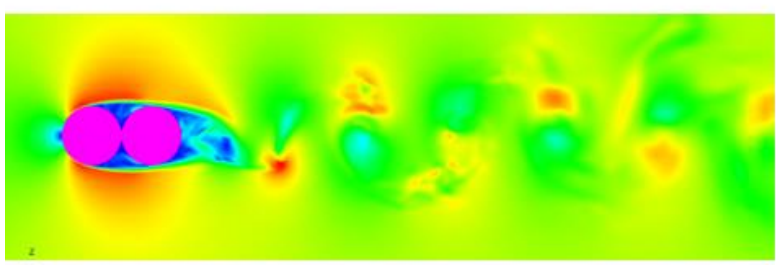

(5)

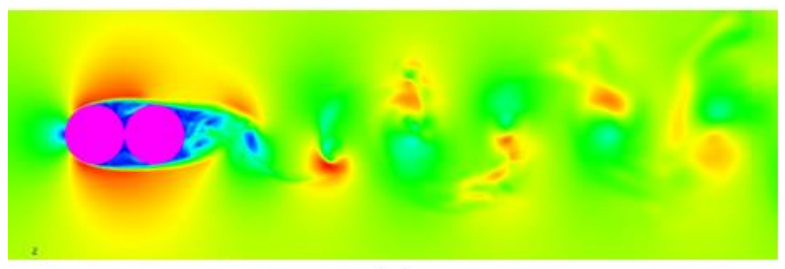

(7)

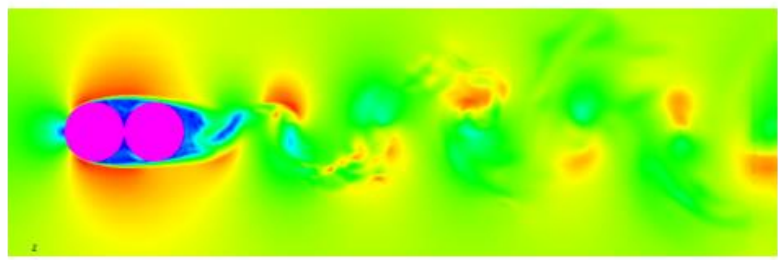

(2)

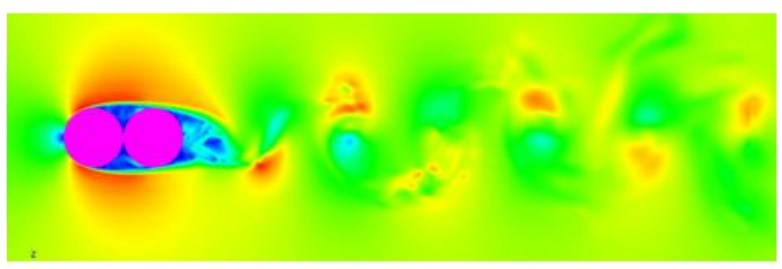

(4)

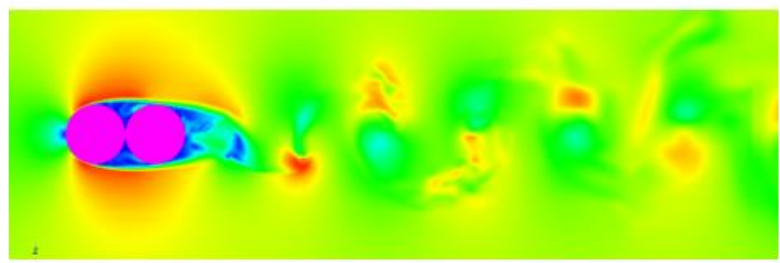

(6)

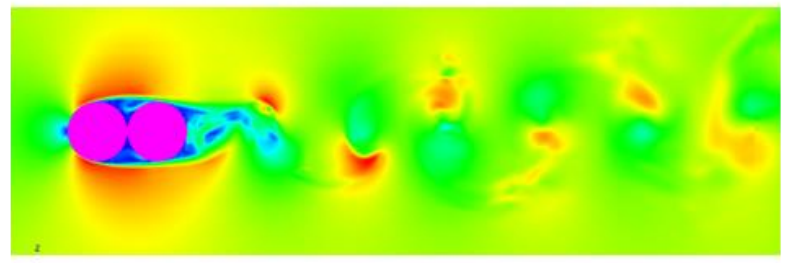

(8)

(9) 
Figura 87 - Contorno de magnitude de velocidade do menor pico: caso $L / d=1,0$ - Instantes 1 a 9 ilustrados na

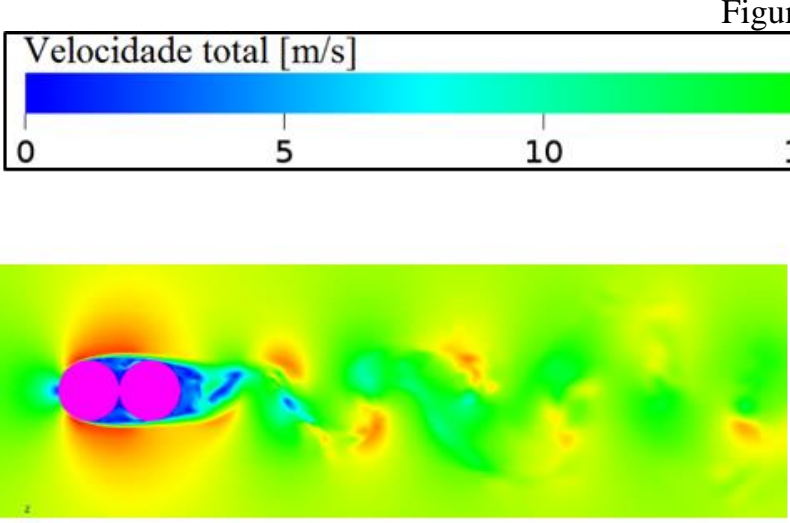

(1)

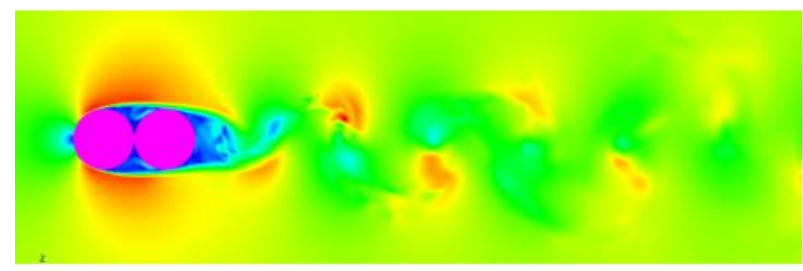

(3)

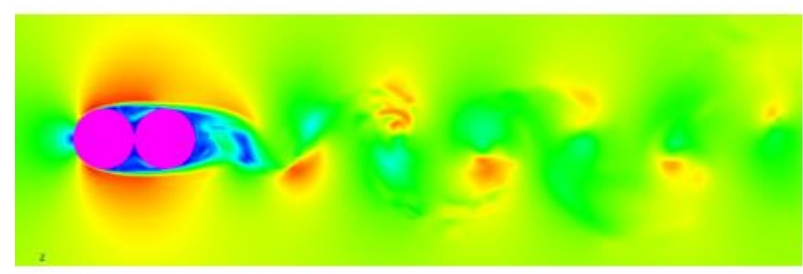

(5)

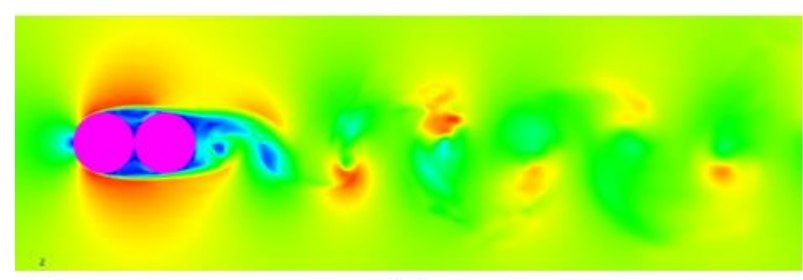

(7)
$15 \quad 20$

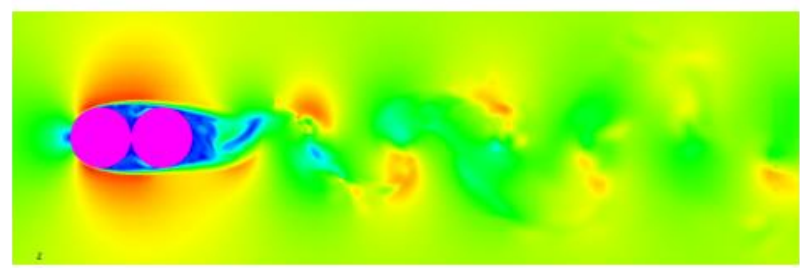

(2)

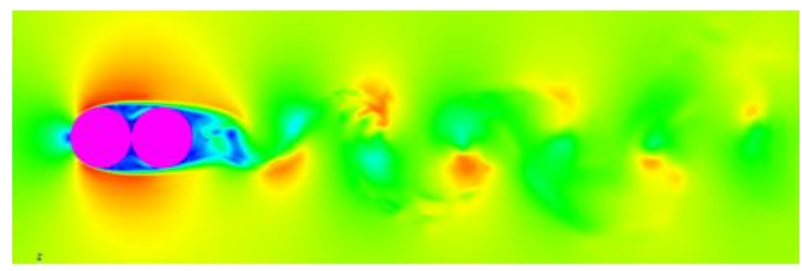

(4)

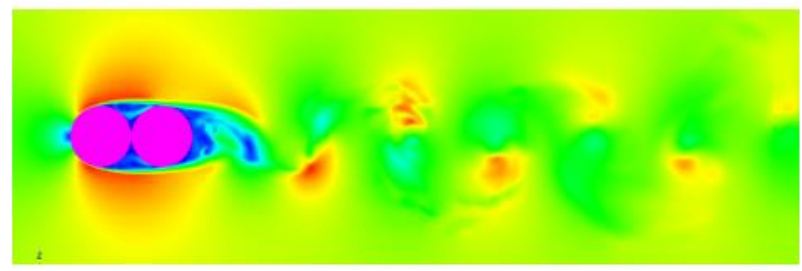

(6)

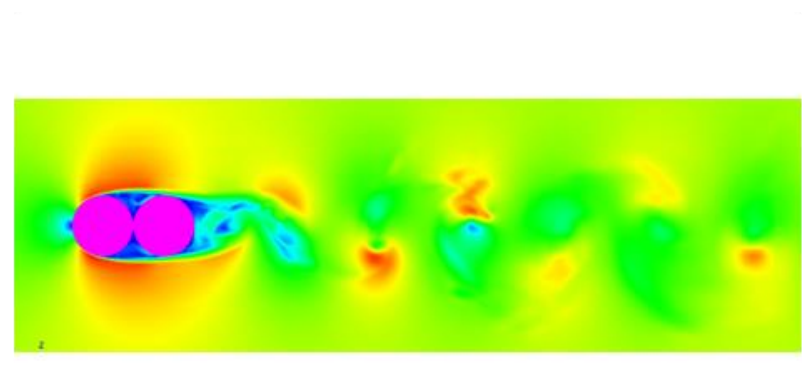

(8)

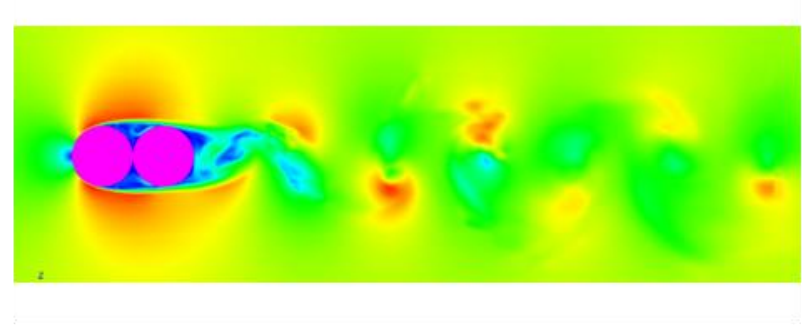

(9) 
Figura 88 - Contorno de vorticidade do maior pico: caso $L / d=1,0$ - Instantes 1 a 9 ilustrados na Figura 20

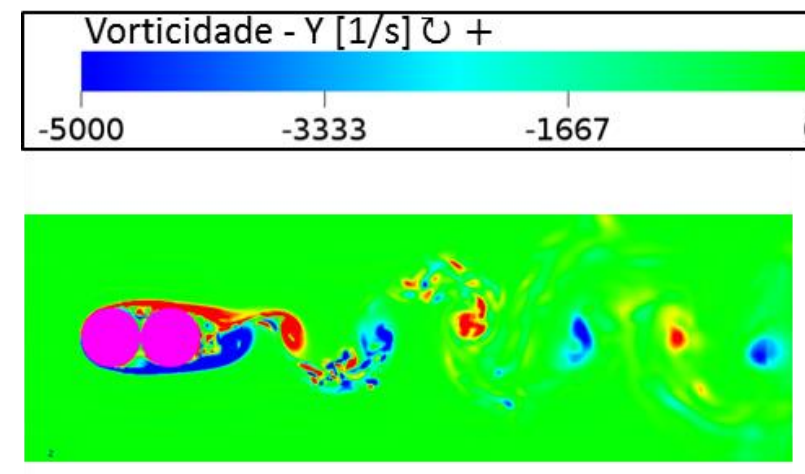

(1)

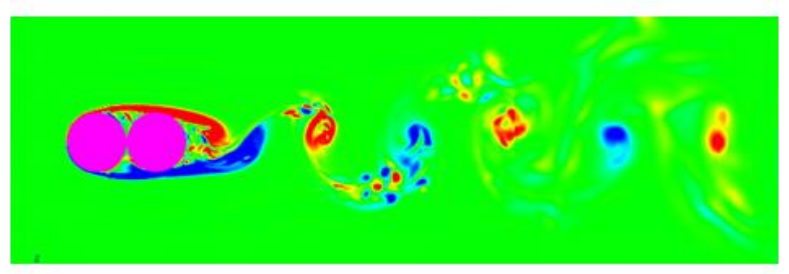

(3)

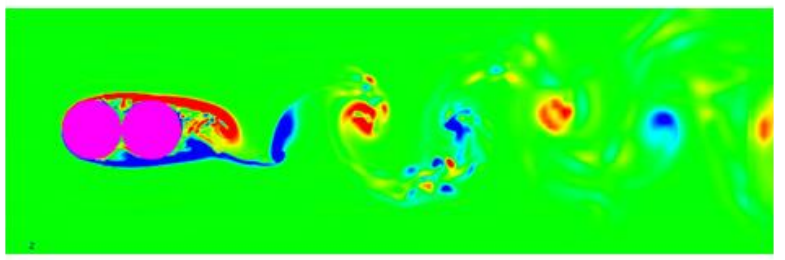

$(5)$

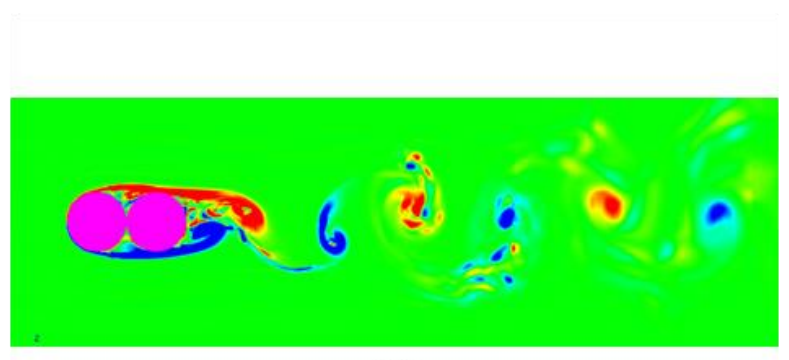

(7)

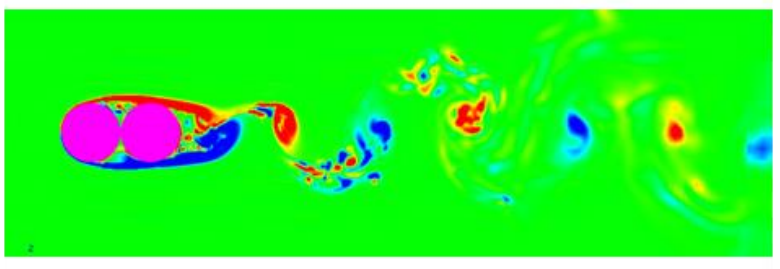

(2)

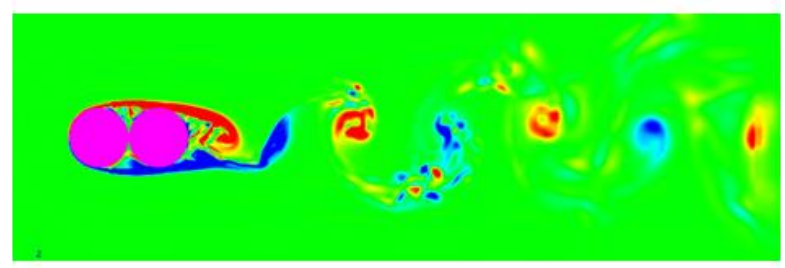

(4)

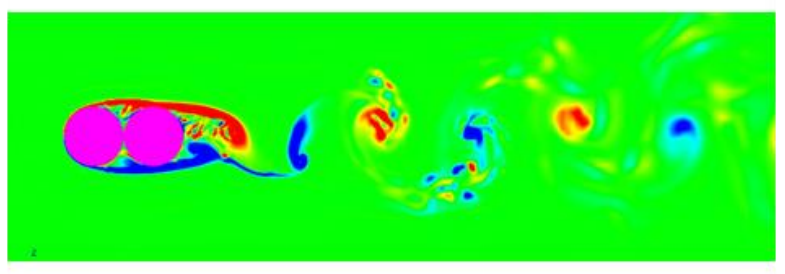

(6)

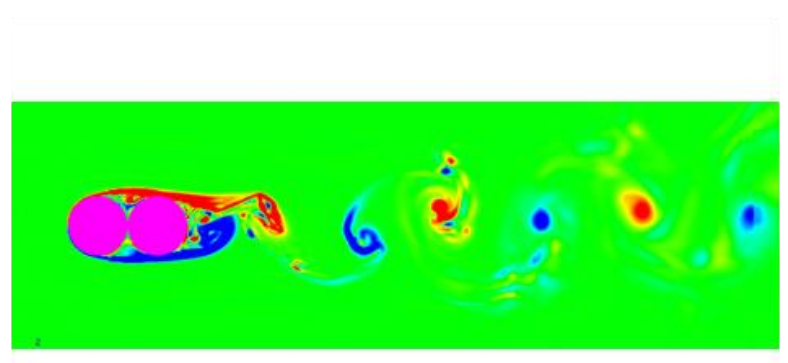

(8)

(9) 
Figura 89 - Contorno de vorticidade do menor pico: caso $L / d=1,0$ - Instantes 1 a 9 ilustrados na Figura 20

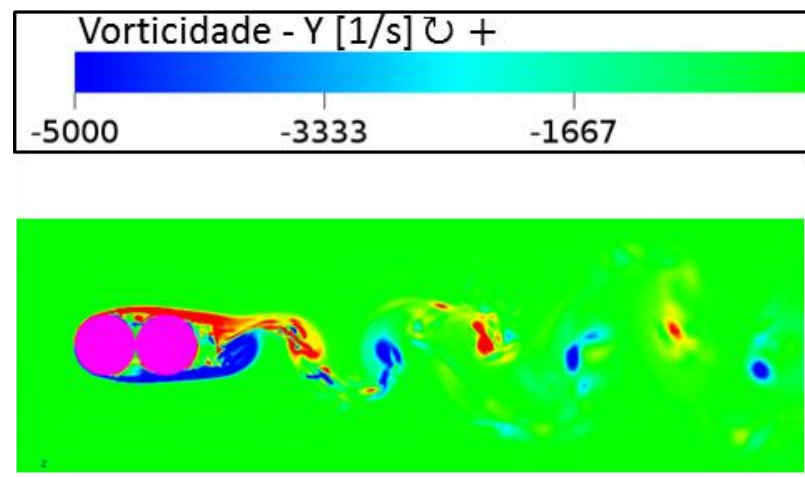

(1)

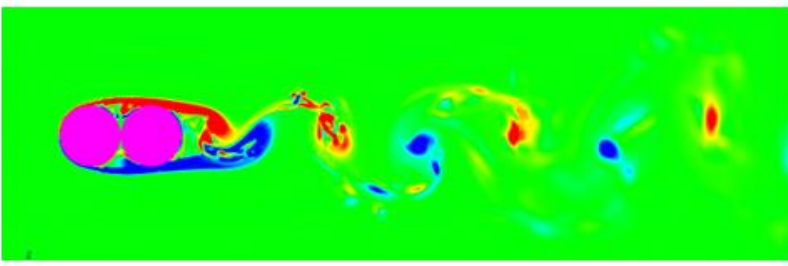

(3)

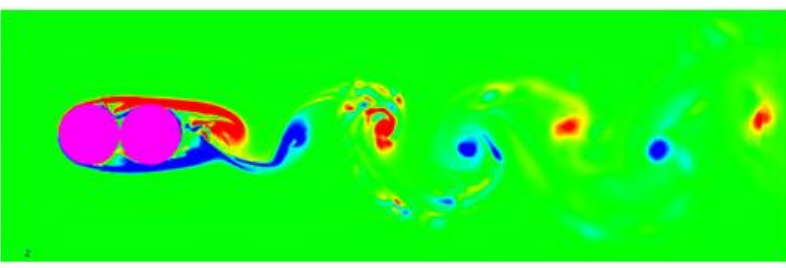

(5)

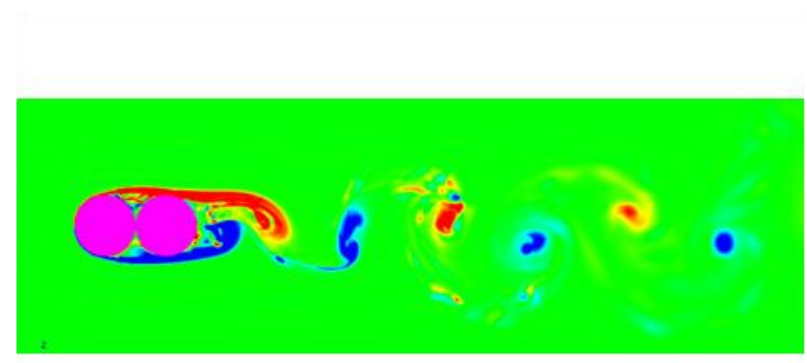

(7)
0

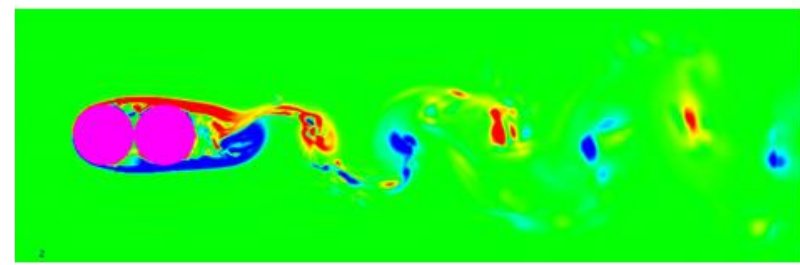

(2)

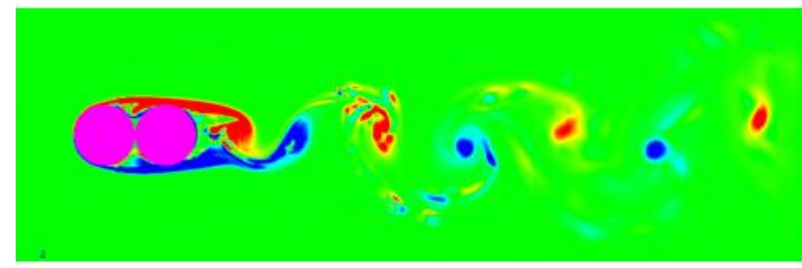

(4)

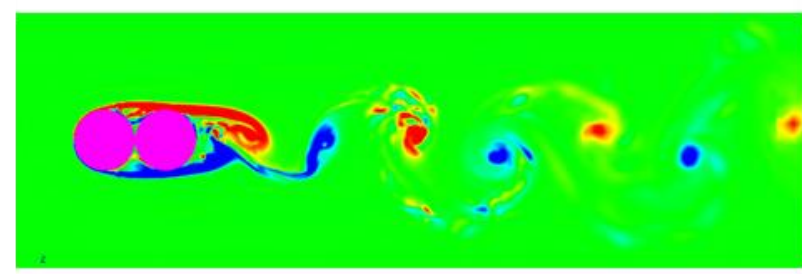

(6)

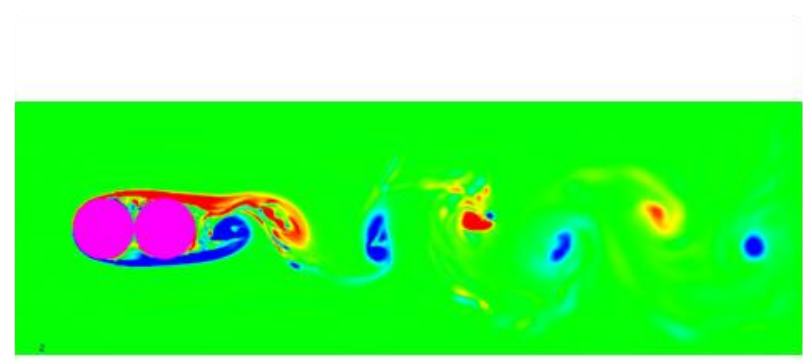

(8)

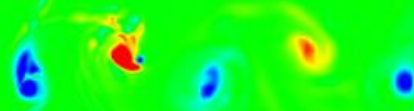

(9) 
Figura 90 - Contorno de magnitude de velocidade do maior pico: caso $L / d=2,5$ - Instantes 1 a 9 ilustrados na

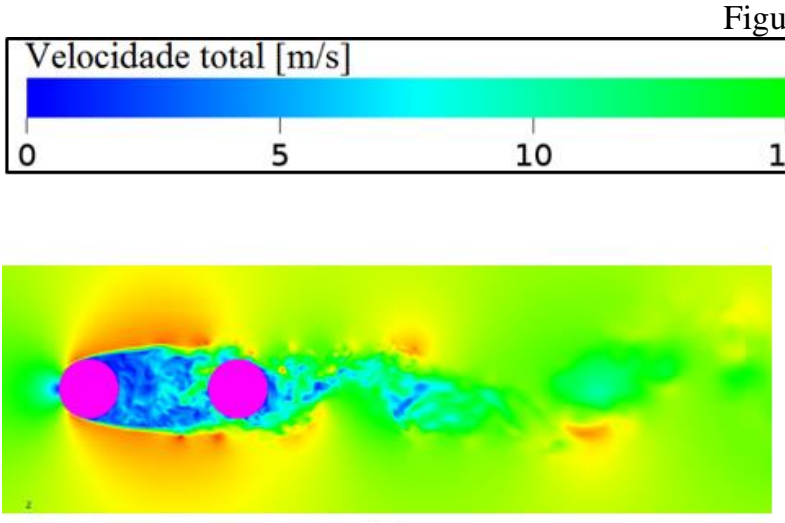

(1)

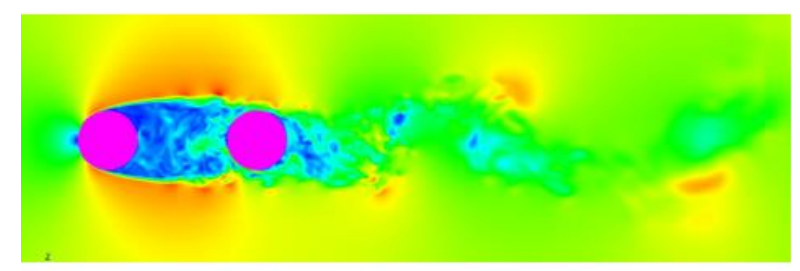

(3)

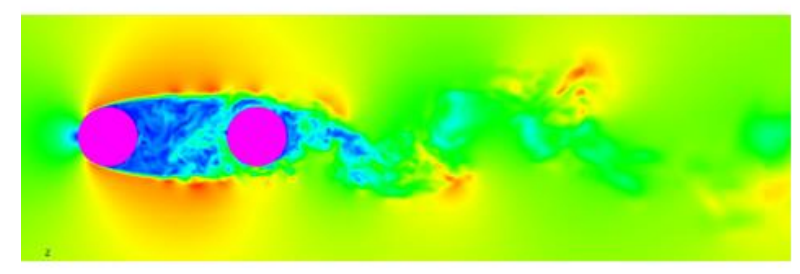

(5)

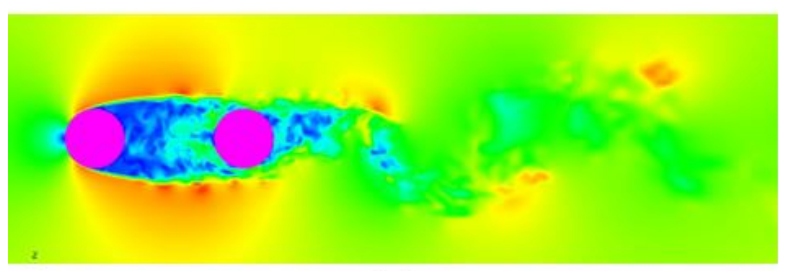

(7)
Figura 20

15

20

25

30

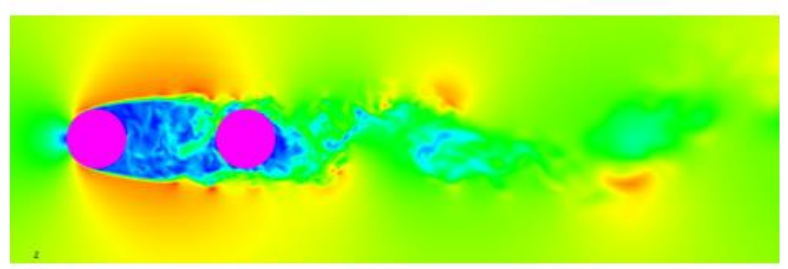

(2)

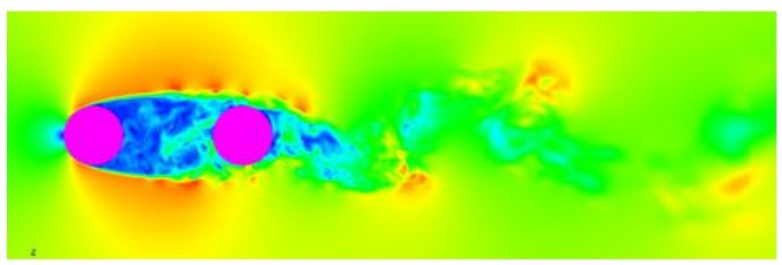

(4)

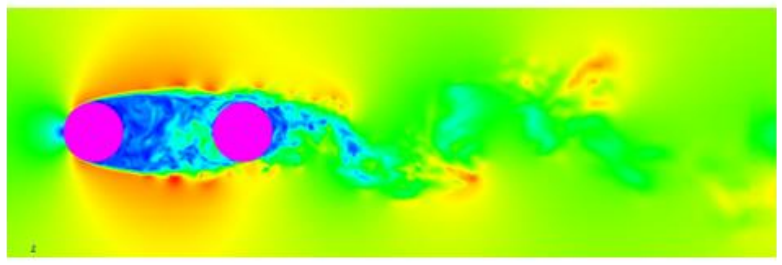

(6)

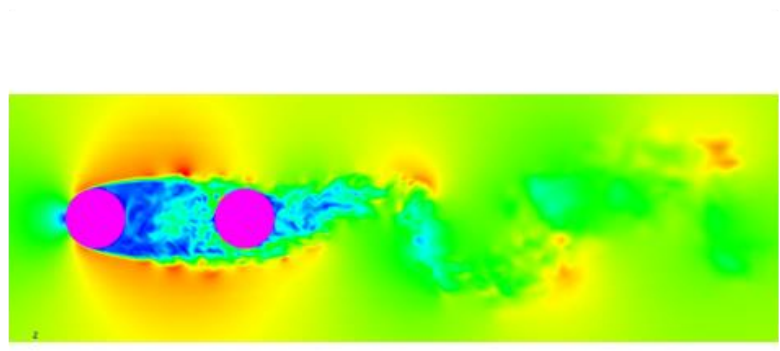

(8)

(9) 
Figura 91 - Contorno de magnitude de velocidade do menor pico: caso $L / d=2,5$ - Instantes 1 a 9 ilustrados na

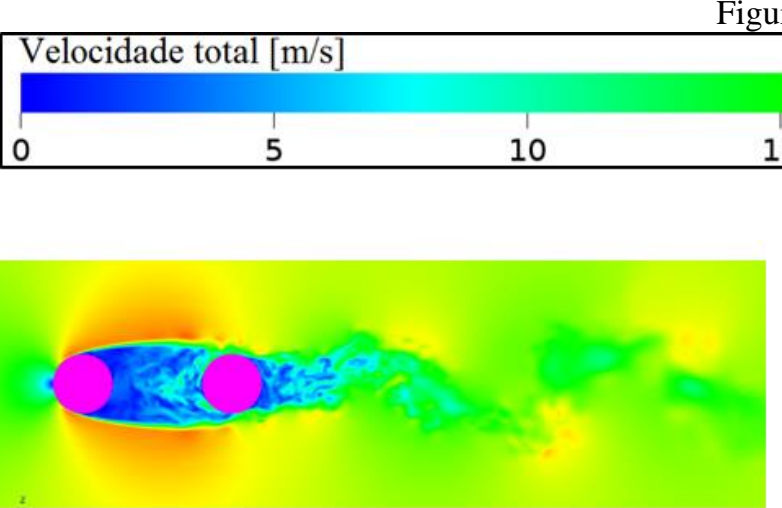

(1)

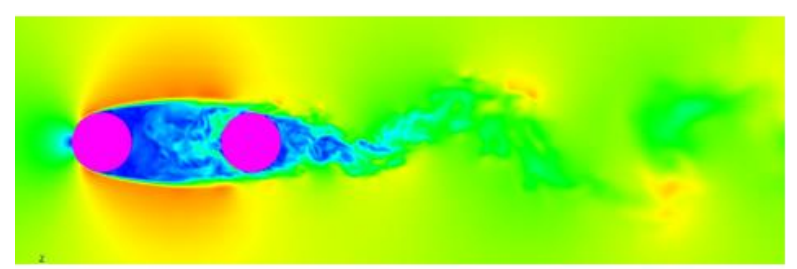

(3)

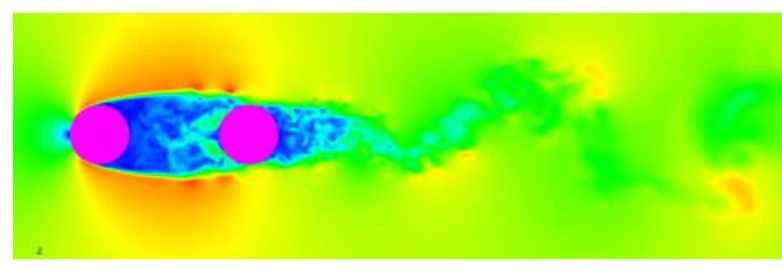

(5)

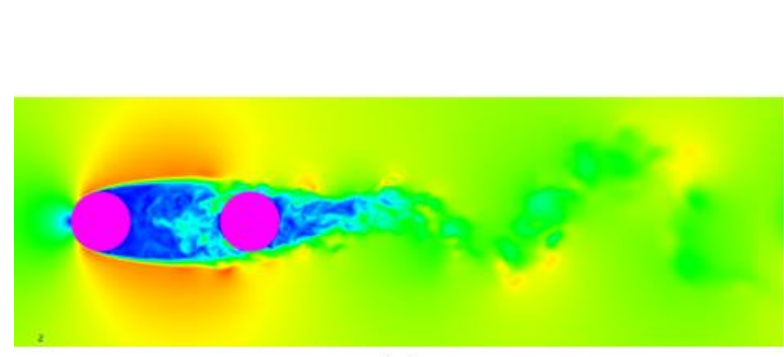

(7) Figura 20

15

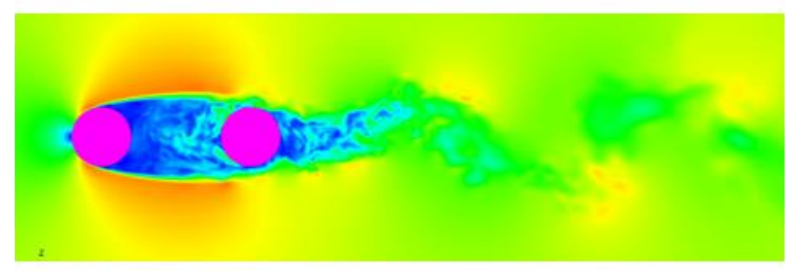

(2)

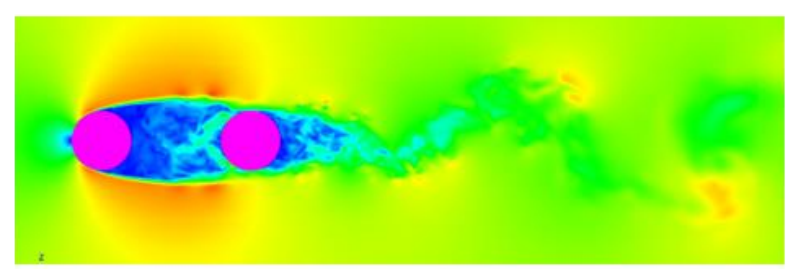

(4)

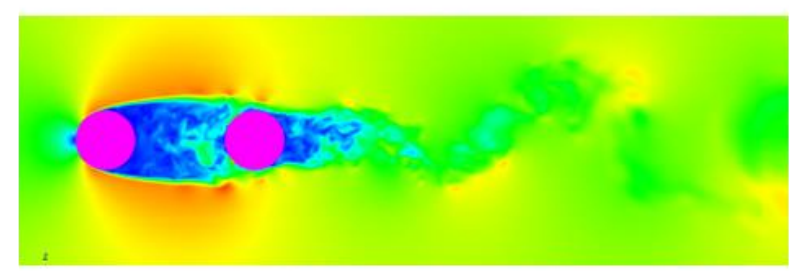

(6)

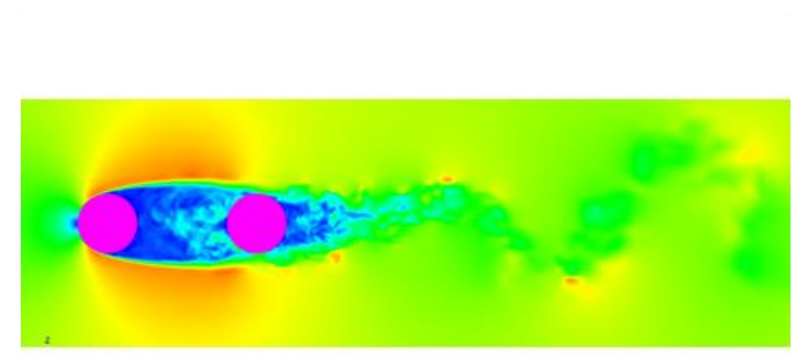

(8)

(9) 
Figura 92 - Contorno de vorticidade do maior pico: caso $L / d=2,5$ - Instantes 1 a 9 ilustrados na Figura 20

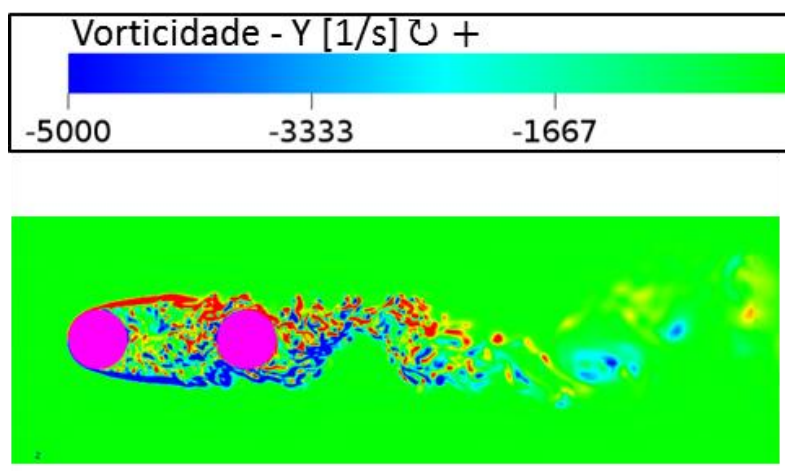

(1)

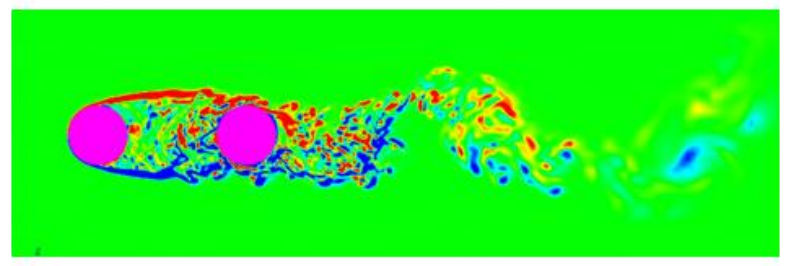

(3)

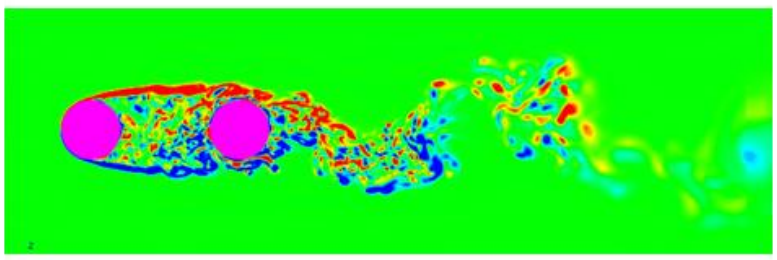

$(5)$

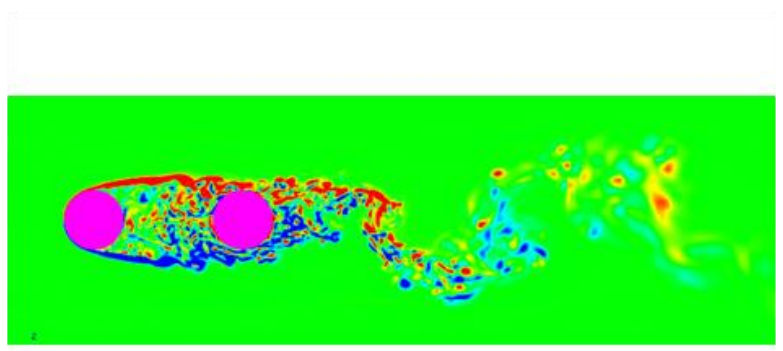

(7)

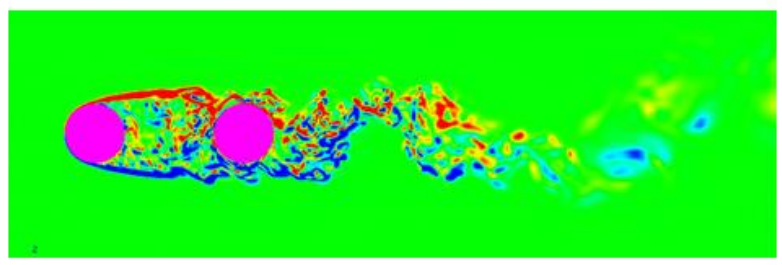

(2)

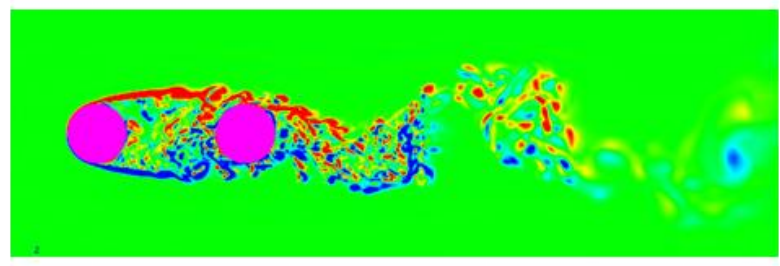

(4)

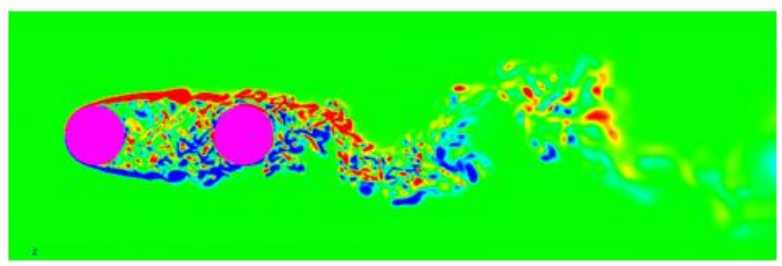

(6)

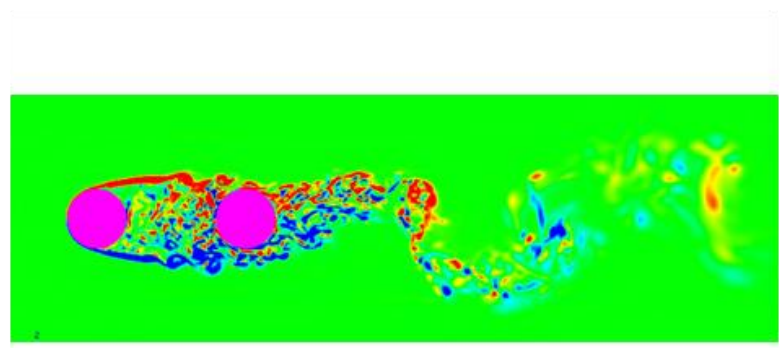

(8)

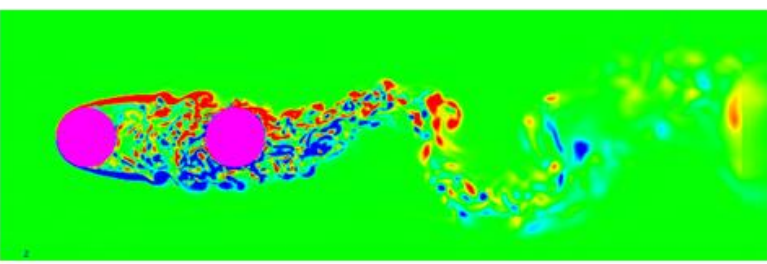

(9) 
Figura 93 - Contorno de vorticidade do menor pico: caso $L / d=2,5$ - Instantes 1 a 9 ilustrados na Figura 20

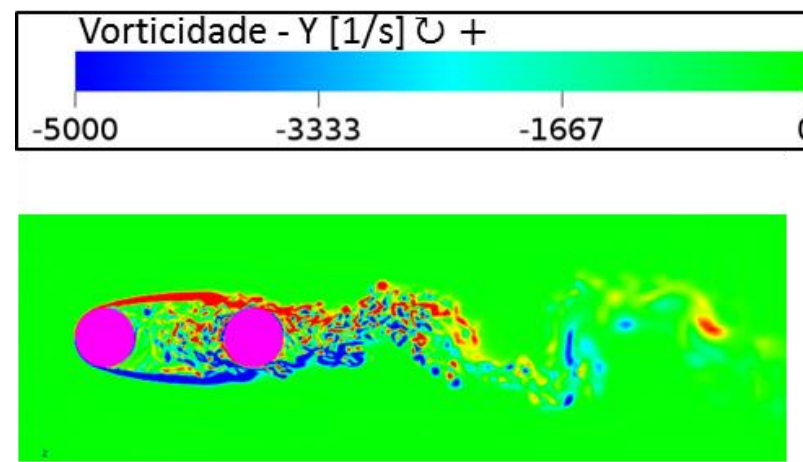

(1)

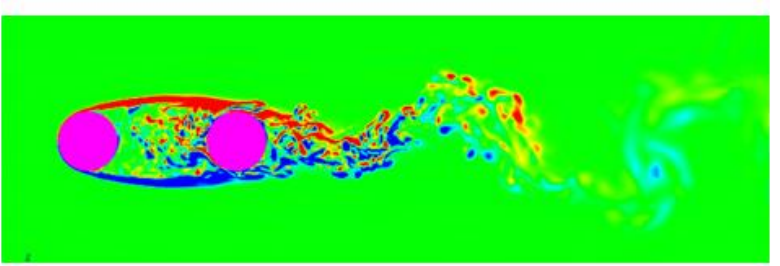

(3)

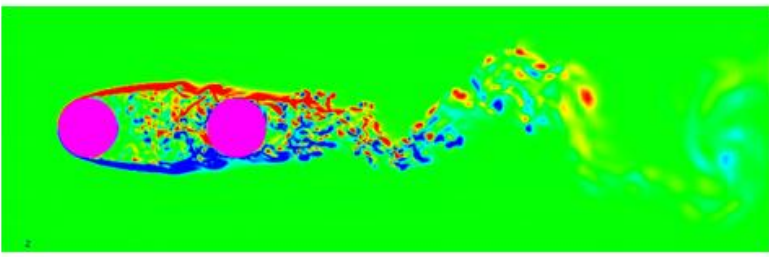

(5)

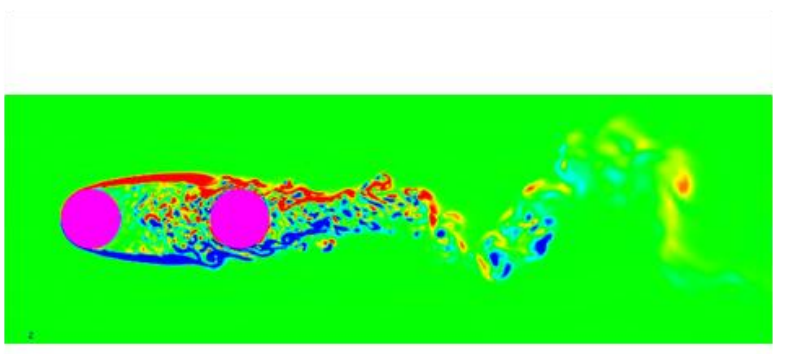

(7)

$0 \quad 1667$

3333

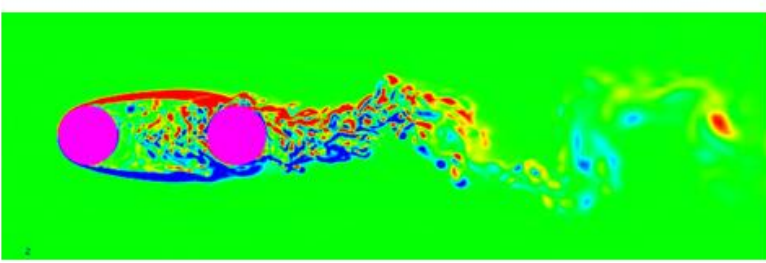

(2)

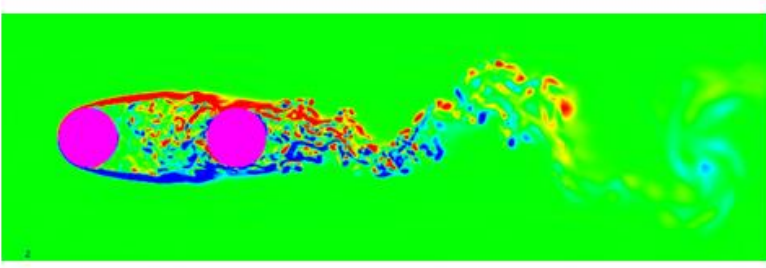

(4)

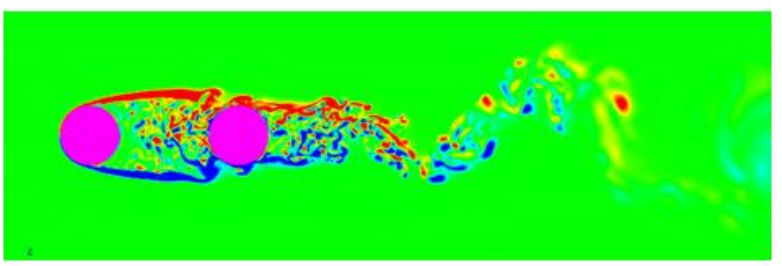

(6)

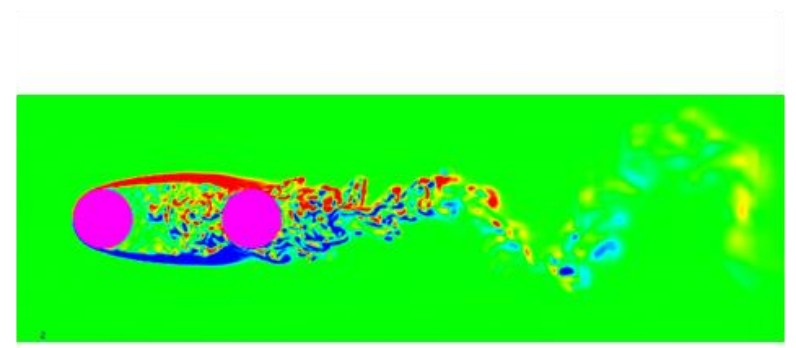

(8)

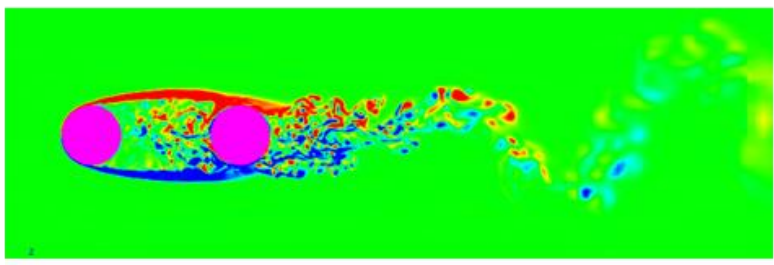

(9) 
Figura 94 - Contorno de magnitude de velocidade do maior pico: caso $L / d=4,0$ - Instantes 1 a 9 ilustrados na

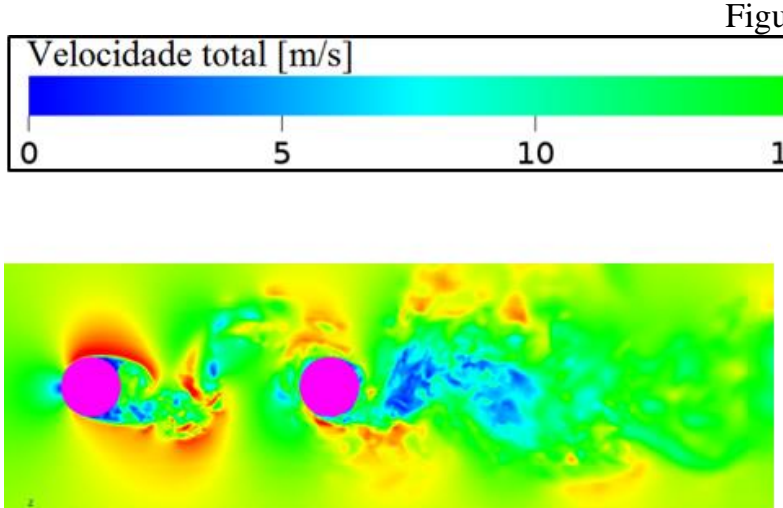

(1)

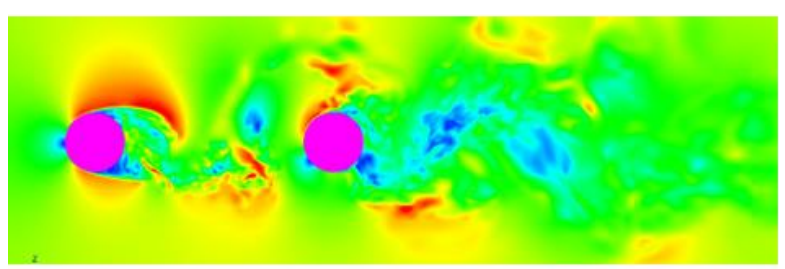

(3)

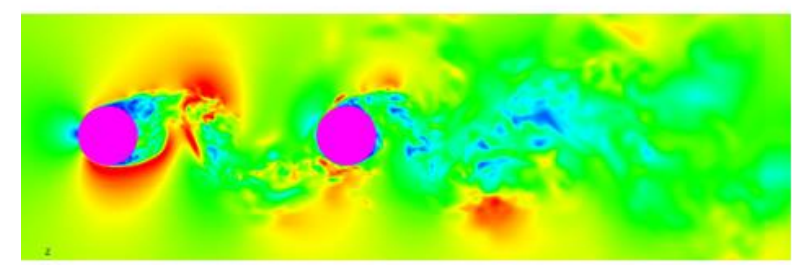

(5)

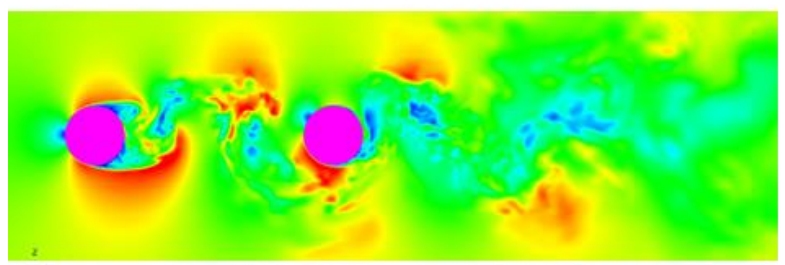

(7)
Figura 20

15

20

25

30

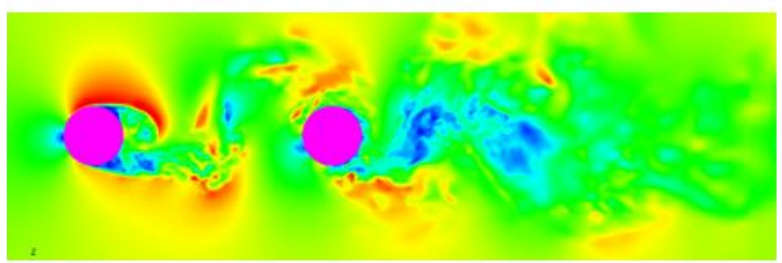

(2)

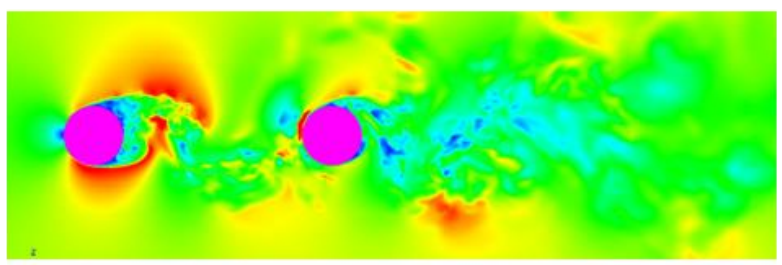

(4)

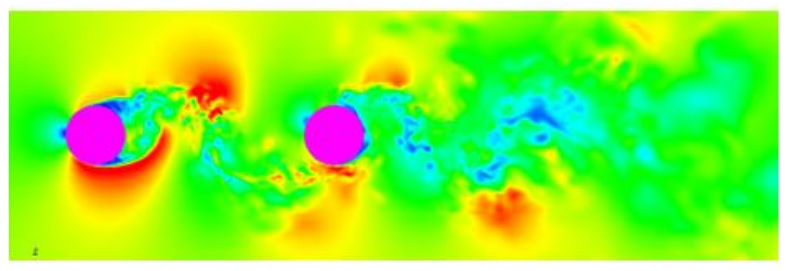

(6)

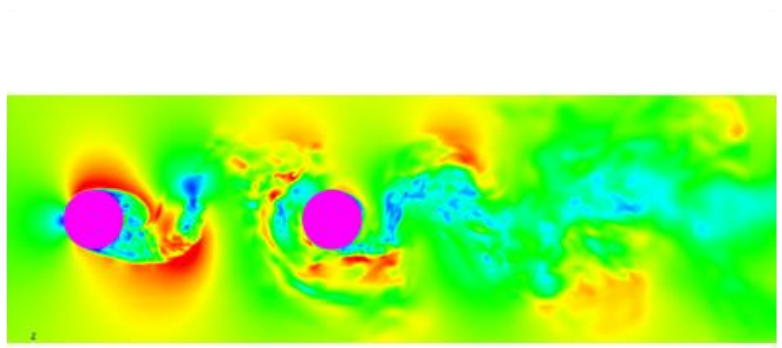

(8)

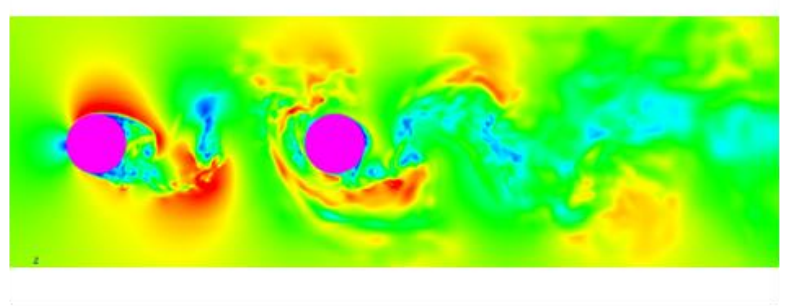

(9) 
Figura 95 - Contorno de magnitude de velocidade do menor pico: caso $L / d=4,0$ - Instantes 1 a 9 ilustrados na

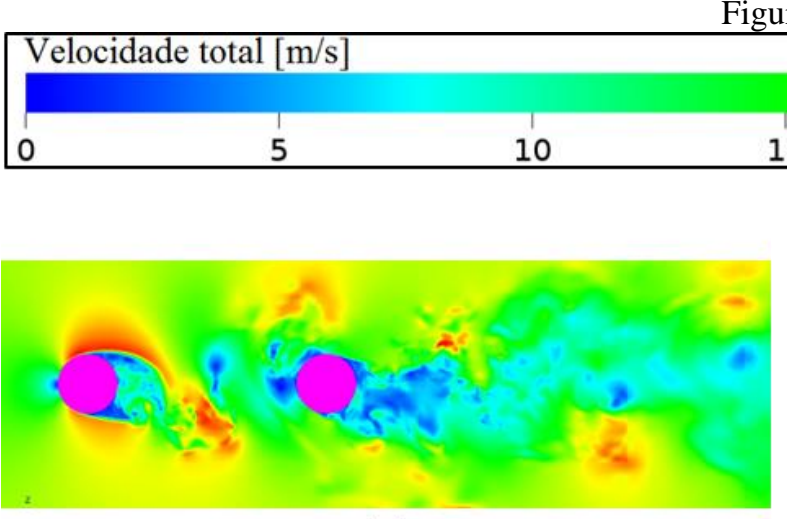

(1)

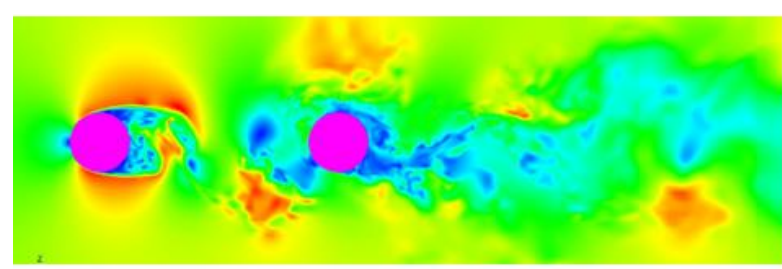

(3)

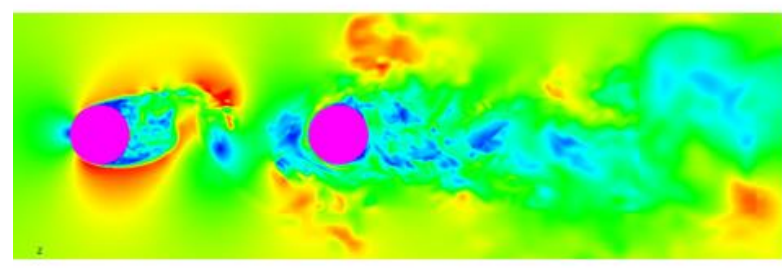

(5)

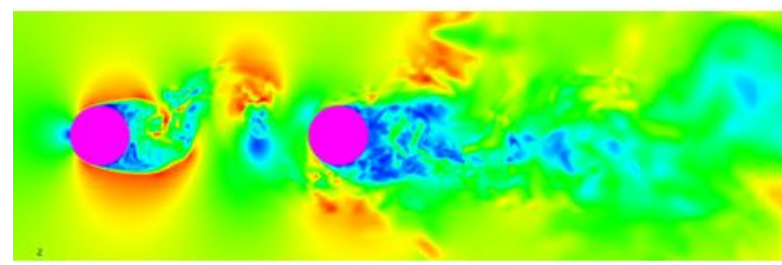

(7)
15

20

25

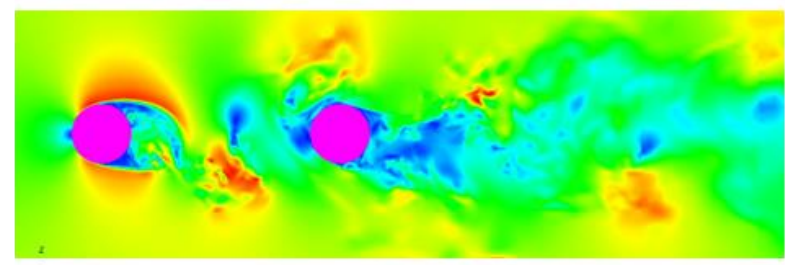

(2)

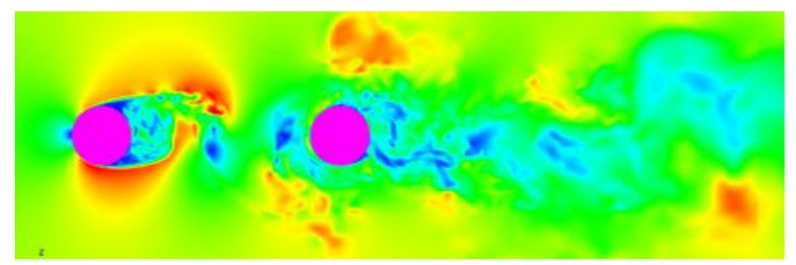

(4)

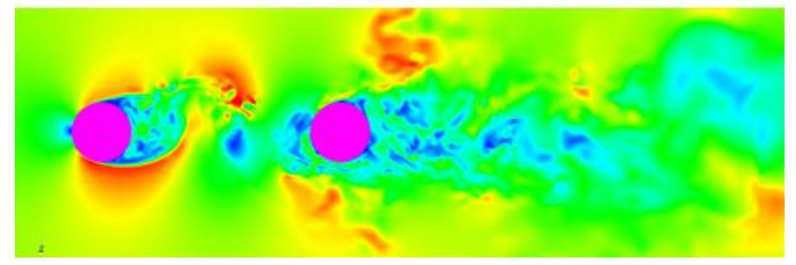

(6)

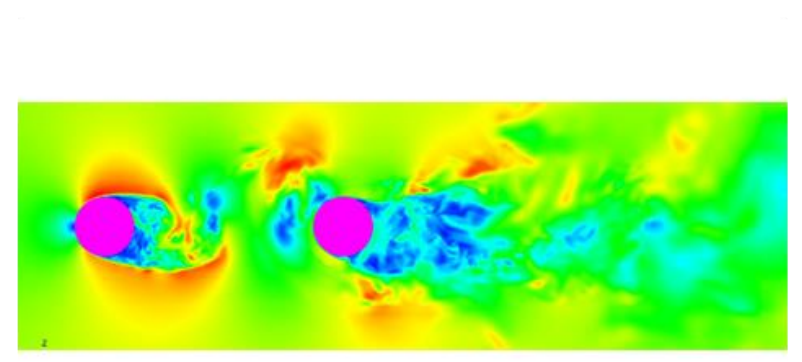

(8)

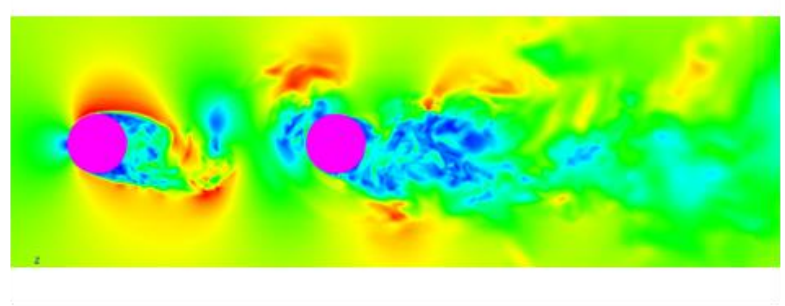

(9) 
Figura 96 - Contorno de vorticidade do maior pico: caso $L / d=4,0$ - Instantes 1 a 9 ilustrados na Figura 20

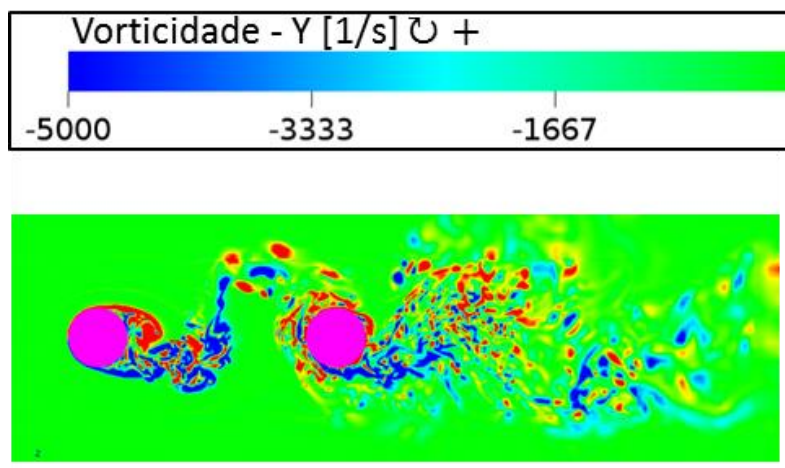

(1)

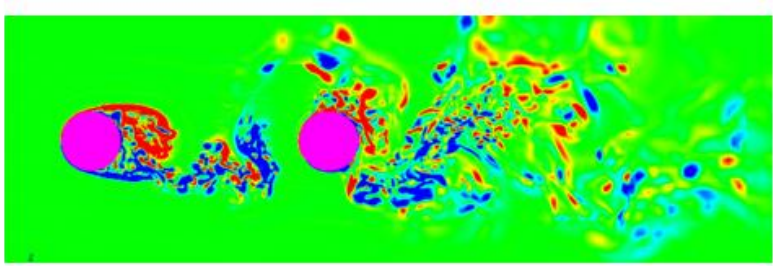

(3)

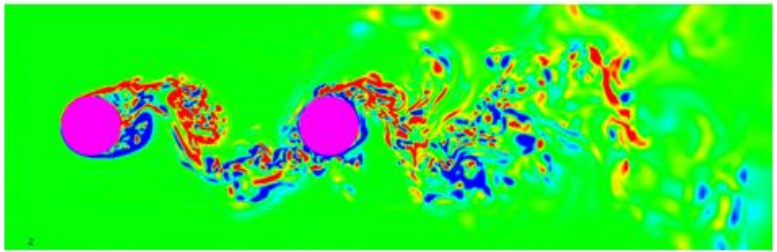

(5)

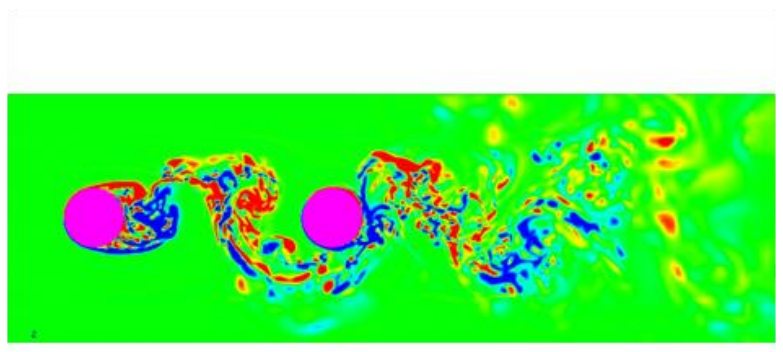

(7)

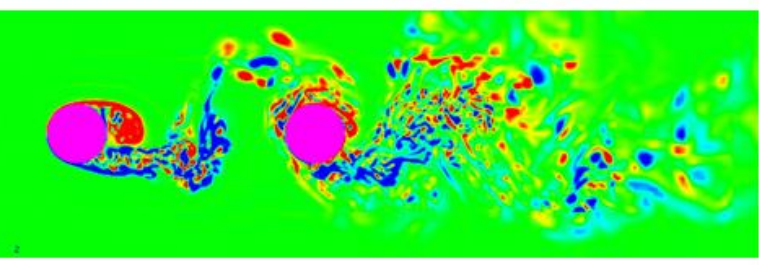

(2)

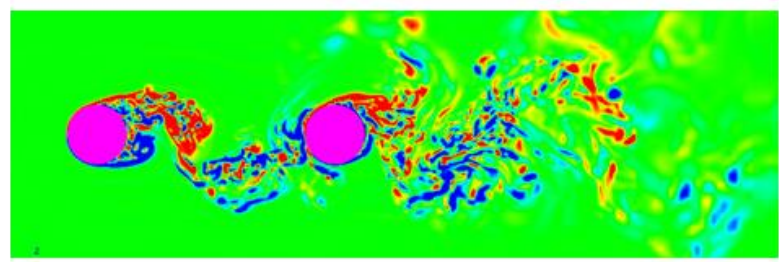

(4)

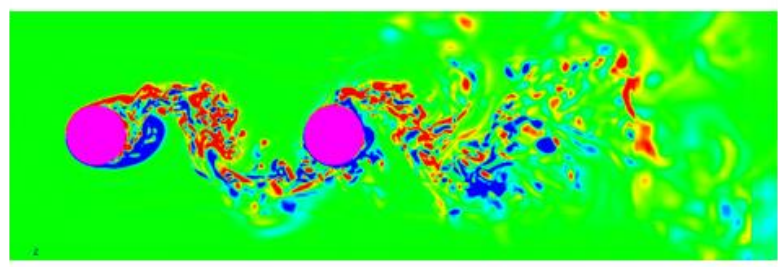

(6)

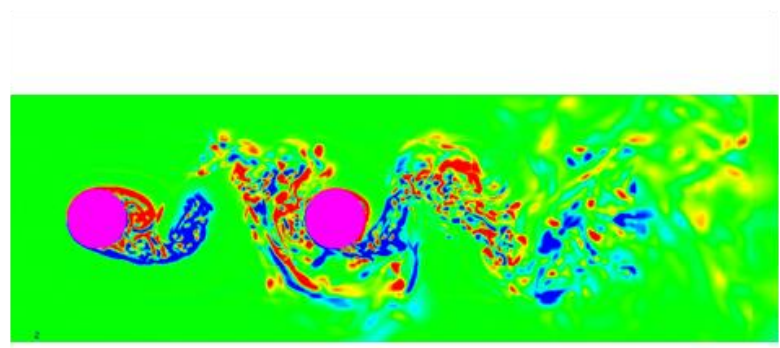

(8)

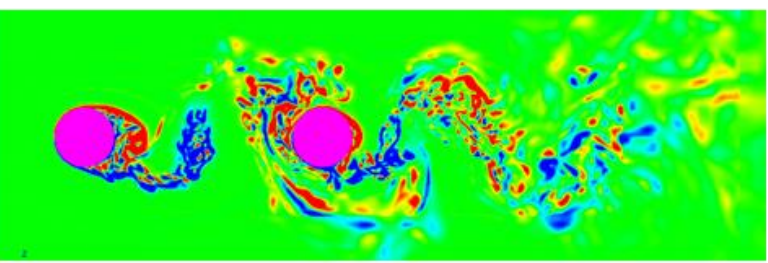

(9) 
Figura 97 - Contorno de vorticidade do menor pico: caso $L / d=4,0$ - Instantes 1 a 9 ilustrados na Figura 20

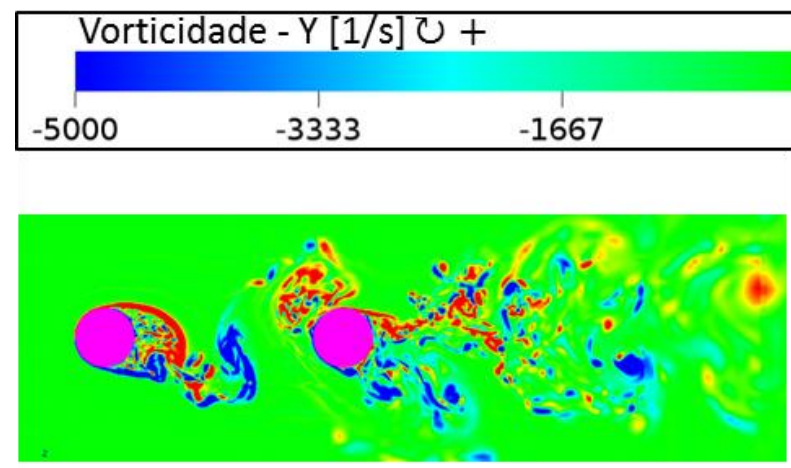

(1)

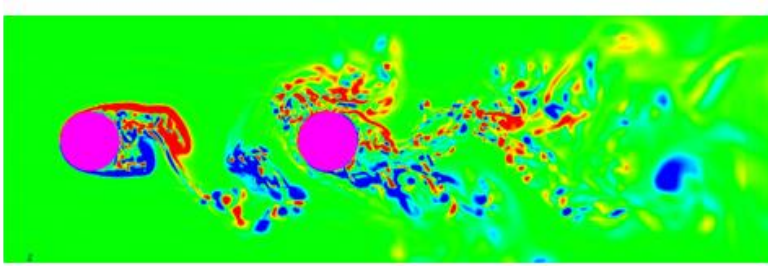

(3)

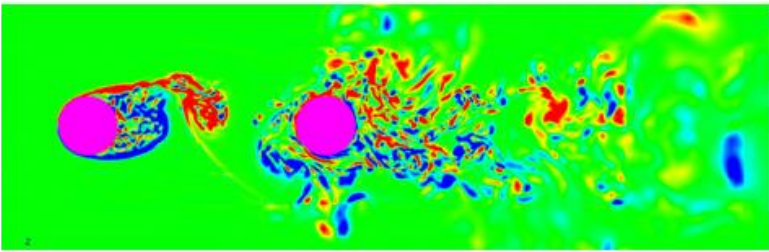

(5)

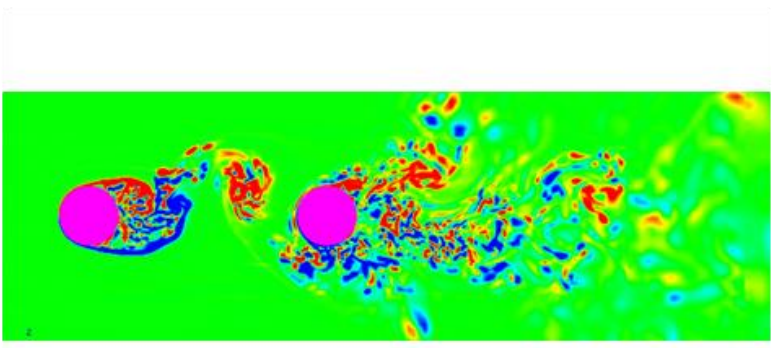

(7)

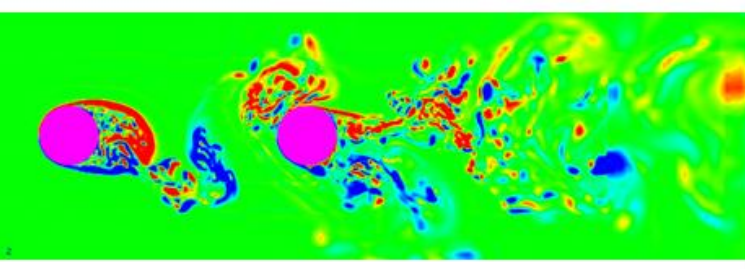

(2)

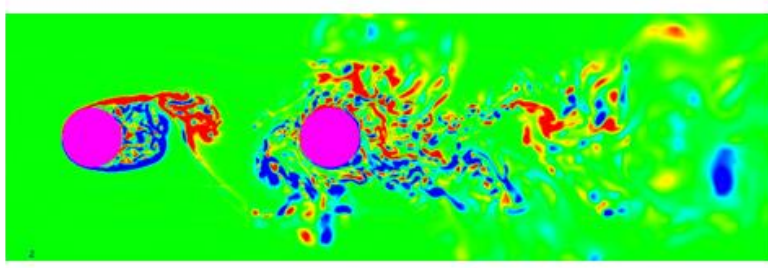

(4)

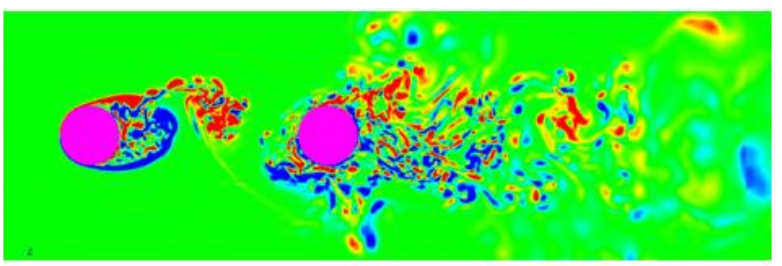

(6)

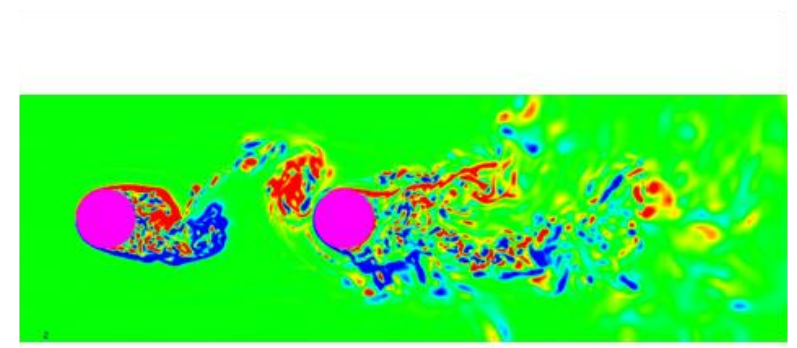

(8)

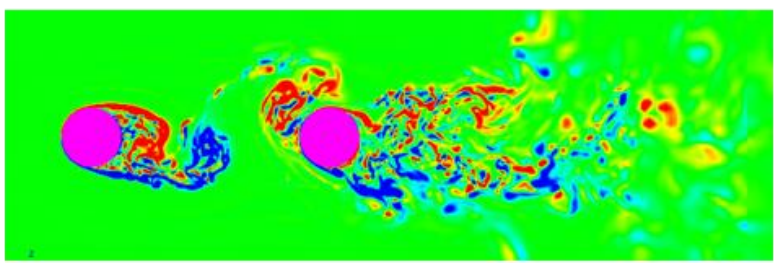

(9) 


\section{APÊNDICE C - CAMPO FLUIDODINÂMICO: CASO SEMI- ANECÓICO}

Figura 98 - Contorno de magnitude de velocidade do maior pico: caso semi-anecóico - Instantes 1 a 9 ilustrados na Figura 20

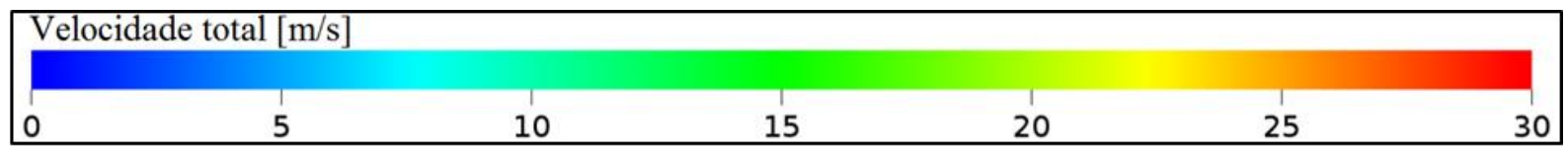

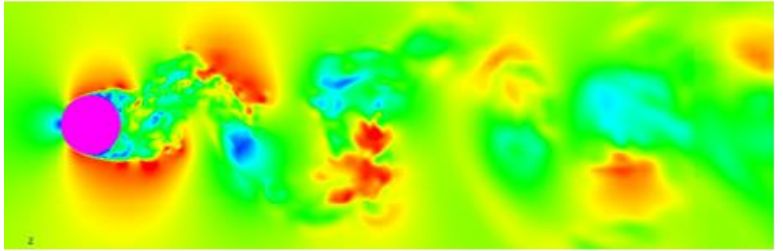

(1)

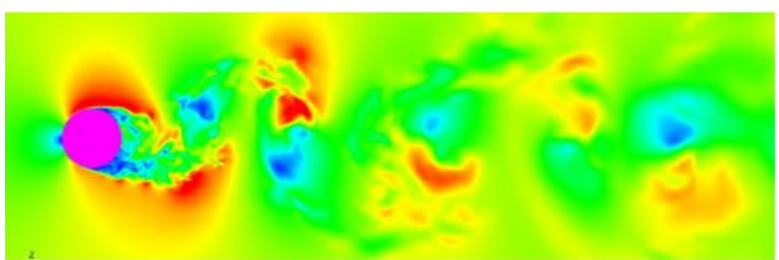

(3)

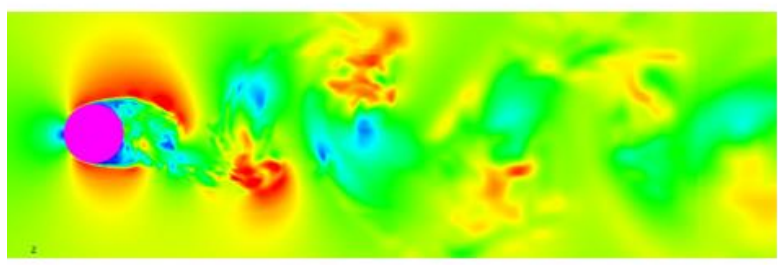

(5)

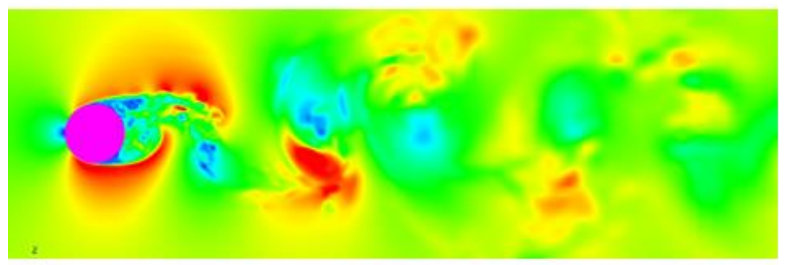

(7)

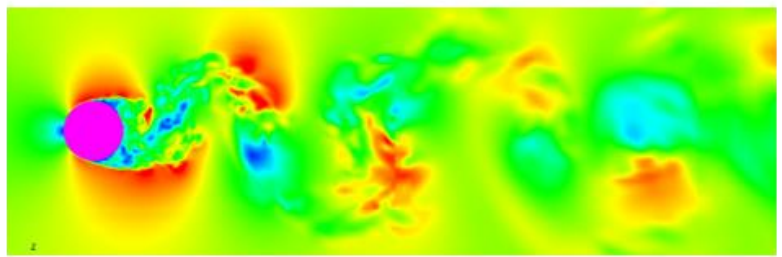

(2)

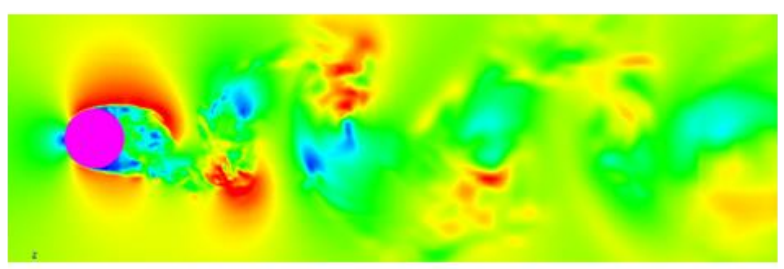

(4)

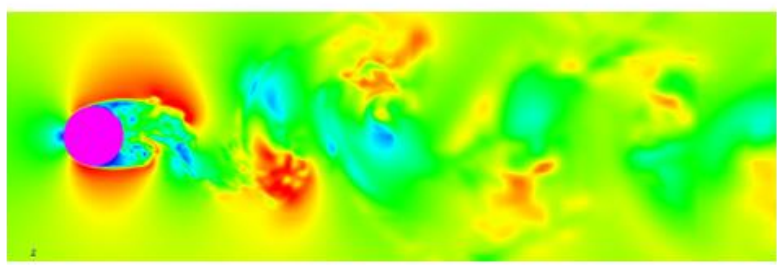

(6)

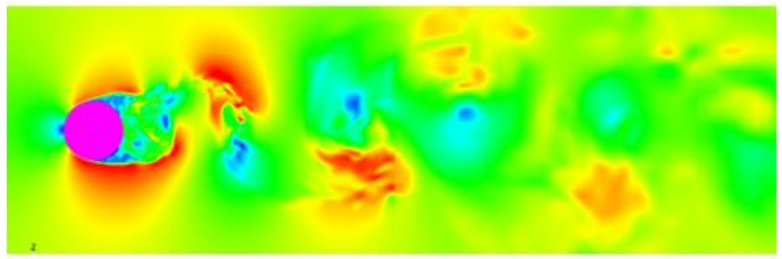

(8)

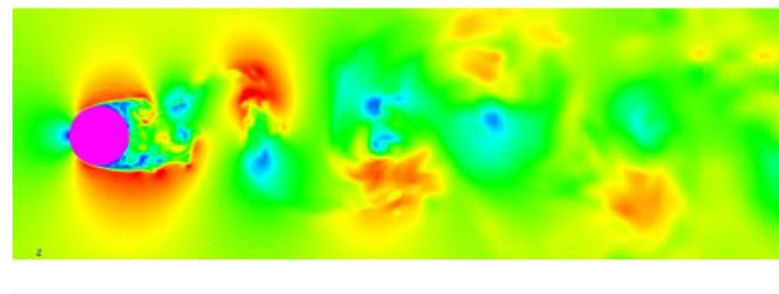

(9) 
Figura 99 - Contorno de magnitude de velocidade do menor pico: caso semi-anecóico - Instantes 1 a 9 ilustrados na Figura 20

\begin{tabular}{|lllllll|}
\hline \multicolumn{2}{|l|}{ Velocidade total $[\mathrm{m} / \mathrm{s}]$} & & & & & \\
\hline & 5 & 10 & 15 & 20 & 25 & 30 \\
\hline
\end{tabular}

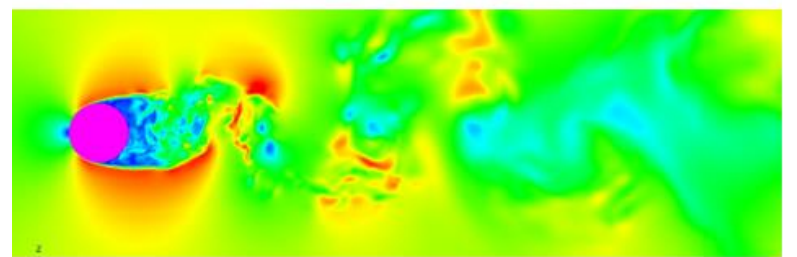

(1)

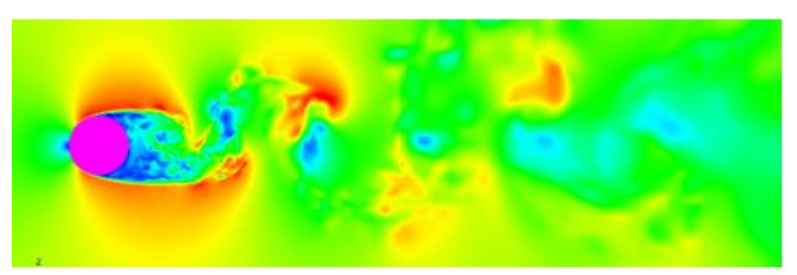

(3)

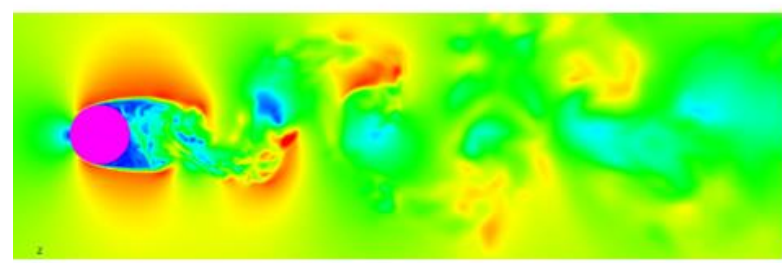

(5)

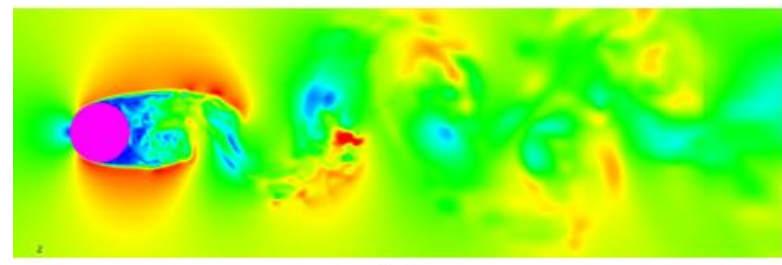

(7)

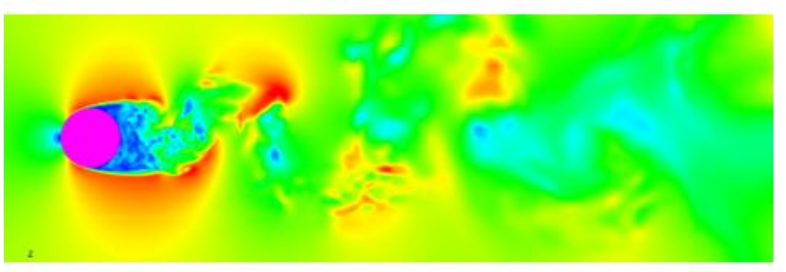

(2)

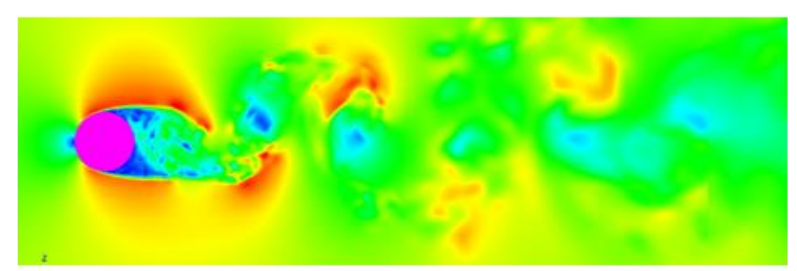

(4)

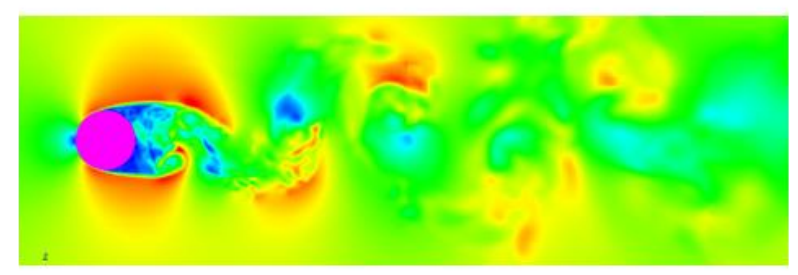

(6)

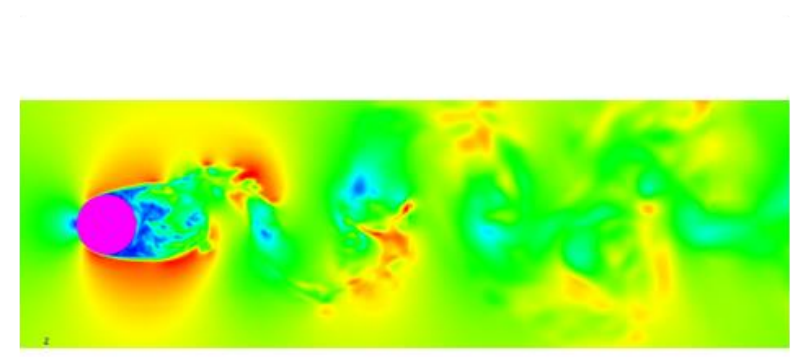

(8)

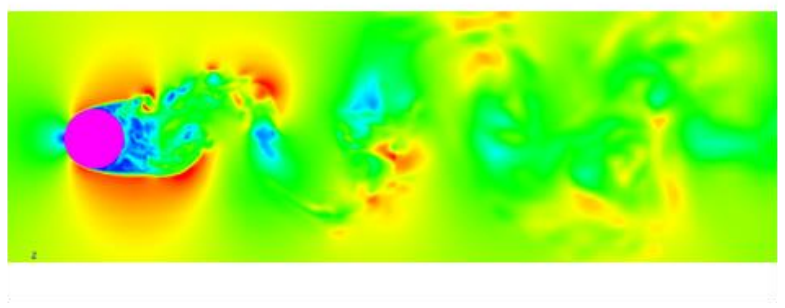

(9) 
Figura 100 - Contorno de vorticidade do maior pico: caso semi-anecóico - Instantes 1 a 9 ilustrados na Figura 20

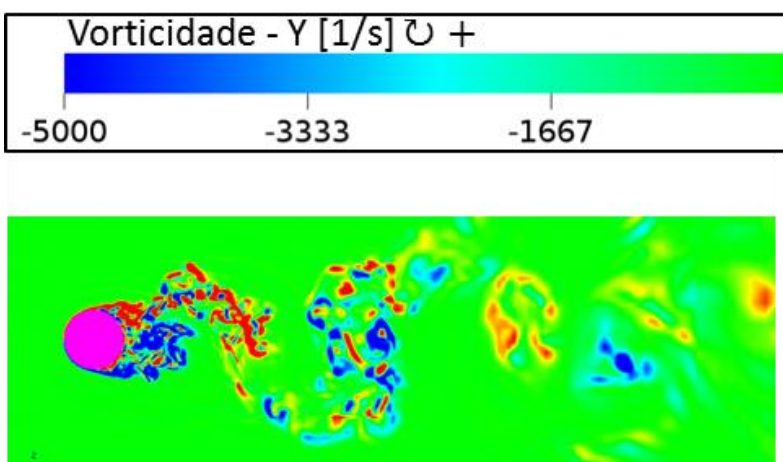

(1)

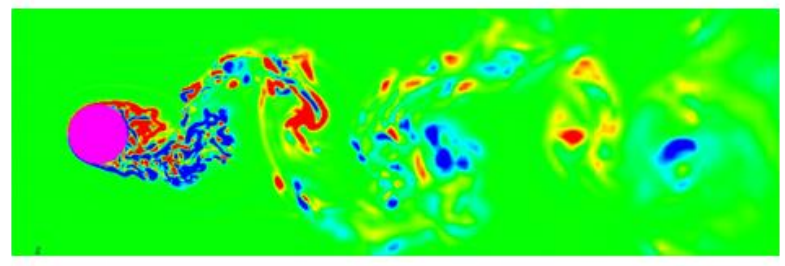

(3)

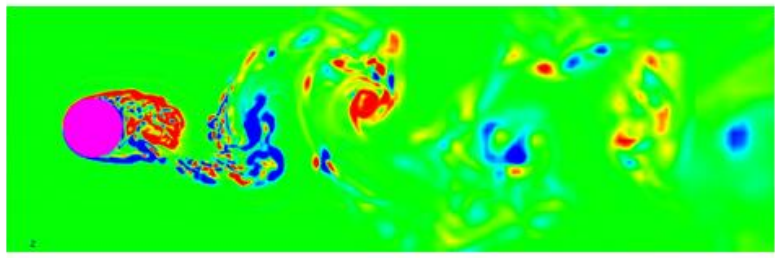

(5)

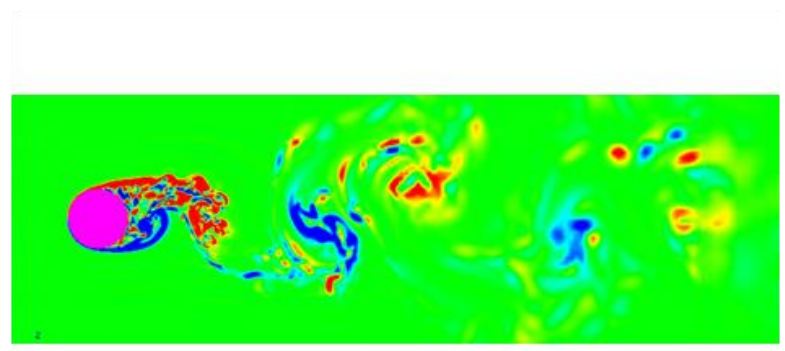

(7)

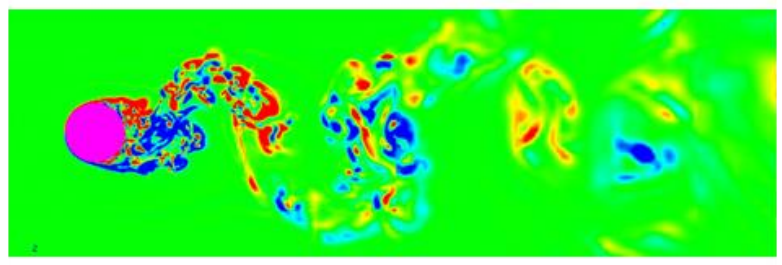

(2)

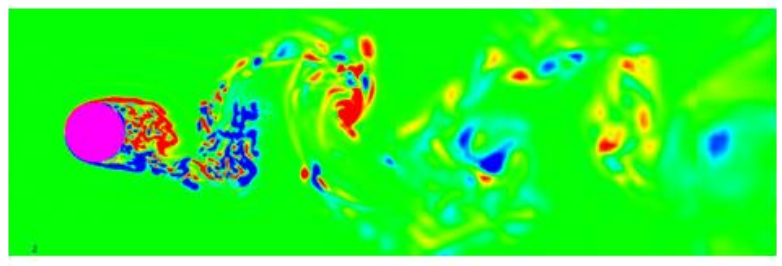

(4)

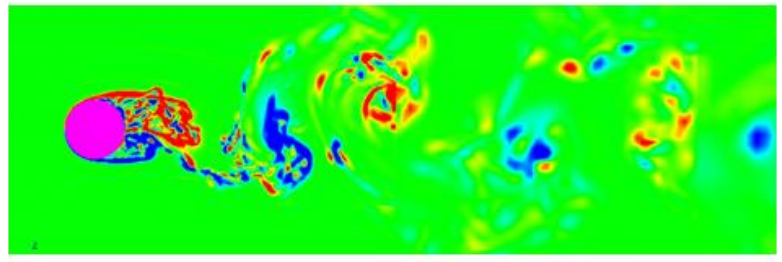

(6)

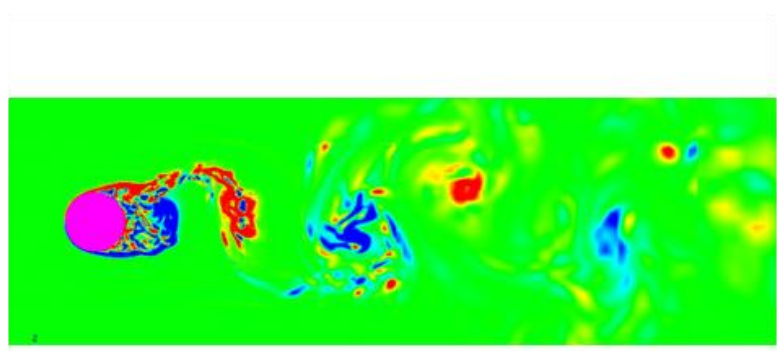

(8)

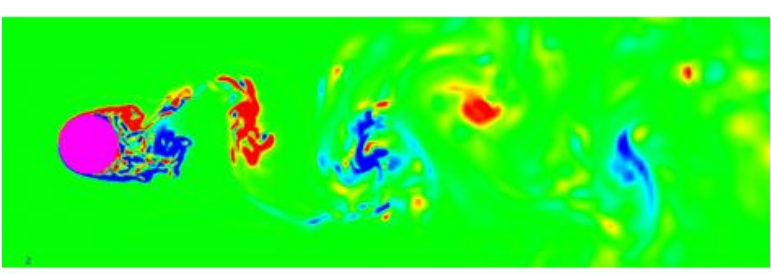

(9) 
Figura 101 - Contorno de vorticidade do menor pico: caso semi-anecóico - Instantes 1 a 9 ilustrados na Figura 20

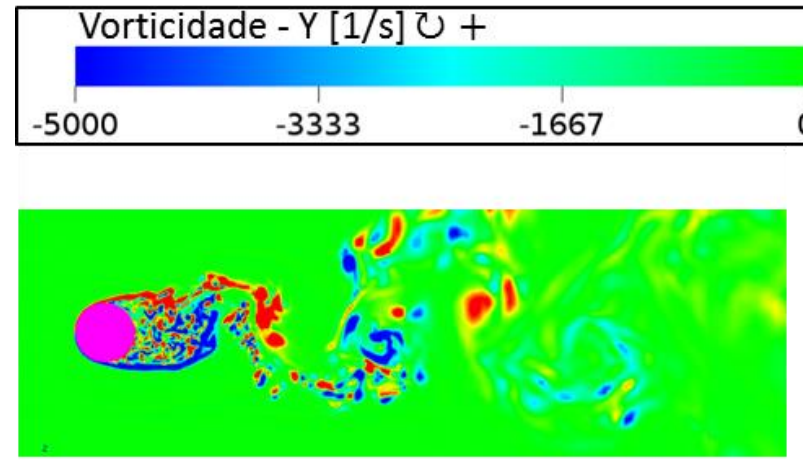

(1)

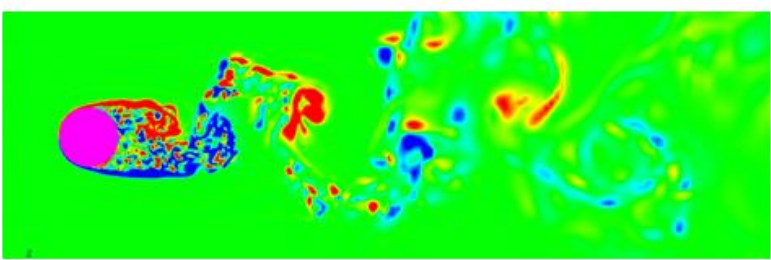

(3)

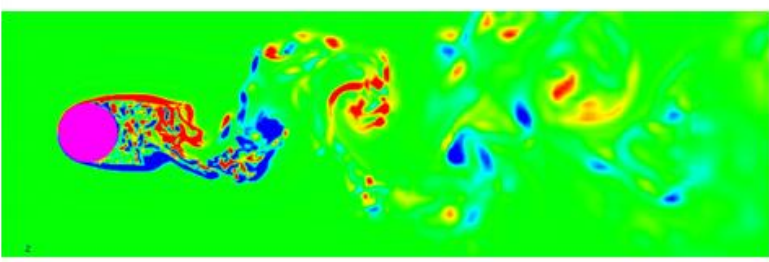

(5)

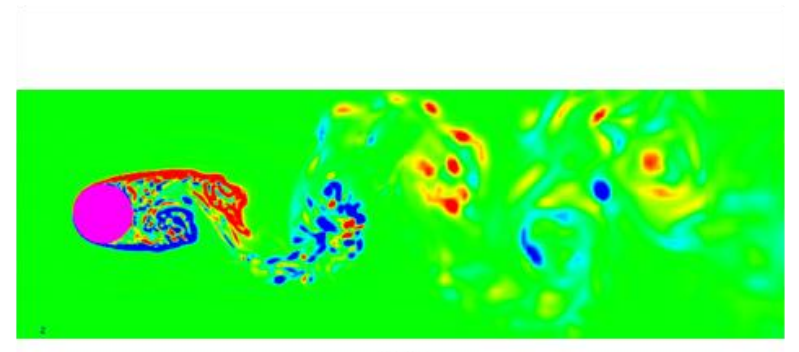

(7)
1667

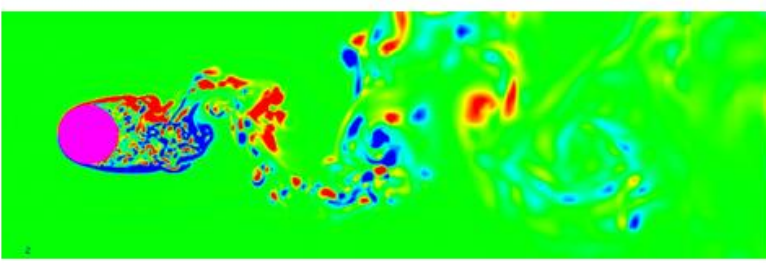

(2)

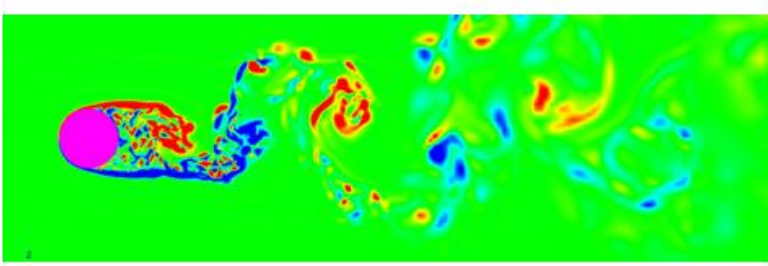

(4)

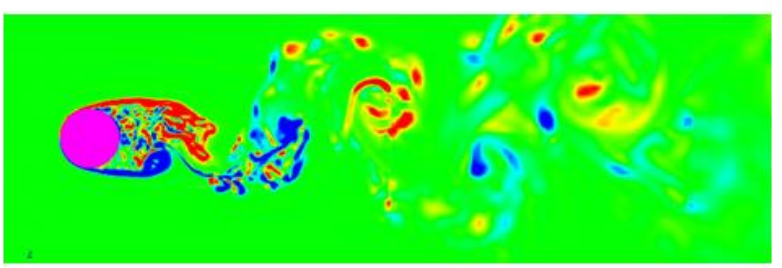

(6)

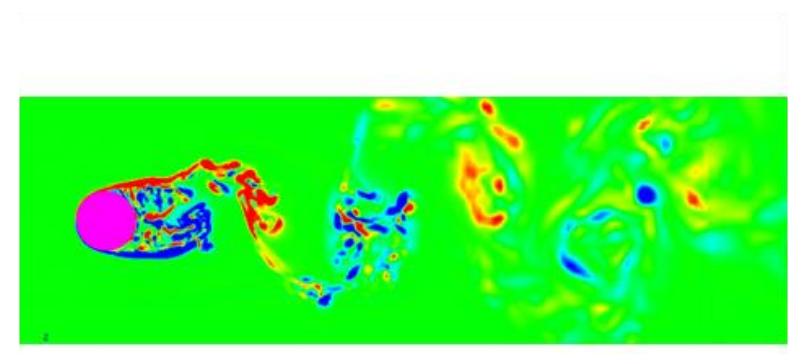

(8)

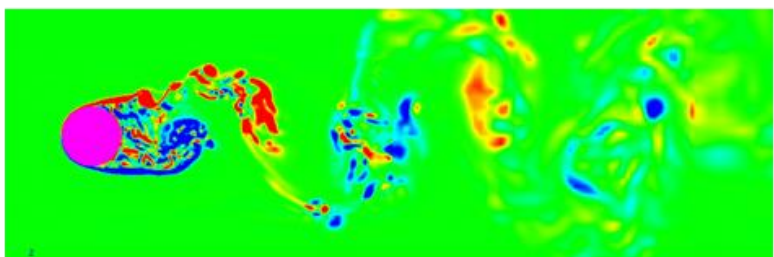

(9) 